University of Louisville

ThinkIR: The University of Louisville's Institutional Repository

$12-2010$

\title{
The social and cultural constructions of the self-identity of white American corporate businesswomen in historiography, literature, and popular culture (1963-1985).
}

Qin Ma 1974-

University of Louisville

Follow this and additional works at: https://ir.library.louisville.edu/etd

\section{Recommended Citation}

Ma, Qin 1974-, "The social and cultural constructions of the self-identity of white American corporate businesswomen in historiography, literature, and popular culture (1963-1985)." (2010). Electronic Theses and Dissertations. Paper 871. https://doi.org/10.18297/etd/871

This Doctoral Dissertation is brought to you for free and open access by ThinkIR: The University of Louisville's Institutional Repository. It has been accepted for inclusion in Electronic Theses and Dissertations by an authorized administrator of ThinkIR: The University of Louisville's Institutional Repository. This title appears here courtesy of the author, who has retained all other copyrights. For more information, please contact thinkir@louisville.edu. 
THE SOCIAL AND CULTURAL CONSTRUCTIONS OF THE SELF-IDENTITY OF WHITE AMERICAN CORPORATE BUSINESSWOMEN IN HISTORIOGRAPHY, LITERATURE, AND POPULAR CULTURE (1963-1985)

By

Qin Ma

B.A., Beihang University, 1997

M.A., Beijing Foreign Studies University, 2004

\begin{abstract}
A Dissertation
Submitted to the Faculty of the Graduate School of the University of Louisville in Partial Fulfillment of the Requirements for the Degree of
\end{abstract}

Doctor of Philosophy

Division of Humanities

University of Louisville

Louisville, Kentucky

December 2010 
Copyright $(2010$ by Qin Ma

All Rights Reserved 

THE SOCIAL AND CULTURAL CONSTRUCTIONS OF THE SELF-IDENTITY OF WHITE AMERICAN CORPORATE BUSINESSWOMEN IN HISTORIOGRAPHY, LITERATURE, AND POPULAR CULTURE

(1963-1985)

\section{By}

Qin Ma

B.A., Beihang University, 1997

M.A., Beijing Foreign Studies University, 2004

A dissertation approved on

November 22, 2010

by the following dissertation committee

Dissertation Director 


\section{DEDICATION}

This dissertation is dedicated

to my parents Tingjun $\mathrm{Ma}$ and $\mathrm{Yi} \mathrm{Lu}$

and

my Husband Yizhen Zhu and daughter Liye Zhu,

with Love 


\section{ACKNOWLEDGEMENT}

First and foremost, I would like to express my deep and sincere gratitude to my director, Dr. Robert N. St. Clair, for his constructive comments and important support throughout this work. He was always there to meet and talk about my ideas, and to give advice. Additionally, his thorough and meticulous editing of this dissertation was most appreciated.

I wish to express my warm and sincere thanks to Dr. Annette Allen and Dr. Osborne P. Wiggins for their support and guidance over the past four years, and Dr. Allen's willingness to participate in my dissertation. I would also like to thank the other committee members, Dr. Manuel Medina and Dr. Mary Makris for their comments and assistance. Thanks are also due to other teachers in this $\mathrm{PhD}$ program, Prof. Elaine $\mathrm{O}$. Wise, Dr. Pamela Beattie, Dr. Guohua Chen, Dr. Jian Zhang, Dr. Li Jin, Dr. Youzhong Sun, Dr. Yi'an Wu, and Dr. Zaixin Zhang, whose inspiring teaching opened my eyes.

I am also greatly indebted to Dr. Xiujie Sun, who helped to make this $\mathrm{PhD}$ program possible and offered a lot of timely help to us. Additionally, I am very grateful for the friendship of all of the members of this PhD program. I warmly thank Zhenping Wang, for her valuable advice and friendly help. Her extensive discussions around my work have been very helpful for this study. I also want to thank Cassie Book from the Writing 
Center of the University of Louisville who helped to proofread my dissertation.

Special thanks to Jing He, Yan Zhang, Harry Xu, Dongqing Chen, Jiajia Lin, Mark

Collins, Megan Collins, Teresa A. Robinson, and Megan A. Alexander, whose emotional support, camaraderie, entertainment, and caring helped me get through the difficult times when I have to take care of my 4-year-old daughter alone while writing this dissertation in Louisville, the United States, in 2010.

I am forever indebted to my parents, Tingjun Ma and $\mathrm{Yi} \mathrm{Lu}$, for giving me life in the first place, for educating me with aspects from both arts and sciences, for their endless patience and unconditional support and encouragement when it was most required. I owe my loving thanks to my husband, Yizhen Zhu, for unwavering love, support and understanding during the many hours I dedicated to achieving this milestone in my life and career; and to my lovely daughter Liye Zhu, for allowing mommy to leave her temporarily to pursue her interests. 


\begin{abstract}
THE SOCIAL AND CULTURAL CONSTRUCTIONS OF THE SELF-IDENTITY OF WHITE AMERICAN CORPORATE BUSINESSWOMEN IN HISTORIOGRAPHY, LITERATURE, AND POPULAR CULTURE
\end{abstract}

(1963-1985)

\title{
Qin Ma
}

November 22, 2010

The purpose of this cross-disciplinary dissertation is to explore how the epistemic ruptures, such as WWII and the Second Wave Feminism, change the American society between 1963 and 1985. From a humanistic and historical point of view, it focuses on (1) the "self-identity" of modern white American corporate businesswomen (WACB) between 1963 and 1985, (2) the change of their self-identity in comparison with the historical period between 1920 and 1963, and (3) how their self-identity is socially and culturally constructed by analyzing evidence from 3 disciplines-historiography, literature, and popular culture. The major theories used for the hermeneutic interpretation of the cultural evidence include the Identity theories, Social Constructionism, and post-structural Feminism. 
The results show that the self-identity of the white American corporate businesswomen between 1963 and 1985 has changed. First, in the attitude toward their work, businesswomen began to seek long-term careers in the business world, the traditional man's word, rather than just regarding their work as a temporary job which they would give up if there were enough income from their husbands; instead, they believe that they can find great satisfaction in careers. Second, in their relationship with their families, businesswomen tended to believe that they should "have it all" by wearing all the hats of full-time wives, mothers, and career women, which means that they wanted to find great satisfaction in careers without ignoring their mates and/or their children. Third, in their relationship with their male counterparts, especially those in the workplace, they have changed from supporters of businessmen to businesswomen themselves who worked hard to be respected for their skills and abilities.

As Betty Friedan states in her book The Second Stage (1998), the old problems of balancing the social roles of wives, mothers and workers still exist and the Feminism theories have not found a solution. As we know, the women's movement still has a long way to go in the search of a solution. The last chapter of this dissertation claims that the Third Wave Feminism, led by Julia Kristeva and Luce Irigaray, may serve as another epistemic rupture in the new era, which gives us some new hope for the solution. 


\section{TABLE OF CONTENTS}

PAGE

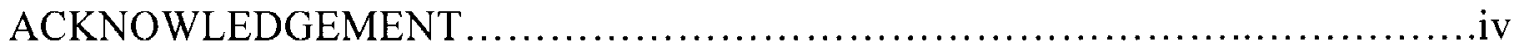

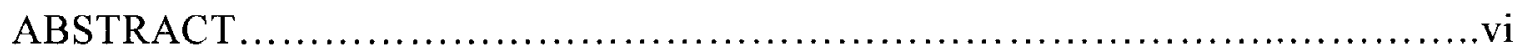

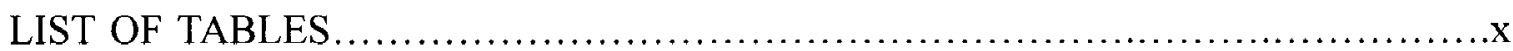

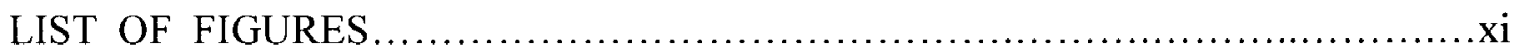

\section{CHAPTER}

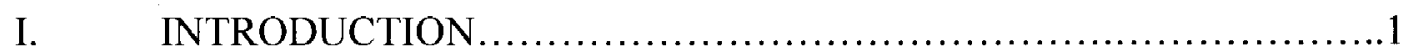

Social and Cultural Background.....................................

Research Purposes and Research Questions..........................18

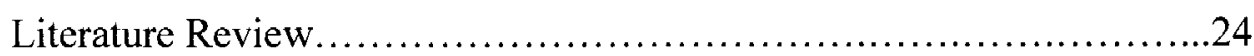

About the Present Study ..............................................28

Introduction to the Later Chapters.......................................32

II. THEORETICAL AND CONCEPTUAL FRAMEWORK ..................35

Addressing the Existential Self........................................ 35

Concepts of Identity, Self-Identity and Social Identity...................39

Socialization, Vygotsky and Identity Formation.........................55

Essentialism and Social Constructionism............................63

Social Construction of Self-Identity ................................ 71

Social Construction of Gender........................................ 75

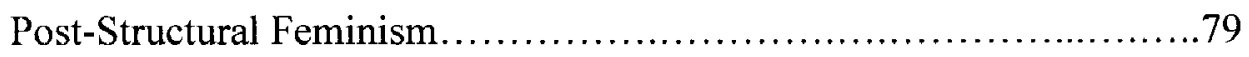


Implications for This Study.

III. GENDER IDENTITY OF WHITE AMERICAN CORPORATE BUSINESSWOMEN (WACB) (1920-1963) ...........................83

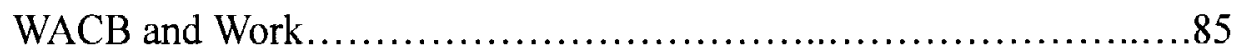

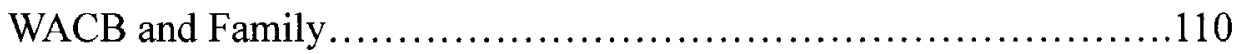

WACB in Relation to Men...................................... 120

IV. YOU CAN HAVE IT ALL:

THE CREST OF THE SECOND WAVE $(1963-1985) \ldots \ldots \ldots \ldots \ldots \ldots . \ldots 140$

Achievement-motivated Businesswomen..............................143

Work and Family: Womanhood Redefined............................166

WACB in Relation to Men............................................183

V. LACAN, KRISTEVA, IRIGARAY AND THE NEW WAVE ...............196

Jacques Lacan and His Theory of Structuralism......................197

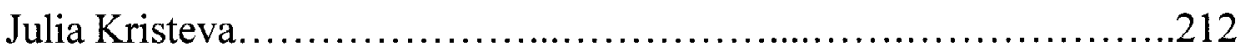

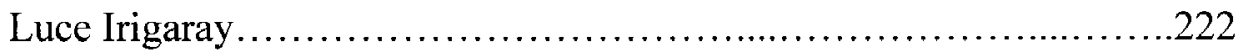

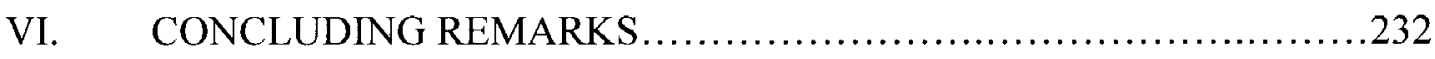

Review of the Three Waves.........................................233

Contributions and Implications...................................246

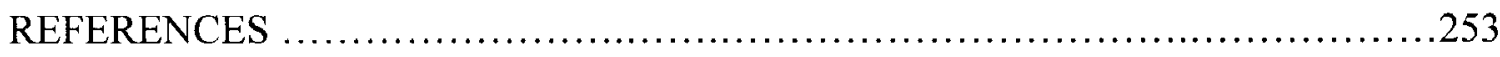

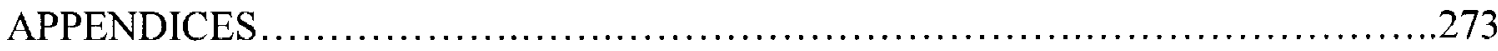

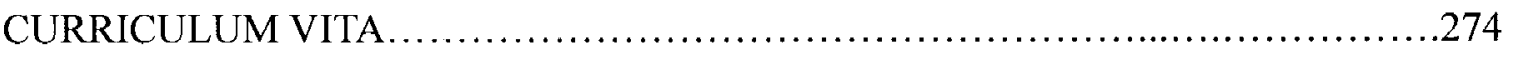




\section{LIST OF TABLES}

TABLE

PAGE

1-1. Marvin Harris's Model on Universal Components in Societies...................5

1-2. Three Waves of Feminisms and the Epistemic Ruptures....................

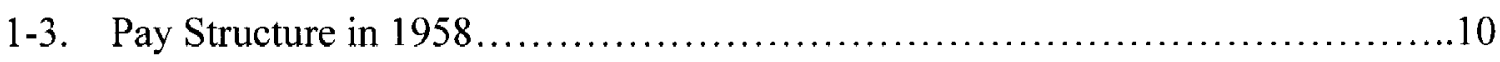

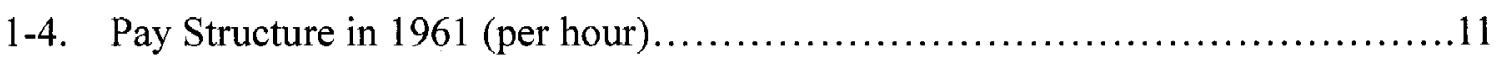

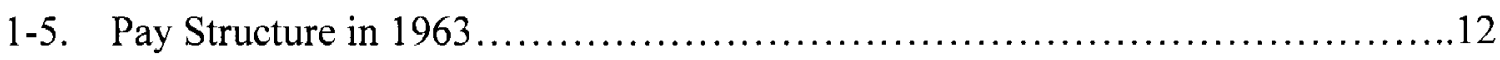

1-6. Share of Employed Women Working in Clerical Occupations,

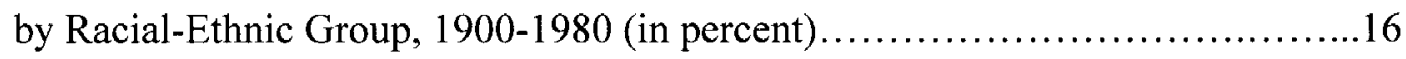

1-7. Occupational Distribution of European American Women,

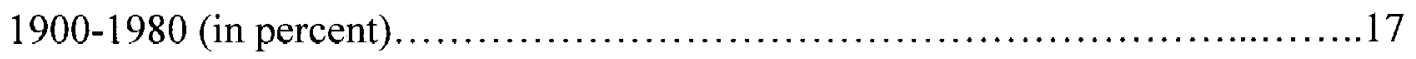

1-8. Krisman's Classification of Businesswomen by Historical Period.................21

2-1. Mead's Development of the Self through Social Interaction.....................56

2-2. Instruments Used by Human Beings in Social Interaction $\ldots \ldots \ldots \ldots \ldots \ldots \ldots \ldots \ldots . .58$

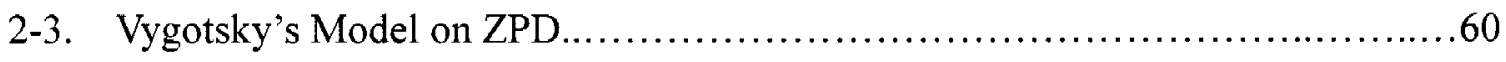

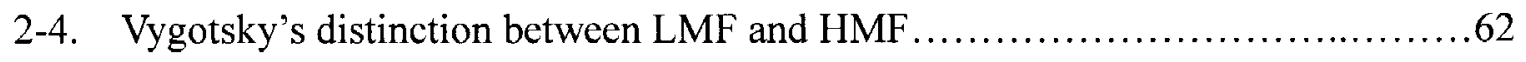

2-5. Distinction between Constructionism and Constructivism.....................68

4-1. The Dress-for-Success Wardrobe for Women............................ 161 


\section{LIST OF FIGURES}

FIGURE

PAGE

2-1. St. Clair's Model on Reality Loop..........................................42

2-2. Berger and Luckman's Model on the 3 processes operative in language................65

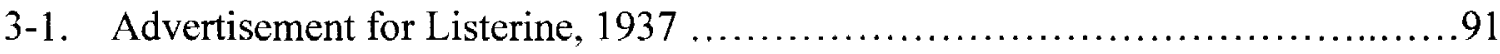

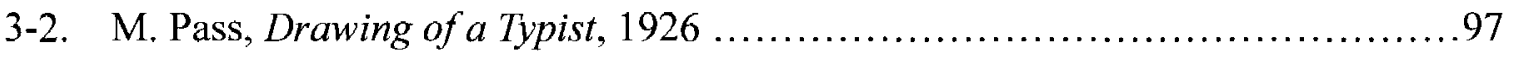

3-3. William Siegel, Office Worker's Lunch Hour, 1930_..........................97

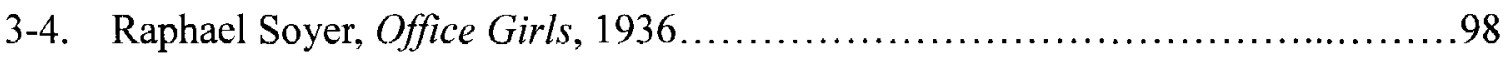

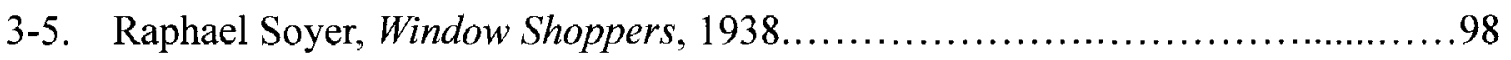

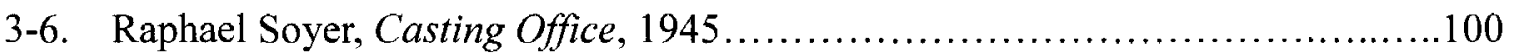

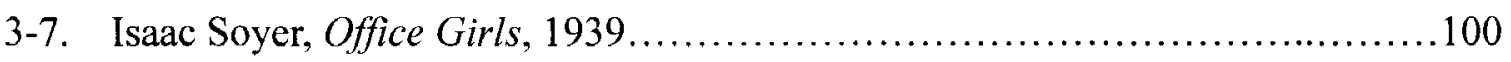

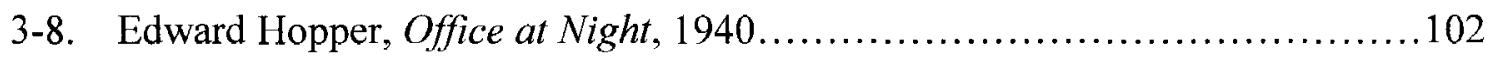

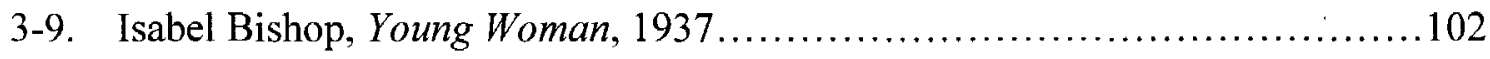

3-10. Isabel Bishop, Lunch Hour (detail),1939.................................... 103

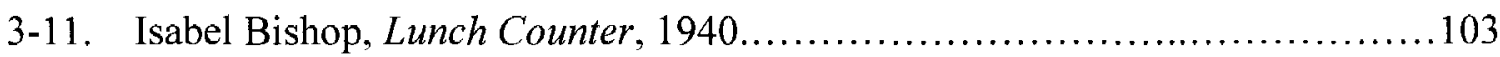

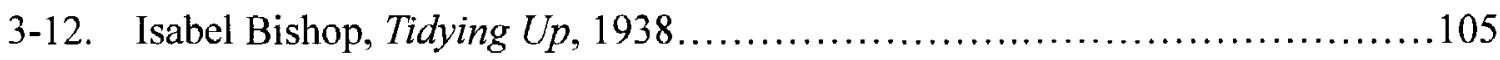

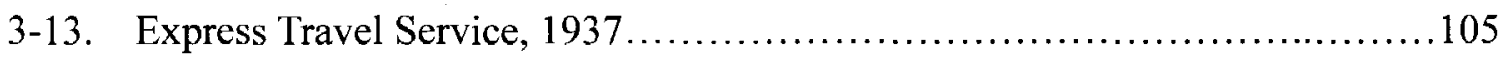

3-14. Charles Dunn, Drawing of the article "Romance Versus the Boss," 1937........131 
3-15. Loretta Young and Ricardo Cortez in Big Business Girl (1931)

3-16. Poster of the Movie Big Business Girl (1931)

4-1. Tess McGill in the movie Working Girl (1988). 162

4-2. Image of Gert Boyle as a tough mother. 176

4-3. Image of Gert Boyle as a tough mother. 176

4-4. Poster of the Movie Baby Boom (1982) 181

4-5. Poster of the Movie Nine to Five (1980) 192

4-6. Poster of the Movie Nine to Five (1980) 192

4-7. Cover of the album 9 to 5 and Odd Jobs by Dolly Parton. 194

5-1. Diagram of Freud's psyche theory .200

5-2. Lacan's Paradigm of the Imaginary Order and the Symbolic Order 203

5-3. Chart of consonant phonemes in English 205

5-4. Kristeva's Distinction between the Semiotic and Symbolic 213 


\section{CHAPTER I}

\section{INTRODUCTION}

\section{$\underline{\text { Social and Cultural Background }}$}

The topic under investigation has to do with what Foucault calls an epistemic rupture. In his stratificational model of historiography in the history of ideas, events become known and their structures are totally evident. When such events become present, they connect the past and the present. Foucault $(1972,1994)$ developed an earthquake metaphor in which historical knowledge is laid down upon the strata of the past. This hidden historical knowledge remains difficult to comprehend from the perspective of the present except at a time of an epistemic rupture, the equivalent of an earthquake in which the layers of knowledge of the past and the present are juxtaposed and open to interpretation in the present. What are epistemic ruptures? They are major epistemic events that change a society. For example, the bubonic plague (or the Black Death) in the 1330 s was an epistemic rupture. It broke up the old system of the clergy dominated hegemony in the middle ages and restructured social life all over Europe. There were 
three major classes of society: the clergy (Lat. clericus), the military (Lt. militares), and working people (Lat. labores). The world plague destroyed these social classes. It decimated the clergy, and soldiers were allowed to become priests; it also decimated the military, and servants were allowed to enter the military. After those changes took place, European society was forever restructured. Such is the nature of an epistemic rupture.

Major wars also create epistemic ruptures. They change the social life of a nation-state forever. The battle of Hastings in 1066 A.D., for example, was an epistemic rupture in that England lost the war to France and this led to the occupation and control of the French Normans for over three centuries. In that period of time, Old English, a Germanic language, underwent significant changes due to the fact that French was the new official language spoken in London. The result was the juxtaposition of two languages, French and English. The former was a Romance language and the latter a Germanic language. From this forced marriage of disparate tongues there emerged a hybrid language and a hybrid culture that is characteristically associated with Middle English.

A more recent example of an epistemic rupture occurred during Second World War (WWII). It was a war that took place between the United States and Germany in the Atlantic and the United States and Japan in the Pacific. In the process of fighting for survival, Blacks were called to serve in the military in the United States. They fought for a country that treated them as second class citizens. When they returned from the war, they had undergone a transformation. They began to fight for their own status as first 
class citizens. Women during this time were asked to leave their maternal roles and work in the factories that produced military planes, guns, and ships. After the war, they were no longer satisfied with their former roles as homemakers and they began to petition for better status and recognition in the marketplace.

The earthquake metaphor that Foucault used was meant to reveal the hidden knowledge of the past. He referred to this process as one done by archeologists who dig into the layers of the past in order to reveal new interpretations of people's understanding of the present. In this dissertation, the focus is not only on past knowledge and how it must be interpreted in the light of new evidence; it is also on the fact that earthquakes are seismal events caused by major forces interacting with each other beneath the earth's surface. These major forces are called faults. These are caused when one tectonic plate pushes against another and the result is a great tension that can only be relieved by means of a rupture in one or more of these plates. The metaphoric fault in this dissertation is the movement that began with Susan B. Anthony before the turn of the twentieth century and reappeared in the writings of Simon de Beauvoir (1964, 1972 and [1949] 1984) and Betty Friedan (1963, 1976 and [1949] 1998) in the middle of the twenty-first century. Were these events due to separate faults or to the same one? It appears that these events resulted from the same epistemic fault and that the major protagonists in the historiography of the movement were accurately predicted by seismographers who pointed out the fact that there was an earthquake about to happen. The metaphor of epistemic ruptures is an investigatory instrument into the history of this movement. With 
these historiographic changes, there were significant transformations among women. These were transformations of self-concept and self-identity. What these changes were and how they developed is the focus of this investigation.

\section{Background Information on This Period}

Prior to discussing the "epistemological raptures" among businesswomen in the United States from 1963 to 1985 , one needs to understand the background information that led to these ruptures. What was the nature of this revolution? Marvin Harris (1989, 1981, 2001), a Marxist anthropologist, has written much about the cultural changes that took place after WWII in the United States. His framework is known as cultural materialism and he argues that the changes in the sociology of everyday life at that time led to the civil rights era (1955-1968) and the women's movement. He provides a wealth of information on how this came about, and how the economics of the Second World War provided an epistemic rupture for women. The economic model used by Harris (1968) is discussed by him in The Rise of Anthropological Theory. His own model of Cultural Materialism incorporates and refines Karl Marx's categories of superstructure and base; Harris modifies and amplifies such core Marxist concepts as means of production and exploitation. However, he rejects two key aspects of Marxist thought. He disagrees with the concept of the Hegelian dialectic in which change is brought about by positing a thesis with its opposite (antithesis) in order to arrive at a compromise (the synthesis). He feels that this dialectic is not necessary and that it fails to account for anthropological 
change. He also rejects the belief that there could be a unity of theory and practice. Such a Marxian claim, he argues is inappropriate. Harris (2001) modifies Marx to develop a theory that explains culture as based on the practical problems of earthly human existence. In his model he defines three universal components in all societies: Infrastructure, structure, and superstructure (see Table 1-1.).

\section{Table 1-1.}

Marvin Harris's Model on Universal Components in Societies ${ }^{1}$

\begin{tabular}{|l|l|}
\hline Superstructure & $\begin{array}{l}\text { Superstructure consists of shared cognitive and ideological } \\
\text { patterns and behaviors in the society. }\end{array}$ \\
\hline Structure & Structures have to do with domestic and political economies. \\
\hline Infrastructure & $\begin{array}{l}\text { The infrastructure has to do with modes of production (a } \\
\text { Marxian concept) and birth and death rates (a Malthusian } \\
\text { concept). These are the fundamental elements needed for } \\
\text { survival. }\end{array}$ \\
\hline
\end{tabular}

How does this model differ from that of Marx? Marx (1967) only has two levels: infrastructure and superstructure. He also argues that the infrastructure determines the superstructure (The Principal of Infrastructural Determinism). Harris (2001), on the other hand, argues that there are three levels and that the infrastructure influences structure and it further influences superstructure. The strongest influence on structure comes from the domestic and the political economy. It is the domestic economy where one finds the

\footnotetext{
1 Table 1-1 is a brief summary of Harris's ideas on universal components in societies, which is adapted from the table by Harris (2001: 53). In addition, Harris (2001: 46-76) has detailed illustration of Superstructure, Structure, and Infrastructure.
} 
family, kinship structure, gender roles, and age roles. After all, the women's movement was about gender roles. The political economy has to do with class structure, and modes of political organization. Similarly, the women's movement was about women entering society at a new level and participating in political organizations in a new way.

The Women's Movements in the US

There are three major stages in women's movements in American history-the First Wave Feminism (1848-1920s), the Second Wave Feminism (1960s-1980s) and the Third Wave Feminism (1990s-present). Both of the first two waves regarded the economic independence as an important factor in women's liberation - the pursuit of gender equality. Although there were many successes during the Second Wave, such as the Title VII of the Civil Rights Act of 1964 passed, Formation of National Organization for Women (NOW), the rise of radical feminism during the 1970s, Title IX in the Education Amendments of 1972 passed, the Feminist Sex Wars of the late 1970s and 1980s, and the Roe vs. Wade decision decided, the Second Wave Feminism failed in the ratification of the Equal Rights Amendment (ERA). Therefore, the Third Wave Feminism arose as a response to the failures of the Second Wave Feminism in the 1990s. Many Third Wave feminists continue to focus on the activist goals of the day, but the "philosophy is more oriented towards individual empowerment than it is towards activism and social change" (Rockler-Gladen, 2007, para. 5). Gardner (2006) illustrates in detail the epistemic ruptures that took place as a result of the three waves of Feminism, which are 
summarized in Table 1-2 as follows:

Table 1-2.

Three Waves of Feminisms and the Epistemic Ruptures ${ }^{2}$

\begin{tabular}{|l|l|l|}
\hline \multicolumn{1}{|c|}{ Events } & Time period & \multicolumn{1}{c|}{ Epistemic ruptures } \\
\hline $\begin{array}{l}\text { First } \\
\text { Wemine }\end{array}$ & $1848-1920$ & $\begin{array}{l}\text { Challenges to the legal and social inequalities to women; } \\
\text { reforms on the right of women to own property, marital } \\
\text { laws, education and female suffrage; challenges to the } \\
\text { ideology of "separate spheres"; women asked for both } \\
\text { personal and economic independence. }\end{array}$ \\
\hline $\begin{array}{l}\text { Second } \\
\text { Fave }\end{array}$ & $1960 \mathrm{~s}-1980 \mathrm{~s}$ & $\begin{array}{l}\text { The ideal woman's destiny of "finding a husband and } \\
\text { bearing children" was challenged and women were } \\
\text { encouraged to seek new roles and take on new } \\
\text { responsibilities; women sought their own personal and } \\
\text { professional identities rather than having them defined by } \\
\text { the outside, male-dominated society. }\end{array}$ \\
\hline $\begin{array}{l}\text { Third } \\
\text { Wave } \\
\text { Feminism }\end{array}$ & $1990 \mathrm{~s}-n$ ow & $\begin{array}{l}\text { There is a lack of a single cause; more oriented towards } \\
\text { individual empowerment; often seen as an extension of } \\
\text { the second wave. }\end{array}$ \\
\hline
\end{tabular}

As we can see from Table 1-2., the First Wave Feminism (or old wave feminism) refers to the period of challenges to the legal and social inequalities of women from the mid-1800s to 1920 in the United States and the United Kingdom. Activists worked for, among other things, "female suffrage, the right of women to own property, the reform of marital laws, and education reform" (Gardner, 2006: 93). Much of the feminist philosophy shows the concerns of these activists and the goals of social reform. In this period of time, the ideology of "separate spheres" was still prevalent and it influenced

\footnotetext{
2 This table is a brief summary of the social and cultural changes of the three waves of Feminism, which is based on Humm (1992b: 11-15, 53-60), and the corresponding dictionary entries in Gardner (2006) and Humm (1995).
} 
women's social, political, and cultural status (Gardner, 2006). According to this doctrine, women belong to the private sphere, which is concerned with domesticity and other personal issues. Men belong to the public sphere and concentrated on social, political, and cultural concerns. Many feminist activists focus on understanding separate spheres and women's experiences with this ideology. Harriet Taylor Mill ([1851]1994), for example, holds that married women should be allowed to work outside the home, which would give women both personal and economic independence. Barbara Leigh Smith Bodichon wrote in 1895 that "adult women must not be supported by men if they are to stand as dignified rational creatures before God..." (1859: 30-31). Only the possibility of economic independence allows men and women "to form equal unions" (ibid.). In Charlotte Perkins Gilman's work in 1898, Women and Economics: A Study of the Economic Relation Between Men and Women as a Factor in Social Evolution (1966), Gilman points out that the economic and social dependence of women on men is unnatural and it hampered women's development. In general, women's economic position received much attention from the First Wave Feminists.

During the 1950 s and early 1960 s, WWII had come to a close, "feminism was almost nonexistent compared to earlier decades when the struggle for women's suffrage was still going on" (Harris, 1981: 79). However, changes that took place at that time still continued to operate within American society. One of the biggest changes had to do with the shifts in the labor force. During the war an increasing number of married women entered the labor force. In 1944, Senator Harry Truman said: "Many women who have 
gone into factories and done such splendid work will want to continue working, and they are entitled to the chance to earn a good living at jobs they have shown they can do" (Chafe, 1972: 176). At the end of the war, women were encouraged to be housewives and homebody husband-pleasers. In this period of postwar prosperity,

there was a surge in the invention and production of consumer goods, many of them convenience items that reduced the burden of housekeeping: automatic washers and dryers, automatic dishwashers, wrinkle-free garments, frost-free refrigerators and home freezers, microwave ovens, and frozen packaged foods all added free time for women who worked as homemakers. For the first time, they had hours available to do something outside the home. Since these convenience items were also expensive, for many women the "opportunity" to enjoy free time was won when they earned money to pay for the tools that created it. A climate was created in which women not only could work outside the home, but often had to do so to be able to enjoy the quality of life they wanted for themselves and their families. (Kozmetsky, 1989: 138)

In addition, there was the well-known post-World War II "baby boom." Nevertheless, the baby-boom parents soon found it "increasingly difficult to achieve or hold on to middle-class standards of consumption for themselves and their children, and the wife's job had begun to play a crucial role in family finances" (Harris, 1981: 91). Therefore, more and more women went back to the labor force again and did not want to be merely housewives. According to Harris (1981), it is the housewives' going into the labor force that leads to the women's liberation or the intensive consciousness-raising in the post-war years, not vice versa.

One of the problems noted after the WWII was the disparity in pay structures between men and women. In 1958, "women professionals earned on the average 64 
percent of what men earned: women sales workers were paid 44 percent of what men were paid; and women service workers were paid 53 percent of what men received," as shown in Table 1-3 (Workers Fact Book, 1960, Bureau of Labor Statistics, as cited in Plopper, 1963, para.16).

\section{Table 1-3.}

$\underline{\text { Pay Structure in } 1958^{3}}$

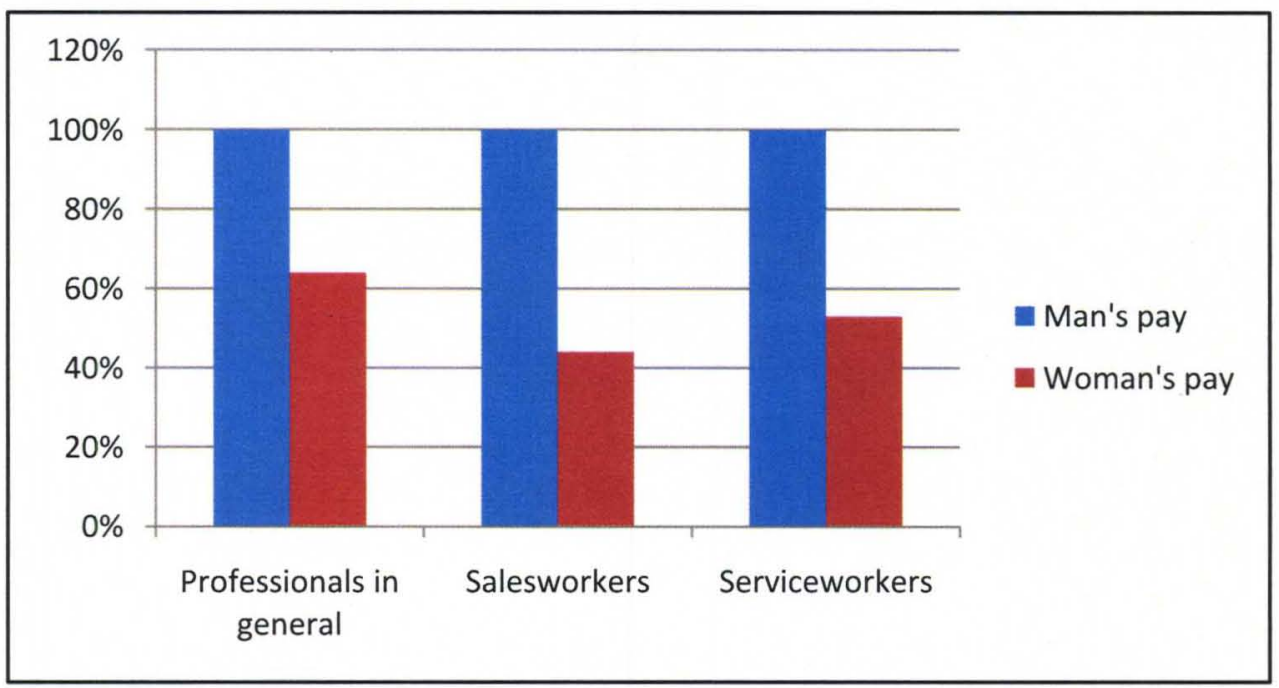

In 1961, according to Plopper (1963, para.10), the average hourly earnings of women in the retail field are consistently less than those of men. In the retailing business, women averaged $\$ 1.52$ an hour as compared with $\$ 1.77$ an hour for men in supermarkets; the figures were $\$ 1.36$ and $\$ 2.01$ respectively for women and men in department stores; $\$ 1.03$ and $\$ 1.38$ in variety stores; and $\$ 1.14$ and $\$ 1.79$ in drugstores (see Table 1-4).

\footnotetext{
${ }^{3}$ This table is based on the data provided by Plopper (1963, para.16).
} 


\section{Table 1-4.}

$\underline{\text { Pay Structure in } 1961 \text { (per hour) }}$ ( $^{4}$

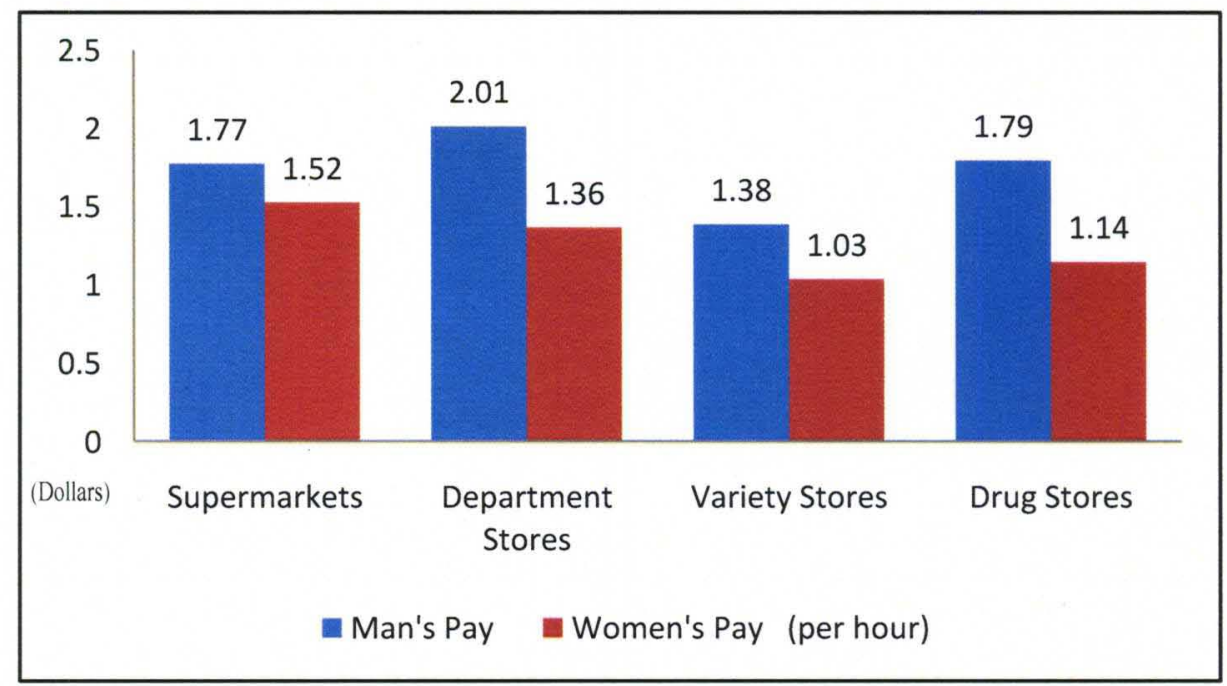

In 1963, "the average working woman earned only 63 percent of what a man made" (Hamby, 2006: 201. See Table 1-5). In this year, the Equal Pay Act (EPA) was signed into law by the president John F. Kennedy, aiming at abolishing wage disparity based on sex. However, some critics deemed the EPA as a failure because the average wages given to women were still lower than those of men long after 1963.

\footnotetext{
${ }^{4}$ This table is based on the data provided by Plopper (1963, para.10).
} 


\section{Table 1-5.}

$\underline{\text { Pay Structure in } 1963^{5}}$

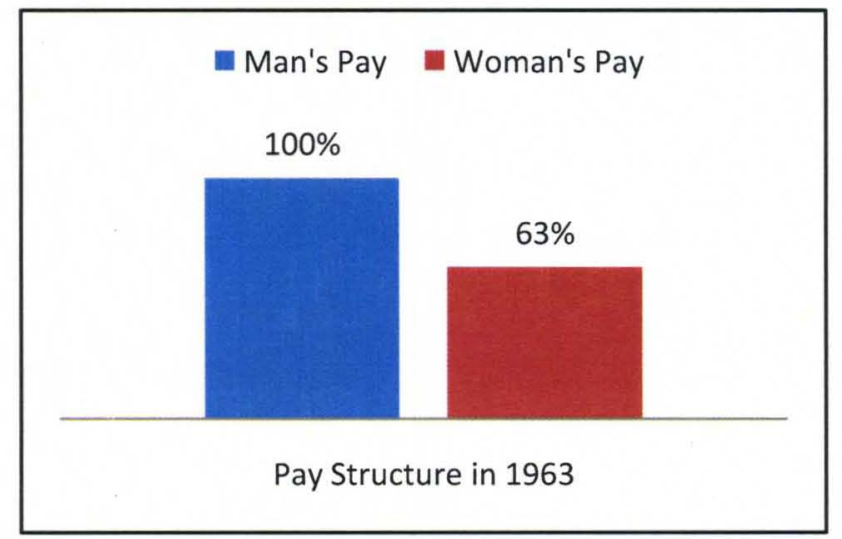

The year 1963 is important also because it was the year when author Betty Friedan published The Feminine Mystique. It was an explosive critique of middle-class patterns. It also articulated what was a pervasive sense of discontent. Friedan argued that women often had no outlets for expression other than "finding a husband and bearing children." (Friedan, 1963: 58) She encouraged her readers to "seek new roles and take on new responsibilities and to find their own personal and professional identities rather than have them defined by the outside, male-dominated society" (Hamby, 2006: 201). The feminist movement in the 1960s and the 1970s, extending through the late 1980s, in both Europe and the United States is regarded as the Second Wave Feminism.

As noted by Harris $(1989,1981)$, the Second Wave Feminism drew inspiration from the Civil Rights Movement. It was organized by a spirit of rebellion. It was a rebellion

\footnotetext{
5 This table is based on the data provided by Hamby (2006: 201).
} 
that affected large segments of middle-class. Associated with this rebellious spirit were the counter-culture movement in the 1960s and the emergence of the sexual revolution. Part of the Civil Right Movement was integrated into the women's movements.

One of the consequences of the Second World War and its impact on social movements in the US was the fact that it prompted reform legislation; for example, there was the enactment of the Civil Rights Bill in 1964. An amendment was added that outlawed discrimination on the basis of gender as well as race. Both the amendment and the bill passed. Dr. Martin Luther King Jr. said in his speech in Western Michigan University on "Social Justice" in 1963 that some people believed the idea that "legislation cannot really solve the problem and that it has no great role to play in this period of social change because you've got to change the heart and you can't change the heart through legislation" (King Jr., 1963, para.30). However, he argued that: "it may be true that morality cannot be legislated, behavior can be regulated. It may be true that the law cannot change the heart but it can restrain the heartless. It may be true that the law cannot make a man love me but it can keep him from lynching me and I think that is pretty important" (ibid.).

In addition, the Presidential Commission on the Status of Women (PCSW) was established by John F. Kennedy's executive order 10980 signed on December 14, 1961, to advise the President of the United States on issues concerning the status of women. By 1966, the National Organization for Women (NOW) was formed. The purpose of this group was to "take action to bring women into full participation in society - sharing 
equal rights, responsibilities and opportunities with men, while living free from discrimination." ${ }^{6}$ By 1967, 1,000 women had joined; four years later membership reached 15,000 . NOW and similar organizations helped make women increasingly aware of their limited opportunities and strengthened their resolve to increase them.

Feminism, or organized activity on behalf of women's rights and interests, reached high tide in the early 1970s. Journalist Gloria Steinem and several other women founded a new magazine, Ms., which began publication in 1972. Between 1971 and 1976, Our Bodies, Ourselves, a handbook by a woman's health collective, sold 850,000 copies. During the 1970s, NOW was the most vocal advocate that promoted the Equal Rights Amendment (ERA) to the U.S. Constitution. After Congress approved the amendment in 1972, it was quickly ratified by 28 states. ERA declared, "Equality of rights under the law shall not be denied or abridged by the United States or by any State on account of sex" (Eisenberg \& Ruthsdotter, 1998, para.40). Over the next several years, 35 of the necessary 38 states ratified it. The courts also promoted sexual equality. In 1973, the Supreme Court, with Roe v. Wade, sanctioned women's right to abortion during the early months of pregnancy - a significant victory for the women's movements. In the mid- to late 1970s, however, the women's movement stagnated. It failed to broaden its appeal beyond the middle class. Divisions arose between moderate and radical feminists. Conservative opponents mounted a campaign against the ERA, and it died in 1982 without gaining the approval of the 38 states needed for ratification (Eisenberg \&

\footnotetext{
${ }^{6}$ See http://www.now.org/about.html (para.1); accessed on July 1, 2009.
} 
Ruthsdotter, 1998, para.42). Although the Second Wave Feminism failed in general, it did change people's hearts, especially women's hearts, to a great extent. This dissertation will use evidence from historiography, literature and popular culture to show these changes.

\section{Feminization of the Corporate Office}

The total U.S. population grew more than seven-fold between 1870 and 1980, from almost 40 million to over 225 million, through a combination of immigration and childbearing. This population growth added fuel to the rapid industrialization of American economy, as the labor force grew from 13 to 98 million. Since the 1880 s, the corporate form of business organization became more and more prominent, and more new jobs were created. As a result, women got more opportunities to work in business corporations. Amott and Matthaei's (1996) research shows that the paid work performed by women from 1900 to 1980 changed dramatically. One of the most important occupational changes for women in the twentieth century was the growth of clerical work. According to Amott and Matthaei (1996), women's clerical employment grew from 320,000 in 1900 to over 2 million in 1930 and 12 million in 1980. Amott and Matthaei expressed that:

In the $19^{\text {th }}$ century, a clerk was typically an educated white man who worked in an office as training for managerial work. When the typewriter was introduced, young European American middle-class women were hired to operate the machine and the job was feminized: the clerical worker's career path to management was eliminated, and clerical workers found themselves low-level assistants to male managers, treated as office 
wives. (1996: 335)

In 1900, as shown in Table 1-6, only white women were significantly employed in clerical work. U.S. women of color were almost "totally excluded from this new, relatively high-status job" (Amott \& Matthaei, 1996: 335) and they "remained overly concentrated in the pre-industrial sectors of agriculture and domestic work" (Amott \& Matthaei, 1996: 351).

Table 1-6.

Share of Employed Women Working in Clerical Occupations, by Racial-Ethnic Group, 1900-1980 (in percent)

\begin{tabular}{|l|c|c|c|c|}
\hline & 1900 & 1930 & 1960 & 1980 \\
\hline African American & 0.1 & 0.6 & 8.0 & 25.8 \\
\hline European American & 6.9 & 25.3 & 34.5 & 32.3 \\
\hline American Indian & 0.1 & 3.3 & 14.2 & 27.4 \\
\hline Chinese American & 0.5 & 11.7 & 32.1 & 24.7 \\
\hline Japanese American & 0.1 & 3.7 & 30.5 & 31.6 \\
\hline Filipina American & n.a & 1.6 & 24.3 & 28.2 \\
\hline Chicana & n.a & 2.8 & 21.8 & 26.2 \\
\hline U.S. Puerto Rican & n.a & n.a & 13.9 & 31.9 \\
\hline Island Puerto Rican & 1.2 & 2.3 & 16.9 & 26.9 \\
\hline
\end{tabular}

In the post-WWII period, this racial-ethnic and gender segregation was partially broken down. Married women, especially white, middle class, married women, rapidly entered the paid labor force. Feminist and civil rights struggles challenged the legal and ethical basis for gender and racial-ethnic segregation. Table 1-7 shows the occupational

\footnotetext{
7 Table 1-6 is adapted from the table by Amott \& Matthaei (1996: 338). See Amott \& Matthaei (1996: 337-354) for detailed comparison of the share of employed women working in clerical occupations, by racial-ethnic group, 1900-1990, as a result of the rise of office work.
} 
distribution of employed white women from 1900 to 1980 . By 1900, over 10 percent of white women workers held professional and technical jobs. Many of these jobs were directly linked to social homemaking. Since 1930s, more and more white women held clerical work.

Table 1-7.

Occupational Distribution of European American Women, $1900-1980$ (in percent) ${ }^{8}$

\begin{tabular}{|l|c|c|c|c|c|}
\hline & 1900 & 1930 & 1960 & 1970 & 1980 \\
\hline Agriculture & 9.8 & 4.1 & 1.5 & 0.7 & 1.0 \\
\hline Manufacturing & 32.6 & 21.2 & 18.5 & 16.8 & 12.6 \\
\hline Private Household Service & 29.8 & 12.0 & 4.4 & 2.1 & 0.8 \\
\hline Service (Not Private Household) & 3.8 & 8.1 & 13.2 & 15.3 & 15.3 \\
\hline Sales & 4.1 & 9.3 & 9.2 & 8.0 & 12.1 \\
\hline Clerical & 6.9 & 25.3 & 34.5 & 36.8 & 32.3 \\
\hline Professional \& Technical & 10.2 & 16.2 & 14.6 & 16.3 & 18.0 \\
\hline $\begin{array}{l}\text { Managerial, Administrative, \& } \\
\text { Official }\end{array}$ & 2.9 & 3.6 & 4.3 & 3.9 & 7.9 \\
\hline
\end{tabular}

In fact, between the 1900s and 1960s, white men monopolized the top managerial, administrative and professional jobs, while white women monopolized the feminine professions and clerical work. European American sociologist Margery Davies calls this phenomenon the "feminization of the office" (1982).

\footnotetext{
${ }^{8}$ Table1-7 is adapted from the table by Amott \& Matthaei (1996: 125). See Amott (1996: 125-140) for detailed analysis of the occupational distribution of European American women, 1900-1990.
} 


\section{$\underline{\text { Research Purposes and Research Questions }}$}

The self-identity of corporate businesswomen has to do with the history of women, history of business and history of labor. However, women rarely appeared in business or labor history, perhaps because the field was slow to adopt the concerns of the new social history, or perhaps because there appeared to be no place for them. We know that when U.S. President Calvin Coolidge declared in the 1920s that the "chief business of the American people is business," he was not thinking about women (Drachman, 2002: 160). Given the above-introduced social and historical factors, this dissertation will investigate a range of matters associated with the self-identity of white American corporate businesswomen (WACB) between 1963 and 1985 as the consequences of the epistemic rupture, and how they were culturally and socially constructed from a post-structuralist point of view.

Why do I focus on the business world, rather than other professions, such as civil servants or politicians? The reason is that it is in the business world that a cultural shift in favor of women is identified. Traditionally, people believe that the world of business is set up by men for men, and women's occupations should have nurturing or supporting characteristics, such as in teaching and nurseing. However, during the 1960s, women's social roles and self-identity changed dramatically-their view toward their work in business changed from "job" to "career"; their views toward family and men also 
changed, which led to a new definition of womanhood. Although the white American corporate businesswomen between 1963 and 1985 were not the first women who broke through the chauvinist barriers to become successful in a male-dominated business world, they have new identities for themselves in this period, and their images have not yet been depicted completely by the contemporary scholars.

This research will focus on white American corporate businesswomen between 1963 and 1985. Among the reasons:

First, the status of white American corporate businesswomen increased rapidly in general during this period. Their non-white counterparts, such as African Americans, Hispanic Americans (Latinas) and Asian Americans, however, maintained a comparatively minority status throughout both American business history and women labor history, though they have been part of the business landscape. In a way; the change of the self-identity of the white American corporate businesswomen is believed to be a representative of the western world. Their self-identity offers special reference to women in business in other countries, especially in the eastern world, such as Chinese businesswomen.

Second, I chose 1963 to be the beginning year in this study because, in this year, several significant events happened. For example, Betty Friedan wrote The Feminine Mystique, which signals the beginning of the Second Wave feminist movement. In fact, Betty Friedan was one of the seismologists who identified the feminist movement earthquake. In addition, the American congress passed the Equal Pay Act in 1963, which 
allowed women equal pay for equal work; and Harvard Business School began admitting women students and encouraged them to pursue their own business. What is more, three influential white American corporate businesswomen started their business in this year: (1) Mary Kay Ash broke free of the domestic restrictions Betty Friedan exposed in The Feminine Mystique and began her cosmetics company. Later, she built it into the largest direct-sale multilevel cosmetics company in the world; (2) Marion Sandler, together with her husband Herbert Sandler, formed Golden West Savings \& Loan and built it into a Fortune 500 company; and (3) Jean Nidetch, a Brooklyn homemaker, founded Weight Watchers, which now operates in about 30 countries around the world (Krisman, 2005: xxxi). It is true that big corporations only accounts for five percent of American business, and the majority is small businesses; however, these events encouraged women, especially white women, to bravely change their lives (or social roles), which laid a solid foundation for the status of White American corporate businesswomen.

Furthermore, the year 1985 is the ending year in this research because after the mid-1980s, the self-identity of American businesswomen must have undergone some new changes because of the development of science and technology, such as the pervading computers (before that, typewriters were the most popular tools for business work), and the new development of Feminism. In addition, in Encyclopedia of American Women in Business: from Colonial Times to the Present (2005), Carol H. Krisman puts American businesswomen into seven historical periods as shown in Table 1-8.:

Based on Table 1-8, we can say that, between the year 1963 and 1985, the 
self-identity of modern white American corporate businesswomen is comparatively stable,

which provides the author with a platform to do research.

\section{Table 1-8.}

$\underline{\text { Krisman's Classification of Businesswomen by Historical Period }}{ }^{9}$

\begin{tabular}{|c|c|c|}
\hline No. & Historical Period & Time Period \\
\hline $\mathbf{1}$ & Colonial businesswomen & $1539-1800$ \\
\hline $\mathbf{2}$ & Pre-industrial businesswomen & $1800-1830$ \\
\hline $\mathbf{3}$ & Industrial businesswomen & $1830-1880$ \\
\hline $\mathbf{4}$ & Corporate businesswomen & $1880-1930$ \\
\hline $\mathbf{5}$ & Mid-century businesswomen & $1930-1963$ \\
\hline $\mathbf{6}$ & Modern businesswomen & $1963-1985$ \\
\hline $\mathbf{7}$ & Contemporary businesswomen & 1985 -present \\
\hline
\end{tabular}

Due to the development of science and technology, the voice of the white American corporate businesswomen between 1963 and 1985 is heard from all sources of media-books, magazines, TV programs, movies, and advertisements, etc. They expressed their identity and power almost everywhere! By placing this group of women properly in history, we can see clearly the social and cultural constructions of their self-identity.

This research will have three layers. In the first layer, Mary Kay Ash's autobiography Mary Kay: the Success Story of America's Most Dynamic Business Woman ${ }^{10}$ (1987) will be used as the primary source for her self-identity. Mary Kay Ash was chosen because

\footnotetext{
9 Kwolek-Folland (1998) has a similar classification of women and business by historical period: (1) Female Economies: Women and Business in Preindustrial America, 1550-1830; (2) Mills and More: Women's Business and the First Industrial Revolution, 1830-1880; (3) Personal Work: Women's Business in a Corporate World, 1880-1930; (4) Crisis Management: Women and Business at Midcentury, 1930-1963; (5) Difference at Work: The Renewal of the Businesswoman, 1963-1997. Since this classification focuses on the business work of women rather than the characteristics of businesswomen, this study adopts Krisman's classification.

${ }_{10}$ To make it simple, Ash's autobiography is often referred to as Mary Kay (1987).
} 
she wrote extensively and has great influence in American business world (she was accepted in the U.S. Business Hall of Fame). The author believes that her self-identity as reflected in her autobiography can be seen as a representative among the whole group of white corporate businesswomen. In the second layer, the characteristics of her self-identity will be projected on other white corporate businesswomen in the American society between 1963 and 1985 by drawing out similar characteristics of the self-identity from them through the cultural evidence. In the third layer, the historical changes of their self-identity, and how their self-identity (between 1963 and 1985) was culturally and socially constructed will be analyzed from a poststructuralist point of view. This offers a productive framework for understanding the mechanisms of power in the society and the possibilities of change. Then the scope of this research will be extended into the 1990 s to see that the Second Wave Feminism has not achieved the complete success in solving working women's problems, and the Third Wave Feminism may bring some solutions to the problems.

The following list provides a range of research questions concerning this period of changes in the self-identity among white American corporate businesswomen between 1963 and 1985:

(1) The following three aspects are seen as the core of businesswomen's self-identity: (i) their views on career achievement-the pursuit of independence, leadership and success in the business world; (ii) their views on the relationship between work and family; and (iii) their views on their relationship with men, especially 
at their workplace ${ }^{11}$. Through Mary Kay Ash's autobiography Mary Kay (1987), the author will analyze and identify her self-identity, i.e. how does she sees herself and others as corporate businesswomen? What are her views on these three major aspects of businesswomen's self-identity?

(2) By projecting Mary Kay Ash's self-identity to the American society between 1963 and 1985, the author is trying to find out how, as the results of the epistemic ruptures, the white American corporate businesswomen between 1963 and 1985 see themselves and others. What are their views on the major aspects of businesswomen's self-identity? What are the changes of their self-identity that took place before and after 1963? It is believed that they were showing a new definition of womanhood. So, what is this new definition of womanhood? In what ways is it different from the previous ones as a result of these women's interaction with the society?

(3) What are the cultural evidence from three different disciplines-historiography, literature, and popular culture that can embody and help construct socially and culturally the corporate businesswomen's self-identity between 1963 and $1985 ?$

(4) Historically speaking, to what extent does the social construction of the self-identity of the white American corporate businesswomen between 1963 and 1985 reflect the view of the nature of gender differences in American society as a

\footnotetext{
11 These three aspects were extracted from the autobiographies of several American corporate businesswomen, which include: Mary Kay Ash's Mary Kay (1987), Estée Lauder's Estée: A Success Story (1985), Mary Wells Lawrence's A Big Life in Advertising (2002) and Gert Boyle's One Tough Mother (2005). These three aspects are the common major concerns in all the four books.
} 
result of Second Feminism and WWII? Most importantly, what are the changes, as the results of these epistemic ruptures, which took place in the views before and after the period between 1963 and 1985? Is there any new epistemic rapture that can be identified after 1985 ?

\section{$\underline{\text { Literature review }}$}

In her path breaking book, The Feminine Mystique (1963), Betty Friedan first spoke of "the problem that has no name," by which she means that being a wife and mother failed to provide the fulfilling life for which many women aspired. The analysis of this problem led her to the discussion of identity and the self. As a result, the real "question which has no name" turns out to be "who do I want to be?" (Friedan, 1963: 61). Based on her own experiences, Friedan tells us that the young heroine in the book had a very good education (with a doctoral degree), but she abandoned the possible career without really knowing why. She got married, had children and became a suburban housewife, but there was a lack of purpose in life. In the end, she broke with the old identity and saw that she needed self-fulfillment elsewhere. Through her heroine, Friedan (1963) points out that women's traditional personal identity was threatened because there were more options available for women. It is just in these alternatives that women realize that the modern culture does not "gratify their basic need to grow and fulfill their potentialities as human beings..." (Friedan, 1963: 68). In the conclusion, Friedan (1963) encourages women to do a good life plan and create new self-identities in the previously unexplored public 
domain. This new life-plan includes a commitment to personal growth, a rethinking and reconstruction of the past, and the recognition of the risk in the unknown future.

There are quite a few books and research that focus on American women in business. In her book, Historical Encyclopedia of American Women Entrepreneurs: 1776 to the Present (2000), Jeannette M. Oppedisano chronicles some of the extensive entrepreneurial contributions of American businesswomen to the national economy in the widely accepted categories of agriculture and mining, communications, construction, manufacturing, service, transportation, and wholesale and retail trade. Her book in fact corrects the recorded history of American women.

On how the American businesswomen see success, there is Virginia O'Brien's Success on Our Own Terms: Tales of Extraordinary Ordinary Business Women (1998), in which the author interviewed 54 women at various management levels in 23 major companies and their subsidiaries and asked them to tell her about their careers, to define success, and to explain why they balanced their lives. O'Brien also did a national survey in conjunction with Executive Female Magazine. Almost 700 women responded. The results show that businesswomen describe success in terms of being happy, meeting goals, and having passion about their work and their lives. In Edgehill B. Awkward's How Sixteen Professional Business Women in the Northeastern USA think about Career Success and how Their Thoughts Influence Their Approach to Achieving It (2005), a quantitative study was done on (1) how professional business women define career success; (2) what mental models and theories-in-use underlie and influence how they 
achieve career success; and (3) what factors they report as supportive to the achievement or career success. The results show that (1) self-awareness and the development of "voice" is critical to forming and expressing a personal definition of career success; (2) mental models for career success must be followed by consistent strategies for career success if career success is to be achieved; (3) a structured process for ongoing reflection is important to achieve career success; (4) the role of the manager is critical to a professional women's ability to achieve career success. In general, the stories of the women revealed that "they were achievement oriented and motivated to succeed, but not at the cost of 'losing themselves' to the organization," which shows that these business women were influenced by American culture and values (Awkward, 2005: 169).

There are also several business historians who summarize the stages that businesswomen underwent in American history. In Incorporating Women: A History of Women and Business in the United States (1998), Angel Kwolek-Folland offers a division of five periods for the history of women and business. They are Pre-industrial America (1550-1830), First Industrial Revolution (1830-1880), Corporate World (1880-1930), Midcentury (1930-1963) and the Renewal of the Businesswoman (1963-1997) (Kwolek-Folland, 1998: vii). In her book, Enterprising Women: 250 Years of American Business (2002), Virginia G. Drachman roughly divides the history of enterprising women into four stages. In the first stage, from 1750 to 1830 , women in business were seeking independence; in the second stage, from 1830 to 1890 , they were primarily making profit in the service of women, especially in the business of beauty; in the third 
stage, from 1890 to 1960 , they broke new ground and entered most of the business fields; In the fourth stage, from 1960 to 2000, they took charge. From the different divisions of the history of American women in business, we can see a common ground: businesswomen after 1960s (especially after 1963) went on the historical stage with a new outlook.

Some researches focus on the identity of American women in business from a historical or sociological point of view. For example, there is Candace A. Kanes' American Business Women, 1890-1930: Creating an Identity (1997), which depicts businesswomen's immerging identity in the end of $19^{\text {th }}$ century and the beginning of the $20^{\text {th }}$ century through the roles and endeavors of their organizations and publications, such as magazines and journals; Similarly, in Maureen Anne Carroll's Office Girls/Business Women: Work, Gender, and Civicism in Atlanta, Georgia, 1919-1940 (1995), business women's organizations also play a crucial role in combining rank and file clerical workers and retail clerks with career-oriented office managers, entrepreneurs, and professional women. Within these organizations, white-collar working women struggled with concepts of business women's identities and attempted to integrate their work lives with their community, religious, and familial obligations. In Beyond the Typewriter: Gender, Class, and the Origins of Modern American Office Work, 1900-1930, Sharon Hartman Strom (1992) explores the office working conditions and practices, drawing upon archival and anecdotal data. She analyzes women office-workers' ambitions and illustrates how the influences of scientific management, personnel management, and 
secondary vocational education affected office workplaces and hierarchies.

In addition, there are also two books that describe the contemporary businesswomen's experiences and identities in the U.K. that are worth mentioning. They are Jane McLaughlin's Up and Running: Women in Business (1992) and Robert Goffee and Richard Scase's Women in Charge: the Experiences of Female Entrepreneurs (1985). In these two books, the authors believe that businesswomen in the 1980s and 1990s are trying to establish their own unique identity in business, which "inevitably involved cutting themselves loose from the convention that all women were nurturers whose identity was sublimated in caring for their husbands and children" (McLaughlin, 1992: 183).

From the above literature review, we see three points that the majority of the research shares: (1) it is carried out from sociological and historical perspective, (2) it seldom mentions and compares the change of the identity of businesswomen in different historical periods, and (3) except for some sociological interviews, it seldom touches the self-identity of businesswomen, i.e., how they see themselves and others from different aspects of life in different social roles, such as business people, mothers, wives, daughters, or women in relation to men.

\section{$\underline{\text { About the present study }}$}

This interdisciplinary dissertation will fill in the blanks that the majority of the research on businesswomen left out. From a humanistic point of view, it will focus on (1) 
the "self-identity" of modern white American corporate businesswomen between 1963 and $1985,(2)$ the change of their self-identity in comparison with the historical period between 1920 and 1963, and (3) how their self-identity is socially and culturally constructed by analyzing evidence chosen from three disciplines-historiography, literature, and popular culture. The author will use the theories related to Self-identity, Social Constructionism, and post-structural Feminism as the tools for analysis. These theories will be introduced in Chapter II. Before that, it is necessary to first define the key terms of "corporate businesswomen" and "white American corporate businesswomen."

\section{Corporate Businesswomen ${ }^{12}$}

According to the Library of Congress Subject Heading catalog ${ }^{13}$, the organizational tool used by most libraries to help patrons locate books and articles, there are listings for "Businessmen," and "Businesswomen." However, under "Businesswomen," the catalog notes: "Use Women in Business." "Business" and "men" are combined into one idea and one word. However, in "Women in business," according to Kanes, "the gender notation comes first and 'women,' instead of being linked to business, are a subsidiary, or smaller part, attached by a preposition" (1997: 1-2). The author believes that the term "Women in business" has more emphasis on "being women," and has a much broader sense than "Businesswomen," therefore, in this dissertation, the term "Businesswomen," rather than

\footnotetext{
12 The author believes that there is no difference between the terms "Businesswomen" and "Business women." Therefore, "Corporate businesswomen" equals to "Corporate business women."

${ }^{13}$ Library of Congress Subject Headings $19^{\text {th }}$ Edition (Washington, D.C.: Library of Congress, Cataloging Distribution Service, 1996), Vol. I A-C, 747 and Vol. IV Q-Z, 5875.
} 
"Women in business," will be used to show a sense of occupation. In addition, the women office workers in the early twentieth century generally made a distinction between "business girls" and "businesswomen"- the former remained female identified while the latter had traded their femininity for the rewards of a career (Kwolek-Folland, 1994, 1998). In order to use terms consistently, the term "Businesswomen" will be used, which includes those business girls in the early twentieth century.

Susan Lewis (1992, 1995, 1997 and 2003) does research on businesswomen in Albany. She gives a definition to "businesswoman"- "any woman who was making money but not through wages; She is running a small business and usually self employed ranging from peddlers to women running large cooperated business"14 (Lewis, 2003). In this study, we will exclude the peddlers, but include those clerical workers who may earn wages, such as the typists. We will focus on corporate businesswomen, who are businesswomen working for business corporations, and they do not have to be the business owners. Here is the working definition of "corporate businesswomen"-"any woman who is working for a business corporation and her work should have some relation to corporate business; she may or may not be the business owner." According to this definition, corporate businesswomen include all the women ranging from the low-paid corporate clerical workers or office workers, to mid-level and top-level women corporate business managers or leaders. The reason why the author puts them together

\footnotetext{
${ }^{14}$ This definition of businesswoman is based on the transcript of a MP3 on-line audio interview (time: 40:58) of Susan Lewis' research on Businesswomen in Albany, New York, 1830-1885. This research has uncovered over 2,000 individual women engaged in business enterprises in the city of Albany between 1830 and 1885 .
} 
under the term of "corporate businesswomen" is that a lot of clerical workers have the dream of becoming business leaders and the majority of the women business leaders were clerical workers when they first entered the companies. So, their roles in the companies are changing along a hierarchy, and after 1963, due to the impact of WWII and the new thoughts of the Second Wave Feminist movement, the office workers of lower rank were encouraged to climb along the corporate ladder. Sometimes, they become business executives within years.

\section{White American Corporate Businesswomen}

As the research objects in this dissertation, the white American corporate businesswomen between 1963 and 1985 refer to the corporate businesswomen that were/are white American citizens with middle-class background. This does not mean that these businesswomen had to belong to the middle class when they were born, because business is one of the most effective means to help a person to climb (up or down) the social ladder. It is quite possible that a person born in a poor family becomes a tycoon due to the success of his/her business career. Generally speaking, the white American corporate businesswomen in this study include the women office ladies, women entrepreneurs, women merchants, and women running cooperative business in the world of corporations within the United States. 


\section{$\underline{\text { Introduction to the later chapters }}$}

Chapter I introduces the social and cultural background; research themes and topics; research questions and a brief literature review. Chapter II introduces the theoretical and conceptual framework. The major theories used for the hermeneutic interpretation of the cultural evidence include the Identity theories, Social Constructionism, and post-structural Feminism. Chapter III shows the self-identities and the social interaction of white American corporate businesswomen in the historical period between 1920 and 1963 from three perspectives - (1) their views on their business work; (2) their views on the relationship between work and family; (3) their views on their relationship with their male counterparts, especially at their workplace. In Chapter IV, the self-identities and the social interaction of white American corporate businesswomen in the historical period between 1963 and 1985 as the consequences of the epistemic ruptures, mainly WWII and the Second Wave Feminism, are depicted from the same three perspectives. Changes in comparison with the previous period are found, which reveals a new definition of womanhood in these businesswomen's eyes. In both Chapter III and Chapter IV, cultural evidence is chosen from three disciplines, historiography, literature and popular culture, which include autobiographies, oil-paintings, advertisements, movies etc.

Then, the field of vision in this research is extended into the 1990s to see that feminism has not achieved the complete success in solving working women's problems. Chapter V introduces the new wave of feminism beginning from 1990s represented by the thoughts of Julia Kristeva and Luce Irigaray, which is developed on the basis of the 
psychoanalytic theories of Sigmund Freud and Jacques Lacan. Since the Second Wave Feminism did not solve women's problem in their self-identities, Kristeva proposes that "the annihilation of all identity, especially sexual identity" (Grosz, 1990: 167) is the goal of feminism, and women's movements should demand attention to individual differences. Irigaray attempts to overthrow female identity as "the identity of an Other" (Green, 2002: 7). She seeks to encourage women to find their true desire and a potential position for women as speaking subjects, which is a process she terms "becoming woman" (Irigaray, 1985a: 22). Both Kristeva and Irigaray offer a balanced way for women to avoid looking at their identity in an oppressive way.

Chapter VI reviews the three Waves of Feminism from a historical point of view and summaries that there are big changes in the "self-identity" of modern white American corporate businesswomen between 1963 and 1985 in comparison with that of the historical period between 1920 and 1963 as a result of the epistemic ruptures. As revealed in Betty Friedan's book The Second Stage, there has been "a blind spot in feminism" (1998: 22) and "the insatiable demands of female machismo" (1998: 101). In other words, the old problems of balancing the social roles of wives, mothers and workers still exist, and Feminist theory has not found the solution. As we know that women's movements still have a long way to go, but what is the solution? This last chapter claims that the Third Wave Feminism may serve as another epistemic rupture in the new era, which may help to solve the problems. As a result, the American businesswomen must have new outlooks about themselves and there must be the corresponding representations in 
historiography, literature and popular culture, which is subject to further research.

In addition, although this dissertation may include some postmodernist ideas, it is not a postmodern work. Elements of Foucault, Kristeva and Irigaray are used judiciously in support of the waves of Feminism metaphor. 


\section{CHAPTER II}

\section{THEORETICAL AND CONCEPTUAL FRAMEWORK}

\section{Addressing the Existential Self}

At the heart of the feminist movement, women found themselves addressing certain basic issues of self-identity. They began to inquire into the mysteries of being. Gabriel Marcel, the first French existentialist, had previously addressed this question in his books on the Mystery of Being (1951a, 1951b). His focus was on the modern individual's struggle in a technologically dehumanizing society. Marcel recognized that when human beings interact they characterize "the other" as objects. His quest went beyond this. He wanted people to perceive each other both objectively and subjectively. This is the same kind of question that women were asking. Who am I? Do you merely define me by what I do for you or by whom I really am? Marcel was a playwright. He wrote some 30 plays in which he exemplified his philosophy of existence through the characters in his play. He also wrote books on philosophy, but he really wanted to be recognized as a playwright. The irony of this situation is that Marcel was known for his philosophical works and not 
for his literary contributions. His competition came from Jean-Paul Sartre, a French existentialist whose literary contributions were acclaimed. Marcel distinguished himself from Sartre. It was Marcel who coined the term "Existentialism." He (1951a, 1951b) argues that philosophy begins with concrete experience rather than with abstractions. Consequently, his philosophy was based on the experiences of life. There is a theme in what Marcel wrote about, which is the focus of this dissertation. Marcel looks at the events of the Second World War as a "broken world," and addresses that this war served as an epistemic rupture that transformed the lives of people around the world. The order that preceded these events was turned into turmoil. After the war, women would never return to the social order in which they were suppressed by social and economic forces. It was at these times that one's self identity was questioned. The significance of the existentialism of Marcel was a recurring theme during this time.

Another French philosopher who addresses the epistemic ruptures of the Second World War is Jean-Paul Sartre. He served in the French army during the Algerian War of Independence from 1929 to 1931 . At this time he developed the idea that each individual Frenchman was responsible for the collective crimes against these people. It was also at this time that he developed the theme in his writings of the destructive ways in which people adhere to oppression. It was "bad faith" (Sartre, 1956: 89). He argues that they needed to live authentic lives, authentic ways of being. He claims that existence precedes essence, which means that we are thrown into existence first without a predetermined nature and only later do we construct our nature or essence through our actions. Hence, we 
have no predetermined nature or essence that controls what we are, what we do, or what is valuable for us and we are radically free to act independently of determination by outside influences. We create our own human nature through these free choices. We also create our values through these choices. We create our own nature. This is a theme that can be found in his work Being and Nothingness (1956). Many of his influences came from the writings of German philosopher Martin Heidegger. He read Heidegger's Being and Time ([1927] 1996) when he was captured by the Germans in 1940 and spent nine months as a prisoner of War. With the rise of the Second Wave of Feminism, women also addressed these existential questions. They asked themselves if they were living authentic lives. However, there was another influence on Sartre and it came from his lifelong companion Simone de Beauvoir.

In 1949, Simone de Beauvoir wrote The Second Sex ([1949] 1984). It was a book that marked feminist philosophy. It reworked her earlier The Ethics of Ambiguity (1964) in being very concrete. In her earlier books she attempted to define morality independent of a social context and blurred the boundaries between philosophy and literature. In this work on The Second Sex, she presents a more concrete personal account of her situation. She reflects on how morality is embodied in her experience as a woman. She describes the concrete situations of real women. She exposes the ways in which patriarchy exploits the sexual difference between men and women. She also addresses the issue of the essence between the sexes. According to Beauvoir ([1949] 1984), Plato, in his The Republic ([around $382 \mathrm{BCE}] 2006$ ), sees sex as an accidental quality and goes on to argue that men 
and women are equally qualified to become members of the guardian class. However, he argues that the standard of equality is the male body. Beauvoir ([1949] 1984) contests this claim. Along with Sartre, she argues that existence precedes essence. Women as embodied beings must engage the world and lead authentic lives. From an existential-phenomenological perspective, she finds it unjust and immoral to use sexual difference to exploit and alienate women from their embodied capacities. She also looks at the body and gender as a phenomenologist and examines the ways in which women experience their bodies. She wanted to establish how these experiences are determined by common sense assumptions about gender. As a feminist phenomenologist, she wants to assess the meanings of the lived female body and explore the ways these meanings affect one's place in the world (Evans, 1998). Beauvoir makes a distinction between sex and gender. This is evident in her statement that "One is not born but becomes a woman" (Beauvoir, [1949] 1984: 267). This distinction opens the way for the forms of consciousness-raising that are characterized by the Second Wave Feminism. It validates women's experiences of injustice; it provides a program for liberation. She called on women to take up the cause of their liberation. Several concepts are crucial to the argument of The Second Sex. The concept of the Other is one of them. It is a critical element in the discussion and analysis of marginalized people. She returns to this concept in her last major work, The Coming of Age (1972), in which she presents a critique of the ways in which the elderly are marginalized by society. The concept of the Other is based on Hegel's account of the master-slave dialectic. She revised the dichotomy into one of Subject and the Other. 
The Subject is absolute and the Other is not essential. She went on to note that the Subject is man and the other is women (Beauvoir, [1949] 1984). Women, she notes, are unable to identify the origin of their Otherness. They cannot reestablish their lost status. They cannot document their otherness. They are dispersed among the world of men and identify themselves with the status of their oppressors, the world of men. They lack the solidarity that is needed for them to identify themselves as a group of equals. They remain the ambiguous other of men (ibid.). Hence, Beauvoir ([1949] 1984) argues that women must show their solidarity, take account of their existence, and begin to lead authentic lives.

Thus woman may fail to lay claim to the status of subject because she lacks definite resources, because she feels the necessary bond that ties her to man regardless of reciprocity, and because she is often very well pleased with her role as the Other (Beauvoir, [1949] 1984: xxiv-xxv)...This phenomenological-existential statement needs to be read in the context of Beauvoir's ethical-political question, how can a human being in a woman's situation attain fulfillment? (Beauvoir, [1949] 1984: xxxiv)

This discussion of the phenomenology of women sets the tone for other works to come within the Second Wave of Feminism. All of the recurring questions of the feminine identity have their origins in the existentialism of Sartre and Beauvoir.

\section{Concepts of Identity, self-identity and social identity}

The concept of Identity emerged as the central theme of cultural studies since the 1990s. As noted earlier, it had its origins in French existentialism and in the writings of Simone de Beauvoir. In this chapter, we address some of the more recent accounts of the 
concept of identity. For example, according to Baldwin etc., identity is about "how we define who we are" and in cultural theory, "identity is used to describe the consciousness of self found in the modern individual" (2005: 224). In other words, the "identity" I have is the "self" I am. In Chris Barker's book Cultural Studies: Theory and Practice (2003), his definition of Identity is:

A temporary stabilization of meaning or description of ourselves with which we emotionally identify. Identity is a becoming rather than a fixed entity involving the suturing or stitching together of the discursive 'outside' with the 'internal' processes of subjectivity. Points of temporary attachment to the subject positions which discursive practices construct for us. (Barker, 2003: 442)

Barker (2003) argues that identity is a contingent culturally specific production. What it means to be a person is social and cultural "all the way down." That is, identity cannot 'exist' outside of cultural representations. It is understood to be performative, not based on any essential characteristics, but rather is a performance based on cultural expectations. It is a set of expectations derived from the person's social position, thus it implies the extent to which a role is internalized as part of the self. What Barker claims is very familiar. It is reminiscent of what Simone de Beauvoir says about gender. For example, Simone de Beauvoir claims in her famous The Second Sex ([1949] 1984) that one is not born, but rather becomes a woman, which means that one's gender identity is culturally and socially constructed. In other words, biology determines our sex, culture and society determines our gender. As noted earlier, she also argues that all societies are patriarchal, which means that a human being is a man and the male position is believed to be gender 
neutral. In this context, woman is looked upon as "the Other" who is placed in a position of subordination to man. Furthermore, motherhood is a passive submission to nature and biology, and it is naturalized and trivialized. Even gender equality is explicitly defined in male terms: "The 'modern' woman accepts masculine values. She prides herself on thinking, taking action, working, creating on the same terms as men; instead of seeking to disparage them she declares herself their equal" (Beauvoir, [1949] 1984: 727). This is why she claims that man is the model in patriarchal societies. This culturally/socially-determined identity is an important contributor to people's wellbeing. Identifying with a particular culture makes people feel they belong and gives them a sense of security. It also provides access to social networks, which provide support and shared values and aspirations.

According to Barker (2003), the cultural repertoire of the self in the western world assumes that:

- we have a true self;

- we possess an identity that can become known to us;

- identity is expressed through forms of representation;

- identity is recognizable by ourselves and by others.

That is, identity is an essence that can be signified through signs of taste, beliefs, attitudes and lifestyles. Identity is deemed to be both personal and social. It marks us out as the same and different from other kinds of people. We may agree that identity is concerned with sameness and difference, with the personal and the social as understood through forms of representation. (2003: 220)

There are several problems with how Barker (2003) establishes the concept of self 
and this needs to be addressed. He does not consistently distinguish between the psychological self (the ego) and the social self. An example of this distinction can be found in an article on "Reality-Loops and Activity Theory" by St. Clair (2010b). Fig. 2-1 shows St. Clair's model on the Reality Loop:

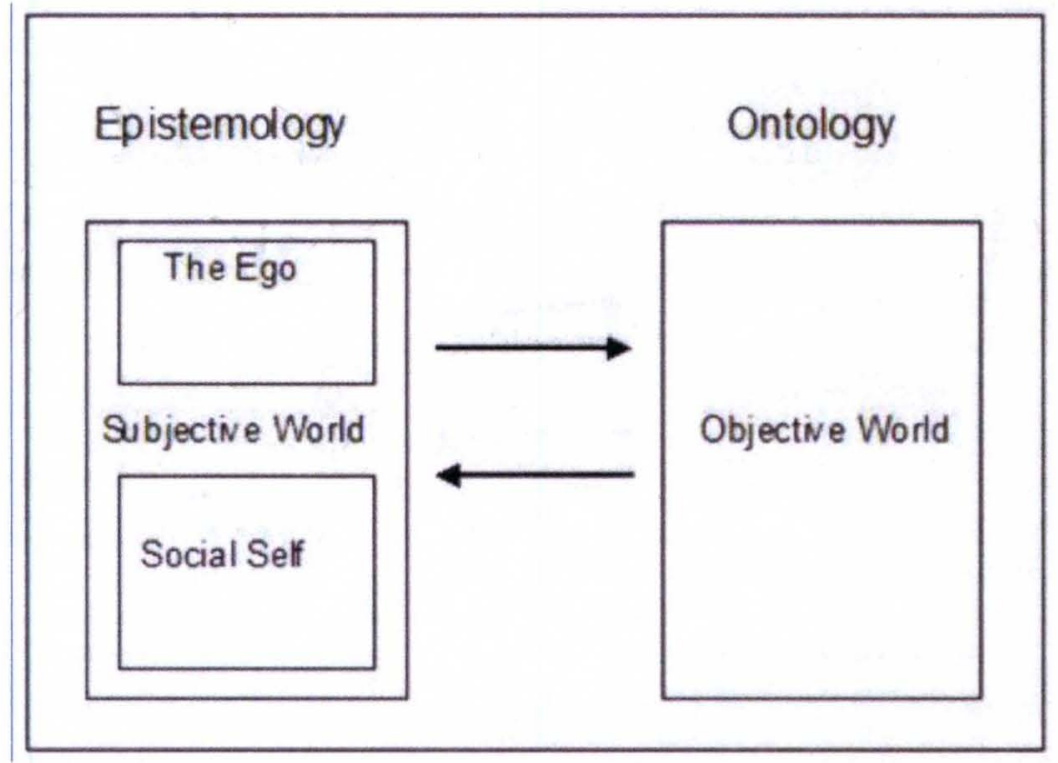

Fig. 2-1. St. Clair's Model on Reality Loop ${ }^{15}$

In this model, the ego and the social self belong to the subjective world of epistemology. Expressions and manifestations of self are seen as objective behavior and are situated in the objective world. The individual externalizes his or her ideas through language and behavior. This process is called "structural semiosis" (St. Clair, 2010b). It is deemed to be structural because the contents of the subjective world can only be known through objective forms, patterns, or expressions. Concepts without expression are ineffable. On the other hand, there is society. It exists as structures and institutions

\footnotetext{
${ }^{15}$ Fig. 2-1 is in St. Clair (2010b), in which the model on Reality Loop is discussed in detail.
} 
and these are interpreted by the individual and integrated into a system of meanings. A major part of this system of meanings has to do with the social self. The process of taking forms and giving them meanings is called structural hermeneutics (ibid.). The ego has to make adjustments between the personal self (identity) and the social self. These adjustments have been documented by developmental psychologists in the form of identity crises (such as the teenager, the mid life crisis, and the retirement crisis). What we want to argue here is that women also go through a similar kind of crisis when they deal with being treated by society as the Other. There is one more thing about the aforementioned model that needs to be commented upon. St. Clair (2010b) places the Freudian concept "Id" in the personal self. Therefore, St. Clair's model has Freudian implications in that the Id, the Ego, and the Superego are intrinsically related to his model of the Id, the Ego, and the Social Self (ibid.). He sees society as the equivalent of a functioning parental authority. It dictates how one should behave.

In identity theory, the core of an identity is the categorization of the self as an occupant of a role, and the expectations associated with that role and its performance (Burke \& Tully, 1977). What Burke and Tully are describing here is the social self (St. Clair, 2010b). Similarly, according to Stryker et al., identities are "self-cognitions tied to roles and thus to positions in organized social relations" (2000:28), and the roles are "normative expectations ties to positions in organized groups. Expectations are meaning attached to roles, partly products of culture, partly products of group interaction. Meanings of roles are widely shared, but variation based on sub-cultures, non-group 
interactions, and idiosyncratic experience exists" (2000: 37). Stryker et al. (2000) argue that Identity theory is a theory of role-related choice behavior deriving from a "structural symbolic interactionism" which assumes that "humans are actors, recognizing the possibility of choice in human life" (2000: 26). Stryker et al. further assume that human behavior and the interaction between human and society are shaped by "definitions of situations" (ibid); furthermore, these definitions are:

based on shared meanings developed in interaction; meaning persons attribute to themselves-self-conceptions-are shaped in interaction and are outcomes of others' responses to persons. These assumptions lead to the basic proposition of symbolic interactionism: society shapes self shapes social behavior. (ibid.)

This social behavior, according to Stryker et al. (2000), is specified by focusing on role-related choices, and role choice is affected by "identity salience," or "specifying self." And commitment, or "specifying society," is taken to affect identity salience. In the model of reality-loops, the commitment to society takes place within the realm of the subjective self (St. Clair, 2010b). It is the link between the ego and the social self. Or in the words of Stryker et al., "commitment affects identity salience affects role choice" (2000: 27). The "identity salience" concept builds on "a multifaceted self composed of identities or internalized role designations" (ibid.). That is to say, people potentially have as many identities as role relations in which they participate. What needs to be clarified in the model of Stryker et al. is how identities are related to "self-cognitions tied to roles and thus to positions in organized social relations" (2000: 28). This interactionist view 
holds that self reflects society while society affects self, and asks us to conceive self "in the image of society" (Stryker et al., 2000: 27). In addition, "self must be seen as multifaceted, composed of parts sometimes highly interdependent and sometimes not, some conflicting and some reinforcing, a self organized variously" (ibid.). What symbalic interactionists do not articulate clearly enough are the structures that are formed through structural semiosis and how they are interpreted through structural hermeneutics. These are separate processes. In addition, the interaction between the ego and the social self also needs to be more fully integrated into the interactionist theory. In other words, what Stryker et al. mean by the "multifaceted self composed of identities" is the social self because it is intrinsically related to "society," and the "role relations" that one participates in (St. Clair, 2010b).

Deaux (1996) also argues that identities based on relationships should be viewed as more central and desirable than those not so based. Since persons' lives and activities affect one another, person's identities, based on role relations, may affect one another. For example, family problems may be introduced into work settings, or work demands may affect family life. One can have several identities simultaneously. In this research, one could be a businesswoman, a mother, a wife and a woman, depending on the person's relationship with others. What Deaux (1996) is addressing here is the concept of "søcial emergence." The concept of "emergence" is common to systems science and it is used to explain how the combination of things can be changed by their structural organization. A good example of emergence can be found in the example of water. It is made up of 
oxygen and hydrogen. By itself, oxygen is highly inflammable and by itself, hydrogen is highly inflammable. However, when two molecules of hydrogen and combined with one molecule of oxygen, the combination is water and water is not highly inflammable. As a matter of fact, water is used to quell fires. Something has happened in this process. A new structure has arisen. Things within that structure behave differently from when they exist outside of those structures. What Deaux (1996) wants to say is that there are elements within the social self that emerge and change when they are involved in emergent structures. The self who interacts with a parent is a different self from one that acts as a CEO of a corporation.

Many theorists focus on different aspects of identities, such as role identity (Stryker, 1980), group identity (Tajfel, 1981 and Turner, 1985), personal identity or self-identity (Erikson, 1959, Giddens, 1991), collective identity (Melucci, 1995), and social identity (Tajfel, 1981). In fact, all identities are social in that they are all products of social and symbolic processes (Gecas, 2000: 93). They have to do with the social self. In order to analyze how the white American corporate businesswomen between 1963 and 1985 see themselves and others, we need to focus on the concept of "self-identity"; and since the relationship between self and society is so close, complicated and interactive, the concept of social identity is also important. We need to know what the concepts of "self-identity" and "social identity" are, where to find them, and how they are formed.

In fact, there are quite a few theorists who provide definitions of "self-identity" and "social identity." According to Giddens, there are "new mechanisms of self-identity 
which are shaped by - yet also shape - the institutions of modernity" and the mechanisms which "prise social relations free from the hold of specific locales, recombining them across wide time-space distances" (Giddens, 1991: 2). Giddens (1991) believes that Self-identity "is not a distinctive trait, or even a collection of, traits, possessed by the individual. It is the self as reflexively understood by the person in terms of her or his biography" (1991: 53). Giddens has a different agenda involved in his discussion of self and it needs to be explicated. He is trying to merge agency and social structure and he calls this conflation "structuration" (Giddens, 1984: 18). He does not use the concept of structure in the same way as other social theorists. For him, structure is tantamount to a system and agency is the equivalent of the rules and resources that one uses in social interaction. What makes Giddens different is that he overemphasizes agency and almost obliterates institutional forces on the individual. He places a heavy emphasis on reflexivity.

In the St. Clair model (2010b), reflexivity occurs between the ego and the social self. It is a place of reflection of how the individual must adjust or adapt to the demands of the social self. It is also a place in which agency takes command and the individual takes command of his life. Giddens (1991) wants to make this a constant process. He wants to make individuals highly reflexive when in reality they are highly ritualistic in their behaviors. Hence, when Giddens (1991) writes about self, he is really discussing a process between the ego and the social self. He argues that identity stories attempt to answer the critical questions: "What to do? How to act? Who to be?" and "these are focal 
questions for everyone living in circumstances of late modernity - and ones which, on some level or another, all of us answer, either discursively or through day-to-day social behavior" (Giddens, 1991: 70). Where do these identity stories occur? They are the reflexive interaction between the ego and the social self. Memories of these reflexive activities are treated as personal biographies and that is why Giddens (1991) also claims that in the post-traditional order, self-identity is not inherited or static; rather, it becomes a "reflexive project of the self"-an endeavor that we continuously work and reflect on (Giddens, 1991: 5). It is not a set of observable characteristics of a moment, but becomes an account of a person's life. When one considers what Giddens (1991) means by reflexivity, it becomes obvious that he is correct. The interaction between the ego and the social self is not an observable part of one's life. It is highly subjective and personal. "A normal sense of self-identity is the obverse of these characteristics. A person with a reasonably stable sense of self-identity has a feeling of biographical continuity which she is able to grasp reflexively and, to a greater or lesser degree, communicate to other people" (Giddens, 1991: 54).

In fact, Giddens (1991) does not really address the concept of self identity. He wants to address the ego that is interacting with its social self and the actions of an individual with others and how they define him or her. These are different processes. They confuse rather than elaborate on his theoretical model of self. Therefore, just as Charles Taylor says: "Man is a self-interpreting animal". and "to say that man is a self-interpreting animal is not just to say that he has some compulsive tendency to form reflexive views of 
himself, but rather that as he is, he is always partly constituted by self-interpretation, that is, by his understanding of the imports which impinge on him," self-identity is developed through self-reflection, instead of being firmly fixed at any point in time (1985: 72). This is another example of the interaction of the ego and the social self.

We have mentioned the role-related choice in human life. Can one be what he/she chooses to be? Putnam (1990) argues that self-identity in fact sets limits to what the agent considers imaginable or viable and "that choice requires self-knowledge, for surely... one cannot become just anyone one chooses to be" (Putnam, 1990: 74). Self-knowledge is obtained during the process of self-interpretation which is deeply influenced by the interaction between the person and the society; therefore, one's social identity is also important to self-interpretation. In comparison with self-identity, which is a description of ourselves with which we identify; social identity refers to the descriptions others have of us (Barker, 2003). Hence, self-identity is the interaction between the ego and the social self and social identify refers to the social self as demanded by society itself. Tajfel (1981) defines Social Identity as "the part of the individual's self-concept which derives from his knowledge of his membership in a social group (or groups) together with the value and emotional significance attached to that membership" (1981: 225). This assumes "strong needs to identify as a member of a group (or groups) and to regard one's own group(s) positively, needs satisfied through social comparisons derogating out-groups" (Stryker et al., 2000: 23-24). Giddens argues that social identity 
associated with normative rights, obligations and sanctions which, within specific collectivities, form roles. The use of standardized markers, especially to do with the bodily attributes of age and gender, is fundamental in all societies, notwithstanding large cross-cultural variations which can be noted. (1984: 282-3)

Although self-identity and social identity seem to emphasize different perspectives, social identity has great influence on a person's self-identity by way of the person's social interactions (Davis 2000).

We have discussed the definitions and characteristics of identities, but where do we find them and how they are formed? Davis (2000) holds that "self-identity does not come easily. It is not, as it were, handed out ready-made; nor can it be self-generated as a free and spontaneous expression of itself. Identity is developed, rather through a series of decisive inner transformations and crises" (2000: 201). That is to say, when one tries to integrate the ego (personal identity) with the social self, this requires some kind of action or commitment. This is what Beauvoir ([1949] 1984) refers to as the difference between the Subject and the Other. In her work, she sees the Subject as a social self. The Other is also part of the social self but it is defined through the Subject. She wants to create the Other as an equal part of the social self. To do this, she needs to redefine society and establish within it the concept of the Other as a Feminist Subject. This requires social action. One must first interact with society and then let society reflect those values back on the social self. This is what St. Clair (2010b) calls the reality-loop. It is a bond between meanings and forms within the individual and his or her society.

Giddens (1991), it should be noted, also introduces the sources of self-identity. He 
believes that it is

not to be found in behaviour, nor - important though this is - in the reactions of others, but in the capacity to keep a particular narrative going. The individual's biography, if she is to maintain regular interaction with others in the day-to-day world, cannot be wholly fictive. It must continually integrate events which occur in the external world, and sort them into the ongoing 'story' about the self. (Giddens, 1991: 54)

There is another problem associated with Giddens (1991) that needs to be discussed at this time. He does not deal with enduring structures. For him, structures occur and they disappear. In order for structures to continue to exist, they need to be regenerated. This is why he sees social structures as virtual. He is against society as an objective form of being. This is why he needs a narrative to regenerate structures. In his model, the individual creates and upholds society. Without them society fails. This is not a realistic model of social theory.

For social identity, Davis (2000) believes that it is expressed "not in terms of ego-based utterances but in terms of superficial signs: clothing, style of life, advertising, and so on" (2000: 204). According to Barker (2003), social identity of a group of people is not fixed; rather, it is discursively constructed and changes as the consequences of historical and social events that change a society. There seems to be some confusion in the literature with regards to self and creativity. It is true that a group of people is not fixed but their group is structured and it is most likely an emergent structure. Therefore, when an individual enters into an emergent structure, he loses much of his freedom. He becomes the group. This is why the focus of action is on changing the structure of the 
group. It is on making the old group into a new one (Barker, 2003). As Beauvoir ([1949] 1984) says, it is in changing the group known as the Other into a new group based on a new solidarity and redefining it as a new Subject group.

Gecas (2000) argues that, in spite of social structural contexts, such as social roles and group membership, which are "indeed important sources of identity, critical to self-definitions, social interaction, and the maintenance of the social order," there is another important location for identities—values system, or believes (2000: 94). Similarly, Turner observes that "the self-conception starts with values and aspirations, and continues to be represented in value and aspiration terms" (1968: 97). In addition, Smith (1963) discusses the importance of "self-values" as components of self-definition as well as standards individuals use of self-evaluation. According to Gecas, "identities anchored in values and value systems are important elements of self-conception, perhaps among the most important, since values give meaning, purpose, and direction to our lives" (2000: 94). The sources of values are the society and the interaction between persons and society. In this sense, self cannot be separated from society, or in other words, the importance of society on self-identity should never be overlooked. What is overlooked in these comments about values is that there are two kinds of values. One comes from the ego and its interaction with the social self, and the other comes from society and the interaction that the individual has with it (St. Clair, 2010b). In both cases one is involved with society. One is either adjusting the personal ego to society or learning from society through interacting with it. A more realistic model of this interaction can be found in the 
writings of Lev Vygotsky (1978). His theory of socio-cultural cognitive development offers a great theoretical foundation for this, which will be discussed in the next section.

As we see from the above analysis, the majority of theorists agree that identity is within a socio-cultural context, and it is affected by gender, race, class, sexuality, personality traits, upbringing, regional background, educational background, values and assumptions about the world, etc (Palmer, 1997). In the setting of modernity, the small community was broken down and replaced by "much larger, impersonal organizations" (large business corporations, for example); therefore, "the individual feels bereft and alone in a world in which she or he lacks the psychological supports and the sense of security provided by more traditional settings" (Giddens, 1991: 33). According to Giddens, "the altered self has to be explored and constructed as part of a reflexive process of connecting personal and social change" (ibid.). Not all social theorists, it should be noted, place such a heavy emphasis on agency over structure and the ego over the social self. He is correct in arguing that individuals change through the courses of their lifetimes as do their conceptions of what is good for them, but this does not mean that their entire personalities change. What he has left out is that society also changes the individual. For him, "the reflexivity of modernity extends into the core of the self" and self-identity is subject to change which is based on its changing relationship with modern institutions (Giddens, 1991: 32). The "new sense of self" is not confined to "life's crises, but a general feature of modern social activity in relation to psychic organisation" (Giddens, 1991: 33). 
What is interesting about this exploration into identity theory, self-identity and social identity is that it acknowledges the importance of the individual's goals and choices. It offers a good platform for us to analyze how businesswomen see themselves and others between 1963 and 1985, a period in which the American society underwent great changes. Up till now, we still have the question of how identity is formed, or the mechanism of the formation of identity. This will be discussed after we see what an important role the society plays.

\section{Socialization, Vygotsky and Identity Formation}

In order to find out how identity is formed, it is necessary for us to review how a person develops a sense of self and understands who he/she is. This process of self development concerns the process of human socialization. Socialization is "the process by which people acquire cultural competency and through which society perpetuates the fundamental nature of existing social structures" (McIntyre, 2002: 143). Charles Horton Cooley's ([1902] 1964) metaphor "Looking-glass Self" expresses that we are socially created by our interactions with others, and "Self" comes about as a result of the way one perceives the responses of others towards him/her or "a reflection of what he imagines others think of him" (as cited in Handel, 2006: 15). This is "the process in which individuals use others like mirrors and base their conceptions of themselves on what is reflected back to them during social interaction" (Thompson \& Hickey, 2002: 86). Jon M. Shepard explains that "children learn to judge themselves in terms of how they imagine 
others will react to them...others serve as mirrors for the development of the self" (2002: 95).

It is important to go back and look at the work of George Herbert Mead (1934) who emphasized the two-part structure of the self-the I and the me. The "I" refers to spontaneous, creative, impulsive self, and the "me" refers to the social self who is concerned with how he/she is viewed by others, which "consists of the attitudes of others that the child adopts and makes his own" (Handel, 2006: 15). Language, it should be noted, is important in bringing about this process. Mead (1934) introduces four stages of socialization through which the self develops through social interaction. They are (1) Pre-play Stage; (2) Play Stage; (3) Game Stage, and (4) Generalized Other Stage. They are briefly reviewed in Table 2-1.

Through his concept of the "I," Mead (1934) expresses the idea that the self is not merely the sum of others' attitudes but that it has, importantly, a subjective phase or aspect. The main source of this I, as explained by Mead, is the biological organism, the impulses that arise in one's own body; thus while the self arises in social interaction, it is not merely a social product but includes, as well, one's own awareness of one's physical self. (as cited in Handel, 2006: 16)

Handel (2006) also introduced two perspectives of socialization. The first one focused on the child as he proceeds from an un-socialized newborn to an increasingly socialized participant in society. From this perspective, socialization is "concerned with the face-to-face social interaction in which the child is engaged with significant others ${ }^{16}$ and

${ }^{16}$ Significant other is a term coined by George Herbert Mead (1934). 
with the outcomes of those interactions: the development of a self, the growth of human sentiments, and the acquisition of language" (Handel, 2006: 16).

Table 2-1.

Mead's Development of the Self through Social Interaction ${ }^{17}$

\begin{tabular}{|l|l|}
\hline \multicolumn{1}{|c|}{ Stages } & \multicolumn{1}{c|}{ Development of the Self } \\
\hline Pre-play Stage & $\begin{array}{l}\text { In the Pre-play Stage, children learn to associate certain } \\
\text { meanings to certain types of cries and learn by imitating the } \\
\text { actions of people around them. For example, they will smile at } \\
\text { someone who smiles to them. At this stage, they cannot take } \\
\text { the role of the other. "I" develops as a result of reinforcement, } \\
\text { with "me" in the background \& beginnings of a "self." }\end{array}$ \\
\hline Play Stage & $\begin{array}{l}\text { In the Play Stage, they begin to learn to take on the roles of } \\
\text { their primary care-takers (usually their parents). Play is very } \\
\text { important at this stage as children often learn by acting out } \\
\text { what they think others do. For example, they may pretend to } \\
\text { be doctors and diagnose for dolls. At this stage, they still have } \\
\text { a fairly simple understanding of who they are. "Me" grows } \\
\text { stronger as the approval of others becomes more important to } \\
\text { the children. }\end{array}$ \\
\hline Game Stage & $\begin{array}{l}\text { In the Game Stage, they gradually have a more sophisticated } \\
\text { understanding of themselves in relation to others. They can } \\
\text { take on the roles of many others in one situation. This means } \\
\text { that they can think about what other people might do in a } \\
\text { certain situation. This ability is crucial in playing games that } \\
\text { have rules. }\end{array}$ \\
\hline Generalized Other & $\begin{array}{l}\text { In the final stage, they develop adult selves by learning to take } \\
\text { the role of "the generalized other." This means being able to } \\
\text { see themselves from the point of view, not just of those close } \\
\text { to them or playing games with them, but from the point of } \\
\text { view of others "generally." They now have "an integrated } \\
\text { conception of the norms, values, and beliefs of one's } \\
\text { community or society" (Shepard, 2002: 97). Mead suggests } \\
\text { that this is the most important stage in becoming a socialized } \\
\text { human being. After human beings finish the four stages, they } \\
\text { can perceive themselves as objects and have self-awareness. }\end{array}$ \\
\hline Stage
\end{tabular}

17 Table 2-1 is based on Mead (1934: 144-163), which briefly summarizes the characteristics of the four stages in the development of self through social interaction. 
The second perspective considers socialization from the perspective of the society. A child's significant others are regarded as socialization agents. Other social agents include schools, media, and sometimes churches. In addition, Handel (2006) also distinguishes between primary socialization (of the child) and adult socialization. An adult must "learn to function in any group or organization that he enters: he must learn not only new practices, but also often new values and norms, a new and specialized vocabulary, new ways of interacting with others" (Handel, 2006: 18). When a person enters an occupation, he/she must make a significant change in his/her life that he/she can be described as "developing a new self" (ibid.). Similarly, if there is a social change, the society may have new expectations to its members and one also needs to re-socialize themselves by adapting to new values and norms. In this sense, the social change that took place during the 1960s in America had great influence on individual's socialization process.

It has been discussed that social interaction is quintessential for socialization. Lev Vygotsky's theory of socio-cultural cognitive development also draws special attention to social/cultural interaction as being absolutely necessary to cognitive development, not just beneficial to it. As Vygotsky (1978) implies, it is through others that we become ourselves. In his theory, which in fact includes three main elements-culture, language, and social interaction, Vygotsky (1978) offers a complex account of the role of socio-cultural processes in the development of mental functioning and expresses the leitmotif of his cultural-historical conception: "the idea that a person and his activity may 
undergo a kind of social and cultural 'strengthening,' 'amplification,' 'rounding out' to their fully functional forms-although not, of course, always relative to the tasks the person faces" (Puzyrei, 2007: 45). According to Vygotsky (1978), this social interaction is mediated by the use of culturally based signs, symbols and tools, the most important of which is speech, based on which the "structure of higher-order mental functions" is shaped (Vygotsky, 1981; Vygotsky \& Luria, 1994). The instruments that human beings use to carry out social interaction, according to Vygotsky (1981), are summarized in Table 2-2.:

\section{Table 2-2.}

Instruments Used by Human Beings in Social Interaction ${ }^{18}$

\begin{tabular}{|c|c|c|}
\hline \multicolumn{2}{|c|}{ Instruments used by Human Beings } \\
\hline Symbolic Instrument & Language & Realm of Epistemology \\
\hline Instruments of Technology & Technology & Realm of Ontology \\
\hline
\end{tabular}

As shown in Table 2-2, there are two kinds of tools used by humans. One is the symbolic tool of language, an epistemological tool, and the other is the physical tools of technology. "What this means is that each child does not invent these instrumental

\footnotetext{
18 Table 2-2 is based on St. Clair (2006: 117). In addition, St. Clair (2006, chapter 6) has detailed discussion about Vygotsky and his activity theory.
} 
systems; they are passed down across generations" (St. Clair, 2006: 117). For Vygotsky (1978), intelligence had to do with the capacity to learn from instruction with tools. Hence, the teacher plays a central role in this context (St. Clair, 2006: 117).

What is more, Vygotsky believes that "behind all the higher functions and the relationships between them stand genetic social relationships, real relationships between people" (Vygotsky, 1986: 54). Although Vygotsky was not concerned with identity and did not use this term in his writings, his socio-cultural cognitive development theory offers a very good perspective in understanding and explaining identity formation. By saying the "transition from a social influence external to the individual to a social influence internal to the individual...is at the center of our research" (Vygotsky, 1981: 116), he emphasizes that individual mental phenomena have their origins in social activity (Vygotsky, 1978, 1981). In this sense, identity formation is not fixed or static, but an ongoing and incomplete process of "...identification with and against others" (Jagose, 1997: 79). And according to Vygosky's socio-cultural cognitive development theory, one needs to extend the idea of "identification with and against others" to with and against larger social, institutional, and historical norms (ibid.). For example, a woman can create a businesswoman-self identity within specific historical, social, and institutional contexts. Based on Vygotsky's perspective, Holland et al. (1998) write about how the complicated development of identities is mediated between individuals and the cultural, social, and historical worlds that they live within: 
Identities are improved...from the cultural resources at hand. Thus persons...are caught in the tensions between past histories that have settled in them and the present discourses and images that attract them or somehow impinge upon them. In this continuous self-fashioning, identities are hard-won standpoints that...make at least a modicum of self-direction possible. (Holland et al, 1998: 4)

An example of how the development of identities is mediated between individual and society can be found in the concept of the Zone of Proximal Development (ZPD), which is "the move from the present level of development to the new potential level of development" (Vygotsky, 1978, as cited in St. Clair, 2006: 117). This zone is too difficult for a child to manage alone and for this reason it is done with a mentor, a teacher, or a helping adult. The use of this sort of mentoring in education is called scaffolding (Vygotsky, 1978). The teacher helps the student to move to the next rung on the ladder of ZPD. Vygotsky's ZPD process is summarized in Table 2-3 (St. Clair, 2006: 117):

Table 2-3.

Vygotsky's Model on ZPD ${ }^{19}$

\begin{tabular}{|c|c|c|}
\hline $\begin{array}{l}\text { Child's Understanding of } \\
\text { the world }\end{array}$ & $\begin{array}{l}\text { Zone of Proximal } \\
\text { Development (ZPD) }\end{array}$ & $\begin{array}{l}\text { Adult's Understanding of } \\
\text { the world }\end{array}$ \\
\hline$X$ & & $\mathrm{Y}$ \\
\hline \multicolumn{3}{|c|}{$\begin{array}{l}\text { One moves from position } \mathrm{X} \text { to position } \mathrm{Y} \text { with the help of a mentor or teacher. The task } \\
\text { is determined by the teacher as a ZPD. After the first task is accomplished, a new task } \\
\text { is arranged. This series of tasks is called "scaffolding." Hence, learning is a social } \\
\text { process. }\end{array}$} \\
\hline
\end{tabular}

${ }^{19}$ Table 2-3 is in St. Clair (2006: 117). Vygotsky's Model on ZPD is discussed in detail in St. Clair (2006, chapter 6). 
According to St. Clair (2006), what Vygotsky is saying is that

these new mental tools are developed through a teaching-learning process that involves social exchange in which shared meanings are developed through joint activity. These changes in higher mental functions are not universal. They are culture specific. Many of the cognitive categories and functions that cultural psychologists have argued are universal are not. (2000: 117)

Vygotsky $(1981,1983)$ introduces an important distinction between lower mental functions (LMF) and higher mental functions (HMF), which is summarized in Table 2-4. It can be argued that many of the lower mental functions are, indeed, universal. According to Vygotsky $(1981,1983)$, these include

"biological and physiological abilities that involve neural processing (visual, auditory, tactile, etc.), perception (visual forms, color, hues, saturation, auditory patterns, phonemic patterns, and tactile impressions), constancy phenomena (light constancy, color constancy, shape constancy), recognition of shapes and forms, the expression of emotions, speech, etc" (as cited in St. Clair, 2010b).

The higher mental functions that one acquires in life are different from these because they go beyond forms of local knowledge and local culture that most people experience within a given system of daily experience (Geertz, 1973, 1983). So what are these higher mental functions? They include many of the concepts that are developed through education and through secondary socialization (Vygotsky, 1981, 1983). Sex, for example, is a lower mental function and gender is a higher mental function. Sex has to do with biology. It is 
physiological. Gender, on the other hand, is learned socially and is processed as a higher mental function.

Table 2-4.

Vygotsky's distinction between LMF and $\mathrm{HMF}^{20}$

\begin{tabular}{|l|l|l|}
\hline Lower Mental & $\begin{array}{l}\text { Ciology of the Functions } \\
\text { all human beings which } \\
\text { include bunctions } \\
\text { physiological abilities. }\end{array}$ & $\begin{array}{l}\text { Commentary } \\
\text { social functions from non-social } \\
\text { ones. Hence, they assume that all } \\
\text { cultures use the same cognitive } \\
\text { functions. They do not. }\end{array}$ \\
\hline $\begin{array}{l}\text { Higher Mental } \\
\text { Functions }\end{array}$ & $\begin{array}{l}\text { Social functions that are } \\
\text { developed through schooling, } \\
\text { and other forms of education } \\
\text { and other learning processes. }\end{array}$ & $\begin{array}{l}\text { Cultures differ in which higher } \\
\text { mental functions they want to } \\
\text { nourish and develop. Politeness and } \\
\text { the development of a higher social } \\
\text { self is a higher mental function. } \\
\text { Some societies invest in these, } \\
\text { others do not. Logic is a higher } \\
\text { mental function. Some encourage it, } \\
\text { others do not. }\end{array}$ \\
\hline
\end{tabular}

Where does this discussion lead? It states that the aforementioned analyses, the social self is socially-constructed within specific social and cultural contexts. This leads to our next important concept and theory—Social Constructionism—which will be introduced in detail in the next section.

\footnotetext{
${ }^{20}$ Table 2-4 is adapted from the table in St. Clair (2006: 118) and based on the discussion by Goldstein (2002). In addition, St. Clair (2006, chapter 6) has detailed discussion and commentary about Vygotsky's distinction between LMF and HMF.
} 


\section{Essentialism and Social Constructionism}

Before we discuss Social Constructionism, it is necessary to mention the long-existing Essentialism first. Essentialism "assumes that words have stable references so that social categories reflect an essential underlying identity. By this token there would be stable truths to be found and an essence of, for example, femininity. Here words refer to fixed essences and thus identities are regarded as stable entities" (Barker, 2003: 439). In this sense, identity is considered as a "thing" to be found, which represents a fixed "essence" of the self. In contrast, it has been argued by the non-essentialists that "identity is cultural 'all the way down,' being specific to particular times and places" (Barker, 2003: 221). This suggests that the root of identity is within society. In other words, identity is socially constructed. This concept is not new. It is inherent in how things are logically classified. For example, a class of things is defined by the elements in them. If all of the elements share a common property, they define the class or group. In the study of feminism, this concept becomes important because human beings are socially classified and women are treated differently than men.

Ludwig Wittgenstein (1999) questions the reality of such a classificatory logic. He argues that not all classes are defined in terms of the unique elements that constitute them. Wittgenstein argues for a new kind of classification based on the idea of a family resemblance. He notes that in a picture of a family, one finds that all of the people in the picture make up a group known as the family. There is no common element to be found 
in that picture. What one finds instead are some of the people in the picture have similar shaped noses; others have similar shaped jaws; and other have similar types of fore brows. What makes them a family is their resemblance to each other. With regards to the classification of women, traditional logic puts men and women into separate groups based on biological differences. They overlook the family resemblances between these two groups.

It is now time to consider the concept of Social Constructionism. It is "a metatheoretical position that describes how our sense of reality-as we know it-is achieved" (Gergen, M., 2001: 1044). It has two central tenets: "(1) the ways in which the world is understood are produced through relations among persons, and most through forms of language, and (2) through our communicative practices we originate, sustain, transform, and undermine reality claims" (ibid.). Thus, the world, as we understand it, is constructed socially and social life is understood as communally constructed realities. Social constructionists focus on the "social interaction" from which meaning is derived and they grant the necessity of embodied functions to operate successfully in the world (Gergen, M., 2001: 1049). Each individual learns to know him/herself through the reflection others shed on them.

Social constructionism became prominent with Peter L. Berger and Thomas Luckmann's The Social Construction of Reality (1966). Berger and Luckmann argue that reality is socially constructed and all knowledge, including the most basic, taken-for-granted common sense knowledge of everyday reality, is derived from and 
maintained by social interactions. Reality is socially and discursively constructed to the extent that people understand, communicate and agree upon versions of reality. In this process, language acts as the medium of reality construction and is used "as a social fact" and "plays an important role in this model of reality construction because language provides the epistemological medium for human social interaction" (St. Clair, 2006: 23).

Berger and Luckman (1966) put forward that there are three processes operative in language at all times (see Fig. 2-2.) —externalization (the encoding or in-forming of knowledge), the sedimentation of forms or objectification (the establishment and legitimation of knowledge systems), and the process of internalization (the incorporation of social knowledge, scripts, plans and behaviors).

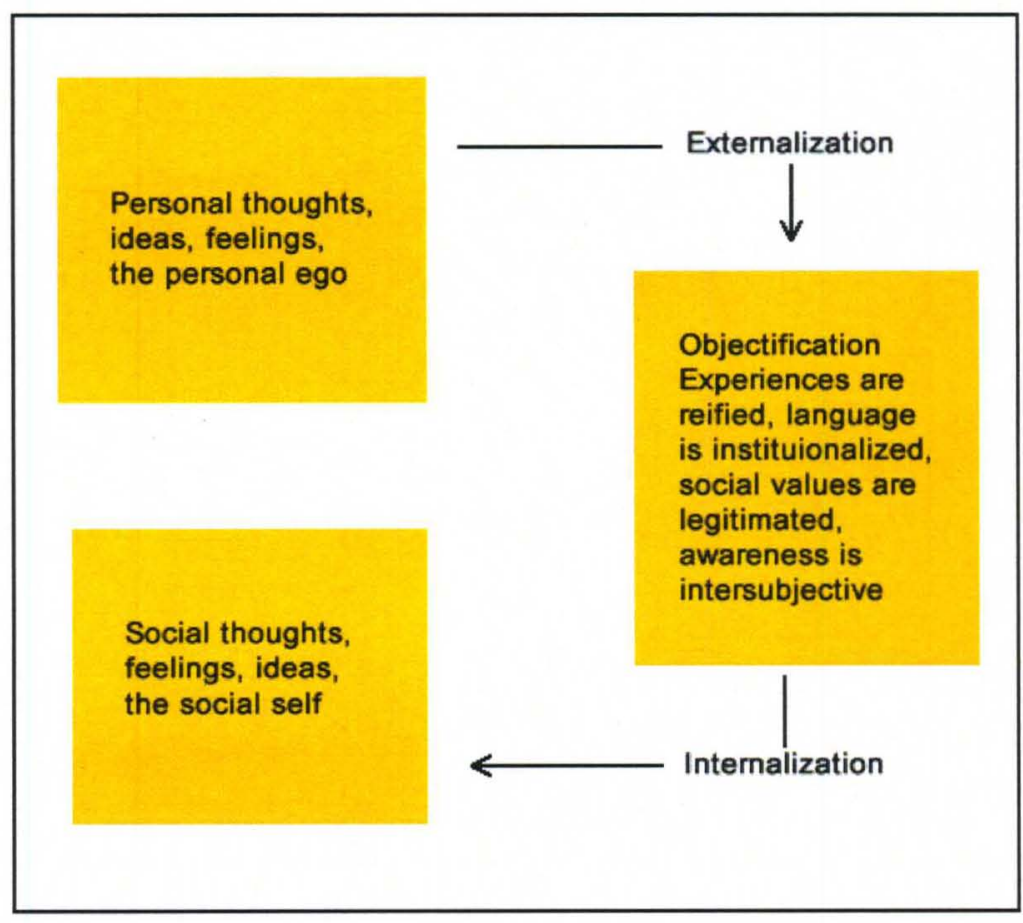

Fig. 2-2. Berger and Luckman's (1966) Model on the 3 processes operative in language ${ }^{21}$

${ }^{21}$ See St. Clair (2000: 24) for the image of Berger and Luckman's (1966) Model. 
In addition, all the three processes take place simultaneously. This model also asserts that all human activity is subject to habitualization, which is "any action that is repeated frequently becomes cast into a pattern, which can then be reproduced with an economy of effort and which, ipso facto, is apprehended by its performer as that pattern" (Berger \& Luckman, 1966: 53). Generally speaking, Berger and Luckman (1966) consider the social world as the result of conscious processes, and emphasized the importance of the subjective experiences, which parallel but never copy exactly the objective world that people can interact with physically.

As a source of the postmodern movement, Social Constructionism has been influential in the field of cultural studies. "Postmodernist epistemology is aligned with social constructionism and is characterized by an emphasis on the discursive aspects of producing knowledge" (Gergen, M., 2001: 1050). The concept of socially constructed reality stresses the on-going mass-building of worldviews by individuals in dialectical interaction with society at a time. In fact, it "emphasizes the part played by social learning in the acquisition of supposedly 'essential' characteristics and can be regarded as a more realistic point of view which is better equipped to do justice to the diversity of experiences encountered by persons within a category" (Baldwin etc., 2005: 139).

Over the past two decades, Social Constructionism has been gradually absorbed into gender studies. It draws attention to the ways in which "the conditions of women and men are delimited by the social categories that hold them in their place" (Gergen, M., 
2001: 1050). Social constructionist feminists argue that "the move away from essentialism is not necessarily negative" because essentialism tends to assume that there are distinctive qualities associated with any category which is stable, complete, and inevitable (ibid.). "Because of this fixedness, the essentialist position deprives many voices that do not properly fit the prevailing categories of sex and gender from being heard. In this sense, essentialism is a concept that has failed to address the recurring issues of diversity that exist within social categories" (Gergen, M., 2001: 1051). This is why Wittgenstein's Family Resemblance Model provides a better account of how diversity can occur within a group. In other words, Social constructionist position is beneficial to silenced voices and believes that there is always space for them to be heard.

Furthermore, Social Constructionism does not agree that there are unassailable, universal moral values. Social constructionists argue that "moral principles and ethical standards are created within social groups, and they do not necessarily carry over from one group to another. Thus, moral goods are negotiated, controversial, and dependent on the social group that invokes them" (Gergen, M., 2001: 1052). Or in other words, moral and ethical arguments are based in specific historical contexts and that no one position has any claims to foundational truth. At the same time, "this does not prevent anyone from taking a moral stance. Indeed, from a constructionist perspective, it is very difficult to claim that one's position does not have moral, ethical, and social implications" (Gergen, M., 2001: 1052).

At last, it is necessary to distinguish the differences between the term "social 
constructionism" and "social constructivism." According to Mary Gergen, social constructivists "focus on invisible entities within the brain/mind, where the organizing of schemas, concepts, constructs, and other posited cognitive mechanisms and processes function," and social constructionists focus on "the social interaction from which meaning is derived" while "granting the necessity of embodied functions to operate successfully in the world" (Gergen, M., 2001: 1049). This distinction is summarized in Table 2-5.

Table 2-5.

$\underline{\text { Distinction between Constructionism and Constructivism }^{22}}$

\begin{tabular}{|c|l|l|}
\hline Group & \multicolumn{1}{|c|}{ Phenomenon } & \multicolumn{1}{c|}{ Philosophical Realm } \\
\hline Constructivists & $\begin{array}{l}\text { Cognitive and information } \\
\text { processing of information }\end{array}$ & $\begin{array}{l}\text { Cognitive Sciences and } \\
\text { Epistemology }\end{array}$ \\
\hline Constructionists & $\begin{array}{l}\text { The negotiation of meaning } \\
\text { through social interaction }\end{array}$ & $\begin{array}{l}\text { Symbolic interactionism and } \\
\text { social ontology }\end{array}$ \\
\hline
\end{tabular}

According to Ian Hacking's book, The Social Construction of What? (1999), the social construction approach is often applied not only to worldly items - things, kinds and facts-but also to our beliefs about them. Hacking writes about the validity of social construction. He argues that what is being socially constructed may entail very different notions of what is being constructed. For example, he takes the concept "Women Refugees" in Helene Moussa's The Social Construction of Women Refugees (1992) as an

22 Table 2-5 is based on Gergen, M. (2001: 1049-1052). 
example. Moussa's intention in this dissertation is certainly not to insist on the obvious fact that certain women come to be refugees as a consequence of social events. Rather, the idea is to expose the way in which a particular belief has been shaped by social forces: the belief that there is a particular kind of person - "the woman refugee"-deserving of being singled out for special attention. In this dissertation, as Ian Hacking (1999) claims, the primary use of "social construction" is for raising consciousness, which is done in two distinct ways, one overarching, the other more localized. In the first way, "it is urged that a great deal (or all) of our lives experience, and of the world we inhabit, is to be conceived of as socially constructed" (Hacking, 1999: 6). In the second way, the local claims are "about the socially construction of a specific X" (ibid.).

According to Hacking, people begin to argue that $\mathrm{X}$ is socially constructed precisely when they find that: " $(0)$ In the present state affairs, $X$ is taken for granted; $X$ appears to be inevitable" (1999: 12). Statement (0) is not an assumption or presupposition about X, but it states a precondition for a social constructionist thesis about X. Without (0) there is no inclination to talk about the social construction of X. Besides, Hacking puts forward three points that social constructionists about $\mathrm{X}$ tend to hold:

(1) X need not have existed, or need not be at all as it is. X, or X as it is at present, is not determined by the nature of things; it is not inevitable. Very often they go further and urge that:

(2) $\mathrm{X}$ is quite bad as it is.

(3) We would be much better off if X were done away with, or at least radically transformed.

A thesis of type (1) is the starting point: the existence of character of $\mathrm{X}$ is 
not determined by the nature of things. $\mathrm{X}$ is not inevitable. $\mathrm{X}$ was brought into existence or shaped by social events, forces, history, all of which could well have been different. Many social construction theses at once advance to (2) and (3), but they need not do so. One may realize that something, which seems inevitable in the present state of things, was not inevitable, and yet is not thereby a bad thing. But most people, who use the social construction idea enthusiastically want to criticize, change, or destroy some $\mathrm{X}$ that they dislike in the established order of things. (Hacking, 1999: 6-7)

According to Hacking (1999), the gradations of constructionist commitment arise from increasingly strong reactions to (1), (2), and (3). He gives names to the six grades of constructionism: Historical, Ironic, Reformist, Unmasking, Rebellious and Revolutionary (1999: 19). Historical is the least demanding grade of constructionism about X. It emphasizes the history of $X$ and argues that $X$ has been constructed in the course of social processes. As the contingent result of historical events, $\mathrm{X}$ is not inevitable. A historical constructionist may refuse to tell whether X is good or bad. This approach, according to Hacking (1999), does not have much difference from history but the matter of attitude. The second grade of commitment takes an ironic attitude to X. Although we believe that $\mathrm{X}$ belongs to "an inevitable part of the world or of our conceptual architecture," it could have been quite different (Hacking, 1999: 19). The third grade is the reformist constructionism. It takes (2) seriously: $\mathrm{X}$ is quite bad and it is. It hold the idea that "we have no idea at present how to live our lives without X, but having seen that $\mathrm{X}$ was not inevitable, in the present state of things, we can at least modify some aspects of $X$, in order to make X less of a bad thing" (Hacking, 1999: 20). The fourth grade, unmasking constructionism, believes that not only (1) that $\mathrm{X}$ is not inevitable, but also (2) 
that $X$ is a bad thing, and probably (3) that we would be better off without $X$. Unmasking is an intellectual exercise in itself. The fifth grade is rebellious constructionism, which actively maintains (1), (2), and (3) about X. In addition, an activist "who moves beyond the world of ideas and tries to change the world in respect of X" belongs to the sixth grade, the revolutionary constructionism (Hacking, 1999: 20).

\section{$\underline{\text { Social Construction of Self-identity }}$}

The social constructionist approach has been used in many types of identities, such as self, gender, mind, child, the old, morality and lesbian identity (Averill, 1982; Cantor \& Brown, 1981; Gergen, K., 1977; Gergen, K., \& Gergen, M., 1982; Kessen, 1979; Kessler \& McKenna, 1978; Kitzinger, 1987; Sabini \& Silver, 1982). Social constructionism is useful in interpreting those identities because it emphasizes the communal basis of knowledge, processes of interpretation, and concern with the values inherent in scientific accounts (Gergen, K., 1985). Giddens (1991) claims that self-identity is well-suited to a social constructionist perspective for several reasons. First, since a person's self-identity is actualized in the process of the interaction between a macro social structure and a micro individual life, self-identity represents the social influence on the person. Second, both social constructionism and self-identity encourage the subjects (research objects) to author their own experiences. Third, the social constructionism put a strong emphasis on the context surrounding human behavior and it 
suggests that the origins of self-identity are likely found in socio-cultural and political contexts.

From the social constructionist perspective, we learn that self-identity is not as a fixed entity but as "an emotionally charged discursive description of ourselves that is subject to change" (Barker, 2003: 220), therefore, self-identity is by nature "heterogeneous, shifting, and tenuous as signification itself" (Dunn, 1998: 28). Moreover, postmodernist writers, such as Derrida and Foucault, frame identity as constructed in and through discourse, therefore, people create their own self-description and language is the most important symbol because "it allows people to construct their own reality" (Curry \& Schwirian, 2002: 76).

Ferguson's (2000) discussion of the two opposing but linked notions of identity is beneficial for understanding the relationship between self-identity and society. The first one states:

identity means simply that each individual is the same as every other individual; that they are identical. In terms of the distribution of public social roles, the division of labor and the large-scale organizations in which individuals are organized as anonymous units, no essential differences distinguish those in authority from those in subordinate position: those who are highly rewarded from those who are not. That is to say, personal qualities are irrelevant to modern forms of social differentiation. (Ferguson, 2000: 181-182)

The second one avers:

Identity in everyday usage refers to the unique individuality of the person, to the absolute difference upon which the experience of the self and its 
world is founded. In this perspective, it is not the distinctiveness, but the arbitrariness of the individual which is problematic. This is the central difficulty which emerged in the Romantic tradition of modernity, exemplified by Rousseau. The absolute inner freedom of the individual provided each person, so to speak, with impregnable grounds of difference, but left each individual with the task of creating his or her own uniqueness. (Ferguson, 2000: 182)

While Ferguson (2000) is putting forward these two meanings of identity, he is quite aware of the difference between social-identity and self-identity: the former "conceives the individual in relation to a specific group or community" and the latter "refers to this same relation, as it were, from the "inside," in terms of an individual perspective on social relations" (Ferguson, 2000: 182). In this context, Ferguson argues that two specifically modern theses emerge: 1) "a fateful disjunction between a personal and a social identity (or series of such identities) has become visible"; 2) "an equally momentous rupture cannot be felt between the experience of the private self as an 'ego' and the self-evidential ' $I$ ' of discourse" (2000: 182). Ferguson says: "expressions of identity link the individual to a social group" (ibid.), the socially-constructed language works as a medium through which self-identity was constructed. This means that the self, no matter how much freedom it has, cannot control its self-identity, just as Griffiths (1995) argues that "self-identity is to be understood as a kind of web, the construction of which is partly under guidance from the self, though not in its control (1995: 93).

The other part refers to the society. Miller (1976) points out that "self is relational" by saying that "a woman's sense of self becomes very much organized around being able to make and then maintain affiliation and relationships" (1976: 83). Concerning the social 
circumstances that are greatly defining selves, Griffiths (1995) claims that they are found "in our relationships with other people, as individuals or as social groups, rather than in other perceptions and understandings which are unaffected by relationship" and "the most significant of the relationships are ones of love, resistance, acceptance and rejection" (1995: 85). These four types of relationships are made in a number of realms in society, such as family, neighborhood, school and work. During the process of individual's day-to-day experience, he/she also feels the views of others, societal expectations, and the organizational practices. These interactions between the individual and society will definitely influence the social construction of self-identity.

In addition, Snow and McAdam (2000) believe that "there is considerable indeterminacy between identities and their roots in either personality or social structure" (2000: 46). As a result, attention shifts from the dispositional correlates to "their construction and maintenance through joint action, negotiation, and interpretive work" (ibid). Snow and McAdam (2000) also argue that in the context of social movements, self-identity also undergoes great changes. They identify four stages in this changing process--identity amplification, identity consolidation, identity extension, and identity transformation (Snow \& McAdam, 2000: 49). 


\section{$\underline{\text { Social Construction of Gender }}$}

The social differences between women and men got little attention in the classic social theories. Marx, Weber and Durkheim are not known for their insight into sex inequality and they in fact tend "to consider women's subordinate social role as a natural 'given"' (Holmes, 2007: 3). Weber even saw women's dependent social position as fundamentally determined by "the normal superiority of the physical and intellectual energies of the male" (Sydie, 1987: 59). No wonder that the Essentialist view toward women has a long history. It supposes that "there is some essence (usually with a bodily basis) which is what makes a woman a woman" and within Essentialist thinking about gender, "the 'natural' or real body is understood to be the basis onto which social and cultural ideas about femininity and masculinity are imposed" (Holmes, 2007: 88-89).

The Essentialist perspective is represented by Helena Cronin, who argues that there are profound psychological differences between women and men, and "men are by nature more competitive, ambitious, status-conscious, dedicated, single-minded and persevering than women...This is a two million year-old fact [and] we should accept it" (as cited in Tripp, 2000: 1-2). In Cronin's model, women and men are deemed to "have innate and distinct characteristics which remain fundamentally unchanged and unchangeable throughout history and across cultures" (Tripp, 2000: 1).

In the 1950 s and $1960 \mathrm{~s}$, Fundamentalism was dominant in social theories and it "contributed to sociological understandings of differences between women and men as 
socially constructed" (Holmes, 2007: 4). Since the 1970s, gender studies has become a field of study after "Feminism distinguishes between the word sex, which refers to our biological constitution as female or male, and the word gender, which refers to our cultural programming as feminine or masculine, which are categories created by society rather than by nature" (Tyson, 1999: 84). That is to say, gender tends to be in agreement with social expectations. Hoffert (2003) further discusses that:

Gender is one of the most fundamental categories that we use to frame our understanding of who we are and of our place in society... It affects the way we work and worship and play. It affects the way we are educated...an understanding of gender and the role it plays in society will help us to appreciate the ways in which men and women experience everyday events differently. (2003: 10)

Oakley (1972) is among the first theorists to use the term gender to distinguish sex. She assumes that sex (biological difference) is the basis of gender distinctions but disputes that biology is destiny. She is also one of the first to offer ideas about socialization to try to understand how gender is learned and how femininity and masculinity are socially constructed (Holmes, 2007: 42-43). Oakley (1972) identified that boys and girls are treated and talked about differently from birth, with girls entering what Jessie Bernard (1981: 120) referred to as "the 'pink world' of those up to five years of age." According to Oakley (1972), the society has different expectations about what is 'normal' for girls and what is 'normal' for boys. Through the interaction with the social institutions, boys and girls may learn quickly how men and women are expected to behave. Homles (2007) points out that Oakley's model is not complete because gender 
socialization continues when people enter the workplace and Oakley attributes great importance to early socialization within families and schools.

As Hacking (1999) illustrates if we let $\mathrm{X}=$ gender in the points (1) to (3) that we have reviewed previously, feminists convinced us "(1) that gendered attributes and relations are highly contingent; they also urged (2) that they are terrible, and (3) that women in particular, and human beings in general, would be much better off if present gender attributes and relations were abolished or radically transformed" (Hacking, 1999: 20).

There are many gender theorists who hold the idea that gender is a social construct. For example, feminist theorist Alcoff (1988) argues that not only is there a lack of evidence for innate difference, but in addition Essentialism "is in danger of solidifying an important bulwark for sexist oppression: the belief in innate 'Womanhood' to which we must all adhere lest we be deemed either inferior or not 'true' women" (Alcoff, 1988: 414). Similarly, Germaine Greer (1989) believes that human beings are social creatures, and the ways in which women and men think, behave and interact, have a great deal more to do with the particular culture in which they live than with nature, and will vary significantly from culture to culture and from one period of history to another. The conception that gender is culturally specific and ever-changing is best summarized by Liz Yorke (1991), another feminist critic, who writes that "things have changed and are changing in ways that seemed inconceivable, 'unthinkable', even as recently as the sixties. I remind myself that what is 'unthinkable' now may eventually become acceptable ways of thinking for the future - for both women and men" (1991: 5). 
In the book The Social Construction of Gender (1991) edited by Judith Lorber and Susan A. Farrell, we can find a diverse range of essays focusing on the following topics: gender construction in $19^{\text {th }}$ century family life; gendered workplace that keeps women poor; intersection of race, class and gender in the women of ethnic background in America; and the strategies for change. In Paradoxes of Gender (1994), Lorber argues that the idea of gender is a social institution rather than a biological imperative. She divides her book into three sections. In the first one, "Producing Gender," she discusses the social, biological and cultural construction of gender separately; in the second section, "Gender in Practice," she makes known how deeply embedded gender is in our society, particularly in families, workplaces and relationships; and in the third section, "Politics of Gender," she explores how politics are related to construction of gender. In the last chapter, she calls for the deconstruction of gender. By doing that, she envisions a society structured for equality, where no gender, racial, ethnic, or social class group is allowed to monopolize positions of power.

Susan A. Basow in Gender: Stereotypes and Roles (1992) discusses a series of questions concerning gender roles from a social constructionist's point of view. The questions range from how gender roles are established, transmitted and maintained, to how they affect us in the society. At last, she puts forward several possibilities for change, and for moving beyond gender stereotypes. In The Lenses of Gender: Transforming the Debate on Sexual Inequality (1993), Sandra Lipsitz Bem explores the institutional, ideological, and psychological mechanisms that keep women powerless in the society. 
The author identifies and examines three "gender lenses" embedded in society. After analyzing the shortcomings of four of the major theoretical perspectives on the social construction of gender over the last 50 years, Bem proposes a new model, "gender depolarization," in which biological sex would no longer be the core of human identity (1993: 192). Although gender is regarded as a social construct in the above-mentioned works, it is constructed in different ways. In other words, the authors explain the mechanisms behind the construction from different perspectives.

\section{Post-structural Feminism}

Among the first to connect a constructionist epistemology to feminism in the United States is philosopher Sandra Harding. In her two books, The Science Question in Feminism (1986) and Whose Science, Whose Knowledge? Thinking from Women's Lives (1991), she distinguishes three types of feminist approaches: (1) the empiricist, (2) the feminist standpoint position, and (3) the postmodern. For the first approach, a dominant one, the scientific method of doing objective science is accepted without critical reflection. The second approach relies on women's experiential reports to attain knowledge. The third one puts emphasis on the discursive aspects of producing knowledge.

After discussing the failure of Liberal, Radical, and Socialist Feminisms in accounting for the family's appeal, although they are "all critical of the family to varying 
degrees," Chris Weedon puts forward the Poststructuralist Feminism (1987: 18). The theory of language, subjectivity, social organization and power for knowledge production in Poststructuralism can serve feminist interests in choosing "between different accounts of reality on the basis of their social implication" (Weedon, 1987: 29). According to Poststructuralism, there is no underlying 'truth' behind the appearances-the point is to analyze the 'appearances' (Foucault, 1994, and Barthes, 1967). Foucault, as one of the most influential figures in the move towards Post-structuralism, sought to understand how 'things' and 'words' are connected in ever shifting ways. He believes that the changing "discourses" systematically organize ways of making meaning and exert power upon human bodies. In other words, individuals may be the authors of their discourses and therefore have some power to affect and resist the status quo (Merriam and Caffarella, 1999).

Poststructuralist Feminism suggests that femininity and masculinity are not universal and eternal categories but discursive constructions and are "constantly open to redefinition" (Weedon, 1987: 137). In other words, any absolute meaning of femininity and masculinity is constantly deferred in an on-going process. However, in order to make sense of the gendered society and ourselves, we have to assume subjectivity. According to Barker, Poststructuralist Feminism is concerned with the "cultural construction of" subjectivity per se, including a range of possible masculinities and femininities" which are "a matter of how men and women are represented" and "ways of describing and disciplining human subjects" (2003: 282). 
Then, how can we analyze the subjectivity if it does not have a fixed meaning? According to Weedon (1987), the fixing of the signifiers, such as 'woman' or 'man,' relies on "the simultaneous fixing of subjectivity in a particular discourse" and the temporarily fixed meaning is realized "on behalf of particular power relations and social interests" (1987: 98). This process of obtaining a temporarily fixed meaning is described as a battle for the signified between options. In addition,

although the subject in poststructuralism is socially constructed in discursive practices, she none the less exists as a thinking, feeling subject and social agent, capable of resistance and innovations produced out of the clash between contradictory subject positions and practices. She is also a subject able to reflect upon the discursive relations which constitute her and the society in which she lives, and able to choose from the options available. (Weedon, 1987:125)

In general, Poststructuralist Feminism provides us with a very good perspective in understanding the mechanisms of power when we intend to analyze the social and cultural construction of gender identity or femininity as long as we put it in specific discourses.

\section{Implications for this study}

The literature review for the theoretical and conceptual framework for this study describes a link between women's self-identity and women's social experiences or social interactions. We have learnt that the "self is made and makes itself in the changing circumstances in which she lives and in a direction strongly affected by her own 
understanding of herself" (Griffiths, 1995: 82), or in other words, the self is developed in relation to others. In addition, gender differences are produced through language, and woman's self-identity is a social construction through discourses. It is from this perspective that this study is carried out to find how American corporate businesswomen between 1963 and 1985 see themselves and others, and how society constructs their self-identities through these businesswomen's "voices" or discourses in historiography, literature and popular culture.

Businesswomen have several social roles in the society. This study will focus on three types of roles which are crucial for businesswomen. They are represented in three types of relationship: (1) their relationship with their work (as business persons); (2) their relationship with their families (as wives, mothers or daughters); (3) their relationship with men, especially at their workplace (as women). They see themselves through their interactions with work, family and male counterparts. The self-identity of businesswomen in these three types of relationship will be discussed in Chapter IV. Since businesswomen's social roles cannot be fully separated from one another, there may be some overlapping in the discussion. For example, the relationship between a wife and a husband in a family can be regarded as the relationship between a woman and a man. In this case, this type of relationship will be counted as in a family setting. The relationship between women and men will be put in a larger context which includes the whole society, but the emphasis will be on the working environment in this study. 


\section{CHAPTER III}

\section{GENDER IDENTITY OF WHITE AMERICAN CORPORATE BUSINESSWOMEN (WACB) (1920-1963)}

In order to establish the self-identity of white American corporate businesswomen between 1963 and 1985, we need to review the self-identities of white American businesswomen before 1963 and trace the changes. According to Kwolek-Folland (1998), the corporate form of business organization in the United States became more prominent in the 1880 s. During the period between the 1880 s and the 1920 s, white American women had already preoccupied the majority of the office clerical positions and finished the process of effeminating the corporate office. However, after the two World Wars, a large number of women were encouraged to give up their works and be "happy" homemakers. Those who did work in corporate offices between 1920 and 1963 were deeply affected by this trend. This chapter is going to find out how white American corporate businesswomen between 1920 and 1963 see and evaluate themselves through their own voices, including stories they told and poems they wrote. By telling stories, they are experimenting with and continually creating and recreating their self-identities. 
In addition, by projecting their self-identities into the society, we can see how the society constructed their self-identity through novels, poems, paintings, advertisements, etc.

The journal articles, poems, advertisements in the magazine Independent Woman $(I W)^{23}$, the official publication of the National Federation of Business and Professional Women's Clubs, INC. (1920-1956), will be used as the corporate businesswomen's voices, through which we can see clearly their self-identities. As we know, one of the most enduring images of women is that of a homemaker/mother, however, corporate businesswomen have more social roles in society. This study will focus on three types of roles which are crucial for them. They are represented in three types of relationship: (1) their relationship with their work (as business persons); (2) their relationship with their families (as wives, mothers or daughters); (3) their relationship with men, especially those in the workplace (as women). They see themselves through their interactions with the "significant others"-work, families and men. Of course, the businesswomen may also interact with other women or men as friends. Due to the limitation of time and space, we will only focus on the type of woman-man friendship when it is related to business working environment.

${ }^{23}$ The magazine Independent Woman was published from 1921 to 1965. 


\section{$\underline{\text { WACB and Work }}$}

According to Kwolek-Folland (1998), the notion of equal pay for equal work has been around since the late $19^{\text {th }}$ century, and the women's organizations, such as National Woman's Party (NWP), Business and Professional Women (BPW), and Women's Bureau (WB), have been publicly discussing the issue since the 1920s. Although the BPW believed in women's right to equality as female workers and businesswomen, it supported the view that "the gender segregation of jobs benefited women by providing them a guaranteed space for their talents and energies" (Kwolek-Folland, 1998: 140). In comparison, the Women's Bureau was more conservative. It saw "women's business role as supportive to men's and emphasizing women's basic status as wife and mother" (ibid.). Both these groups, though for different reasons, "wanted to maintain the gender segregation of the labor force" and believed that to undermine this view would "challenge an assured position for women within the business world and encroach on men's territorial rights to male-defined arenas"(Kwolek-Folland, 1998: 140-141). In general, corporate businesswomen's role by 1960 was well defined as "supportive, nurturing, lower in status and pay than that of men, composed of skills perceived to be intrinsically female, outside of the promotional track for male management positions, and expendable" (Kwolek-Folland, 1998: 201).

This role definition was best represented by white corporate businesswomen's own voices in the magazine Independent Woman. Since the 1930s, vivacious and attractive 
young misses who enter corporate business, make a success at their chosen work, and more often than not, meet her husband through her work. These corporate businesswomen believed that women should go out to work, achieve business success, and be economically independent. However, under the impact of postwar social thought that women should go back home to be homemakers, the mainstream idea of the businesswomen's attitude toward business work is regarding it as a "job" rather than a "career." In most cases, business work in offices is an ideal stopgap for young women between school and marriage. Being beautiful and attractive in offices was the top concern of these businesswomen. Next, articles in Independent Woman are analyzed to show how the corporate businesswomen see their relationship with work.

In "Business as an Aid to Cupid," Mary Jacobs (1932) recorded an interview with Helen Woodward, author of Through Many Windows (1926) and a famous woman in advertising business, who is writing a syndicated column of advice to girls and women in a number of newspapers. Concerning whether women should go to work or not, Woodward says:

Nowadays, particularly among young married people, both husband and wife must work to make both ends meet. Even if Tom is sufficiently established in his field to make a good salary, it is a relief for him to realize that, if necessary, Ellen could contribute to the family funds... and from the feminine standpoint, the working woman has the greater chance for happiness in marriage. Not so many years ago she had to get married for a meal ticket; today she can marry for love. (as cited in Jacobs, 1932: 5)

Woodward further states that: "anyone who argues about its being a good or a bad 
thing for women to go to work is just being silly. They have to work. The work is there and they must do it," because "economic conditions have forced women into industry and the professions....Being in business or a profession has, fortunately, attached a premium to young women. Tom is more likely to lead Ellen (a working woman) to the altar than a Miss-Stay-At-Home, who must be supported" (Jacobs, 1932: 38). Here, Woodward argues that corporate businesswomen or professional women should be economically independent, so that they can have an equal status with men and find true love. In addition, she also believes that "business and professions have helped enormous numbers of women to get husbands... the girl who works might never meet her husband if not for her work; because of it she acquired the social ease that made possible her meeting him on equal footing, and holding his interest” (Jacobs, 1932: 5).

Responding to the men who believed that working destroys feminine charms in the 1930s, Woodward argues by saying that these men "must be keeping their eyes closed and covered with blinders and black handkerchiefs. Most offices have a lot more feminine charm than they actually need" (Jacobs, 1932: 38). In fact, Woodward has realizes the importance of being attractive at workplace. She believes that only "the girl who works has a chance—which she certainly makes the most of - to display her charms properly" and "she dresses better than her home-staying sister, she takes better care of her hair and her skin, she spends more money in beauty parlors and on clothes. The self-supporting girl feels she has a right to spend some of her money on beautifying herself" (ibid.). 
In another $I W$ article "Your Feet on the Ground," Helen Henifin points out in that "really clever women, they say, never commit the error of being capable" (1932: 51). She finds out that, most young business women are aimless about their work and:

they have no plan of life-spend all their savings for clothes and trips, hoping some Prince Charming will appear to take over all responsibility. Sometimes, alas, Prince Charming never appears at all. Or if he does, he may bring romance, but no cash.... I must admit I also floundered for years; found it hard to adjust myself to that relentless law of the survival of the fittest; found it almost impossible to save...for like most women I am naturally domestic and fond of a home. And owning a house was a distinct business asset to me. (Henifin, 1932: 51 and 68)

Ethel J. Bein (1932) did an interview with Dr. Joseph Justrow on whether success is within businesswomen's grasp. Dr. Justrow believes that a woman in a corporate office "must determine what work has essential value for her, and certainly feminine traits tact and grace will be most helpful in her work" (Bein, 1932: 70). Similarly, in "The Use of Adversity," Verna Vernier (1932) also emphasizes the importance of working woman's attractiveness in achieving success by saying that "though the professional woman has little time to cook and sew, she must always choose her clothes carefully, has her hair waved and her nails manicured. To be well groomed is part of her stock in trade," and "most of the things we long for-good times, good friends, good jobs, love, success, and happiness--involve other people. You can't imagine a woman all alone on a desert island winning them. In order to achieve them you must like other people, make other people like you" (Vernier, 1932: 12). Therefore, it is necessary for a working woman to be nice to look at. In the magazine Independent Woman, we can see numerous articles which 
teach businesswomen rules to look younger and smart. They instruct them how to keep skin smooth, soft pliant and wrinkle free, how to obtain beautiful faces, hairstyles or even voices, and how to choose colors and styles of clothes. For example, in "Chic Is the Thing," Jane Pennyfield (1932) points out that:

Woman's appearance is very much what she herself wants it to be. She can be charming or elegant, perhaps even sophisticated, depending on how much she really in her heart admires these particular characteristics....today the admired woman is the smart woman-since this seems to be the spirit of the world and time about us...Business women particularly are learning to value this new attribute of smartness, just as neatness was the ideal of twenty years ago, correctness the thing only a few years back... Individuality of thought and action is again of first importance. And this change is apparent in the new standard of fashion-smart clothes that reflect the valued quality of a more personal, individualized taste.... If your look just like everybody else-if you look just neat and trim or nice and correct it really is pretty much your own fault. (Pennyfield, 1932: 94 and 116)

In "New Ways To Beauty," Mary Constance Ford (1932a) introduces a new product

which can solve the problem of coloring graying hair without health risks. In another article, "The Witchery of Lovely Hands," she emphasizes the importance of having a pair of attractive hands by saying:

A business girl's hands are even more in evidence and more important than a home woman's hands. All day long in dozens of yeas she uses her hands conspicuously-holding the telephone receiver, handling mail, studying samples, dealing with commercial or professional clients in various ways. Her hands are constantly before the eye... To keep the clean, smooth look so attractive in one's hands, I find the most essential thing to do is to strive for softness... (Ford, 1932b: 59)

There are also advertisements that urge businesswomen to learn to be charming. For 
example, the advertisement of Kathryn Murray's 5 min-a-day Facial Exercises goes like this: "Give 5 minutes a day, look as young as you please!...through exercise of the tiny under-skin face muscles upon which beauty depends, you can regain or regain the youthful attractiveness that all admire." 24 In another advertisement, a free Margery Wilson's "Charm-Test" is offered to urge more businesswomen to participate in Margery Wilson's courses on cultivating charm. It quotes Sir James Barrie's words to emphasize the importance of charm: "if you have it, you don't need to have anything else--and if you haven't it, it doesn't matter what else you have.".25

In a 1937 ad for Listerine (see Fig. 3-1), there are three women who represent the most prevalent careers for women-in the estimation of the advertising department—office worker, actress, and schoolteacher (Hill, 2002: 185).

The ad goes like this:

How Career Girls overcome the greatest handicap to success... Business...the stage...teaching...other professions...each is a field sizzling with fierce competition in which no quarter is asked and none given. Who has the better chance of getting ahead-a girl whose breath is sweet and fresh or one whose breath is a continual offense to others?... (Hill, 2002: 185)

\footnotetext{
${ }^{24}$ See Independent Woman, Jan, 1932, p. 40.

25 See Independent Woman, Mar, 1932, p. 118.
} 


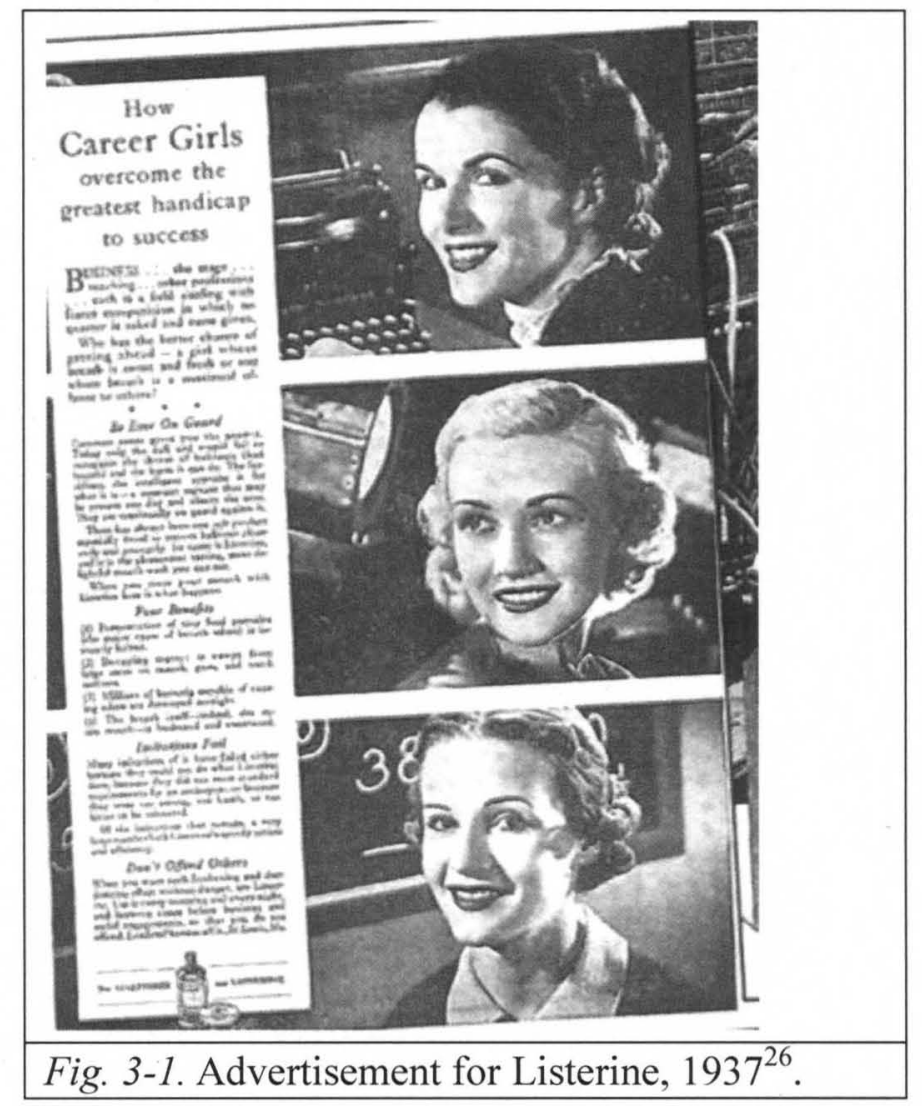

In this ad, woman's attractiveness is embodied in the sweet and fresh breath. And their success is based on the attractiveness. But what was the definition of success for corporate businesswomen? According to "Does It Pay to be a Good Secretary?" by Dorothy Thomas (1932), a successful corporate secretary should fulfill the following tasks efficiently:

She is some one who keeps out creditors, job hunters, book agents, chronic borrowers, and informs all undesirables that her employer is out to lunch, in conference or Europe. After which she goes back into the office and as quietly as possible-so as not to interrupt the golf post mortem he's carrying on with his lawyer-telephones his bootlegger for another consignment. She arranges for his passport, engages the most desirable cabin and even tells him the capital of Bulgaria. She selects a helmet for

${ }^{26}$ See Hill (2002:185). 
his flying daughter, reminds him of his mother's birthday, sees that his art dealer doesn't cheat him. Chooses an anniversary present for his wife, a weekend gift for his hostess, a silver mug for his godchild and gets him the best theater tickets at the last possible moment. She sees that he doesn't forget his luncheon appointment with his suburban aunt, that he sends his grandchild a birthday check and that he isn't late for the board meeting. She knows all about his cruel and brutal business deals that are strictly within the law, but that keep her awake nights wondering if he'll really succeed in keeping out of jail. She hears him gloating over a clever dicker that makes her blush for shame and sigh for his victim. (Thomas, 1932: 314)

In addition, to all these routine office duties, a successful secretary has to "show the diligence of a bee, the wisdom of an owl, the patience of Job, and so earn a good one [job as a secretary]" and "chop off your [her] personal life to fit your [her] job, as did the ogre in the folk tale who cut off visitors' feet to fit his bed" (Thomas, 1932: 314). In fact, a secretary is more like a wife, and the nature of this type of jobs is supportive, which is the extension of household chores. In addition, without decision-making power, these businesswomen had no "self" in the workplace and accepted their roles as service providers who were dictated and dominated by their male bosses most of the time. However, middle class girls between 1930s and 1950s wanted to be corporate secretaries "more than anything in the world" (ibid.).

In answering Mary Jacob's question in "Business as an Aid to Cupid" on whether a successful businesswoman is at disadvantage with men or if men fear her. Woodward says: "a successful woman does create both fear and jealousy among men. But, on the other hand, if she has the ability to be successful in her field, she is, I feel, capable of making friends and sweethearts of equally successful men, who have no reason to fear 
her, but will appreciate her" (Jacobs, 1932: 38). However, grasping the success in business is not easy. In order to be successful, businesswomen made great efforts, but there are still frustrations. In "Is Success Within Our Grasp?-An Interview With Dr. Joseph Justrow," Ethel J. Bein (1932) tells readers that she overheard a chance conversation in the subway which started her trend of thought. The principals were two smartly-dressed, efficient-looking 1932 business girls. One was telling her tale of woe to her sympathetic friend, in which the definition of success is to maintain a job:

'A girl hasn't a chance to succeed,' she complained, 'Even when I got a lucky break and was given Joe Reed's job, I worked twice as hard as he for less money. Now when they have to cut down on the overhead, I'm the one to go, just because the other fellow's married. The fact that I have a dependent mother and sister, and that jobs are as scarce as hen's teeth, seems to have nothing to do with it!' (Bein, 1932: 45)

Similarly, we also read Verona Armbruster's complaint in "Keep Quotable!": "He is a big feeling fellow and he happens to do exactly the same work as I do for more pay because he is a man. Of course he has a wife to support, while all I support is an aunt and uncle and an orphan in college" (Armbruster, 1932: 93). Indeed, we can see that the feelings and the pay riled the businesswomen who wanted to maintain their jobs or were ambitious in achieving success in business. They were struggling in the business world where the unfairness toward women was seen as natural.

The poems published in the magazine Independent Woman also allow us to hear the voices of the businesswomen. In "We Earn Our Future," Ada Simpson Sherwood begs Life to lead her along a joyful street with petals of roses beneath her feet and all other 
beautiful things, "But life all my longings spurned," and said "Your future must be earned!"(Sherwood, 1949: 52). She also cried out to Life: "Build me a future out of the past./ Take my skills when I did my best,/Take my triumphs, my winning zest,/My master strokes, and build for me/A future all may be proud to see" (ibid.). But "Life turned in cold disdain away" and said "You must earn your future day by day!" (ibid.). In this poem, Sherwood (1949) is quite aware that women have to make great efforts to walk their own way, to obtain success, and earn their own future independently. However, what is being successful in work mean? In another poem, "Woman Must Serve Completely..." by Louise Darcy, we see that women are expected to go all out to strive for "union of the heart/And head and hand. Only by doing so, / By gaining mastery of every part,/ Can she advance, continually grow..." to "strive for kindliness [by the heart]," "seek the highest good [by the wise head]," and keep "in readiness [by the useful hand]" (Darcy, 1949: 40). But what is the purpose? The goal is to do "the work which can be understood/ By those who watch to see what women mean/ When they pledge loyalty to world-wide need" (ibid.). So, the "kindliness" and "the highest good" are just in service of others' need, or "world-wide need." In addition, "women must serve completely, as a whole,/ Giving the largesse of her mind and soul" because "Theories are useless; progress must be seen/In noble act and swiftly finished deed" (ibid.). In this sense, we learn that Louise Darcy (1949) believes that women should do their best to serve others, which she takes as a successful "career."

Pauline Dillingham's poem "Popularity" describes an attractive office lady: 
...All men consider her charming,

Many men think she is fair,

Lauding the length of her lashes,

Praising the gold of her hair.

Scores of men say she is witty;

Dozens delight in her walk.

But the real reason they like her

Is that she lets them all talk...

Talk-not of science or business,

Politics, history, or pelf-

But of that topic absorbing-

Every good man of himself. (Dillingham, 1932: 267)

In this poem, the charming and beautiful office lady is successful, not in business work, but in entertaining her male colleagues, which is regarded as the core of her value.

What is more, in Josephine L. H. Barry's "From an Office," an old office lady is expressing her detestation toward a young office girl that is attractive to men:

She walks about the office in a doze,

And those who should be adding up some column,

Are watching all her careless airs and ways

And smiling, ere they see me, and grow solemn.

She flaunts it in my face, her so-called beauty,

She hums, she laughs, at times is near to tears-

She cannot read her notes. I who have done my duty

In this drab place for more than twenty years

Must watch the silly farce and see the men

Hang upon each empty little laugh,

Encourage her and coax her, ever and again,

To be more careless, with their compliments and chaff....

I think that I shall wait just one more day

Before I tell her not to be so gay! (Barry, 1932: 53)

From the above poem, the offices women see that old age is a disadvantage for their work because they are not young and attractive any more, and if they are pretty and 
young, they don't have to be competent at work.

The above self-identities of corporate businesswomen between 1920 and 1963 concerning how they look at work is in accordance with the "social identities/selves" or the "public images" of these businesswomen. Next, let's examine how the society constructs their images in paintings, advertisements, literature, and movies.

First, corporate businesswomen between 1920 and 1963 appear in paintings mainly as office ladies. In the Communist periodical the New Masses ${ }^{27}$, we find M. Pass's Drawing of a Typist (1926; Fig. 3-2) and William Siegel's Office Worker's Lunch Hour (1930; Fig. 3-3). In Fig. 3-2, the office lady is bending over her machine typing agonizingly. Her elongated body and lowered head convey fatigue and monotony. In Fig. 3-3, the office girl is looking up with a sandwich held in her hand during a lunch break. The white light coming from up-left leaves a white contour around her body. The tall buildings of concrete surrounding her act as the walls of a prison, from which she is seeking release in her imagination. What can take her out of the "prison?" Maybe a man or a marriage may do. She is probably imaging the face of her husband and life after marriage. She will be a happy housewife. Obviously, the work in the offices does not bring happy experiences toward the office lady.

27 The Communist periodical the New Masses was published from 1926 to 1948. 


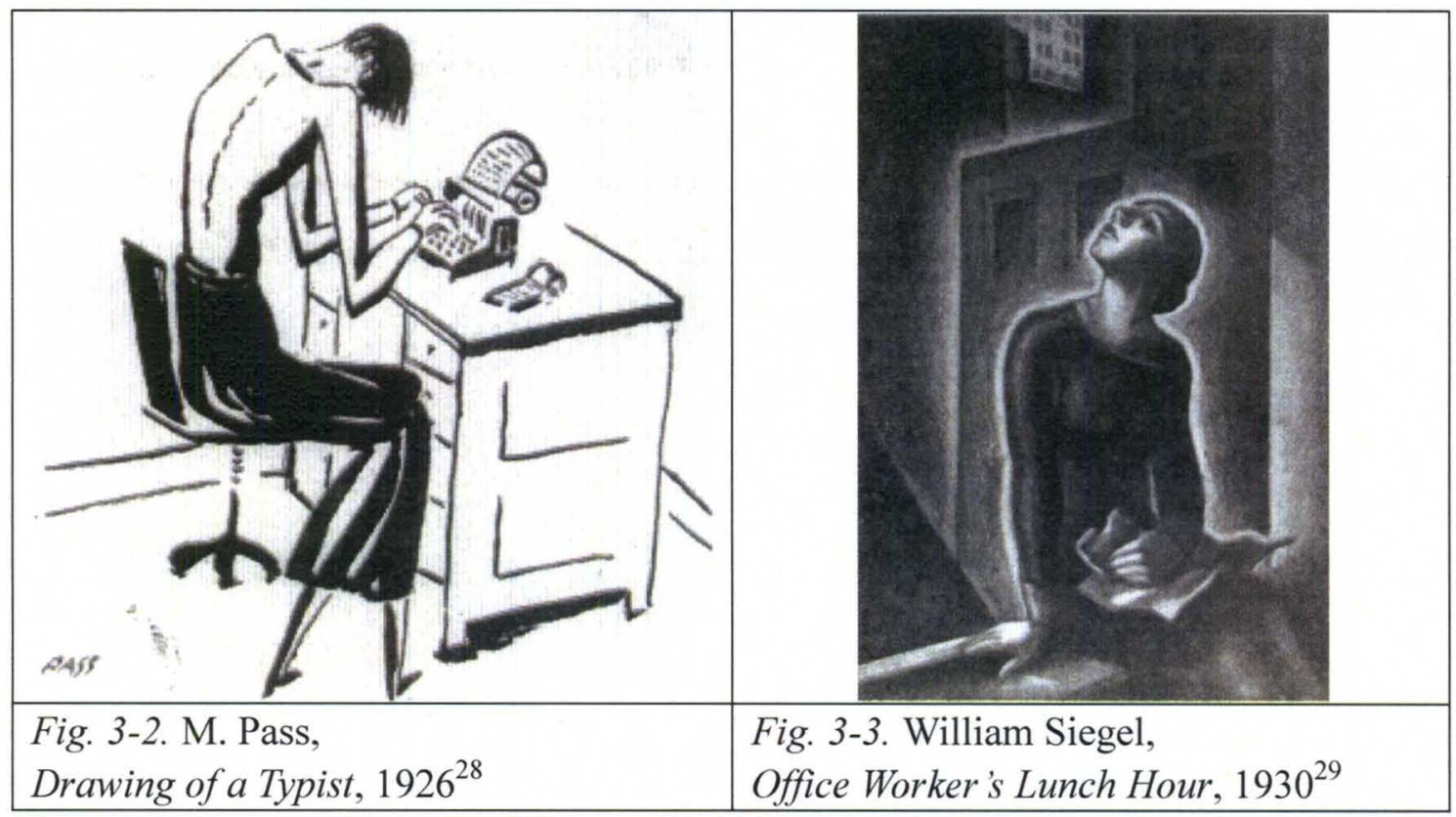

Unlike the office girls sketched in the New Masses, which are miserable and are appealing for social change, those painted by artists from the Fourteenth Street School, such as Raphael Soyer (1899-1987), Isaac Soyer (1902-1981), and Isabel Bishop (1902-1988) are more natural (because they are put in the context of city life), relaxed or pleasant. We know that working women were absent in American art, but why do they appear at this time? According to Todd (1993), "most obviously [it is] because they were everywhere in the Fourteenth Street neighborhood and thus were logical subjects for artists dedicated to American Scene realism-the depiction of modern society as it appeared in their immediate environment" (1993: xxvii). These girls belong to what Todd (1993) called the "New Woman"- "an independent person with a public role" (ibid.), or more precisely, she is "determined and fiercely independent, she was [is] a

28 See New Masses 1, May, 1926, p. 27.

29 See New Masses 5, April, 1930, p. 13. 
business executive, devoted to her family, a dedicated consumer of every conceivable new technology, and clear about women's proper roles - everything imaginable but the priesthood and the presidency" (Todd, 1993: xi). Next, the paintings of the "new women" will be analyzed as visual text to find out their public images and their relationship with business work.

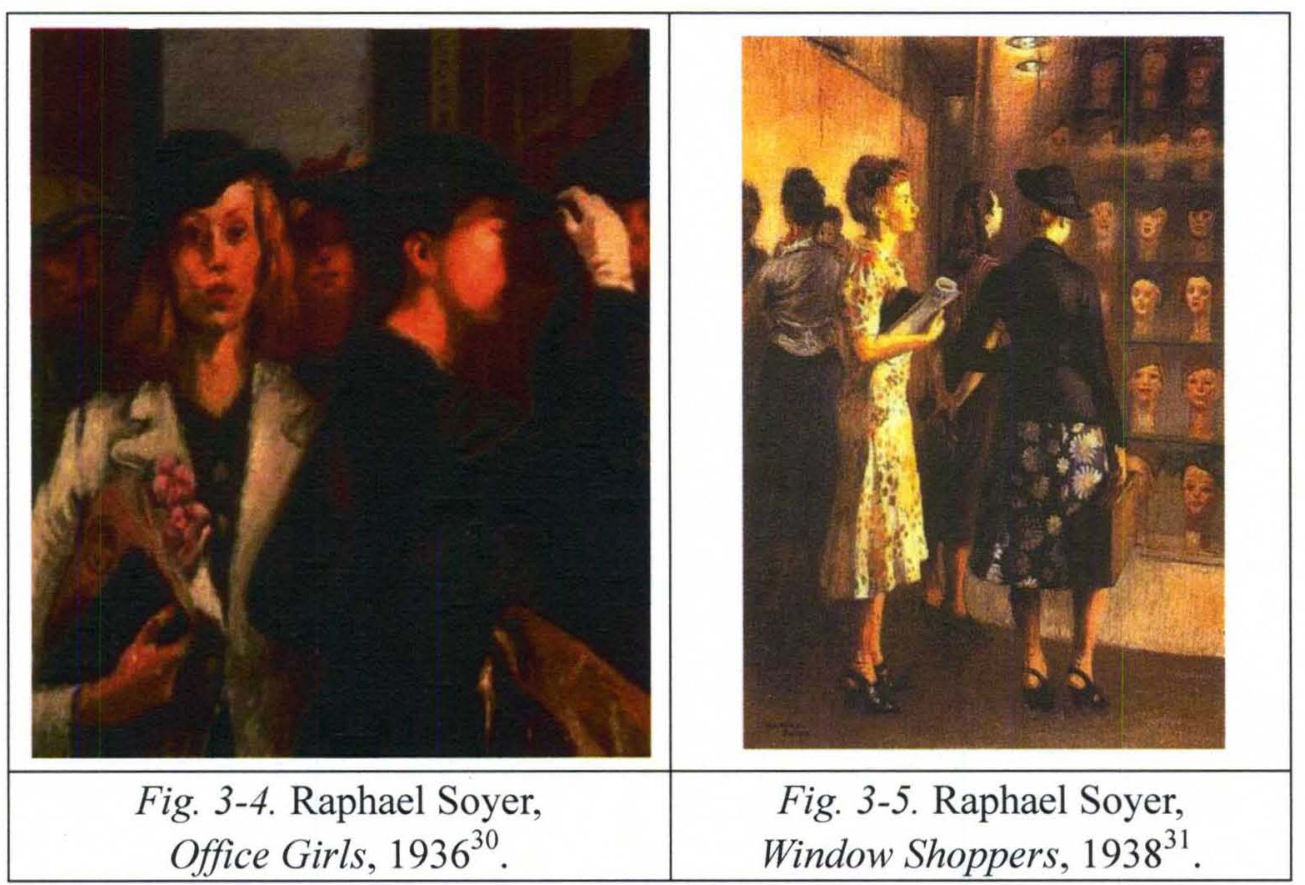

In Raphael Soyer's Office Girls (1936; Fig.3-4), we see a crowd of office girls against a skyscraper backdrop going home in the sunset glow. "The crooked arms of the two principal figures in the foreground of Office Girls unify the figures, but there is no suggestion that the women are acquainted; their isolation or self-preoccupation within

\footnotetext{
${ }^{30}$ Retrieved from http://vruz.tumblr.com/post/294539064/raphael-soyer-office-girls-1936-via on Jan 18, 2009

31 See Todd (1993: 226). New Jersey State Museum, Trenton.
} 
groups thematizes urban anonymity" (Todd, 1993: 287). The profile of the lady on the left suggests that the women are moving quickly. From their fishy eyes and numb expressions, we sense the feeling of fatigue and monotony. Todd (1993) comments on this painting by quoting one reviewer: "'not particularly enticing,' being 'thin, wiry, alert...still showing the nervous strain of their days.' Even though these women were 'the mainstay of our commerce,' this reviewer felt that their work undermined their femininity" (1993: 264).

In Raphael Soyer's Window Shoppers (1938; Fig. 3-5), several roles of woman can be identified. There are three working women who are looking at the rows of hats in the shop windows. They all wear formal and beautiful clothes, and high heels. The one at the right is probably an office lady because she wears a suit jacket and carries a briefcase. The fourth woman is a more simply and casually clad mother, who holds her baby and turns her back to the viewer to enter the store. Compared with the mother, the working women seem to be more concerned on being beautiful and independent. It is well-known that the salary the working women made during this period was usually called "pin money," which made possible the purchase of better clothing or cosmetics. In this sense, these office ladies are interacting with their business work: on the one hand, their work can bring them salary; on the other hand, they use the money to make themselves beautiful, which they believe will benefit their work. The more beautiful and elegant they are, the more chances they have to maintain the jobs or get promoted. In Soyer's another painting, Casting Office (1945; Fig. 3-6), we see two well-dressed office ladies sitting on 
a bench. They are probably waiting for a bus. The one on the right rests her head on an elbow and closes her eyes. We can assume that a day's work makes her extremely tired. However, the one to the left is sitting straight-up and putting powder on her face. She must be tired too, but she is still attentive to her appearance.

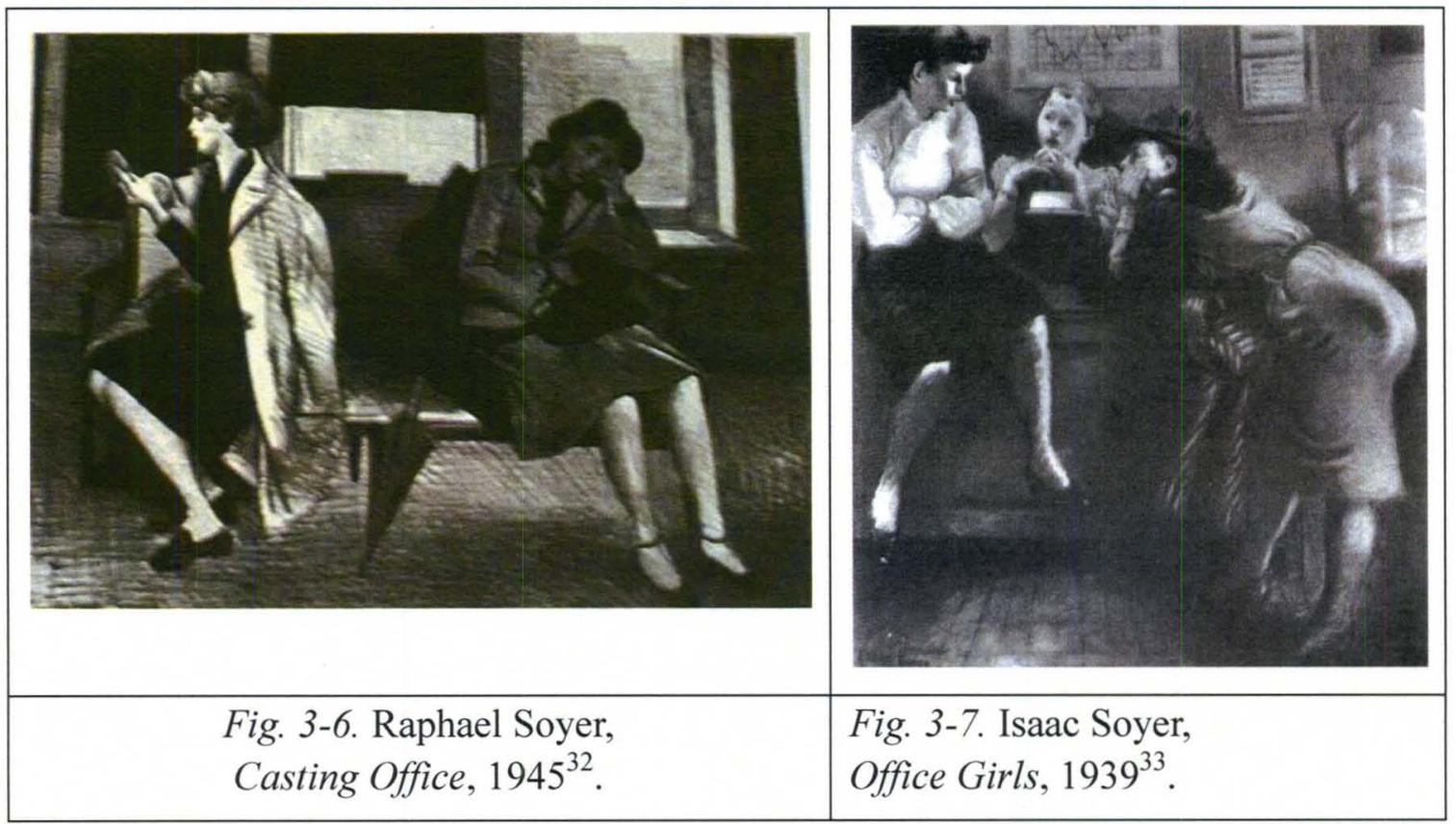

The Office Girls painted by Isaac Soyer (1939; Fig. 3-7) is one of the few paintings of the period that shows businesswomen in an office. We do not know what they are talking about. They may be gossiping or talking about some problems. However, no matter what they are talking about, they obviously are not working. Instead, they are more concerned in showing their attractiveness while talking with each other. They are

\footnotetext{
${ }^{32}$ Retrieved from http://i12bent.tumblr.com/search/Eakins on March 24, 2009.

${ }^{33}$ See Todd (1993: 307). Present location unknown.
} 
put before the viewers as "sexually attractive office ornaments" (Todd, 1993: 307). Todd

(1993) describes them in great detail:

They congregate around a desk, where the central figure pauses momentarily over her typing. The legs of the woman on the left, exposed above the knee, are highlighted and silhouetted against the darker desk. The figure on the right bends over on a diagonal to prop her head in her hands, her brightly illuminated, snugly clothed buttocks projecting toward the viewer. The pose, unselfconscious in an all-female group, acquires a heavy erotic subtext as the figure takes over the entire right side of the canvas. (Todd, 1993: 307)

This scene reminds us what the job counselors urged women to do in the 1930s-while engaging in social activities, keep "an eye out always for a satisfactory marriage" because "no one wanted to pound a typewriter forever" (Todd, 1993: 308). In fact, office ladies were "encouraged to overlook the tediousness of the work since it would be temporary" (ibid.).

Edward Hopper's Office at Night (1940; Fig. 3-8) depicts a private secretary in an office. The male boss is working before his desk, while the secretary is probably looking for some documents in the filing cabinet for him, because we see pieces of paper on the secretary's desk, on the chair, and on the ground. The supportive function of the secretary's work is obvious in this painting. In addition, with her face turning to the male boss, the secretary is having a seductive and twisted posture which "displays her breasts and buttocks simultaneously for both the male viewer and, should he look, the boss" (Todd, 1993: 305). In this way, she was objectified and constructed as the "ultimate office ornament" (ibid.). 


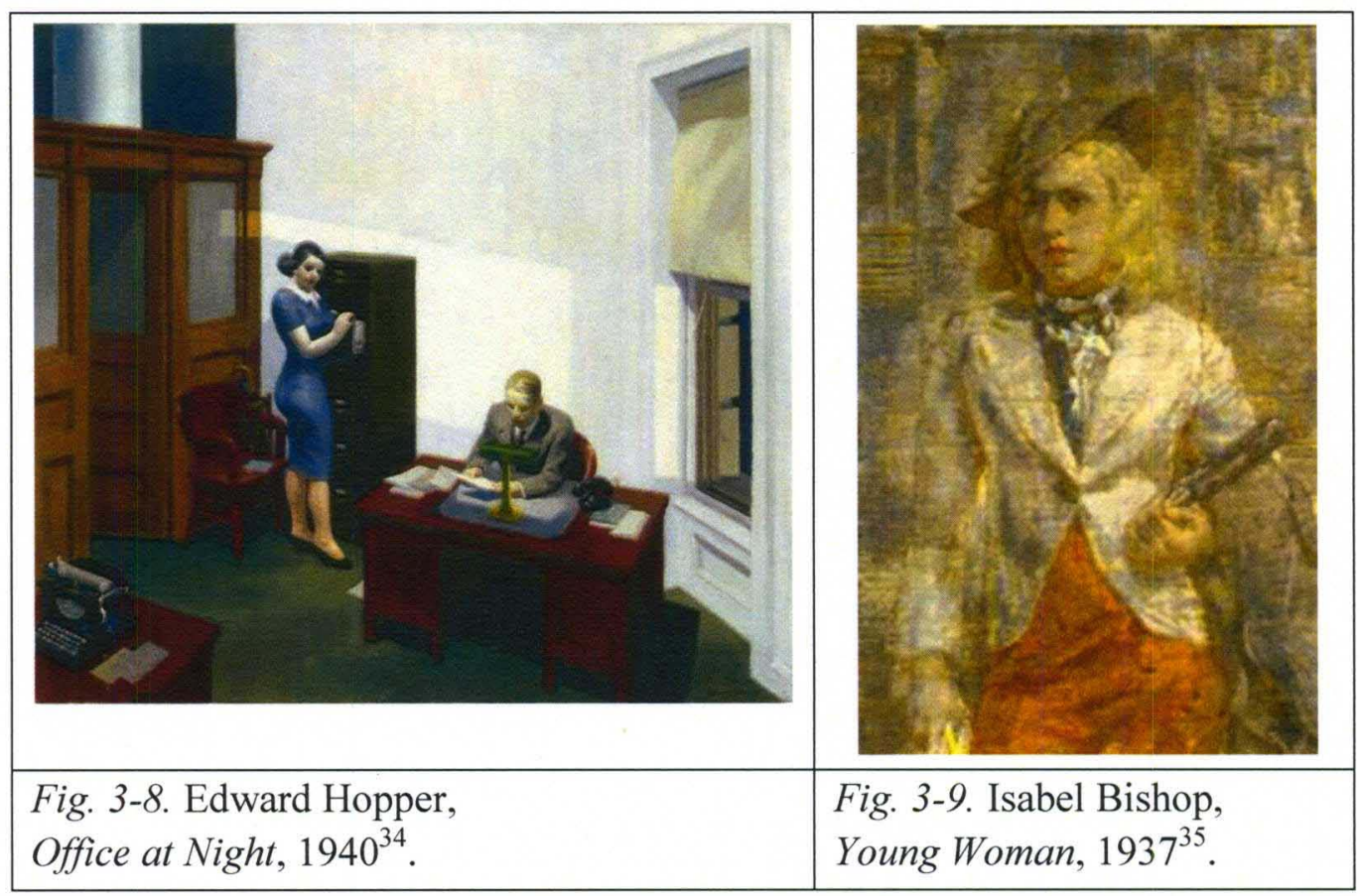

The businesswomen in Isabel Bishop's paintings are comparatively more fashionable and independent. In her Young Woman (1937; Fig. 3-9), the figure looks poised and self-confident with her tailored suit and neatly brushed blond hair. According to Todd (1989, 1993), this figure might be identified as "a stenographer working her way up the office ladder" by middle- to upper-middle-class urban viewers of this work who are familiar with the business world (Todd, 1993: 185). The business work for her is more enjoyable. Similarly, in Bishop's Lunch Hour (detail) (1939; Fig. 3-10) and Lunch Counter (1940; Fig. 3-11), there are office girls who look fashionable and smart. In comparison with William Siegel's Office Worker's Lunch Hour (1930; Fig. 3-3), these

\footnotetext{
${ }^{34}$ Retrieved from http://www.arthistoryarchive.com/arthistory/precisionism/ on April, 3, 2009.

35 See Todd (1993: 286). The Pennsylvania Academy of the Fine Arts, Philadelphia.
} 
office ladies are more content and know what they want. The ice-cream cones and hotdogs and a drink are certainly more delightful than the dry bread.

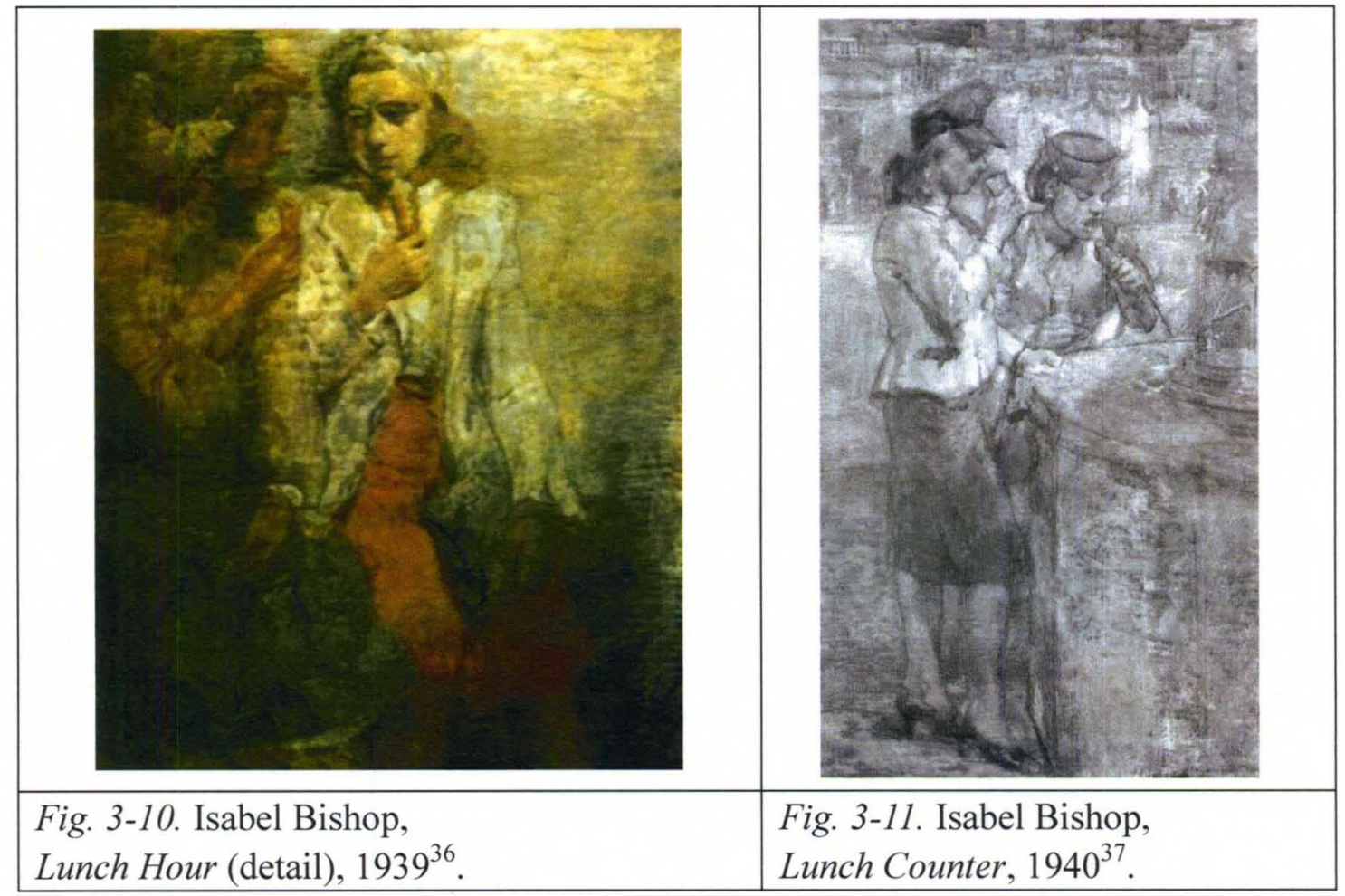

If Bishop's young women look reasonably fashionable, it is because this "established model of artistic beauty assumed a particular meaning in the 1930s, when the office worker's prettiness became increasingly important to her job" (Todd, 1993: 301). Accordingly, job counselors give suggestions to young women about what they should wear and how they should behave if they want to become office ladies. For example, one typical job advice manual states:

\footnotetext{
${ }^{36}$ See Todd (1993: 279). Collection of Mr. and Mrs. John Whitney Payson.

37 See Todd (1993: 278). The Phillips Collection, Washington, D.C.
} 
American Express Travel Service" the pretty businesswoman in the ad thrusts her chin a little bit upward, which indicates that she is proud of herself for being a businesswoman and traveling alone.

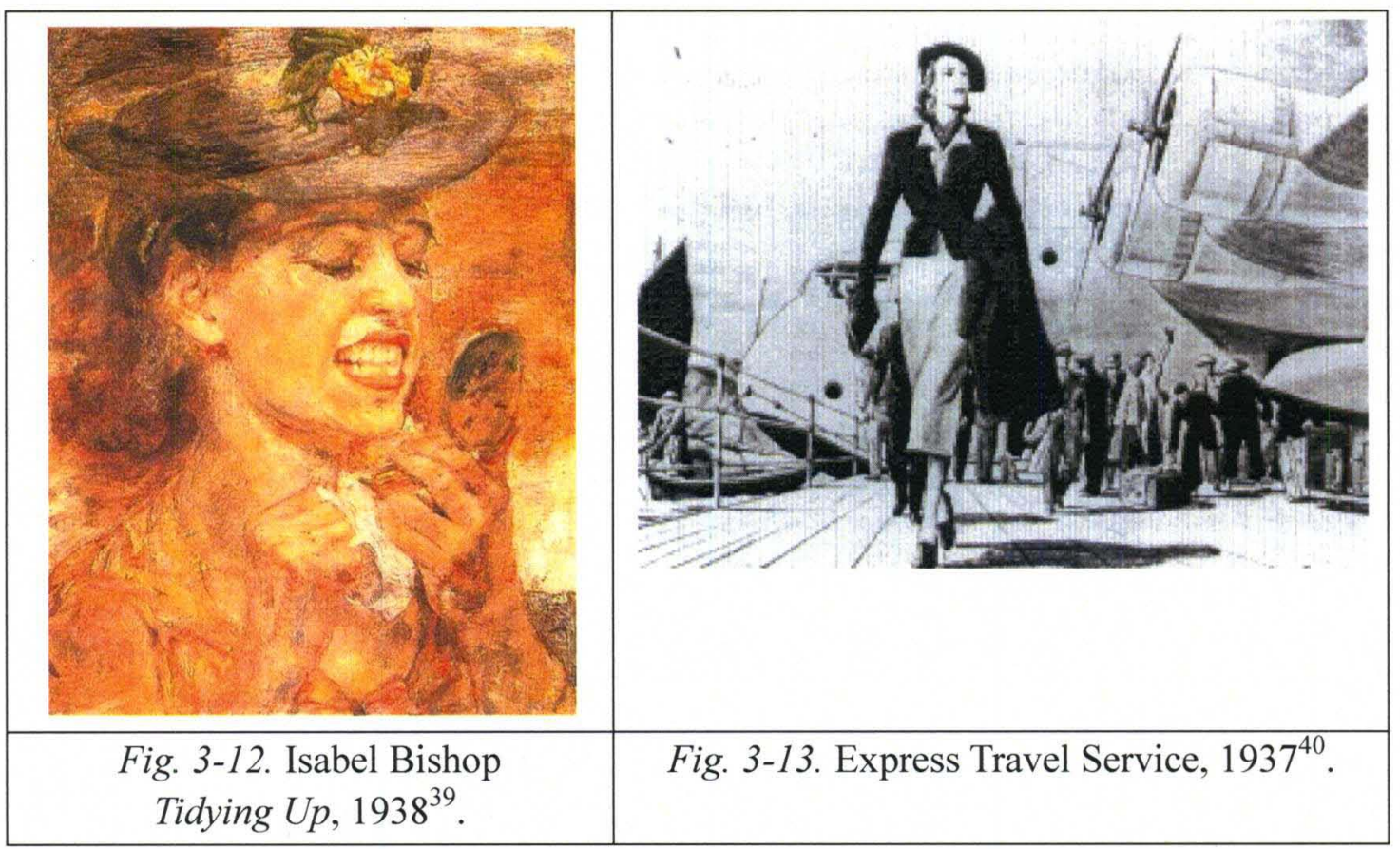

In the popular career movies concerning women between the 1930s and 1950s, such as Big Business Girl (1931), Skyscraper Souls (1932), and Lucy Gallant (1955), we can see clearly that corporate businesswomen are all ambitious at the beginning, and then they encounter inner struggles with their identities as both office business people and women. In the end, their business work turns out to be an obstacle to happiness.

For example, the movie Big Business Girl (1931) offers a narrative of the conflicts encountered by Claire MacIntyre (acted by Loretta Young). Claire postpones marriage to

\footnotetext{
${ }^{38}$ See Harper's Bazaar, Sep.1, 1937, p. 159.

39 Retrieved from http://www.imamuseum.org/blog/tag/isabel-bishop $\% \mathrm{E} 2 \% 80 \% 99$ s-tidying-up/ on Mar.28, 2009.

40 See Harper's Bazaar, Sep.1, 1937, p. 159.
} 
her boyfriend Johnny because she has to work to pay debts and Johnny cannot help her. She makes efforts to fight against the patriarchal possessiveness at work by trying ambitiously to enter man's business world. Her nickname "Mac" is not a feminine first name, which shows part of her adaptation to the workplace. However, other women in the movie kept telling Claire that being ambitious will not lead to good results based on their own experiences. Here is the response of the office factotum Sally Curtin, a middle-aged woman, after Claire tells her that she could barely sleep and was excited about the opportunity to write advertising copy for the company: “...until you've been around here as long as I have, you'll get used to insomnia...I used to be terribly ambitious myself, getting a job at a man's salary. I used to try to write copy..."41 While saying these words, Sally looks dejected. After Claire said that she will succeed or at least "bust a lung trying," Sally said: "It takes more than a successful career to keep a girl warm at night." ${ }^{42}$ In another scene, when Claire is expecting to be promoted to be a copywriter because of her excellent job in advertisement writing for the company, another secretary sympathizes with her. The following conversation takes place between the two office girls:

Secretary: I used to be terribly ambitious myself. I used to try and write copy... have visions of grabbing off a sweet job at a man's salary. However...

Claire: ...I know I can write good advertising copy.

Secretary: Do you like working, Mac?

Claire: I'm going to like it when I quit being a slave to a typewriter...have a job that gives me fine clothes, a nice

\footnotetext{
${ }^{41}$ The lines of the movie Big Business Girl (1931) quoted in this paragraph were transcribed by the author.

${ }^{42}$ Ibid.
} 
apartment with all the trimmings ${ }^{43}$.

Obviously, the frustrated Sally and the secretary are trying to persuade both Claire and the female audience of this movie to avoid ambition, which will ultimately lead to failure. It implies that only the domestic space and marriage can give women a sense of safety, success and happiness. Claire's struggle also takes place after her promotion. When she is happily trying out her telephone and intercom in her new office, she overhears the conversation between her boss Robert J. Clayton (acted by Ricardo Cortez) and his partner. The latter says: "even if this piece of copy was an accident, she's worth a hundred twenty-five a week as an office decoration." ${ }^{44}$ We see that her face freezes for a moment, showing a bit of humiliation on it. Taking for granted that her promotion was only because of her beautiful appearance, Claire changed her attitude toward her job after she struggled for a while. Since then, Claire began to perform her job by taking full advantage of her beauty in the fine clothes for social engagements. The publicity for this movie offers a good summary of Claire's ambivalent situation: "She had a marriage contract she couldn't live up to. Because she had to 'Love, Honor and Obey' her boss to keep her job. The real lowdown on girls in business!" (Berry, 2000: 165).

In the movie Skyscraper Souls (1932), the secretary Lynn Harding (acted by Maureen O'Sullivan) is an attractive secretary with professional ambitions. She even attends evening courses in business at Columbia University to enrich her business mind. Like

\footnotetext{
43 Ibid.

44 Ibid.
} 
Claire, she also postpones her marriage because she wants to be independent economically and her fiancé Tom Shepherd (acted by Norman Foster) is not rich. When Tom pressures her to quit her job after marriage, Lynn rebels by saying: "You haven't thought of me at all—of how much I like my work, how anxious I am to get on with it." On hearing that Tom insists, Lynn finally bursts out: 'No! I won't marry you and give up my job." However, her job in the skyscraper brings her not independence but confusions. Facing the seduction of her boss David Dwight (acted by Warren William), a patriarch of the building, she is vulnerable and couldn't help "falling." This movie offers a lesson for the young ladies who want to go into business.

Lucy Gallant (1955), adapted from the semi-autobiographical novel The Life of Lucy Gallant by Margaret Cousins, is another popular movie in which Lucy Gallant (acted by Jane Wyman), once a successful owner of a corporate of women's clothes, bends to the social gender role expectations by giving up her career to marry a rich man. The story begins in 1941 when the Japanese bombed Pearl Harbor. Lucy rejected the love of a rich oilman Casey Cole (acted by Charlton Heston) and ambitiously turned her small department-store (White Sage Emporium) into the big Gallant's Inc. "This transformation, the film tells viewers, is one hell of a mistake, because all Lucy Gallant has done is build herself a prison in the form the a department store" (Basinger, 1993: 232). Here is a conversation between Lucy and her best friend (acted by Thelma Ritter) concerning Lucy's business ambition: 
Friend: The only thing that stands between you and him (referring to Casey Cole) are the four walls of this glorified dry goods store...

Lucy: But it's my dream!

Friend: Well, wake up...Having your own man is better. ${ }^{45}$

In her friend's eyes, Lucy's business career dream (the department store) is only a prison with "four walls." This is reminiscent of the prison-like working environment in Siegel's painting Office Worker's Lunch Hour (1930, Fig. 3-3). In addition, her friend is trying to persuade the audience that women's career should be getting a man instead of work.

To sum up, young white female clerical workers dominate the corporate business work force between 1920 and 1963. Concerning these corporate businesswomen's attitude toward their work, we have shown evidence from two perspectives- - their own voices (mainly from the magazine Independent Woman) and the social perspective (including evidence of the paintings, advertisements, and movies). Generally speaking, businesswomen's attitude toward their work is quite ambivalent. On the one hand, the work gives businesswomen a new social role and their self-identity contains more meaning than that of the stay-at-home women. Businesswomen during this period are seeking independence both economically and spiritually. In comparison with other work in factories or stores, corporate office positions are very popular with women because they are what people call "white collar jobs," which involve no hard physical work. They are cleaner, more elegant and offer better pay. These businesswomen regard themselves

45 The lines of the movie Lucy Gallant (1955) quoted in this paragraph were transcribed by the author. 
as "the New Women" who have more education and more professional ambition. This is partly reflected in their fashionable and attractive clothes. On the other hand, these businesswomen are quite aware that they are working in a man's world. Their work and man's work are segregated in nature. In addition, they know from their experiences that the society does not expect them to be successful in business. In other words, their ambition is repressed by the society. Although some women have successfully set up their own business, the majority of them seldom believe that they "can" or "should" pursue business success and leadership through their own efforts. They only work to provide support services for men in the offices doing clerical work. The office work is like the extension of the work that women traditionally provide for men at home, which does not require professional skills. Of course, this is not the only purpose of working. Looking for an ideal husband is another important one. This point will be elaborated in the third part of this chapter. In this sense, these women regard their work as "job" instead of "career." They are not sure when they will give up their work (or be saved from the "prison") and begin the safe and happy life of a homemaker. The attitude of white corporate businesswomen between 1920 and 1963 towards family will be discussed next.

\section{$\underline{\text { WACB and Family }}$}

The white corporate businesswomen's attitude towards family is closely related to their attitude toward business work. During the periods of Depression and World War II, 
more women were encouraged to be in the workplace than ever in the United States.

Their work brought them new self and social identities, and economic independence; however, the "persistent definition of women as primary child care providers" kept forcing women to struggle between work and family (Kwolek-Folland, 1998: 186). Women's destiny to reproduce presumed that women were "family members first and individuals second" and this idea was shared by many people including "feminists, business and labor leaders, and social reformers" (Kwolek-Folland, 1998: 135). As Kwolek-Folland (1998) points out:

...conservative attitudes shared by government, business, unions, and many women themselves undermined the potential for radical change in women's access to employment and business opportunities...Many women themselves, even as they enjoyed a level of earning power undreamed of in peacetime, fully expected to hand their positions over to men once veterans returned. (1998: 133)

We see that it is women who are willing to give up their power in the work force. Why? The reason has two aspects: on the one hand, these women held the deeply-rooted idea that women belong to family; on the other hand, they had to face the long-term dilemma and problem for working mothers: what to do about child care and household responsibilities? Women who worked or ran a business outside of the home suffered from what Kwolek-Folland called the pressure of the "double day," that is "when paid labor is done, domestic labor remains. The war made conditions particularly bad. ...after putting in a six-day work week, some women found they had little time left to do the laundry, cleaning, and shopping" (Kwolek-Folland, 1998: 153-154). One working mother even 
complained in 1954 that "Working denies me the privilege of being a good housewife and, shall we say, a more patient mother" (May, 1988: 87, as cited in Kwolek-Folland, 1998: 133). A 1945 Gallup Poll found that only 16 percent of men and 20 percent of women believed that married women should work outside of the home...It was also true, however, that the majority of women themselves wanted domesticity (Kwolek-Folland, 1998: 155).

In those trouble times, the tendency to "see women in terms of the family claim," or to emphasize women's traditional role, according to Kwolek-Folland (1998), "was an attempt to preserve the status quo in the face of disaster" (1998: 134-135). During the postwar era, the concept of family continued to be fully, or even over glorified. As said by one woman in front of the crowded hospital maternity wards, "everyone, and her sister, was having a baby" (Kwolek-Folland, 1998: 133). The nation welcomed its largest generation ever-the baby boomers. Popular magazines are full of advertisements of women as consumers, mothers or wives. The emphasis of women's domestic role from the 1930 s to 1950 s also has detrimental impact on white corporate businesswomen. In other words, their business experiences are shaped by the "expectations surrounding the family claim" (Kwolek-Folland, 1998: 135). Next, evidence from the magazine Independent Woman will be analyzed to show how corporate businesswomen saw family life and their struggle between work and family.

In "Penalizing Marriage," Alma Lutz (1932) shows the disadvantages of women who have entered marriage because "New York, California, West Virginia....... and other states 
are attempting to discharge married women employees" and "the Mayor of Syracuse, New York, recently ordered the dismissal of all married women employed by the city, if their husbands were earning a living wage" (Lutz, 1932: 76). It seems that women should be protected and raised by men and they had no right to jobs as long as some men were unemployed. In fact, Lutz (1932) argues "today under changed economic conditions she [woman] is contributing toward the family income" (ibid). In this sense, they work not only for themselves, but for their families! "Many [women] have parents whom they are supporting, or invalid members of their families; others are helping younger brothers and sisters with their school or college expenses, or perhaps are paying up family debts" (ibid.). According to Lutz (1932), if a wife does not work, her husband needs to earn $\$ 100$ per month to raise the family. However, "there are many husbands who can never earn more than $\$ 100$ a month. If the wife can earn a salary, they can perhaps buy a home and build up a fund for emergencies and the education of their children" (ibid.). We see that if women work, the biggest beneficiary is the family.

In this social situation, before a young woman who is earning a salary marries, she must consider it well. For example, in "Does It Pay To Be A Good Secretary?", Dorothy Thomas (1932) claims that a good secretary will be "cautious against rushing into a marriage with a young man who is making less money than she is" because "the better the secretary, the better the pay and the more exacting the work" and she knows that her job is not a part-time job, which demands her energy, time and health (Thomas, 1932: 314). In addition, her responsibility toward family, especially the husband, will not be 
fulfilled at times. For example, instead of doing the household chores, "she's got to spend a good many non-working hours resting for working hours" and "if she's arranged to meet her husband for dinner, and her boss wants to dictate some letters, husband has to wait. If she has planned to go to church at twelve and her boss decides to go out early she can't meet him" (ibid). As a result, one secretary "broke her engagement to a man in Boston because her boss had to open an office in New York" and "another, finding her job so interesting and remunerative, kept postponing her marriage until the young man wed another" (ibid).

From the above examples, we can see that businesswomen regard family life as a threat to their work. They know that after they get married, they have less energy devoted to their work and are not free any more. However, when they pass the age of thirty, they will begin to worry about their status of being bachelorettes. Or at least the people surrounding them will worry about them and pressure them to get married. In "Scuttling For Home" (1932), the author Gene Allen Taylor is at the cross-road of her life and confused. Her friends also have their own ways of finishing their episodes of being thirty. For example, there is Martha, who scuttled for home to think life over by getting married. And there is an Engineer Man who at thirty has just finished a big construction job. He told the author "how comforting it is to think things out loud while his mother is working around the house, although she never says anything to help him decide" (Taylor, 1932: 47). Then he decides to stop "rooming around" and "get into a town on a job long enough so that he could buy a house with a Colonial door and have hollyhocks in his garden" In 
addition, he feels that the author is "one of the girls who might do to take care of that house" (ibid). In order to decide what one should make of the next thirty years, the author suggests that the solution is to "scuttle for home just like a brood of scared chickens to peep out at life again from beneath the warm, safe wings of mother hens" and learn from our parents (ibid).

In "The Use of Adversity," Verna Vernier (1932) relates a story about how a businesswoman changes her attitude toward housework and housewives during the Depression. In the story, the businesswoman loses her job and her husband loses his. Her friends are similarly affected. Incomes are suddenly altered. Expenses have to be cut. After careful consideration, she decides to cut food expenditure by "eating in" instead of "eating out." Then, she begins her housekeeping experiments. She will explore the neighborhood, learn to buy the supplies for dinner, and cook in person. While doing these, she keeps thinking about her work:

While I shop I can decide what I'll say tomorrow to Mr. L. to sell him my proposition. First he'll object out the expense and I'll-now was it this chain store or the one at the other corner where they were selling peaches at sixteen cents a can? No, the other corner. It's only five cents saved, but I need the exercise; I ought to walk more. And I can decide what I'll say to Mr. L. Let's see, we had chops last night. We haven't had steak for three nights. There isn't time to roast anything. Steak, chops. Here we are. Why is this store always so full of women shopping? Why are so many housewives fat and mussy? I'm never going to allow myself-I wouldn't dare. I'd lose all my business. Now, while I wait my turn, I'll think up how I'll meet Mr. L's objection. Oh dear, the peaches aren't on sale after all. It's pears. Well, I'll take pears. Yes, yes, I'm next. No, I'm next. I've been waiting just ages. Yes, a can of pears and a bunch of carrots and-... (Vernier, 1932: 13) 
Home in the kitchenette she continues: "Now I'll think this out while I dice the carrots. Anyone can dice carrots and think. Now he'll say, 'but right now we're cutting down expenses wherever we can, we're not—'" (Vernier, 1932: 13). Then, seven pieces of diced carrot slide to the floor. "I'll let them stay there. The maid can sweep them up tomorrow. And I'll say to Mr. L.--" she thinks (ibid). Then, "she steps on the carrot dice, frowns, stoops down, laboriously picks up five, searches carefully and at last captures the remaining two. Battle is pitched between directed thinking and unthinking carrots. The carrots soon win...Seven carrot dice slide to the floor. The incident repeated. The carrots win. They always win" (ibid).

This is the businesswoman's experience of being a housewife. She could not do the shopping and cooking smoothly because she couldn't help being absent-minded thinking about her work. Then, after sometime, she found that "any woman can learn to cook-that is, if she wishes to do nothing else at the same time" (Vernier, 1932: 13) and her "superiority complex" in front of housewives has been completely destructed (Vernier, 1932: 37). This is a discovery at which the businesswoman arrives "slowly and rebelliously" (Vernier, 1932: 13). We can see this clearly in her conversation with her friend, another once successful businesswoman who also suffers during the Depression and "cooks in":

Friend: "Listen to us talking like a couple of inveterate housewives. See how we've degenerated. A year ago we would have been discussing a new book. A year ago we'd both have looked down 
scornfully on two women talking about vegetables. Now I wonder about them, those women who cook and scour all day. And most of them with children besides. I wonder that they manage to have any intellectual life at all."

Businesswoman: "I've being thinking about it, too," I confided. "I don't feel so superior to them as I once did, either. This everlasting cooking! I find myself thinking about nothing else. I haven't had a bright idea for a month."

Friend: "But do you know...I like cooking. It's lots of fun! I really enjoy it!" (Vernier, 1932: 37)

In this story, we see that the businesswoman and her friend have finally have respect and understanding toward the housewives who must stay at home, dice carrots, choose between canned peaches and canned pears, consider the price of peas and the relative merits of electric stoves etc. They even begin to enjoy the life at home shopping and cooking although they didn't choose to stay at home. Here, the traditional role of women as homemakers is glorified. As in the story, the carrot is a symbol of family and the businesswoman finds out with her own experience that "the carrots soon win...They always win" (Vernier, 1932: 13).

In her "Inventory of Frustrations" (1949), Eleanor Metheny lists complaints most commonly made by career women, in which we can see that no matter how successfully they are, they long for the common family life. For example, the first one is "I have no real home life. I'm tired of eating out. The sight of the four walls of my room drives me to distraction. I have no family circle. I have no one with whom to spend vacations and holidays" (Metheny, 1949: 12). An unmarried career woman sometimes feels lonely because "no one in the world really needs or depends on me [her]. If I [she] died 
tomorrow, no one would really care" (Metheny, 1949: 13). In addition, she may not have a proper social life because she has nothing in common with the women in most social groups. On the one hand, she does not "fit in with the married groups of my [her] age"; on the other hand, "constant association with 'the girls' bores me [her]" (ibid.). This kind of embarrassment urges career women to want to be married: "I'm tired of being an "extra" woman. I want to be taken care of by someone who will do all the worrying for me" (ibid.). To deal with these feelings of frustration, the author gives a series of solutions. For example, she encourages them to "invite to your home people you like—old and young, married and single, men and women—in exactly the same way you would do if you were a homemaker with a husband to help you create a social life," and "If you want a home, make one for yourself. Give yourself all the comforts you expect of a home - space, comfortable and attractive furnishing, well-balanced and attractively served meals" (Metheny, 1949: 14). In fact, these career women do not want to be placed in a "non-normal" masculine situation; instead, they sometimes long for the life of traditional homemakers.

On the whole, in the businesswomen's own voices during the 1930s and 1940s we sense that whenever they mention family or home, they are full of tender feelings and tend to believe that the purpose of their hard work in business is for the well-being of their family. They feel that life will not be complete if they do not have their own families. Boozer (2002) says that "during World War II, the government encouraged women to take jobs because of military needs, but by 1955 , women were discovering new work 
motivations based on the need for family goods and services" (2002: 52). This reflects the deep-rooted belief that women are family members first and individuals second.

The movies in this period also reinforce this idea. At the end of Lucy Gallant (1955), the successful businesswoman Lucy made a seemingly wise decision—she marries the wealthy oilman, and becomes a homemaker. When she is locking the door of Gallant's, Inc., she feebly asks: "Haven't I the right to do two jobs at once" and "Is there any reason why the women can't get in on this boom town?" She has passion toward her career; however, society does not expect her to have both marriage and career at the same time. The movie makes it clear that Lucy "has finally realized her proper place and will find happiness under her husband's patriarchal authority" (Boozer, 2002: 60). It is true that, in this period, "the American movie-going public was still not ready for young, competent, much less sexually assertive career women whose idea of success might apply both to their own family and to their career of choice" (2002: 64).

All in all, women in this period were encouraged and cajoled into believing that their place was at home, and marriage should be their main job. For those women who have already chosen to work for corporate business, "family" is the ultimate purpose why they work. Family is competing with business work for their time, and it always win. They try their best to make money for their families, not just earn their "pin money." 


\section{$\underline{\text { WACB in Relation to Men }}$}

The relationship between women and men is the basic concern in Feminism. In this part of the dissertation, how men are seen in the eyes of the corporate businesswomen between 1920 and 1963 will be illustrated mainly through the cultural evidence from the magazine Independent Woman, and several movies. Corporate businesswomen's relationship with men is based on how they see their work and how they see family life, because they may work with men (in the capacity of colleagues or bosses), live with men (such as their husbands), or regard men as friends. As it is mentioned in the previous two sections, the corporate businesswomen between 1920 and 1963, on the one hand, wanted to keep their identity as career women who are financially independent; on the other hand, one of the most important purposes of their working is to support their family. Of course, they have other purposes such as showing their attractiveness, looking for a husband, and making "pin money" for themselves.

In general, businesswomen in this period wanted to pursue equal status with their male counterparts in many aspects—work, marriages and friendship etc.; however, they finally realized that the social conventions did not change, and then they gave up. Next, we will see in detail how the corporate businesswomen see men through articles in the magazine Independent Woman.

In "The Use of Adversity," Verna Vernier (1932) believes that "The modern business or professional woman is the spoiled child of the century. For twenty years or more she 
has been a success. No one questions longer nor argues about a matter so definitely settled. Her friends, including her husband, admit that she is at least the equal, possibly the superior, of the average man" (Vernier, 1932: 12). In "Paging Mr. Plato," Catherine Cathcart Wilson (1932) depicts the ideas that the "new women" hold toward the ideal relationship with men, and how they become disappointed after they have their personal encounters. At first, the article's author begins with a kindly old Greek philosopher who "formulated certain theories concerning friendly relationships between men and women — very sane, very reasonable, very delightful theories that would seem to merit cultivation" (Wilson, 1932: 84). Yet, in actual life, a businesswoman, who has been widowed for more than 10 years, complains that:

I can make my living alone, I can take care of my family alone,...but I can't play alone. Neither can I get the enjoyment and relaxation form playing with other women, talking with them, attending purely feminine social functions that I can from the same diversions when men are part of the picture. Perhaps it's a weakness... or a complex. I don't know. But it's the truth...I've built up this business. The work and the family care have been congenial enough. They have kept me busy and interested. But these upper and nether millstones haven't reduced me to negligibility. I still have a rather large capacity for human enjoyment, and I have an insatiable appetite for growth—not just in business, but in the happy and profitable use of leisure. I like the society of congenial women, but I need the society of men, too. I get more mental stimulus from men than from women - with whom my mind travels parallel. I enjoy the society of men who are alive and interesting - not sentimental and personal. (Wilson, 1932: 84)

According to Wilson (1932), "one of the by-products of modern business seems to be a group of competent, independent, lonely women who do not want lovers, amorous 
adventure, or husbands. They do want and need the companionship of men" (1932: 84). It is a simple and natural enough desire, and the woman mentioned above was simply "one of the thousands of American businesswomen, all very busy, very interested, sharing the industry of the community, yet strangely isolated and marooned in a society of women like themselves" (ibid.). Wilson also recorded a frank discussion of this situation by a group of half a dozen business women, all past their first youth. One of them declared: "I don't want marriage, and I don't want romance and sentimentality, but I do want friendship and association with men of congenial tastes" (Wilson, 1932: 112). Five heads nodded in agreement. Then, another suggested: 'I've been thinking that we ourselves are the ones that keep up the sex barrier. It is one of our inhibitions. We are too self conscious. We are not able to ignore what someone may be thinking. Why aren't we just frankly and openly sympathetic, sincere human beings with men as we are with each other? We aren't now, and we all know it" (ibid.). On hearing this, two other women, Lillian and Sylvia, burst out laughing. Lillian said:

Sylvia and I had this bright thought a year ago. We agreed that it was probably our own fault that we were 'shut within nunnery walls' so far as our social experiences were concerned and that the walls were narrowing every year. So we decided that so far as we were concerned, the time had come to scale the wall...In other words, we intended to do our part in getting acquainted with men who looked as though they might be worth the effort. I had three adventures before I gave up. (Wilson, 1932: 112)

Then, she told them one of her adventures to show that the man of her age she met in the observation car, who was "keen eyed, humorous, intelligent, not too handsome, but 
good enough" (Wilson, 1932: 112) is very promising to be a companion because:

We found a mutual interest in the daily news of the international situation. His opinion was sounder, better informed than mine. I learned something, and that was good. He touched upon an article he had read in the magazine that lay on my lap. His comment was keen and caustic. Wit bubbled out now and then. His golf score was better than mine... (ibid.)

However, the woman soon found that she "had passed from a pleasant and agreeable traveling companion, a friendly chance acquaintance to the special niche that he reserved in his mind for WOMEN" because "his manner was tinged with the personal" - he intended to pay for the lunch, invited her to have dinner, and "stopped long enough to ask whether I [she] would return to the club car or whether he might join me [her] in my [her] own section" (Wilson, 1932: 112). Finally, she concluded "I charged that experiment off to profit and loss, but I tried twice more before I gave it up. Men don't see us possible friendly companions. We are still what we always have been-WOMEN. Give your testimony, Sylvia" (ibid).

Sylvia had a similar personal encounter with a business man. She told him frankly that:

I know you are rather important part of a business concern. You know I am a business woman. So far as our daily habits shape our lives and tastes, we might be two business women or two business men here together, both finding time dragging heavily. Why didn't you take my companionship for a casual hour of waiting as I took you-as I could have taken another woman, or as you could have taken another man? (Wilson, 1932: 112)

The businessman looked at Sylvia in perfectly helpless bewilderment and said "But 
you aren't another man, you see! You're a woman, and a darned attractive one" (Wilson,

1932: 112). Sylvia retorted:

....and you are a man — good enough looking, as far as that goes, with all your features and a sound six foot physique. But I can't get sentimental over you, or enjoy having you hold my hand, or thrill over a surreptitious kiss in the dark... what I want you to tell me is whether it is possible for a man to be good friends with a woman for an hour, a day, or a year without letting the relationship drift into a sentimental channel. We have learned to work together days and years with nothing personal in the air. I could go into your office any morning, go to work, and I would be just part of the machine. Why can't we play, without making it a personal issue? (ibid.)

The man said “...But isn't that what women like?” After telling her story, Sylvia suggested: "He was so sincere, so naïve and bewildered, that in spite of my exasperation, I laughed. So, try it if you like, girls. And luck be with you. Lillian and I have had enough" (Wilson, 1932: 112). We can see clearly that these businesswomen become disappointed with the relationship between men and women based with respect to social conventions. They believe that whenever men see them, their appearance will be judged and the fact of their being WOMEN will be emphasized. If they are young, beautiful and unmarried, they are the ideal girlfriends or wives. It is difficult to maintain the so-called comradeship with men. As a businesswoman, Wilson argues that:

I find more pleasure in these things when agreeable and congenial men are participants. Wit is keener, sympathies deeper and life takes on finer colors and richer hues...we have in this century reached wide freedom of action for women. Yet we are still handicapped by the pseudo sentimental attitude of men, handicapped by their belief that frankness and sincerity and a human desire for comradeship constitutes approach-ability. (Wilson, 1932: 113) 
However, Wilson is still hopeful. She claims that "human relationships in general rise to their highest level with both men and women, at the challenge of the other sex" and "one must believe that sometime there will come about the fine and beautiful understanding between men and women that will make possible simple stimulating comradeship, based on common interests and tastes, that has nothing to do with sentimentalism and passion" (Wilson, 1932: 113).

In "The Worm Turns" written in 1932, Dorothy Dunbar Bromley (1932) vividly envisions that "in the year 1950, the masculine sex has lost its place in the sun" (Bromley, 1932: 245). As a result, the social status of men and women is reversed. It is interesting to see that:

Here and there men got jobs as chief clerks, buyers of notions, and heads of the Men's Department in branch banks, but their women superiors complained that they (men) were 'clock-watchers,' that 'they lacked ambition because they all hoped to get married sooner or later,' and that 'they were happier taking orders than giving them.' (Bromley, 1932: 265)

In addition, we see that "many young men jobseekers were told quite plainly that the organization had no openings for male applicants who were not stenographers" and "very few of the young men who obtained jobs as stenographers or secretaries ever moved on to higher and better positions" (Bromley, 1932: 265). In the better cases, what any aspiring young man of 1950 s can hope for is that "a woman will occasionally, begrudgingly, accord one of them the superlative compliment, 'But he thinks like a woman!"” (ibid.). 
In this fictional article, one of the male graduates of Princeton even wrote plaintively to Donald Dix of the Evening Record for advice: "My father wants me to come out in society now that I am through college, but I hate the thought of being shown off like a prize steer and then waiting for some girl to come along and propose to me. Why can't men have as full lives as women and amount to something in the world?" (Bromley, 1932: 265). The young male's concern is reasonable, because quite a few of young men secretaries "made themselves so essential—in one way or another-to their women employers that the latter proposed marriage" and such an offer is usually "accepted with alacrity, and the secretary gave up his career to keep the home fires burning, confident that he had made the greatest possible success of business" (ibid). In another case, one essayist who called himself a "masculinist" resisted the decline of his sex to the bitter end. So before he died, he willed his brain to the College of Physicians and Surgeons so that they might dissect it and compare it with the brain of the normal woman. "Great indeed would have been his joy if he could have lived to see the headline in the October 2, 1946 issue of the New York Times, which read 'Man's Brain Found Equal to Woman's" (Bromley, 1932: 245).

Although the author Bromley depicts the above scenes in her article in such a natural way, we feel that everything about the relationship between men and women is "unnatural." This is because we are used to see women as inferior to men. Whenever secretaries or stenographers are mentioned, we will think of women automatically. This article expresses businesswomen's aspiration to be of equal status with men and reminds 
women to have awareness that they should be treated equally with men; however, this idea stops in the imagination. No further action is taken to change the actuality.

In "Does It Pay To Be A Good Secretary?" Dorothy Thomas (1932) expresses that the roles of a female secretary before her male boss is "a cross between an efficiency expert, a buffer, a messenger boy, a valet, an accessory to the crime, a reception committee, a travel bureau and a doormat" (Thomas, 1932: 333). The boss does "occasionally really fall in love with their secretaries. But a man usually prefers to keep business and romance quite separate" and "he may never have said a personal word to her or given her more than a handclasp when he came back from his honeymoon, she may grow old and crabbed in his service, she may call him a tyrant, but undoubtedly he has taken the place of lover, husband and child to her" (ibid.). We know that often a secretary "pays a man's household bills, hires his domestic servants and balance his wife's check book" and "there is the self-sustaining sense of being necessary to someone. She may further have the gratification of helping him build up a business, of nursing it through various crises—of knowing how nearly the whole thing went on the rocks, and that she was his confidante during those dark hours" (Thomas, 1932: 333). It is true that if the relationship between businesswomen and their male counterparts in the workplace does not turn to personal relationship, these women may feel a certain type of comradeship with men.

Similarly, Helen Woodward, a famous woman in advertising business, argues that the workplace offers a natural environment for men and women to know each other. In an 
interview in "Business as an Aid to Cupid," she says that:

When men and women work together, side by side, they get to understand each other much better than they do when they meet for a few hours at a party or dance. At such functions, each tries to appear at his best, and conceals his real nature. Constant contact through business enables a woman to see a man as he is, to understand his problems, to sympathize with him. (Jacobs, 1932: 5)

In general, businesswomen in this period know that the true comradeship is impossible to obtain, but their work brings them a platform where they have chances to interact with men and offer their help. In fact, they enjoy the "roles" they play in the business world. Social conventions teach them that "a women's real business is men" (Bayard, 1947: 108) and "woman should be satisfied with the power of her feminine 'influence,' and not ask for such crude and unsatisfactory masculine weapons as the vote and money" (Ford, 1932b: 59). Therefore, these businesswomen are happy because they are needed, although they could not get "real equal status" with men.

There are also some poems in the magazine Independent Woman, which describe the relationship between businesswomen and their male counterparts. For example, in “Oddity,” Lewette Beauchamp Pollock (1947) expresses her feelings toward her boss:

I grow as fond of those I work with

For pay, as those, sans pay, I shirk with.

Yes, even of The Boss. I fear

Sometimes I'll up and call him 'dear'-

Then pray the creature's understood

It's just frustrated motherhood. (1947: 96)

We see that the speaker in this poem regards her boss as the mixture of a lover who 
she loves, a son who she wants to protect, and monster who she fears and want to dodge.

But, the strongest feeling is "frustration," which reflects a kind of resentment that businesswomen have toward their bosses. However, accepting this fact, they have never thought of doing anything to change it. Similarly, in another poem, "Pleasure Before Business":

Why even at the ripe old age

Many a woman that I know

Can type from notes and still survive!

Yet bosses ask that office girls

Be eighteen years to thirty-five;

Now could it be the bosses want

Office machines to play the jive? (Steele, 1947: 296)

The author P. M. Steele (1947) argues that it is unfair for older office ladies to be less wanted just because they cannot provide pleasure, visual pleasure to be exact, for the male bosses, for whom pleasure is more important than the business work.

In her poem, "From Woman Unto Woman," Verna Loveday Harden (1948) pays tribute to women's greatness in comparison with men:

The axis of the world is womankind:

She gives men birth and comforts them in death, As vision of some woman loved, appears

And lends man strength to face eternity.

Redemption is not hers for sin, once lost;

And nothing in the universe aspires

To such exalted heights as she attains.

She fires ambitions, kindles jealousies, And reaches nearest to divinity.

Men fight for her and die for her, and she Inspires their noblest dreams, or casts them down 
To groveling beasts. Men barter for her grace.

Upon her chastity or virtue's sacrifice

Within her power she holds the driving reins

Of what men glibly call their luck or fate.

From woman back to woman moves the world;

On her, men's blessings or their curses rest;

And in her arms are cradled hemispheres! (1948: 64)

Women, according to Harden (1948), are like goddesses. They are "the axis of the world," "[give] men birth and [comfort] them in death," and "[lend] man strength to face eternity" (1948: 64). Most important of all, women have grace, or the virtue of sacrifice. Although they have the power to control everything, they are generous and tolerant to men's curses. Women have never thought of taking revenge, because they regard men as their children whose bad behaviors will always be forgiven.

All in all, we learn from the magazine Independent Woman, the official magazine of the Business and Professional Women's Clubs, that although they want to have equal status and a kind of comradeship with their male counterparts, they are aware that the business world is still a man's world. They know that the social conventions make it difficult to change the status quo, so they give up. Next, let us consider how social conventions are formed through a cartoon, and some popular movies and novels of the same period.

In Charles Dunn's drawing for Marjorie Holmes Mighell's (1937) article "Romance Versus the Boss" (Fig. 3-14), an office lady is comparing her boss with her image of an ideal husband. There is the caption of the lady's words below the picture: "What a let-down! That first boss was plump, jowly, pudgy-fingered, insipidly mustached, losing 
his hair" (Mighell, 1937: 21). This picture reflects the social convention that business work or office work is temporary for the office ladies. No one wants to be a typist forever, and sooner or later, they will find their ends. Therefore, women entering the business field are usually encouraged to overlook the tediousness of the work since it will not last long. According to Todd (1993), in the 1930s, job counselors urged women to engage in social activities "with an eye out always for a satisfactory marriage" (1993: 308).

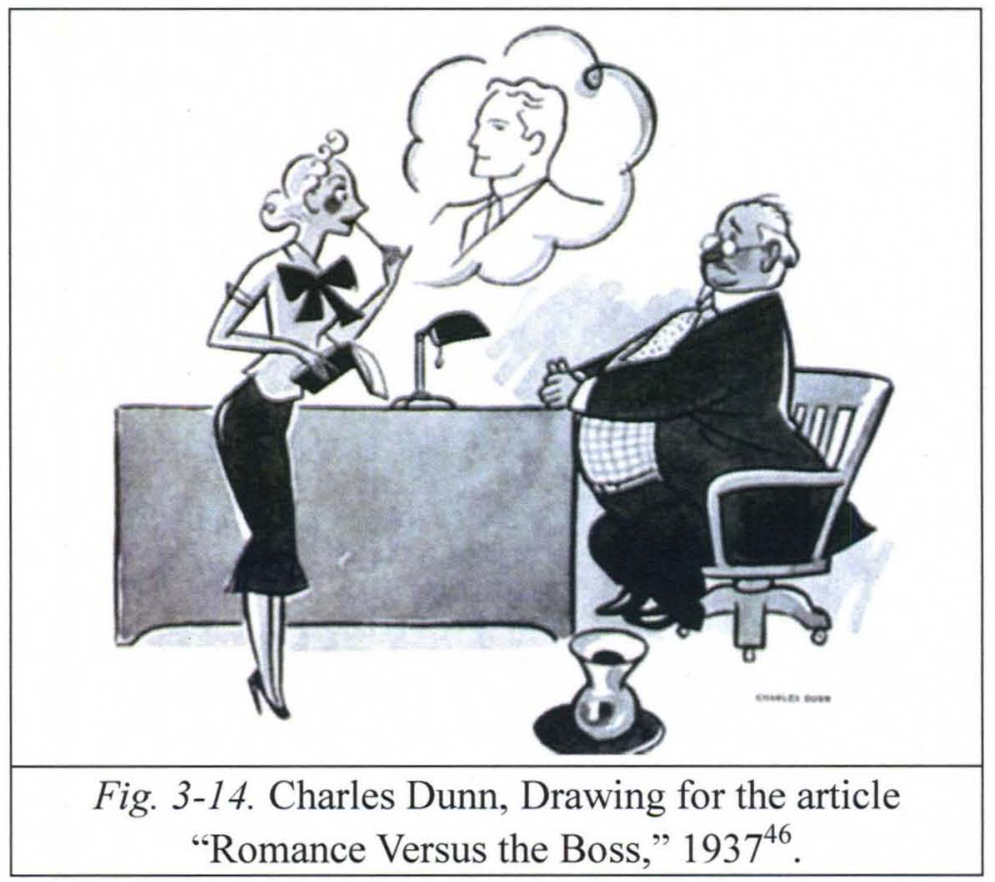

In comparison with a man, who can select actively his interests and goals from an array of possible choices, a woman is expected to be concerned primarily with domestic life. Marriage is thought to be a woman's main job. Consequently, she had to

${ }^{46}$ See Mighell (1937: 21). 
wait, passively, for the right opportunity and embrace it. Todd (1993) further explains women's situation in the 1930s in this way:

She had to learn to respond to external stimuli-whether a male superior's work assignment or his social invitation-rather than develop skills that would allow her to initiate and direct her own behavior. To be selected by men for work and marriage and to be successful on the job and in the home, she had to display compliant, womanly qualities, and she had to wait. Furthermore, what she waited for was still dictated by an ideal of womanly service. (Todd, 1993: 309)

In this sense, the relationship between businesswomen and men is in fact the same as that between the non-career women and men-both businessmen and non-career women are offering their service to men. The only difference is that the former offers service in the work field, the latter in domestic field.

In popular career movies, there are also some businesswomen characters who struggles in their relationships with men. For example, in Big Business Girl (1931), Skyscraper Souls (1932) and Solid Gold Cadillac (1956), we see that women's business careers just bring them personal relationships with businessmen, constructive or destructive, rather than business success.

In Big Business Girl (1931), we see that Claire (acted by Loretta Young) is instructed to flirt with male business customers and Claire's boss followed her into her apartment after a business dinner, which required an evening gown. The close-ups of the details of the items that Claire puts on, and the big walk-in closet from which she selects clothes linger in front of the audience's eyes. Berry (2000) argues that businesswomen in such 
career movies are often "'exposed' in feminine clothing, denying her [their] the ability to control her [their] own professional role[s] or image[s]" (2000: 172). These scenes make the audience feel as if they are at fashion shows and invite them to experience the "visual pleasure" (Mulvey, 1992). Furthermore, in a movie still (Fig. 3-15) and a poster (Fig. 3-16), we can see clearly that Claire is "gazed" by her boss Robert J. Clayton (acted by Ricardo Cortez), who is a representative of the male audience that enjoys her beauty.

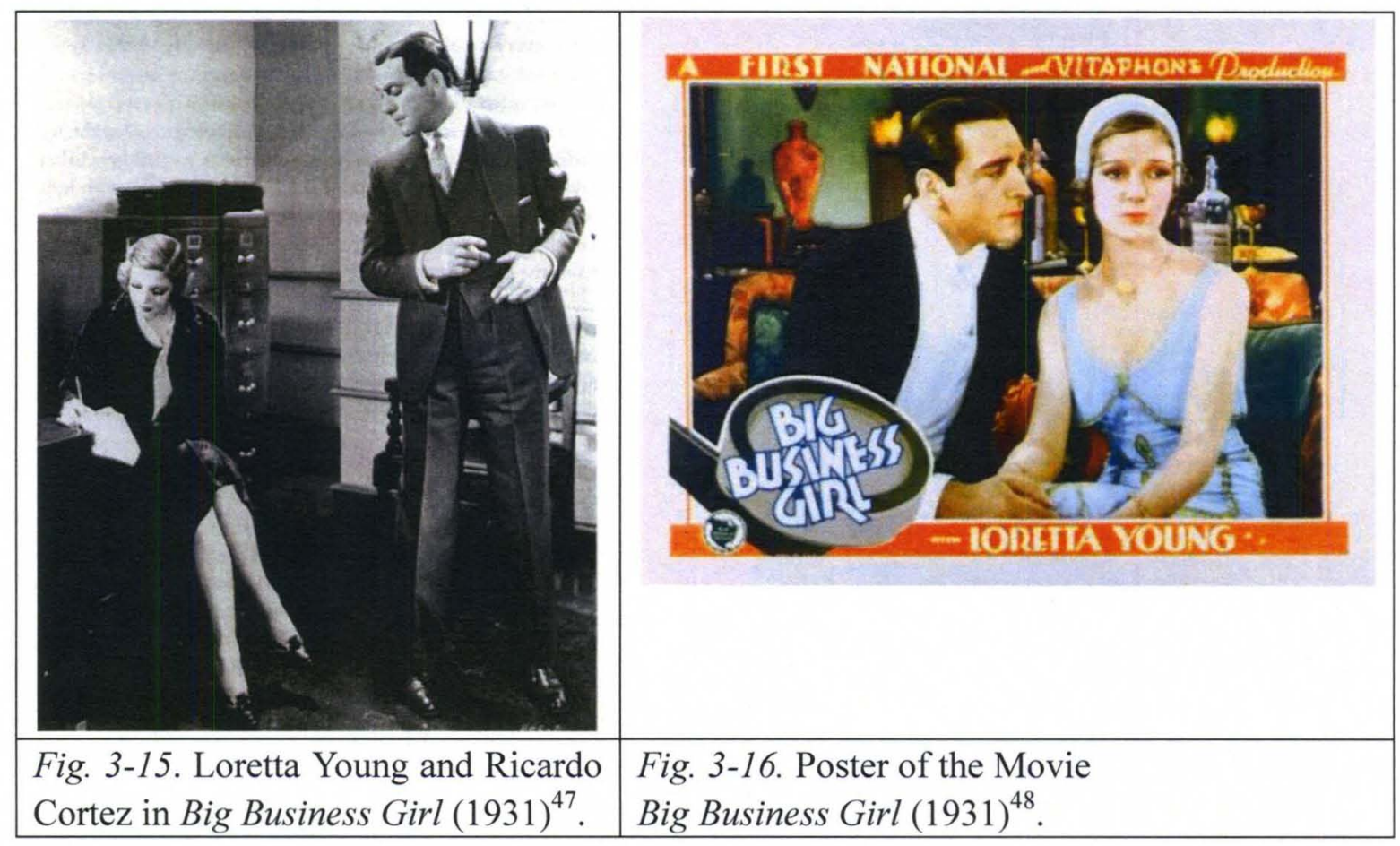

In the seminal article 'Visual Pleasure and Narrative Cinema', the feminist movie theorist Laura Mulvey (1992) criticizes this phenomenon by declaring that the patriarchal society is a phallocentric society. This means that it recognizes the male gender and the sexuality of men as the dominant norm. She goes on to say that "women then stands in

\footnotetext{
47 See Berry (2000: 170).

${ }^{48}$ Retrieved from http://www.allmovie.com/work/big-business-girl-84962 on Dec 10, 2009.
} 
the patriarchal culture as a signifier for the male other, bound by a symbolic order in which man can live out his fantasies and obsessions through linguistic command by imposing them in the silent image of woman still tied to her place as a bearer of meaning" (Mulvey, 1992: 23).

Cinema offers a number of possible sensual pleasures, among them, there is scopophilia, the pleasure involved in looking at other people's bodies (particularly women's bodies) as erotic objects. In the darkness of the cinema auditorium it is notable that one may look without being seen either by those on screen or by other members of the audience. Mulvey claims that the "pleasure in looking has been split between active/male and passive/female" (1992: 27). As Jonathan Schroeder (1998) notes, the "movie has been called an instrument of the male gaze, producing representations of women, the good life, and sexual fantasy from a male point of view" (1998: 208) and "to gaze implies more than to look at-it signifies a psychological relationship of power, in which the gazer is superior to the object of the gaze" (ibid). Movies such as Big Business Girl (1931) and The Solid Gold Cadillac (1956) objectify women in relation to "the controlling male gaze," presenting "woman as image" (or "spectacle") and man as "bearer of the look" (Mulvey, 1992: 33). As Rovert Stam (2000) notes:

The male is made the active subject of the narrative and the female the passive object of a spectatorial gaze defined as male. The man is the driver of the narrative vehicle, while the woman is the passenger. Visual pleasure in the cinema thus reproduced structure of male looking and female to-be-looked-at-ness, a binary structure which mirrored the asymmetrical power relations operative in the real social world. (2000: 174) 
Mulvey (1992) further argues that the pleasure of looking shows the very imbalance of the patriarchal system. The male gaze is active and the female objects are passive. Women, in the world of images, are displayed as sexual objects. The presence of women is an indispensable element in most movies. In addition, Suzanna Walters (1995) suggests a tripartite construction of the male gaze. In the case of a movie, the characters in the movie constitute one level, the viewers of the movie constitute another, and the director a third. In this sense, by accepting masculine values, the businesswomen's self-identities are constructed by the movies, the audience and the directors of the movies as sexual objects.

Similarly, in the movie Skyscraper Souls (1932), the secretary Lynn Harding, a "new woman," is seen half-dressed by her boss David Dwight (acted by Warren William), and then required to work overtime in an evening gown. She works hard, but her boss, a patriarch of the building, only has concerns about taking her as a mistress. He seduced her by asking her to work late and deliver a report to the penthouse where he held a cocktail party. Wearing her new evening gown (encouraged by Sarah, her motherly supervisor), Lynn appeared in the party and was encouraged by Dwight to try some champagne; then, she proceeded to get drunk and passed out in his bed. According to Berry (2000: 169), Lynn's seduction and "fall" are thus catalyzed by the fact that she is "exposed" as sexual rather than professional. Berry (2000) further concludes that:

The disruption of these characters' professional self-presentation suggests 
that women will inevitably be exposed in the workplace as primarily sexual, since that is the way their bosses see them. Feminine clothing functions to discredit them, acting as a "stigma symbol" that undermines rather than supports their desired status and identity. These women are denied the conventional function of work dress codes to allow for the separation of professional from sexual identity-they are prevented from managing their own social identities. (2000: 172)

In the hit comedy movie, The Solid Gold Cadillac (1956), the heroine Ms. Laura Partridge (acted by Judy Holliday) is presented as naïve and beautiful. Her happy ending is not obtained from her professional performance in business, but from her strong willpower and honesty. As a minority stockholder, Laura owns ten shares of stock in a major company. The current CEO, Edward McKeever (acted by Paul Douglas), resigned in order to take an advisory position at the Pentagon. When Laura attends her first stockholder meeting, she questions the board of directors from their high salaries to their operations. In order to stop her constant questions, Laura is given a dummy executive position in the corporation. She uses this position to form a stockholder's association intending to throw out the corporate leaders who act wildly against stockholders opinions, and persuade Edward to come back. When she learns that Edward is not married, she regards him as her Mr. Right. Then Laura succeeds in helping Edward to regain the CEO position and marries him. The movie ends here, and her career after she gets married is no big concern. We can assume from her educational background and professional skills, she probably will quit her job in business. It seems that her cleverness and perseverance is used to look for an ideal husband in the business world, which confirms the social convention that "single women whose career success would be empty without the 
companionship of a good man" (Boozer, 2002: 62). Laura's image supports what Jeanine Basinger and Jack Boozer observe about the images of corporate businesswomen in this era's film romance. They argue that the idea that is almost always reinforced is that "a woman's best choice in life is love. This will be her basic career" (Basinger, 1993: 257), and "their jobs are treated as compensatory or secondary to romance, marriage, and most of all, motherhood" (Boozer, 2002: 51).

In the best-selling book She Strives to Conquer (1937), Frances Maule commented specifically on the movies and the popular romantic novels about 'skyscraper souls' and 'office wives': "the natural and appointed destiny of every business girl is to marry the boss.... Persons who ought to know better do, however, seem to think that every girl goes to business with the idea that she will marry the boss" (Maule, 1937: 159).

In addition, Maule (1937) also claims that the National Federation of Business and Professional Women's Clubs were opposed to the "frustrated spinster in business," but they are in favor of the "married woman worker," because "for the average normal woman, a husband, home and children are necessary to complete and harmonious development. The successful business woman of the future will not only want to do her job well, but to reach this full development by leading a well-rounded personal life" (Maule, 1937: 77).

In this chapter, we have discussed the gender identity of American white corporate businesswomen between 1920 and 1963, the so-called "office ladies" or the "new women." Cultural evidence chosen from both their "own voices" (self-identity) and social 
construction of their images (social identity) were analyzed in the three types of relationships - their relationship with their work, families and men-which represent three of their major social roles.

The articles, poems and advertisements in Independent Woman, the official publication of the National Federation of Business and Professional Women's Clubs (1920-1956), are used to show how these businesswomen see the businesswomen's self-identity. The results show that, first, although the women who work in business have exploited great power in breaking new ground and entered most of the business fields, the majority of them just do clerical work. This type of work is like an extension of the service work that women traditionally provide for men at home. Most important of all, they see their work not as "careers" but rather as "jobs," which are temporary and transitional. They expect to stop working after they get married. In addition, they believe that they can get good jobs as long as they have a nice appearance. Therefore, they are concerned about how to make themselves beautiful. Second, they see their families as their ultimate purpose of their work. Although they want to pursue their business success and regard family as a threat to their work, they know that they will get married sooner or later. Family is their destiny. Third, they want to have equal social status and comradeship with men; however, after they try and fail at last, they eventually give up!

Some representative paintings, drawings, novels and movies of this period were chosen to show how society constructs the identity of businesswomen from a historical point of view. The results show that, first, women do not seem to be very serious about 
their work; they are too busy gossiping or being beautiful! In other cases, business work is seen as a prison which is an obstacle to women's happiness. Second, family is depicted as women's destiny—women are family members first and individuals second. This represents the social encouragement of women's "going home" and the "coming back of traditional femininity." Third, in relation with men, the businesswomen's sexual appealing is emphasized. The male gaze is ubiquitous! Women are degraded to sexual objects.

As we can see, the self-identity of the businesswomen is solidly in agreement with their social identity, which proves that businesswomen's self-identity is deeply influenced by the society. In other words, their self-identity is constructed by the social conventions. In the next chapter, the gender identity of white American corporate businesswomen between 1963 and 1985 will be discussed and the change in comparison with the period between 1920 and 1963 will be traced to see how self-identity is socially and historically constructed. 


\section{CHAPTER IV}

\section{YOU CAN HAVE IT ALL: THE CREST OF THE SECOND WAVE (1963-1985)}

In the last chapter, we reviewed the gender identity of white American corporate businesswomen between 1920 and 1963 through historiography, literature, and popular culture. The results show that these businesswomen "tend to view business, or the office, as a kind of extended family" (Bryant, 1984: 175). As Kwolek-Folland (1998) points out, "by 1963 , on the eve of the transformative social and economic changes of the late twentieth century, women's roles in business as consumers, workers, managers, entrepreneurs, and professionals, seemed firmly rooted in their image as domestic helpmates" (1998: 133). This situation began to change after 1963. In fact, WWII and Second Feminist Wave are the most important social events that affected corporate businesswomen's self-identity. As we know, one of the most exciting results of the feminist movement has been the opening up of career opportunities for women. Women were encouraged to pursue careers instead of just keeping jobs temporarily. They wanted an all-round enriched life, including family, career, and a healthy male-female working 
relationship based on abilities. In this chapter, we will focus on the gender identity of white American corporate businesswomen between 1963 and 1985 in order to discover the changes.

In 1963, Betty Friedan's The Feminine Mystique launched a profound revolution in culture and women's consciousness, helping to set in motion the second wave of Feminism. Friedan identifies the dissatisfaction of the middle-class women who have the dreams of owning a house in the suburbs with a two-car garage and a white picket fence, and of caring for the family on a full-time basis. Their lives just don't seem fulfilling. She calls this dissatisfaction "a problem with no name," "which is simply the fact that American women are kept from growing to their full human capacities..." (Friedan, 1963: 364). Friedan further points out that:

The core of the problem for women today is not sexual but a problem of identity-a stunting or evasion of growth that is perpetuated by the feminine mystique. It is my thesis that as the Victorian culture did not permit women to accept or gratify their basic sexual needs, our culture does not permit women to accept or gratify their basic need to grow and fulfill their potentialities as human beings, a need which is not solely defined by their sexual role. (Friedan, 1963: 77)

Friedan advocates meaningful work outside the home as the solution to the "the problem with no name." However, according to Friedan (1963), in a gender-segregated economy, women are thrown into low-paid, low-status jobs, and at the same time, they are expected to offer full-time services to their child-centered families as wives or mothers. In this situation, they "could not abstract issues of rights from the underlying 
questions of identity" (Evans, 1997: 278). Although the search for identity is not new,

women's search for their identity as human being is new, as Friedan argues that:

For the first time in their history, women are becoming aware of an identity crisis in their own lives, a crisis which began many generations age, has grown worse with each succeeding generation, and will not end until they, or their daughters, turn an unknown corner and make of themselves and their lives the new image that so many women now so desperately need. In a sense that goes beyond any woman's life, I think this is the crisis of women growing up - a turning point from an immaturity that has been called femininity to full human identity. I think women had to suffer this crisis of identity, which began a hundred years ago, and have to suffer it still today, simply to become fully human. (Friedan, 1963: 79)

For those who entered the workforce, Betty Friedan's The Feminine Mystique argues convincingly (for well-educated middle-class women, at least) that "women could find more than a paycheck in the labor market; they could find fulfillment in the form of a career, and at no significant personal sacrifice. Thus, work was not so much a bread-and-butter issue as a means to self-definition beyond the family" (Wandersee, 1988 : 128). As Friedan summaries the voice expressed by the women who suffered and solved the problem that has no name:

To fulfill an ambition of their own, long buried or brand new, to work at top capacity, to have a sense of achievement, was like finding a missing piece in the puzzle of their lives. The money they earned often made life easier for the whole family, but none of them pretended this was the only reason they worked, or the main thing they got out of it. That sense of being complete and fully a part of the world-'no longer an island, part of the mainland'-had come back. They knew that it did not come from the work alone, but from the whole-their marriage, homes, children, work, that changing, growing links with the community. They were once again 
human beings, not 'just housewives.' (Friedan, 1963: 356)

In this sense, working women's sense of achievement and fulfillment comes from all types of social relationships. Or, in other words, they intend to "have it all," to play the role of women. As Gay Bryant, the chief editor of the magazine Working Woman, claims that: "Freud was right when he said that we need love and work to keep ourselves sane. Work is what we do in our offices, but it also informs and shapes everything about our lives, down to our very identities" (1984: 11). Since 1963, women had new life plans and new self-identities. Next, we will focus on white American corporate businesswomen between 1963 and 1985 from the following three aspects: how they see themselves as achievement-motivated business people; how they see the relationship between work and family; and how they see their relationship with men.

\section{Achievement-motivated Businesswomen}

After 1963, more and more corporate businesswomen began to have career aspirations. They made great efforts to seek business success and leadership. The three major working woman's organizations active between 1963 and 1985 include (1) ABWA-American Business Women's Association; (2) BPW-Business and Professional Women; and (3) BWN-Business Women's Network. ABWA (founded in 1953), for example, has a very good mission statement: "To bring together businesswomen of diverse occupations and to provide opportunities for them to help 
themselves and others grow personally and professionally through leadership, education, networking support and national recognition., ${ }^{, 99}$ In addition, the magazine Women in Business (published since 1978) best expresses women's voice to pursue success and leadership in business. The major conferences of American women in business and their publications also express that women aspire to leadership and success. In fact, the businesswomen's organizations after the 1960s function as not only a form of solidarity and encouragement, but also as a means through which businesswomen express their power, leadership, and aspiration to become successful.

Hennig and Jardim (1976) interviews 63 women in corporate business management positions in 1973, and find out that these women separated the concept of "job" and "career" completely: a job is "what one does day-to-day, nine to five, most often it is routine and tedious, it has to be done, it is a means of survival, or earning living" (1976: 32); however, they see career "as personal growth, as self-fulfillment, as satisfaction, as making a contribution to others, as doing what one wants to do" (1976: 33). In short, "a job is in the here and now and a career is an intensely personal goal which the individual alone can judge whether she has achieved" (ibid.). Men's pattern of response, according to Hennig and Jardim (1976), is different. Men tend to visualize the career "as a series of jobs, a progression of jobs, as a path leading upward with recognition and reward implied... and they expressly relate the jobs they do to their concept of career as advancement, as upward progression. For them a job is part of a career" (1976: 33). In

${ }^{49}$ See http://www.abwa.org/ (accessed on May 2, 2009) for this mission statement and other information about ABWA. 
this sense, men have careers regardless, but women have to make great efforts to really own a career. Obviously, women were not satisfied to only have jobs.

Niki Scott (1977) observes that "most of us are just beginning to think in terms of career goals... For us, the old role models are no longer relevant. Now we must ask each other for help and advice...We are learning - to survive in the business world, take risks, set long-range career goals and accept responsibility for our successes as well as our failures" (1977: xv). One office lady interviewed by Scott (1977) expresses that:

$[\mathrm{My}]$ job was going to be temporary-just for a few years until we could afford a house and furniture. Then I was supposed to get pregnant, quit my job, and stay home... but I didn't know how much I'd love my job, when we made all those plans. And it isn't just a job; it's a career and very important to me... I work hard, no doubt about it. But it's never boring and the people I work with are fun and interesting. The days pass so fast. I can hardly believe it when the week is over. (Scott, 1977: 8)

It is in the workplace that women can find their value and fulfillment. They are interested in transforming their own sense of self, especially the working-self. As a result, the long-term career goals have replaced the short-term job plan. It is obvious that not all work in offices bring people the sense of achievement. In 1977, Iris Rivera, a legal secretary in Chicago, was fired for refusing to make coffee for her boss. She does not see herself as a radical, or a women's liberator, but she declares:

I know a lot of secretaries make coffee, and that wasn't the real issue. It's that it was stated as a rule, not a request. That was demeaning to me, as a person. That was wrong...I feel I support my kids, I take care of them at home, and I have my job at the office. I don't take my job home. And I shouldn't have to be a homemaker in the office...Next, they'll tell me to 
sweep the floor-and there's nothing wrong with sweeping floors, I don't mean to imply that. There's nothing wrong with making coffee, either. It just isn't my job. (Scott, 1977: 149)

In fact, women in this period believe what Margaret Mead (1949) claims that women have great human potential and their destiny is not defined by anatomy. Furthermore, Mead says with conviction that "it is good to be a woman, you don't need to copy man, you can respect yourself as a woman" (as cited in Friedan, 1963: 146-147). Next, the cultural evidence chosen from corporate businesswomen's autobiographies, literature and movies will be discussed to find out how women see their work.

As an icon of American businesswomen, Mary Kay Ash set up the direct-sale business "by women for women," which defiantly opposes the tradition in business which is "by men for men." Mary Kay Cosmetics, the company she formed in 1963, registers over $\$ 300$ million in annual sales and provides an income from its marketing program to some 200,000 women throughout the United States, Canada, the United Kingdom, West Germany, and Argentina. Mary Kay Ash was named one of America's Twenty-Five Most Influential Women in 1985 and became a member of the National Business Hall of Fame in 1996. According to Anthony Giddens, "autobiography—-particularly in the broad sense of an interpretative self-history produced by the individual concerned, whether written down or not-is actually at the core of self-identity in modern social life" and he claims that a person's self-identity is closely connected to his/her relations with others (1991: 76). Mary Kay Ash's autobiography Mary Kay (1981) has more than one million copies in print. It shows how May Kay 
grows from a desperate single mom to the business leader of May Kay Cosmetics. In one of her other popular books, You Can Have It All: Lifetime Wisdom from America's Foremost Woman Entrepreneur (1995), she further recalls and reflects her early working years. In both books, May Kay expresses that women are awesome and that there are no limits on what they can accomplish; as long as they believe in themselves, they can succeed in business.

Growing up in Texas with an invalid father and a mother who worked fourteen hours a day as a restaurant manager to support the family, Ash claims that by the time she was seven years old she was ably cooking, cleaning and shopping for the family. She credits her mother's reassuring voice over the telephone, saying "you can do it," which boosted her seven-year-old self-confidence (Ash, 1981: 6). Prior to starting Mary Kay Cosmetics, Ash worked her way up, over a period of eleven years, to the position of national training director in a direct sales company. And while she never actually received the title, according to her job description, but she was performing all the duties of a national sales manager. "Less than a year later, after I had finished training my assistant, the company owner promoted him to the national sales manager position—at twice my salary! I was devastated" (Ash, 1995: 136). Whenever women enter the world of business, they come across this kind of "Glass Ceiling," which is a term coined in the 1970 s in the United States to describe the invisible artificial barriers, created by attitudinal and organizational prejudices, which bar women from top executive jobs. This phenomenon is socially constructed. However, qualified and competent women after the 1960s began to look up 
through the glass ceiling and see what they are capable of achieving. In Mary Kay Ash's case, instead of giving herself over to despair, she began to run her own business.

With the aspiration to succeed, Mary Kay Ash tries to work hard. She believes that the seeds of greatness are planted in every human being and that "a woman can do anything she makes up her mind to do" (Ash, 1981: 113). She encourages herself and other saleswomen by using the bumblebee metaphor. The bumblebee, with its tiny wings and heavy body, shouldn't able to fly. But bumblebees don't know this, and so they fly anyway. "The message is clear: Anyone can be a hero if they have the confidence and the persistence to try" (Bryant, 1984: 135). Ash believes that "Believing in yourself is the vital ingredient in determining your success. Every achievement, big or small, begins in your mind. It starts as a thought. Your self-image comes into play as you act on that thought. Confidence stimulates your ability to perform" (Ash, 1995: 174), and people "appraise not only your grooming but the air of confidence you project, which is a reflection of how you feel about yourself" (Ash, 1995: 183).

Ash decides that "if a woman knew what she had to do to be successful, she would do it. She would have direction" (Ash, 1981: 99); and "I really believe the only difference between successful people and unsuccessful people is extraordinary determination (Ash, 1981: 124-125). She uses Dr. Maxwell Maltz's idea in Psycho-cybernetics (1960) to present the way to achieve one's maximum potential - "setting a long-term goal, writing it on paper, reading it repeatedly on reminder cards and signs, and imagining again and again the realization of the goal" (Ash, 1995: 63), and she further explains that if you 
do the above programming exercise over and over, eventually a little voice in your subconscious will tell you, 'Do that. It will help you get what you want.' The same little voice also signals you, 'Don't do that. It will be a hindrance to what you want.' In time, according to Dr. Maltz, you will be on "automatic instrumentation," a stage in which the little voice steers all your actions in the right direction. Dr. Maltz's 1960 book states that either you can program yourself to succeed or you can program yourself to fail. It's up to you. (Ash, 1995: 63)

Mary Kay Ash loves her career so much that she claims she would do it for no salary.

"To me, happiness is, first, having work that you love to do-something you like so much you'd do it even if you weren't paid! Second, someone to love. And third, having something to look forward to" (Ash, 1981: 136) and "having work you love to do is an essential part of my happiness formula...I feel that to be happy you must love your work. If you hate those eight hours every day, everything else is bound to be colored by that misery " (Ash, 1981: 138). She further explains her formula of happiness this way:

Different things motivate each of us. But I firmly believe that the happiest people are not the ones with the most money, but the ones who really enjoy their work. When our company became a publicly owned corporation in 1968, I became a millionaire. That poor little girl from the wrong side of the tracks in Houston had finally made it! But I didn't think, "Wow, I'm a millionaire! Now I'm happy." I realized that the real thrill was in being able to do the work I loved. Even today, I get up at five and start on my list of the "six most important things I must do today." I love the sense of accomplishment that I feel when at the end of the day that list is completed. But I don't do it for the money. I haven't worked for money in a long time. I've often said that I enjoy what I do so much that I would work for nothing! (Ash, 1981: 137)

Mary Kay (1981) also records the success stories of other Mary Kay saleswomen.

For example, Mary McDowell was sixty-three, widowed twice, and had just recovered 
from a stroke when she joined the company in February 1967. But she was crowned Director Queen of Personal Recruits in 1978 at the age seventy-four. In 1980, her personal Christmas sales exceeded $\$ 17,000$ — very good for a seventy-seven-year-old grandmother! At the 1981 seminar, McDowell was crowned Director Queen of Personal Sales. Her personal endeavor was simple:

I've often asked myself why I began to sell Mary Kay Cosmetics. I believe it's because I wanted my own identity. I had been a preacher's wife for several years, and also a professor's wife, and I had never really developed my own identity. My children are highly educated, and I wanted to do something to make them proud of me... All along, in the back of my mind, I wanted to be a winner so I could prove to my children that I wasn't "over the hill." So every time I was written up in Applause! Or the newsletters, I'd my first $\$ 1,000$ check, I made copies and sent them, too... One of my grandsons called and said, 'Granny, I never dreamed that you'd be the one who would lead the family.' And my other grandson told me, 'You know, Daddy and Mother always sort of took you for granted. Well, we've come to realize that you really are somebody.' (Ash, 1981: 188-190)

In summary, Ash believes in the beautiful potential in every human being, and that "everyone can be successful, with enough encouragement and praise (Ash, 1981:204). In addition, Ash also emphasizes that femininity is one precious quality of women. "I truly believe He [God] made us feminine for a reason, and we should retain our femininity...Women can become successful without discarding their femininity and behaving like men" (Ash, 1981: 108). She offers a word of caution to other businesswomen:

Even though you're are working in a man's world, don't let your ambition detract your womanhood. I've seen females become so aggressive in their 
climb up the corporate ladder, in their fervor to make law partner, or in their desire to be patted on the back by their sales manager, that they stop being ladies. In order to be accepted as 'one of the guys,' not only do they tolerate men using foul language in their presence, they lower their own standards. Soon, their zeal to be up there with the big boys changes them to such a degree, they may even lose the expression of their femininity by the way they dress. In their effort to imitate men, they compromise a major asset, their womanliness, and they are no longer good role models for their own daughters. Their aggression even carries over into family life. It begins to show up in their homes, and eventually, the subtle feminine touches essential to being a loving wife and mother are noticeably missing...Here, too, you must have balance in your life. You can compete aggressively in a man's world while maintaining your femininity. (Ash, 1995: 47-48)

There are other successful businesswomen between 1963 and 1985 who share the same ideas about work. For example, there is Mary Wells Lawrence, who was probably the highest-paid advertising executive in the U.S. in the 1970s and the founder and CEO of her own firm Wells Rich Greene. She was the first woman CEO of a company listed on the New York Stock Exchange. In her autobiography, A Big Life in Advertising (2002), she concludes comments upon her success this way:

When I thought about it at all, I thought that much of my success had to do with timing. I came along just as the world became willing to accept a woman as the chairman of an advertising agency and when advertising was moving to television, a theatrical medium I understood. But success can be born necessity, too. I had to invent my life, an American tradition... My identity, my universe was mine to create. (Lawrence, 2002: 166)

Lawrence knows the rules in the business world before she becomes successful. Commenting on gender difference she said, "People aren't aware, sometimes, that I'm a girl" (as cited in Slappey, 1970: 81). Lawrence claims that men treat her no differently 
from men of comparable power. And she asserts at the same time that she "had not bartered away her essential female self" (Kwolek-Folland 1998: 201). That's why she was shocked to hear that Gloria Steinem, a famous Feminist, commented on her in an television interview that "Oh, well, Mery Wells Uncle Tommed it to the top" ( Lawrence, 2002: 164). Steinem implies that Mary Wells Lawrence acted as a man in the advertising business. However, Lawrence claims that:

I was one of the few women I knew in those days who had bit off what businessmen were chewing, who was performing a man's job in a man's world, in a business I had created from scratch the way men did. I didn't think I had to change my clothing to do what it took- to work hard, make decisions, accept the ultimate responsibility, provide the leadership and the goals, whatever that cost in hours or comfort or personal pleasure. I was also willing to accept the guilt of not giving enough of myself to almost anybody, just as businessmen were used to doing. I wanted a big life. I worked as a man worked. I didn't preach it, I did it. I simply acted as I saw others in business act - at the time, they happened to be, primarily, men. In my corner of the universe, America, I found them welcoming and helpful, I liked them and I just accepted their culture. Gloria Steinem was right that I didn't declare war on men. But I didn't witness offensive male bonding against women. From what I could see, men in business were competitive with anything that walked or talked. They had learned, as boys do, to play games all-out with the idea of winning, so in business they would stretch their psyches to the breaking point to be successful. (Lawrence, 2002: 164)

On how much she loves her career, Lawrence expresses that:

I could see that the advertising business offered opportunities to learn, to love, to live in ways that would make life more than I had ever imagined. Every day became a stepping-stone to my own agency, cast in my own image. Great as that was, though, it wasn't easy, and it certainly wasn't about acquiescence. Gloria Steinem had it wrong, I was no Uncle Tom." (Lawrence, 2002: 192) 
In One Tough Mother (2005), the CEO of Columbia sportswear company Gert Boyle

recalls the early days of her career in 1970 and openly declares that ability, rather than

gender, is what should be considered in business:

I knew I didn't have time to ask myself if I was enjoying what I was doing or whether or not Columbia was going to survive. All I knew was that it had to survive, and I would do whatever it took to make sure it did... All eyes were on me, wondering what I was doing there and doubting my abilities. It didn't take me long to realize that my challenge was made more imposing by the fact that I was a woman in an industry almost totally dominated by male executives. Several bankers suggested that in order for Columbia to survive, I needed to put a man in charge. I had paid little attention to the women's lib movement when I was a full-time housewife and mother, and while I wasn't quite ready to burn my bra (which would have created a three-alarm fire), I did believe that individuals should be judged by their ability rather than gender. I was also finding that some of the skills I had learned as a mother and in running a house-hold were very transferable to the workplace-skills like urging people to get along with each other, and not spending money unless you have it. (Boyle et al., 2005: 67)

In Estée: A Success Story (1985), Estée Lauder shows her positive attitude toward an enriched-life, in which career accounts for a very important part. "Business is a magnificent obsession. I've never been bored a day in my life. Partly because as a true addict it's never been enough to have steady work; I do to love what I was doing. Love your career or else find another" (Lauder, 1985: 160). In addition, she became convinced years after her business success that "strength had less to do with being a female or a male executive than with being an executive at heart. One had to be sure of herself- or at least act as if she was" (Lauder, 1985: 163). On the working styles of businesswomen, 


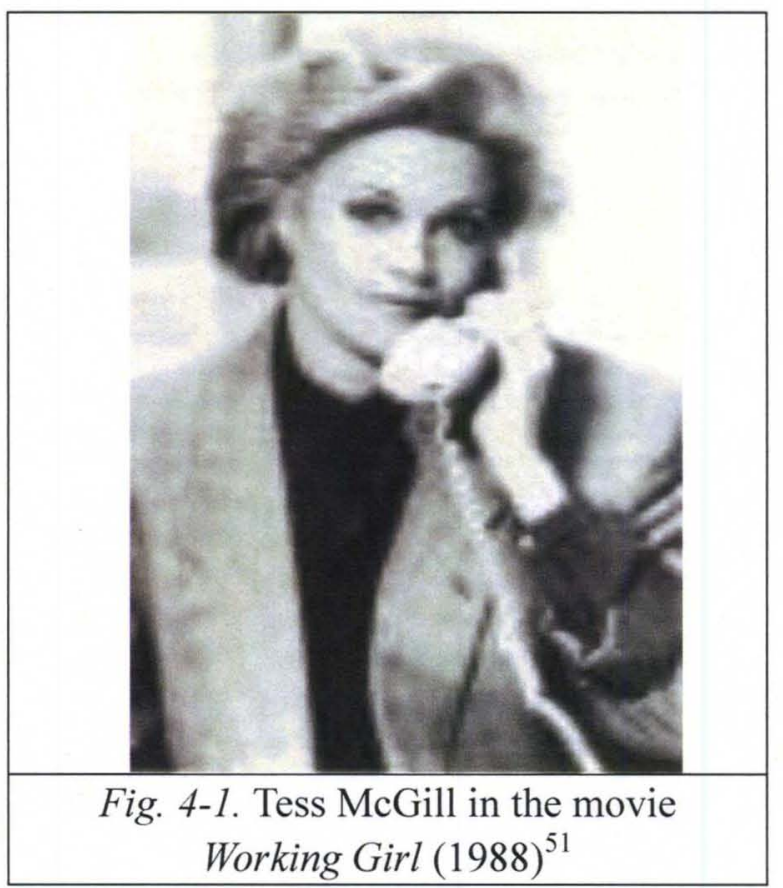

Tasker (1998) believes that this type of female-to-male cross-dressing can be understood as "seeking to naturalize the transition, cast in terms of the desire for the privileges and freedom available to them. At the basic level of plot, the cinema offers us women who achieve freedom and/or success as male or masculine personas, their achievements typically presented as unique" (Tasker, 1998: 37). Similarly, Marjorie Marjorie Garber (1992) argues that "women who habitually cross-dressed were not psychotic; they merely wanted to be men, which in their society was a highly reasonable, indeed healthy, desire" (1992: 98) and "one of the most important aspects of cross-dressing is the way in which it offers a challenge to easy notions of binarity, putting into question the categories of 'female' and 'male', whether they are considered essential or constructed, biological or cultural" (1992: 10-11). After all, the cross-dressing or

51 See Tasker (1998:19). 
dress-for-success phenomenon, although regarded as a joke now, reflects the fact that women after the 1960s begin to have aspirations for career success, and the appearance is one of the major means they think will help them get it.

There are other movies in the 1980s that offer a good illustration on how corporate businesswomen interact with the society in their workplace, such as Baby Boom (1982) and 9 to 5 (1980). In Baby Boom, there is J. C. Wyatt (acted by Diane Keaton), known as the "Tiger Lady," who works 24 hours a day and 7 days a week. Her ambition is to become a business partner in P. R. Company, Sloane Curtis \& Co. She is "tough" or "aggressive" at work. Even her home life with her boyfriend Steve (acted by Harold Ramis) is very convenient and functional. They even study their financial papers in bed. Her "success" in business seems to stem from her ability to mimic the management style of her male colleagues, at the expense of her femininity. Although Ms. Wyatt's lifestyle changes because of the inherited a baby, her working image as a "Tiger Lady" is a representative of many successful businesswomen.

In fact, success in business careers does not always mean the same thing for women as for men, "particularly since the general expectation for women to work (discounting the years of World War II) did not become widespread until the 1970s" (Boozer, 2002: 51). The success in career in the 1970s, according to Hennig and Jardim (1976), is "not just success at the traditional girl's things but also success in ways which it seemed only boys were allowed to achieve" (1976: 115). To achieve this success, a corporate businesswoman "had to be better," "even more committed" and "she had to earn the 
phrase: 'in spite of the fact she's a woman, she is so extraordinarily competent, efficient, effective, motivated'. The costs were high" (Hennig \& Jardim, 1976: 154). One businesswomen interviewed by Hennig and Jardim points out the truth that "until I reached upper middle management, my philosophy about being a woman was to make that fact as unnoticeable as possible" (1976: 141).

Hennig and Jardim (1976) also point out that while law controls the formal structure of business organizations, the informal structure or informal system of relationships "finds both its origins and present function in the male culture and in the male experience" (1976: 13). They further explain that:

Its forms, its rules of behavior, its style of communication and its mode of relationships grow directly out of the male developmental experience. This cannot be viewed as either good or bad. It is real. Men founded and developed the vast majority of the organizations we know. Men made them places where they could work and live and their settings were intended to be both comfortable and familiar. And if organizations in general are dominated by a male culture, then we need to note that at the management level, and particularly in its higher ranks, the informal system is truly a bastion of the male life-style. (1976: 13)

As a result, businesswomen were obliged to become "sociological male" (Kanter,

[1977] 1993, Goetz, 1997: 22) at work if they were to keep their jobs. In her autobiography,

Mary Kay Ash offers a word of caution to other businesswomen:

Even though you are working in a man's world, don't let your ambition detract your womanhood. I've seen females become so aggressive in their climb up the corporate ladder, in their fervor to make law partner, or in their desire to be patted on the back by their sales manager, that they stop being ladies. In order to be accepted as 'one of the guys,' not only 
do they tolerate men using foul language in their presence, they lower their own standards. Soon, their zeal to be up there with the big boys changes them to such a degree; they may even lose the expression of their femininity by the way they dress. In their effort to imitate men, they compromise a major asset, their womanliness, and they are no longer good role models for their own daughters. Their aggression even carries over into family life. It begins to show up in their homes, and eventually, the subtle feminine touches essential to being a loving wife and mother are noticeably missing...Here, too, you must have balance in your life. You can compete aggressively in a man's world while maintaining your femininity. (Ash, 1995: 47-48)

However, it is really not easy to be successful in the business world and maintain femininity while one is in a lower level of business management. The tension between women's traditional domestic role and their increased exposure in public careers makes businesswomen feel guilty and bear a lot of pressure. Scott (1977) argues that women compete too hard in the working place and

our anger was definitely not rewarded; it was "unladylike."...We still pay for that training. Most of us are just beginning to think in terms of career goals. We find it difficult to assert ourselves in a positive way-to ask for the raise we deserve or the promotion we've earned. We tend to sit back, work quietly and assume (hope) our abilities will be recognized, and our competence rewarded. All that may be ladylike, but it sure as hell isn't effective! (1977: xv)

In this sense, a balanced life is the best solution. For example, J. C. Wyatt in Baby Boom (1982) proves in the end that she can be successful both in doing business and being a mother. This will be discussed in detail in the next section of this chapter.

In summary, from the cultural evidence we have presented, we learn that women after the 1960s have long-term career ambition in corporations. They are not satisfied 
with the short-term jobs that they used to have before WWII. Although some of them are not confident, they struggle to get it so that they can have a new life of a higher level一an enriched life, in which they find freedom and personal value. In the next section, we will discuss how businesswomen see the relationship between work and family.

\section{Work and Family: Womanhood Redefined}

In the previous section, we have shown that corporate businesswomen between 1963 and 1985 began to pursue their business career as men do. They no longer regard their work as just a job that they would give up after they get married or have children. In this section, we will see how these businesswomen see the relationship between family and career.

In both 1974 and 1985 the Virginia Slims American Women's Opinion Poll asked women what would give them "personally the most satisfying and interesting life" (Roper, 1986). Being married was selected by $96 \%$ of all women in 1974 and by $94 \%$ in 1985 . This commitment to marriage as an essential element of women's lives holds up across all age groups in the most recent 1985 data. Even the most career-oriented women, those with high educational aspirations and plans for a lifelong career, show no evidence of rejecting marriage and family. In fact, career-oriented young women are nearly identical to those with more "traditional" expectations in their desire to raise children. While career-oriented young women are less likely to plan to have three or more children, most 
of them expect to have two children (Borus et al. 1980; Shapiro \& Crowley 1983).

According to John C. Caldwell (1982),

Because of technology and new economies of scale, household goods could now be manufactured outside the home and sold at an affordable price. As a result, middle-class women and children shifted from being both economic producers and consumers to non-productive consumers. In their new role as consumers and with their time spent at school rather than at work, children became an expense rather than an economic asset. (as cited in McLaughlin et al., 1988: 17)

According to Kanter ([1977] 1993), the family has long been thought of as a private

space separated from the public world and the economy:

If any one statement can be said to define the most prevalent sociological position on work and family, it is the myth of separate worlds. The myth goes like this: In a modern industrial society, work life and family life constitute two separate and non-overlapping worlds, with their own functions, territories, and behavioral rules. Each operates by its own laws and can be studied independently... a Corollary of the myth is the assumed separation of men's and women's domains, with the family, woman's place. ([1977] 1993: 16, 20)

Only since the 1960s with the emergence of the economy and the women's movement, have families been addressed as part of the public sphere. As a result, the "myth of separate worlds" is challenged and the work and family lives of white, middle-class women began to change. Hesse-Biber and Carter (2005) point out that "there is a dynamic interaction between work and families. The ways in which the economy and workplace are organized affect family life. Conversely, the ways families are arranged and organized affect women's experience in the workplace" (2005: 221). 
With increasing numbers of women entering in the labor force after the 1960 s, more and more women suffer from the "double day" which refers to the combination of paid and unpaid domestic work done by these women (Hochschild \& Machung, 1989). Scott (1977) expresses the problem of the working women during the 1970s in this way: "we working women juggle full-time jobs, husbands (or boyfriends), children, household chores, errands, community work, social lives and our own feelings of inadequacy and anger. We give 400 percent of ourselves, every day. And we are, understandably, exhausted..." (1977: xi). In addition, Hoffman and Nye (1974) point out that "the role of housewife and mother, however important it may be to society, carries with it little opportunities for a sense of achievement, competence, and contribution. The educational system and cultural values have tied feelings of achievement to success in the intellectual or business world" (1974: 43). However, no matter how successful the businesswomen are in the business world, they would never give up the responsibility of maintaining a loving marriage or family. In their definition of success, they want to have both self-realization in the workplace and happy families. Therefore, they have to face the "basic conflicts between a woman's ability to build a successful career and to be a successful wife, girl friend and /or mother" (Hennig \& Jardim, 1976: 210).

The greatest difficulty for women with a double day is finding the time for both types of work. "These women report being constantly pressed for time, and feel that their quality of life is greatly diminished by their attempts to shoulder work and family demands. Women in the double day sleep less. They talk about sleep the way a hungry 
person talks about food" (Hochschild \& Machung, 1989: 9). As businesswomen, they certainly want business success; as mothers or wives, they suffer from maternal guilt for their domestic absence, which is commonly called "double bind." They often say that "the only way they can deal with their feeling of guilt over having a career is to try to be a perfect woman/wife/mother simultaneously" (Bryant, 1984: 210). They usually try in several ways to compensate for this absence from their children and/or their husbands. Thus, as Haskell (1973) describes it, women "moved up the employment ladder and down from the pedestal, paying for the one with the fall from the other" (Haskell, 1973: 172). It seems that the business world for women is a "situation where a person cannot win no matter what she does" (Oakley, 2000: 324). But women in business after the 1960s want to win the game, just as Scott (1977) declares:

For the first time, we want it all. We want individuality, independence and jobs that fairly reflect our abilities. But we want marriage too; rose-covered-cottage fantasies are not at all a thing of the past - one need only visit college campuses to see that. And generally we want, or already have, children. Motherhood is still an assumption for most of us. (in "wanting it all," I must add, we want only what men have always had. No one asks a man if he plans to work or have children! It is assumed he can have both. No one asks him if he plans to give up his career when he marries, either-it is assumed he can have both. (Scott, 1977: xiii)

It is true that men don't have to choose between having children and having a career. It's easy for them to have both, because the world assumes they will. Friedan (1963) praises Margaret Mead, who "made a resounding feminine protest, in her life and in her work." Margaret Mead, according to Friedan: 
influenced emancipated modern women to choose, with free intelligence, to have babies, bear them with a proud awareness that denied pain, nurse them at the breast and devote mind and body to their care. It was a step forward in the passionate journey - and one made possible by it - for educated women to say "yes" to motherhood as a conscious human purpose and not a burden imposed by the flesh. (Friedan, 1963: 147)

What's more, one businesswoman interviewed by Bryant (1984) expresses that "it never occurred to me that I would not marry and have children. I just wanted to do more than that. I wanted to be more of a person than my mother was" (Bryant, 1984: 129). After all, in order to have both career and family, women have to make more of an effort and suffer from struggle. Scott (1977) records an interview of a businesswoman who relates her struggle to be both a career woman and a good mother to her son:

I stayed home for two years after Tommy was born, and I was totally miserable. I think a lot of women are cut out to stay home. That's fine, but I'm not - and it took me too long to admit it...I was so bored! And boring too....My husband wishes I were home. He doesn't say so, but I know it. He thinks Tommy would be better off with a full-time mother. Maybe he would be, if he's been born to a different woman-one who didn't want a career, an identity of her own. But he wasn't better off with me home all day. I know, I was there!... My husband didn't see me at two o'clock in the afternoon, when I wanted to scream (and did, sometimes) because I was so sick and tired of picking up the same toys, over and over, and hearing the same two-year-old chatter, and saying the same words and looking at the same four walls, she said, shaking her head and shrugging... He saw our house as a retreat after being in the outside world all day. I saw it as a prison. He thought taking care of Tommy would be interesting and rewarding - because he didn't have to do it all day....We were lucky. We found a warm, loving person to come to our house and take care of Tommy during the week... Tommy is a healthy, happy little kid. He isn't neglected at all because I work. If I thought for a minute Tommy was suffering, I'd quit. But I don't. I see a little boy who gets lots of love and attention-from our housekeeper during the day, and from my husband 
and me at night...When I come home I'm honestly glad to see him. We spend more time taking walks and playing together than we did before I went to work-I'm sure of it. We enjoy each other now...Frankly, I don't have much of a paycheck left by the time I pay our housekeeper. But in two years Tommy will be in school and my expenses will go down. ...In the meantime, I'm getting that much ahead in my profession and earning, enough for some luxuries we wouldn't have with just my husband's salary...More importantly, I'm better mother, a better wife, and a much happier person. I believe firmly that doing what's good for me is good for Tommy, too...We don't have to make a choice between motherhood and having some life of my own, any more. Thank God for that! I could stay home for twenty years, if I had to. But I don't have to; that's the point. I have the best of both worlds now. Tommy does, too. (Scott, 1977: 15-17)

This is a case that woman does find a way out for having both family and career or has balance in life, although there is always the struggle. This idea can be seen clearly in Ash's autobiography Mary Kay (1981). Mary Kay Ash successfully raised three children by herself while working as a saleswoman for Stanley Home products. She believes that when a woman is financially successful, she is able to provide and take care of her family in an even better manner. She claims that a man only wears a "breadwinner hat"; however, a working woman wears several hats-:

working woman can be every bit as much a breadwinner as her spouse, but she almost always has to wear a lot of other hats, too. She's a wife, mother, chef, laundress, housecleaner, chauffeur, and child psychologist (and sometimes she's a psychologist where her husband is concerned, too). She's also expected to be her husband's errand boy, social director, and lover-she has to find time for everything. What does she need more than anything? I often say she needs a 'wife'! (Ash, 1981: 64)

With so many hats on, working women try their best to have it all and balance everything. "[What she] thinks she must excel in every facet of her life is attempting to 
be Superwoman. She toils to reach the top of the corporate ladder, to be named Wife of the Year, to be loved as the world's greatest mom, and to be respected as a dynamic community leader. In other words, she wants it all" (Ash, 1995:145).

Mary Kay Ash writes that "there was very little I ever let interfere with my work-except my family" (Ash, 1981: 60) and one should have a list of priorities: "God first, family second, career third"- "I think working women can easily make the mistake of getting caught up in too many outside activities. While community and civic work is very important, I don't think it should be done at the expense of our families...a working woman has to decide how much time she has and which activities she can afford to participate in" (Ash, 1981: 68-69).

With the family as priority, career success becomes not a matter of the public sphere, but a private matter of one's self and the family. For example, in Taylor's (1988) interview of Pamela Scurry, a successful businesswoman, Scurry accentuates her outlook on her life as a wife, mother, and entrepreneurial person: "I do want it all—but that's just for me and my family. What I have chosen is not for everyone. I think women should have choices but, given my choice, I want to be able to be a happy example for choosing it all" (1988: 92). In this sense, businesswomen want to release their highest potential and have full-interaction with the world. Their goal is not to compete with men, but to lead an enriched life shared with family members.

Ash (1995) points out: "as much as I want women to have everything life has to offer, I recognize that we aren't like men in every respect" (Ash, 1995: 21). It is true that a man 
can put in a sixty-plus-hour work week and still be considered a good husband and father, but a woman usually can't do the same. "Life typically doesn't let you have it all; generally, it requires compromise. The heavy demands of different roles make many women feel they must choose one goal at the expense of another. Often-times the decision means postponement, or even abandonment, or certain career ambitions" (Ash, 1995: 24). Thus, Ash has her own definition of success: "My definition of success would include living a balanced life. Balance means advancing your career up to, but not past, the point where it interferes with your happiness and relationships. Worthy advancement does not promote neglect of your husband and children" (Ash, 1995: 20-21). Bryant (1984) mentions Sigmund Freud's description of love and work—"Liebe und Arbeit"-as the two most important components of life: "Achieving a balance between them and deriving fulfillment and satisfaction from them were both goals and the characteristics of healthy adults" and that of the psychologists in the 1980s: "a combination of work and love is necessary to everyone for a satisfying, challenging life" (Bryant, 1984: 257). Ash may not know the theories of the psychologists, but she expresses from her heart that: "when you enjoy your work this much, it's important to have someone to share it with. Without that somebody, you can be the most successful person in the world, but your happiness somehow is not complete...this is why having someone to love and share your time with is part of my definition of happiness" (Ash, 1995: 139).

Ash (1981) gives an example to illustrate how she balances her career and her husband. Mel Ash liked for her to sit with him for a couple of hours each evening and 
talk or watch television. She confesses that there were times when she thought, "what a waste of time it is to sit in front of this television set, when I could be getting something done!...But I loved Mel, and I knew he was sensitive and needed that time with me" (Ash, 1981: 59). She tried, once in a while, to try to watch television with one eye and read the day's accumulation of mail with the other. When she found that Mel was not happy that she used "his" time working, she changed her schedule: "I'd still go to bed when he did, but I'd get up at five each morning so I could start on my dictation. That way I could do my correspondence and paperwork without Mel feeling I was infringing on his time. Then at seven-thirty, when he got up, I'd change hats again and become Mel Ash's wife" (Ash, 1981: 59). Later, she invited every new sales director in her company to join her Five O'clock Club in order to encourage them to find sometime for themselves and be organized between family and career. She declares that:

What value is professional success if family and personal happiness must be satisfied? Remember, a career is a means to an end: you do well at your work to provide comfort and security for your family. It's important that we keep sight of what really matters in life. If we lose our families and our faith in the process of developing our careers, then we have failed...Making God and family top priorities does not demean the role work plays in our lives. After all, where do we spend more of our waking hours than at work? Career may rank only third, but it is well ahead of a long list of other activities. (Ash, 1995: xii)

A woman's work at home and on the job are totally different. She needs to make conscious transformations several times a day to adapt to her social roles. Wearing the three hats of a full-time wife, mother, and career woman is no easy task. Ash (1995) gives 
an example of how Rena Tarbet, a national sales director in Fort Worth, Texas, integrates her career with her family life. She says her work is not just a career but a way of life. People frequently ask her how many hours a week she works in Mary Kay. Her response is:

I might turn it around and reply, 'Well, let me ask you a question: How many hours a week are you a mother?' Then I'll ask her, 'How many hours a week are you a Christian?' I think of myself as a Christian and mother twenty-four hours every day, but this doesn't mean it's all I do. Likewise, I do Mary Kay around the clock, but this doesn't mean I just do Mary Kay. All of who I am and what I do falls together...During a typical day when my children were young,...I'd make breakfast for the entire family and get the kids off to school. After my husband went to work, I'd conduct a mid-morning skin care class. Later, I might meet a friend for lunch and do some grocery shopping. After school, I'd pick up the kids, drop one off at a piano lesson, and take the other over to the ball field. Around five, I'd pick them up, go home, fix dinner, and go out and have another skin care class or attend a meeting at my church. When I came home, I'd check the kid's homework and spend an hour or so with my husband before going to bed... So, when somebody asks, 'How much was Mary Kay?' or 'How much was family?' my answer is, 'Who cares?' Everything works together, and I never attempt to separate it into compartments. (Ash, 1995:44)

This is exactly what having balance means according to Ash's definition of success.

"No matter how much money and how high a position a woman acquires, she will not know real success if she loses her family in the process... [and] placing your family ahead of your career doesn't mean putting in so few hours that you neglect your work" (Ash, 1995: 64).

In her autobiography One Tough Mother (2005), Gert Boyle expresses her guilt toward her children when she had to work to save the Columbia Sportswear Company: 
I had a twelve-year-old daughter at home who had just lost her father, and now her mother was spending most of her waking hours trying to salvage the family business. I juggled at best I could, trying to find the time in each busy day to make the half hour drive from the office to school to pick up Sally and to ensure that she wasn't home alone. (Boyle, 2005: 67)

She chooses to be strong and combine the family with the career. In 1984, Columbia began the "tough mother" ad campaign, in which Boyle was portrayed as "the world's most exacting boss - a tough mother-who demanded and expected nothing less than the best out of [her] son and [her] company, personally inspecting each and every product [they] manufactured" (Boyle, 2005: 97). Here are the most popular images of Boyle as a tough mother (Fig.4-2 and Fig.4-3):

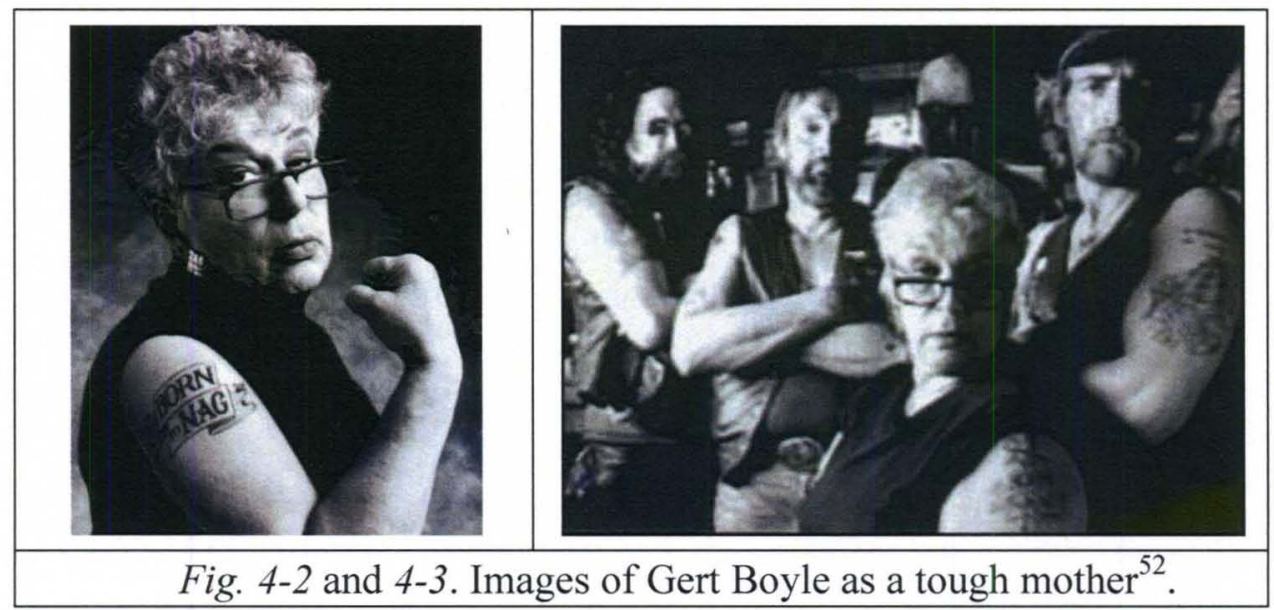

In Estée: A Success Story (1985), Estée Lauder also declares that she refuses to choose either business or family. "I wanted both. And, with both, I invested

\footnotetext{
${ }^{52}$ Fig.4-2 is the cover page of Boyle's autobiography One Tough Mother (2005), which was retrieved from http:/www.brandinsightblog.com/2009/05/11/one-tough-mother-two-marketing-objectives/ on Oct. 13, 2009. And Fig.4-3 was retrieved from http://www.cbsnews.com/stories/2005/12/29/earlyshow/series/main1169764.shtml on Oct.16, 2009.
} 
everything... sometimes too much" (Lauder, 1985: 95) and "I don't want to miss any part of life, and living well is certainly one of the better parts" (Lauder, 1985: 177). She comments others' opinion on family this way:

I hear too many superwomen say that family seems to be superfluous today. Pity... Despite my belief in independence and self-sufficiency, a family or intimate friends add so much texture to one's life. It doesn't have to be blood family...the family I speak of. I know many marvelous women who had "adopted" beloved friends to be the family with whom they share joys and griefs. I hate to be close-minded about it: I suppose many manage to live relatively solitary lives with happiness, and certainly there are female super achievers today who go it alone by choice. But for me, there had to be a balance of family. (Lauder, 1985: 96)

In Arthur Hailey's novel Strong Medicine (1984), Celia de Grey has a perfect life plan, in which she will have career achievement, loving marriage and children. Here is an excerpt of the dialogue between Celia and her husband Andrew when they are on their honeymoon:

An hour later, back on the beach, Celia said, 'As I was saying about our marriage ...'

'It will be a good one,' Andrew finished for her. 'I agree.'

'And to make it work, we must both be fulfilled people.'

Andrew was lying back contentedly, hands intertwined behind his head.

'Still agree.'

'So we must have children.'

'If there's any way I can help with that, just let me-'

'Andrew! Please be serious.'

'Can't. I'm too happy.'

'Then I'll be serious for both of us.'

'How many children?' he asked. 'And when?'

'I've thought about it,' Celia said, 'and I believe we should have two-the first child as soon as possible, the second two years later. That way, 
I'll have childbearing done before I'm thirty.'

'That's nice,' he said. 'Tidy, too. As a matter of interest, do you have any plans for your old age-after thirty, I mean?'

'I'm going to have a career. Didn't I ever mention that?'

'Not that I remember. But if you'll recall, my love, the way we leaped into this marriage caper didn't allow much time for discussion or philosophy.'

'Well,' Celia said, 'I did mention my plan about children to Sam Hawthorne.

He thought it would work out fine.' (Hailey, 1984: 28)

In this excerpt, the ambitious businesswoman Celia makes careful arrangements about family life before she pursues her career. She has a detailed plan on how many children they are going to have and when to have them, so that she can have her career takeoff without feeling guilty. She wants both family and career from the very beginning. When Celia's husband Andrew asks doubtfully: "And that's what you want? Power?" Celia says: "I know what you're thinking, Andrew—-that power can be obsessive and corrupting. I don't intend to let it be either. I simply want a full life, with marriage and children, but also something more, some solid achievement" (Hailey, 1984: 43). On balancing family and career, Celia's priority is always clear-the family and love, which is expressed in her favorite song, Elvis Presley's pop ballad "Fame and Fortune" $(1960)^{53}:$

Fame and fortune/ how empty they can be/ But when I hold you in my arms/ That's heaven to me/Who cares for fame and fortune/They're only passing things/But the touch of your lips on mine/Makes me feel like a king/Your kind of love/is a treasure I hold/It's so much greater/than silver

\footnotetext{
${ }^{53}$ Hailey writes: "Presley had resumed his career after a year in the U.S. Army, his absence having left his popularity undimmed. The women [Celia and Lilian Hawthorne] liked 'Fame and Fortune.' The men [Celia's husband Andrew and Sam Hawthorne] didn't" (1984: 68).
} 
or gold/I know that I'd have nothing/If you should go away/But to know that you love me/Brings fame and fortune my way ${ }^{54}$.

The assumption that business women want to achieve business success by overcoming the obstacle of child care is best represented in the movie Baby Boom (1982). In a dinner conversation between J. C. Wyatt and her boss Fritz Curtis (acted by Sam Wanamaker), Fritz invites her to become a partner in the firm and emphasizes that as a partner her present weekly work commitment of 70 or 80 hours will only get worse. It is at this moment that J.C. is identified as a woman on the way up the corporate ladder by Fritz: "you know that normally I don't think of you as a woman, but in this case, I do have to look at you as a woman-slash-partner. I mean what if you and Steven decide to get married or something down the line? I mean, what if he expects a wife?"55 J.C. expresses that she will not marry Steven because both of them have dreams of work and that is why they are together. We see that she is proudly adjusting her shoulder pads and is excited with the new offer. Although she says she understands "what it takes to make it," Fritz expresses his concern about the sacrifices that she will have to make if she is to "make it" in the "man's world" of business: "...but do you understand the sacrifices that you are going to have to make? I mean a man can be a success, and still have a personal life, a full personal life. ${ }^{56}$. He points out that he himself has a wife to provide him with a home and family life, and concludes by saying "What I'm saying is I'm lucky and I can

\footnotetext{
54 The complete song is found at http://lyrics.elvispresley.com.au/lyrics/fame and fortune.html (accessed on June, 2010).

${ }_{55}$ The lines of the movie Baby Boom (1982) quoted in this paragraph were transcribed by the author.

${ }^{56}$ Ibid.
} 
have it all." ${ }^{.57}$ J.C.'s immediate response is: "Is that all you're worried about? Forget it! I don't want it all. I don't!" which she admits is wrong at the end of the movie ${ }^{58}$.

J. C.'s career fate is changed when she becomes guardian of a baby from an English cousin she has not seen since 1954 . This shifts her priorities from the company and her live-in mate to her role as a mother. She tries unsuccessfully to give away the baby, but meanwhile, she increasingly grows to enjoy having a baby around. Although the baby totally changes J.C.'s life—she loses her partnership, and her boyfriend, her maternal self is awakened by the baby. Then, she chooses to live in a small peaceful town in Vermont, where she eventually grows a small business by selling "Country Baby" homemade applesauce that she makes for her baby. Finally, her former employer wants to buy out her successful new baby food line. Facing the inviting offer, J.C. says "No" and makes a speech in front of the businessmen:

I am very excited about this offer, but I guess I haven't really thought about what it meant, and you see, I am not the tiger lady anymore, I have a crib in my office, and there is a mobile in my office, and I really like that... I mean, Fritz, do you remember that night when you told me that the things that I have to give up and sacrifices that I was gonna have to make? I don't want to make the sacrifice, and the bottom line is that nobody should have to. No! I don't think that this is going to work out. And I will be honest with you. I think I am doing pretty good on my own. To be frank, if the Food Chain can put Country Baby in every supermarket in America, so can I. (Baby Boom, 1982) ${ }^{59}$

This declaration demonstrates how adopted motherhood can be made to function

\footnotetext{
57 Ibid.

58 Ibid.

59 Ibid.
} 
alongside the demands of gainful employment. Mary Desjardin (1992) believes that this film rewards the career mom with superwoman status by rendering "comic the contradictions facing women who are told they can have it all" (Desjardin, 1992: 25). In the following poster for the movie, we can see that the business success and family are perfectly combined (Fig. 4-4).

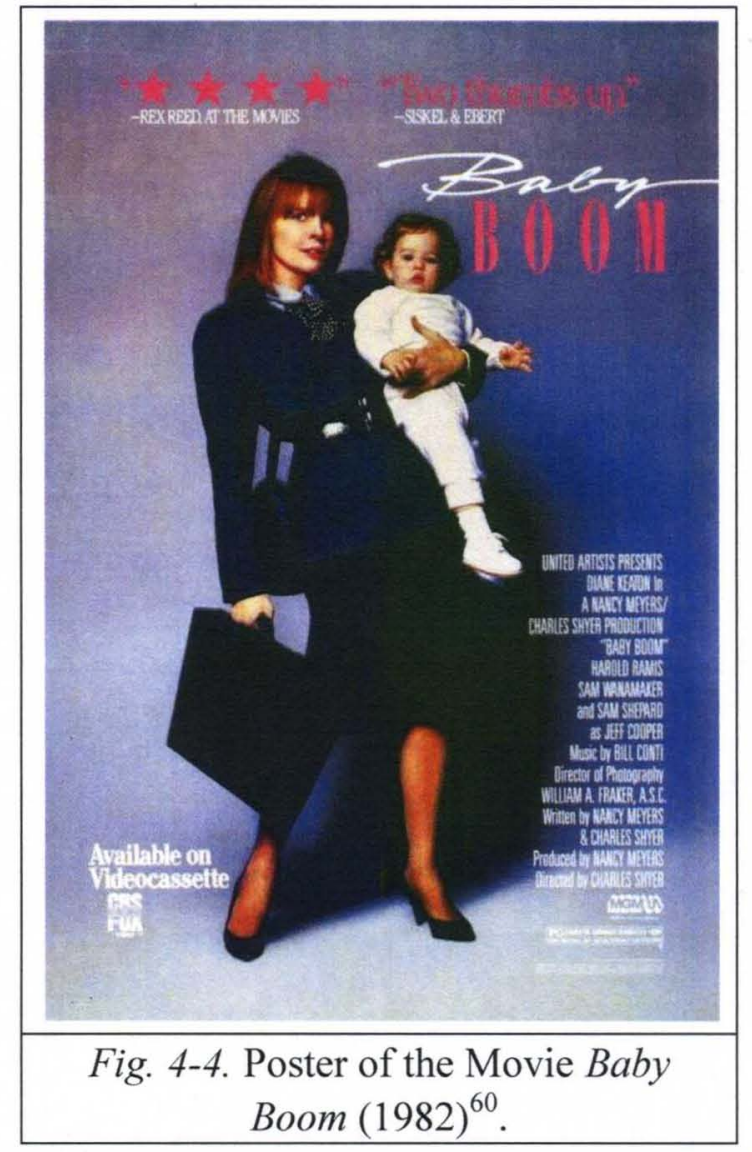

Similarly, at the end of the movie Working Girl (1988), Tess gets both career success and romance. When Jack and Tess are preparing for work in the morning, both in suits, Jack gives her an executive lunchbox, and speaks to her as if she is a child. In addition,

${ }^{60}$ Retrieved from http://www.posterbobs.com/services34.html on Feb. 9, 2010. 
"the infantilizing gesture of the lunchbox, together with his name, 'Trainer', suggests a paternalistic relationship" (Tasker, 1998: 43). In both movies, Baby Boom and Working Girl, the single businesswoman gains success in work, romance, and domesticity. To accomplish this outcome, "each narrative shows to what extent she must inevitably bend her behavior to accommodate dominate economic patterns. The emphasis remains on her ability to prove herself executive material in corporate settings while still upholding her feminine charms and devotion to romance and family" (Boozer, 2002: 76).

To sum up, based on the cultural evidence from historiography, literature, and movies, we can see that these businesswomen between 1963 and 1985 are redefining womanhood. These women appreciate and are happy about their newly acquired self-image as independent businesswomen; at the same time, they do not want to lose their feminine identity in the household. They are renegotiating the terms of their family relationships as well as the basis of work systems. In fact, they do not deny their social role as mothers; they believe that business work and family should not be contradictory to each other. On the contrary, they sometimes utilize their identity to seek business success. They are creating a new womanhood, and for the first time in history, they tend to combine the private sphere and the public sphere because they are trying their best to have an enriched life and have it all. This is what we call "managing both business and family." However, to some extent, from the feminist point of view, this can also be regarded as their compromise in the patriarchal society. Finally, let's consider the declaration of Scott (1977) on behalf of all the working women during the 1970s: 
But I think all of us, deep down inside, have moments of wandering if we're doing the right thing. There may be a working woman who doesn't—but I haven't met her. We wonder if we can have it all. Can we rear happy, secure, well-adjusted children, keep our marriages together and handle a full-time job, too? The answer, I believe, is "yes." But not (for a while) without conflict, guilt, doubt and constant self-examination. And not without time-to learn how to assert ourselves effectively, demand what is rightfully ours, give what is ours to give, and stop feeling inadequate because we can't give all of ourselves, all of the time. (Scott, 1977: xiii-xiv)

\section{$\underline{\text { WACB in Relation to Men }}$}

This section will examine the views of corporate businesswomen between 1963 and 1985 on their male counterparts, especially in the workplace, and the idealized relationship that they want to maintain with them. Generally speaking, there are three types of relationships between men and women in the workplace: First, they can be competitive with each other. These businesswomen are quite aware that, if they want to obtain career success, they need to compete with men. They have to work hard to be better than men, but still, it is easier for men to be promoted and women are the losers. Second, women are viewed as men's sexual objects. Their work and ability is not regarded as important. The first two types of relationships are obviously not preferred. In the third type, women want their male counterparts to appreciate them and their relationship is based on their working abilities and skills, rather than the fact that they are women or they are attractive. In this relationship, men and women are real workmates who help and cooperate with each other. In most cases, a senior man plays the role of a 
mentor or a father who teaches and helps a businesswoman to climb the corporate ladder. Next, cultural evidence will be provided to show how theses businesswomen struggle to maintain the third type of relationship with men.

In both Mary Kay (1981) and You Can Have It All (1995), Ash recalls her experience of retiring from her last job before starting Mary Kay Cosmetics. She worked her way up, over a period of eleven years, to the position of national training director in a direct sales company.

While I never actually received the title, according to my job description, I was performing all the duties of a national sales manager...After I had finished training my assistant, the company owner promoted him to the national sales manager position - at twice my salary! I was devastated... That night, I went home and cried my heart out. (Ash, 1995: 135)

Then Ash planned to write a book about the problems she had encountered as a woman in business. But after making a long list of the qualities of the dream company she would have wanted to work for, she thought, "Instead of writing a book about how a good company should run, wouldn't it be great if somebody run one? And so the idea of Mary Kay Cosmetics was born" (Ash, 1995: 136). In this new company, Ash gives businesswomen enough opportunities to display and cultivate their abilities and to climb the corporate ladder as long as they have outstanding achievements. In this way, Ash uses the success of her female-dominated company to compete with the "male authority" in the business world.

Mary Wells Lawrence was more positive on the male-female relationship in the 
business workplace. In A Big Life in Advertising (2002), she says that:

Gloria Steinem was right that I didn't declare war on men. But I didn't witness offensive male bonding against women. From what I could see, men in business were competitive with anything that walked or talked. They had learned, as boys do, to play games all-out with the idea of winning, so in business they would stretch their psyches to the breaking point to be successful... But there were no mean-spirited bigots getting in my way or holding me down. (Lawrence, 2002: 164)

In Hennig and Jardim's (1976) interview report of 63 business women in corporate business management positions, we can see that all of them have encountered inner conflicts of how to deal with sex and career. They "translated their thoughts into male terms. They talked shop and they sought to act in ways which would obscure the fact that they were women" (Hennig \& Jardim, 1976: 160). One businesswoman describes what this meant:

The strategy with most of the men who had to be dealt with but didn't know you well was to remain unnoticed as a woman but very visible as a highly skilled task specialist. This was very hard to do, and when you had to work with these guys you tired to be just that—one of the guys. It was terribly important not to do anything that might leave yourself open to being accused of acting like a woman. You dressed carefully and remember to swear once in a while, to know a few dirty jokes and never to cry if you get attacked. You fended off all attempts of men to treat you like a woman; you opened the doors before they could hold them, sat down before a chair could be held and threw on a coat before it could be held for you. You wanted to be desired because you were skilled, not because you were a woman. In spite of all this extra work you still couldn't be sure, if a guy seemed to warm up to you, whether it was the skill or the woman he was after. It was terribly easy to turn off anybody who was warm because you couldn't really trust his motives, and by God, you only wanted recognition for your job! (Hennig \& Jardim, 1976: 160) 
These businesswomen believe that they can do a good job in their work and want to be acknowledged because of this, but their identity as women make them less confident in this endeavor. Therefore, in order to be one of the guys, they have to put themselves in male logic while working with men. We can say that, on the one hand, these businesswomen want to integrate sex and career into a coherent whole, although sometimes they have to imitate men; on the other hand, they are challenging the traditional concept of womanhood that women are weaker than men in working abilities.

The relationship between businesswomen and their male bosses or mentors is worth discussing. In Hennig and Jardim's (1976) study, most businesswomen "began as his secretary or administrative assistant and as he moved upward in the organization they moved with him, always at his request" and there is a deep and abiding friendship between them in which "the women likened him to their fathers and described their relationship with him in similar terms" (Hennig \& Jardim, 1976: 155-156). One woman describes this relationship in detail:

As my boss and I progressed in the company, it became increasingly necessary for me to supervise men and to handle accounts which meant working with men clients from other firms. My first reaction to this requirement was that I could do okay with the male subordinates, but I thought I should stay away from direct contact with the clients. I was afraid most male clients were not ready to deal in confidence with a woman. When my boss heard this, he blew his stack. I remember that he screamed at me that it was the damndest time for me to have an identity crisis. What he did was amazing to me: he went out to see every client we had and told them they would be working with me. He told them that I was the most skilled and able publicist in the company and they would be damn lucky if their account happened to be placed in my charge. Before I 
knew what was happening, our clients were actually asking for me, and I was getting more accounts than I and my group could handle. Over the years, I have developed long and close friendships with a number of my male clients, many of whom are now chief executives of their respective firms. I never did have any real trouble with clients. New clients were sometimes reserved, but after I talked with them for a while they became aware of the other accounts that I was managing and for how long I had being doing so. Regardless of what they felt about my being a woman, they knew I knew my trade. I really have to thank Jim [the boss] for all of my success. My dad got me to college and Jim took me from there. (Hennig \& Jardim, 1976: 156-157)

In this case, the boss acts as a mentor and uses his reputation to develop the woman's. According to Hennig and Jardim (1976), "he was the protector and she the protected. His support helped provide her with the extra confidence she needed to take on new responsibilities, new tests of her competence and new positions. He reinforced her own emphasis on competence as the issue of paramount importance" (1976: 157). In fact, the bosses of businesswomen appreciate their working abilities and know their will to succeed. If there isn't the help from their bosses or mentors, the success of businesswomen will be impossible. Therefore, "only with their bosses, as with their fathers earlier, did they feel confident that their gender was taken for granted and primary emphasis placed on their intelligence and ability" and the behavioral style these women adopted with their peers was "as a consequence direct, factual, business- and task-oriented and emotionally distant" (Hennig \& Jardim, 1976: 161).

In another case, businesswomen are supervising and managing their male subordinates. They face similar problems and usually adopt a similar strategy of putting emphasis on working skills and competence. Here is a typical description of this type of 
relationship:

As soon as I began getting male subordinates, I had to examine the situation and decide how I was going to handle it. Until then my managing of people had been limited to typists and researchers. Now I was going to have to learn to manage in the real sense of the word. First, I had to accept that most men would not like to work for a woman, and I was a woman. Second, I had to accept that I had developed a style of being dependent upon my boss for support which I could not do with subordinates. Next, I had to realize what I wanted from them and what they could possibly hope to get from me. I determined it was learning and skill. I wanted them to develop it and use it and if they respected my skills, they might want to get ahead, they wanted this, too. If they respected my skills, they might want to become as skilled, and hence move ahead in their career. I concluded that the thing to do was to try and overlook the man-woman thing and concentrate on making my department the kind of training group that has a reputation for being the place where men can come, learn and get a good promotion. This was my way of getting men to want to work for me. This worked very well, and I never did deal with the men-woman thing but rather I tried to compensate for it in advance. (Hennig \& Jardim, 1976:158-159)

By overlooking the man-woman thing and concentrating on working, businesswomen believe that they can make full use of their abilities and control interpersonal relationships_-"not simply defensively, but more of managing men" (Hennig \& Jardim, 1976: 159). They thought that "if they did allow a sexual relationship to develop the word would spread and the man would inevitably become guilty over it and would reject them. On the other hand, they feared that if they made it immediately clear a sexual relationship was out of the question the man would reject them as being unfeminine" (Hennig \& Jardim, 1976: 155). In this sense, some businesswomen learn an important lesson about sex and work and develop a type of "maybe" relationship in 
which they "never say yes, never say no, always say maybe" (ibid.). Most women believe that the "maybe" relationship is time-consuming and lead to the feelings of real conflict, so they choose to "avoid the issue entirely, basing their relationships on the job to be done, ignoring the innuendoes, double meanings and barely disguised propositions, trying not to care very much about how they were regarded" (Hennig \& Jardim, 1976: 155). It is commonly believed that men view women basically as sexual objects, and if sex appears in the man-women working relationship and not to be entirely ruled out, this relationship will be difficult. However, in order to pursue career success, most businesswomen choose to give up the man-women thing and just talk shop.

In Arthur Hailey's novel Strong Medicine (1984), there is a good example of the mentor-student relationship between Celia de Grey and her boss Sam Hawthorne. From the very beginning, Celia chooses to follow Sam up the ladder at Felding-Roth, because she knows that "the corporate business world is like a private men's club. So a woman must use whatever means she can to become a member and get ahead" (Hailey, 1984: 44). Sam appears as a father-like figure in higher management who is her supporter, her encourager, her teacher and her strength in the company. He appears in every important turning point in Celia's career. For example, in the annual Felding-Roth sales conference, Celia took the chance to put forward her critical idea toward the ill-training of the sales people who have inadequate knowledge about medicine. At first, she was abused by the vice president of sales, a New Yorker named Irving Gregson, who had been recently promoted. "Young woman," he declared, "you have been malicious, presumptuous and 
misguided; also your so-called facts are wrong. You are going to regret it. You will be dealt with later, but for now, I am ordering you to leave this sales convention and not to return" (Hailey, 1984: 64). Celia turns and walks away, heading for an exit. Deep in her heart, she admits that she is defeated, but to her, "the faults [of the company] she had described were so obvious and glaring, the reforms so plainly needed, it was hard to see how others could disagree when facts were pointed out" (Hailey, 1984: 65). When Celia is in despair, it is Sam who stands up and supports her:

'In particular', Sam Hawthorne went on, 'I agree with the opinion that if our industry fails to mend its ways, laws will be passed compelling us to do so. Moreover, those laws will be more restrictive by far than if we accept the good advice we have just heard and clean house ourselves...Finally, about Mrs. Jordan. Several times already she has proved her great value to this company. In my opinion she has just done so again, and if we let her leave this room in this way, we're all shortsighted fools.' (Hailey, 1984: 66)

After these words, the majority of the company leaders and salesmen turn to support Celia, and Mr. Gregson even apologizes with generosity. Afterwards, Celia's position at Felding-Roth rises. Sam knows Celia's ambition and working competence, therefore, when he is promoted, he tries his best to help Celia climb the corporate ladder. Once Sam admits to Celia that "I have to tell you there are still some around here who don't like the idea of a woman being director of anything... To be honest, I used to feel that way myself, but you changed my mind" (Hailey, 1984: 100). In another occasion, Sam walks into Celia's office unannounced and beaming: "By God, we did it...I had to plunge my sword into the entrails of a few male diehards, and blood has flowed, but word has now come 
down. You are director of this bailiwick and, what is more important, Celia, you are officially on the company's fast track" (Hailey, 1984: 100). On the fast track in the company means that Celia is selected to be a candidate for senior management and would be given better than normal opportunities to learn the business and to prove herself. As Sam's student, admirer and helper, Celia certainly was grateful toward Sam for all his guidance and support, but when Sam indicated, more than once, that he would enjoy an affair with Celia, she "had decided long ago that it would be the worst thing for them both, and discouraged Sam's rare overtures with politeness, but firmly" (Hailey, 1984: 241).

The relationship between women and men in the corporate workplace is best represented in the humorous movie Nine to Five (1980). There are three office women: Judy Bernly (acted by Jane Fonda), a housewife whose husband has left her for his secretary; Violet Newstead (acted by Lily Tomlin), a veteran office manager who has not been promoted for a long time; and Doralee Rhodes (acted by Dolly Parton), the secretary of their chauvinistic boss Franklin Hart Jr. (acted by Dabney Coleman). Hart's endless attempts to seduce the happily-married Doralee lead the entire office to think that she's a trollop. When Judy and Violet find that Doralee is innocent, they become friends.

In the fantasies about killing the boss, the three women get their revenge and show how they want to maintain a healthy relationship with their male boss that is based on their work performance. Since Violet is often asked to make coffee for her boss Hart, she feels resentful. Once Violet accidentally poisons Hart's coffee and think he is dead, the 
three ladies are forced to protect themselves by stealing Hart's body from the hospital.

When he turns up alive and had never drunk the coffee, they kidnap him to prevent him from blackmailing them or calling the police. Then they use his power to manage the company. The results turn out to be good-all of them get the well deserved power and respect at their firm. As we can see from the posters (Fig. 4-5 and 4-6.), this humorous movie justifies women's business ability and expresses women's rebellion against male-dominated business culture.

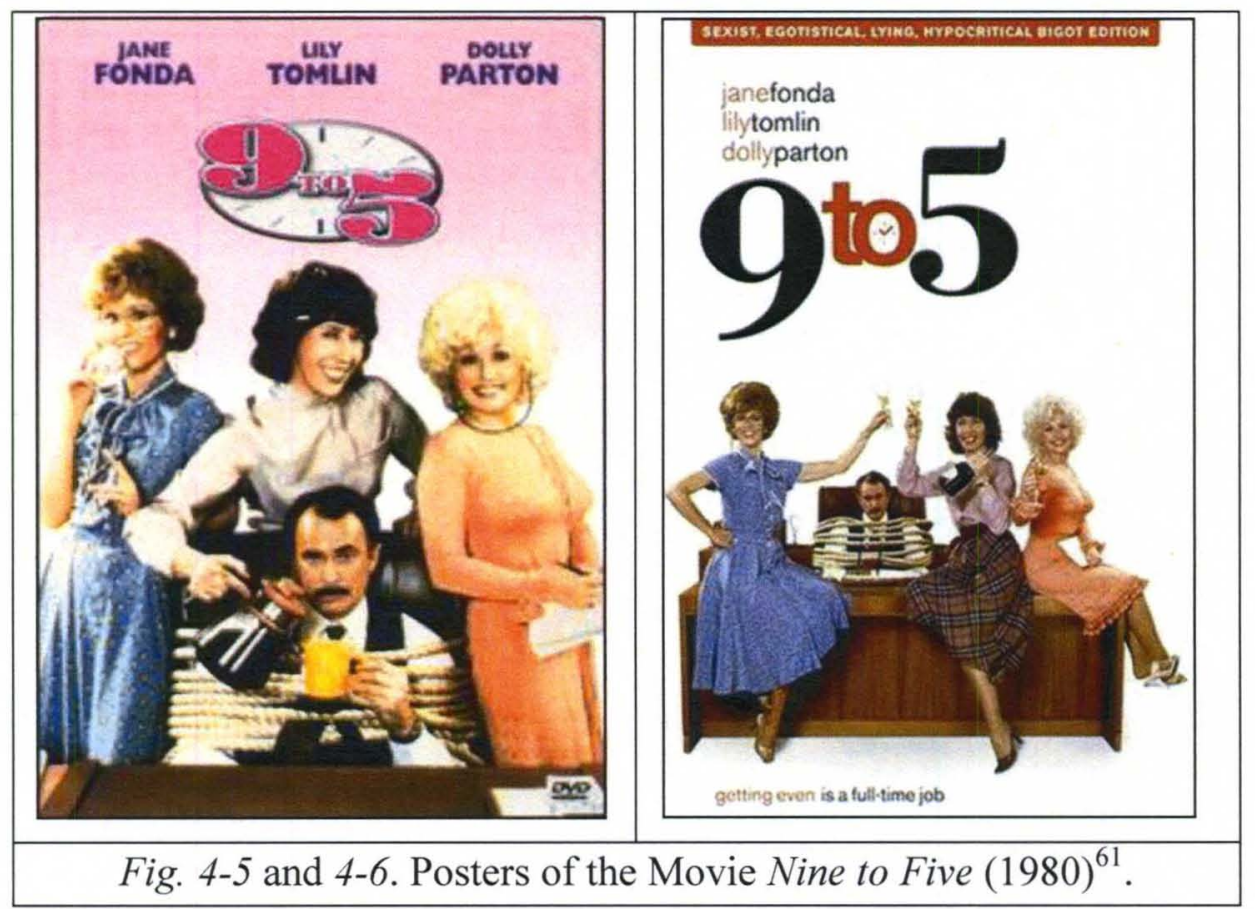

In addition, the theme song "9 to 5" sung by Dolly Parton from her album 9 to 5 and Odd Jobs (1980) also expresses the heart of businesswomen in the 1970s. Here is the theme song 9 to 5 :

${ }^{61}$ Fig. 4-5 and Fig. 4-6 were retrieved from http://www.mooviees.com/596-nine-to-five/movie on Mar.15, 2009. 
Tumble out of bed and stumble to the kitchen;

pour myself a cup of ambition,

and yawn, and stretch, and try to come to life.

Jump in the shower, and the blood starts pumping;

out on the street, the traffic starts jumping,

with folks like me on the job from nine to five.

Working 9 to 5, what a way to make a livin', barely gettin' by

Its all taking and no giving

They just use your mind

But they never give you credit

It's enough to drive you

Crazy if you let it

9 to 5 , for service and devotion

You would think that I

Would deserve a fair promotion

Want to move ahead

But the boss won't seem to let me in

I swear sometimes that man is out to get me

Mmmmm.....

They let your dream

Just a' watch 'em shatter

You are just a step

On the boss man's a' ladder

But you got dream but he'll never take away

You are in the same boat with a lot of your friends

Waitin' for the day

Your ship'll come in

And the tide's gonna turn

An' it's all gonna roll you away... ${ }^{62}$

In this song, the businesswomen express the desire to be recognized for their working abilities although their male counterparts or bosses do not understand and never give credit to them. What is more, on the cover of the album (see Fig. 4-7.), we can see that Dolly Parton is a businesswoman who has too much to do. It seems that the work

${ }^{62}$ The complete song is found at http://www.televisiontunes.com/9 to 5. html (accessed on June 8, 2010). 
will never end.

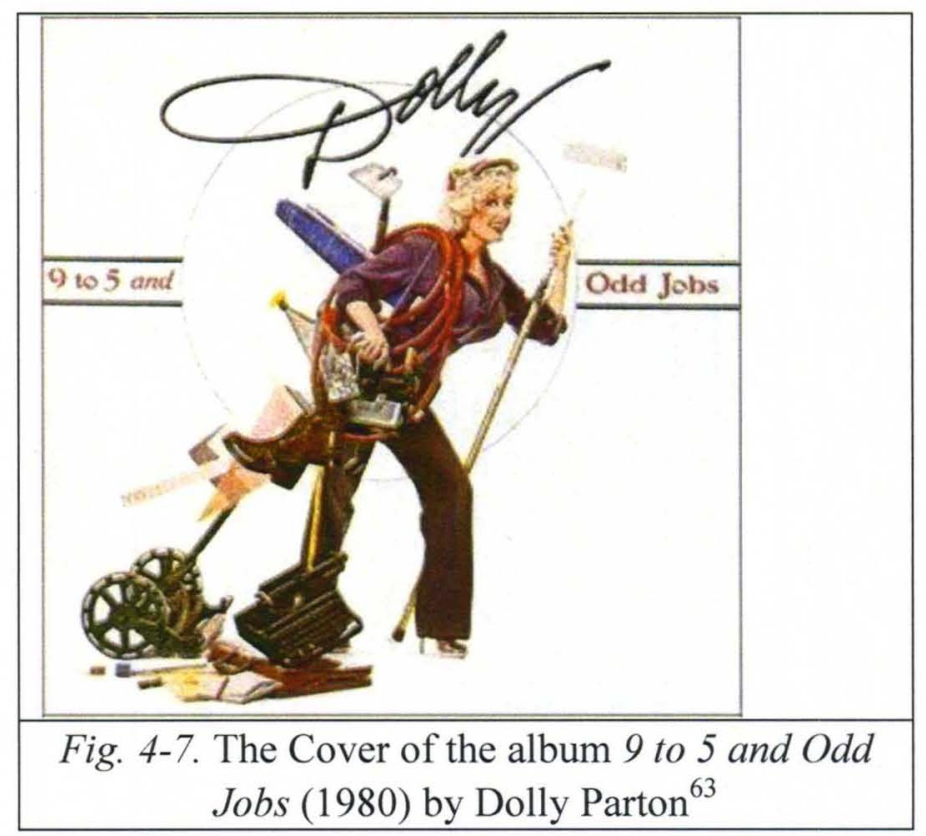

Both the movie Nine to Five (1980) and the song "9 to 5" rebel against the male authority in the business world. They call for a stop to corporate sexism and the improvement of the treatment of women in the workplace.

All in all, this chapter has shown the cultural evidence which reflects the self-identity of white American corporate businesswomen between 1963 and 1985 from these three aspects: (1) their view on business work; (2) how they see the relationship between work and family; and (3) how they see their relationship with men, especially those in the workplace. As a result, we see clearly these businesswomen's new definition of womanhood - a woman should pursue an enriched life in which she has the freedom to "have it all," including both a loving family, a long-term career, and an equal status with

${ }^{63}$ Retrieved from http://www.countryrokmusic.com/album/9_To_5_And_Odd_Jobs/26125/ on May.19, 2009. 
men in the workplace.

The next chapter will extend the scope of this research into the 1990s to see that feminism has not achieved the complete success in solving working women's problems. The new wave of Feminism represented by Julia Kristeva and Luce Irigaray will be introduced; their work is developed on the basis of the psychoanalytic theories of Sigmund Freud and Jacques Lacan. Since the Second Wave Feminism did not solve women's problems, this Third Wave Feminism may serve as a new epistemic rupture that helps find solutions to the problems. 


\section{CHAPTER V}

\section{LACAN, KRISTEVA, IRIGARAY AND THE NEW WAVE}

In the previous chapter, we see that the white American corporate businesswomen between 1963 and 1985 have established their new identities under the impact of WWII and the Second Wave Feminism. However, they still have to face the old problems, such as lower salaries, job discrimination, and sexual harassment. In the 1990s and in the twenty-first century, many more women are running businesses, but the situation does not change much. For example, Carly Fiorina, the chief executive officer of Hewlett-Packard from 1999 to 2005 and previously an executive vice president at AT\&T, is considered one of the most powerful women in business. Under her leadership, in 2002, the company completed a contentious merger with rival computer company Compaq (Fiorina, 2006). Unexpectedly, she was forced to resign by the Hewlett-Packard board in 2005, and most people believe that the reason was because the board thought it was not proper to let a woman lead the company any longer. Do we have solutions to the problems that businesswomen have to face? Will the new epistemic raptures be identified in the new era 
to solve these problems? The Third Wave of Feminism represented by Julia Kristeva and Luce Irigaray may serve as a new epistemic rapture that helps find solutions to the problems. In order to understand Kristeva and Irigaray's thought on Feminism, we need to first review the psychoanalytic theories of Sigmund Freud and Jacques Lacan, which offer a basis for Kristeva and Irigaray's theories.

\section{Jacques Lacan and His Theory of Structuralism}

According to Campbell (2004), the feminists of the Anglo-American second wave began to warn women of the dangers of psychoanalysis in the 1970s.

Betty Friedan, Germaine Greer and Kate Millett argued that psychoanalysis is a patriarchal institution because of its phallocentric prescription of normative femininity. By contrast, French feminists, such as Julia Kristeva and Luce Irigaray, argued that psychoanalysis is a potential feminist ally, because of its account of the psychic register of sexual oppression and liberation. In his contemporaneous seminar, Lacan warns these women not to confuse his revolutionary psychoanalysis with the political and sexual revolution that they hope for...These mutual narratives of the difficulties of feminism/psychoanalysis continue to haunt contemporary feminist and Lacanian movements. Certain strands of Lacanian psychoanalysis regard feminism as a dangerous, if not impossible, attempt to rewrite foundational sexual differences... It seems that a rejection of feminist has become a truism of Lacanian orthodoxy: from the criticism that feminism fails to recognize 'the rock of castration', to the refusal to recognize the legitimacy of same-sex families. Similarly, many feminists reject Lacanian psychoanalysis because of its dangers. (Campbell, 2004: 25)

This section of the chapter investigates what Lacan has to say about his theory of psychoanalysis and how that theory impacts on feminism. It is followed by a re-analysis 
of Lacan's work by one of his students, Julia Kristeva (1980) who has much to say about Lacan and how a revision of his model will enhance feminist theory. Similar comments are made about Luce Irigaray (1985a; 1985b) who was also a linguist in addition to being a psychiatrist. This journey begins with Freud and the study of the unconscious. It will take us into those who reacted to his proclamations and discoveries, Jung and Lacan. It is the latter, however, who is the main focus of this investigation.

\section{The Psychoanalytic Unconscious}

The concept of the unconscious mind was developed by Freud ([1923] 1949) and his followers and it is at the center of psychoanalysis. On the first line, Freud states, "there is nothing new to be said [about consciousness and the unconscious]... the division of mental life into what is conscious and what is unconscious is the fundamental premise on which psycho-analysis is based" ([1923] 1949: 9). The conscious mind has to do with perception but for Freud there was an unconscious mind operating well below the conscious mind. It is a sentient force of will. It is the ability to have subjective perceptual experiences that are influenced by human drive yet operating well below the perceptual consciousness. For Freud ([1923] 1949), the unconscious is the storehouse of instinctual desires, needs, and psychic actions. For example, we all have past thoughts and memories that appear to be deleted from our immediate consciousness, but according to Freud 
([1923] 1949), they are not deleted. They still control our thoughts and feeling from the realm of the unconscious.

Freud ([1923] 1949) calls the mind into the conscious mind (ego), human instincts (the id) and the superego. The ego is a "body-ego"-a mental projection of the surface of one's physical body (Freud, [1923] 1949: 31). Id is the unconscious portion of our psyche. The ego is a "modified portion" of the id that can perceive the empirical world (Freud, [1923] 1949: 29). The superego functioned as a moral guardian; it is the "ego-ideal" (Freud, [1923] 1949: 34), which "is always in close touch with the id and can act as its representative in relation to the ego" (Freud, [1923] 1949: 70). Freud used the idea of the unconscious in order to explain certain kinds of neurotic behavior (pyromania, obsessive compulsive disorder, hysteria, phobias, etc.). Subjects are unaware of the source of these behaviors because they function at an unconscious level. Freud proposed a hierarchical conception of the mind and he used the metaphor of the iceberg (see Fig. 5-1.) to show that there is a conscious mind (what we are aware of) and below that a preconscious mind (everything that we can remember) and further below that, the unconscious mind. What Freud ([1923] 1949) wants to argue is that significant psychic events take place below the surface in the unconscious mind. The conscious and preconscious mind part of the mind he referred to as the ego. It had to do with the reality principle. He referred to the id as the pleasure principle because it involved unconscious urges and desires. It should be noted that the unconscious does not include all that is not conscious. It is concerned only what 
is actively repressed from conscious thought. It is what we are averse to knowing consciously.

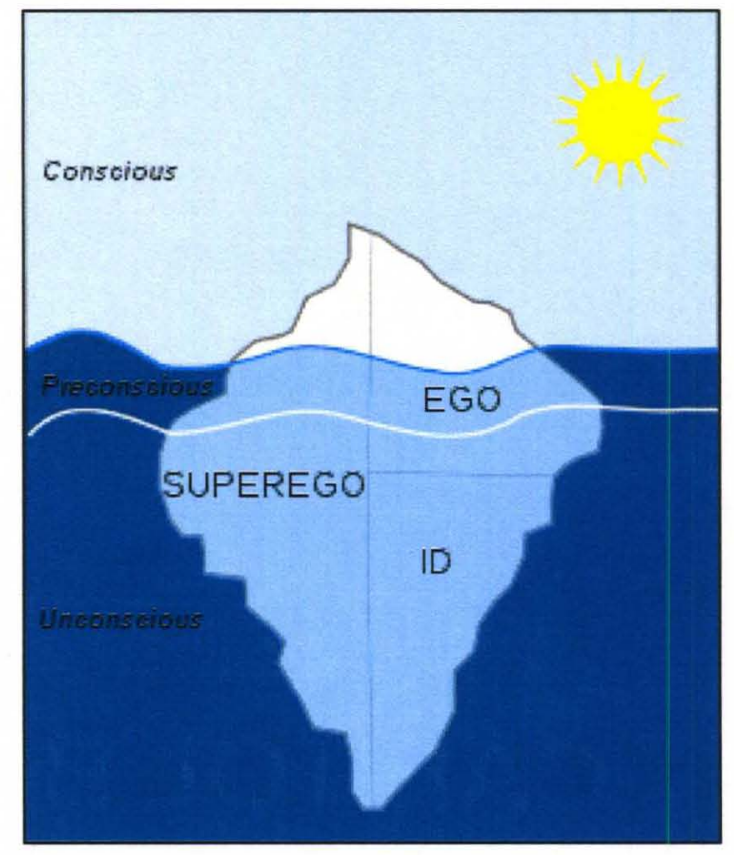

Fig. 5-1. Diagram of Freud's psyche theory ${ }^{64}$

In psychoanalysis, the therapist is the one who attempts to allow the unspeakable to reveal itself. He uses various tools of psychoanalysis to interpret cryptic messages that arise from the conflict between the conscious and the unconscious. The unconscious is, after all, the repository for socially unacceptable ideas, wishes, desires, traumatic memories, painful emotions that have all been repressed. These repressed parts of the unconscious do not remain hidden. They emerge in the form of symptoms. Freud's theory of the unconscious was substantially transformed by some of his followers, among them

${ }^{64}$ Retrieved from http://webspace.ship.edu/cgboer/freud.html on July 23, 2010. 
Carl G. Jung (analytical psychiatry) $(1969,2004)$ and Jacques Lacan $(1977 b, 1991$, 1993).

Carl Jung (2004) has a different idea about the deep forces and motivations that underlie human behavior (depth psychology, archetypal psychiatry). He wants to understand them and integrate them to make the individual whole (individuation). $\mathrm{He}$ finds many answers by turning to the meaning of dreams, folklore, and mythology.

Jacques Lacan (1977b) differs from Freud in many ways. The thesis of the mirror stage (le stad du mirror) is based on the fact that human beings are born prematurely. They are left to themselves at birth. If this condition were to continue, they would probably die. They are always born too early. They can't walk or talk at birth. They have very partial mastery of their motor functions and at the biological level, they are hardly complete. Lacan asks how the child comes to master its relationship to its body. How does it respond to its prematuration? His answer is mimicry (Lacan, 1977b: 1). The child identifies with an image outside himself. For him, this image is complete (Lacan, 1977b: 3). The apparent completeness of this image gives the child mastery over his body. This is because the child identifies with an image outside of himself. Once it identifies with this image, it can do things it could not do before. The child sees himself in the place of another child. He is trapped in the image that is fundamentally alien to him. This alienation corresponds to the ego. It is an alienating identification based on an initial lack of completeness to the body and the nervous system. This was the response of Lacan to Freud in his 1914 paper "On Narcissism: An Introduction." Freud argued that some new 
psychical action must take place to constitute the ego, but he did not say what that was. But for Lacan (1977b), there can never be an absolute self, no autonomous "I" or transcendental ego that exists apart from the Other; the 'I' is always linked "to socially elaborated situations" (1977b: 5) mediated by "linguistic structures ontologically constituted a priori within its social facticity. Thus the I is the Other" (Mills, 2004: 98). In other words, Lacan sees ego as the Other. The ego is "an inauthentic agency functioning to conceal a disturbing lack of unity" (Leader and Groves, 2000: 24). It is fragmented. The task of the ego is "to maintain a false appearance of completeness and coherence," and "the human subject oscillates between two poles: the image which is alienating and the real body which is in pieces" (Leader and Groves, 2000: 26-27). "The phantasy of castration is behind this phantasy of fragmentation... Paranoia involves a sort of decomposition... Ego is constructed in an image outside of the self" (Leader and Groves, 2000: 28-29). Lacan (1977b) argues that this truth about the ego emerges in forms of madness. It is a situation where the world seems to dissolve and the differences between the self and the other is radically put in question. Lacan claims that human knowledge is in its very essence, paranoiac (1977b: 5).

Lacan (1977b) also differs from Freud in that his paradigm establishes a triad of three orders: the Imaginary, the Symbolic, and the Real. The Imaginary order is an outgrowth of the mirror stage in which the relationship between the ego and the reflected images is one of radical alienation (1977b: 138). It is this alienation that constitutes the Imaginary order (Leader and Groves, 2000: 65). It is a field of images, imagination, and deception. 
This order is not only narcissistic but based on illusions. The Imaginary order is structured by the Symbolic order (ibid.). The visual field of the child is structured by symbolic laws. Hence, the imaginary involves a linguistic dimension. This is because the signifier (the expression of a sign) is the foundation of the Symbolic. The signified (the meaning part of a sign) belongs to the Imaginary order (see Fig. 5-2.). Hence, language has Symbolic and Imaginary connotations (Lacan, 1977b). When Lacan (1993) says that "meaning is imaginary," he is saying that our ego is conceptually bound to our conscious self-image or self-representations (1993: 65). In fact, the Imaginary is rooted in the subject's relationship with his body (the image that he has of his body and that exists outside of him). Discourse takes place within the Symbolic order. It is what Lacan (1977b) calls the big Other.

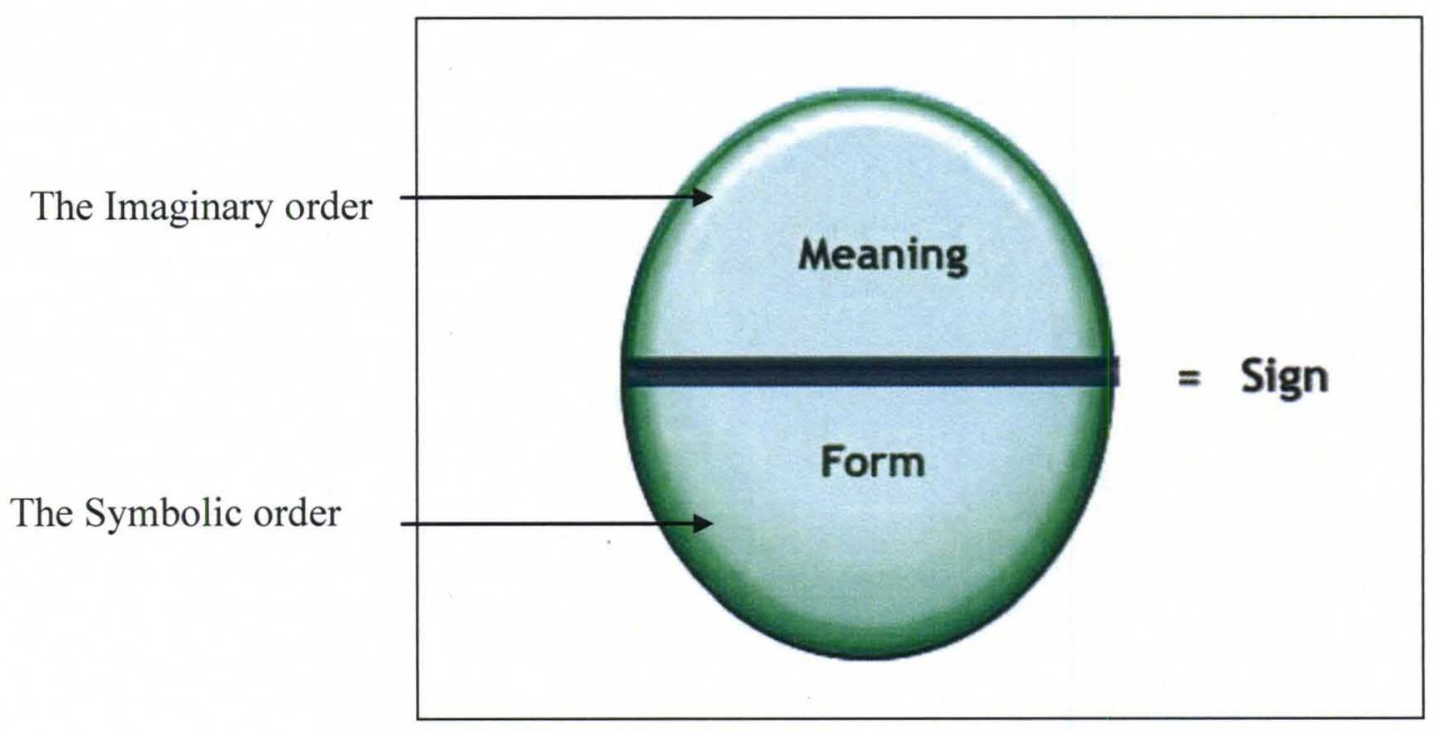

Fig. 5-2. Lacan's Paradigm of the Imaginary Order and the Symbolic Order ${ }^{65}$

\footnotetext{
${ }^{65}$ Fig. 5-2 is adapted from the figure on the structure of Sign by Saussure's ([1916] 1974) in St. Clair (2009) and Lacan's discussion on Imaginary Order and the Symbolic Order (1977b: 137-139).
} 
Lacan (1977b) proposes that the Symbolic provides the way to dislodge the Imaginary order. This is done when the analyst transforms images into words. The Symbolic order is important. The concepts of law and structure depend on it. He argues that the Symbolic Order does not have a positive existence. It exists by virtue of its mutual difference to other relationships. This comment can be explained by looking at selected linguistic examples of how structures function within language. Linguists study actual sounds and they call this area of investigation phonetics. They mark off phonetic sounds with brackets, "sigh" [say]. They also investigate sounds that are perceived by the native speaker of a language and they call this investigation phonemics. Phonemes (abstract perceptual entities) are marked off by means of slant lines, "kin" /kín/ [k"ín]. What we find in these examples is that the phonemic level marked by slanted lines is abstract whereas the phonetic forms marked by brackets are concrete (St. Clair, 2010a). These abstracts are based on a system of oppositions. Phonemes are abstractions. They are not real. They are created by contracting concrete sounds with one another within a system of sounds. Those systemic sounds are abstract. Consider the following phonemic chart (see Fig. 5-3): 
English Consonants

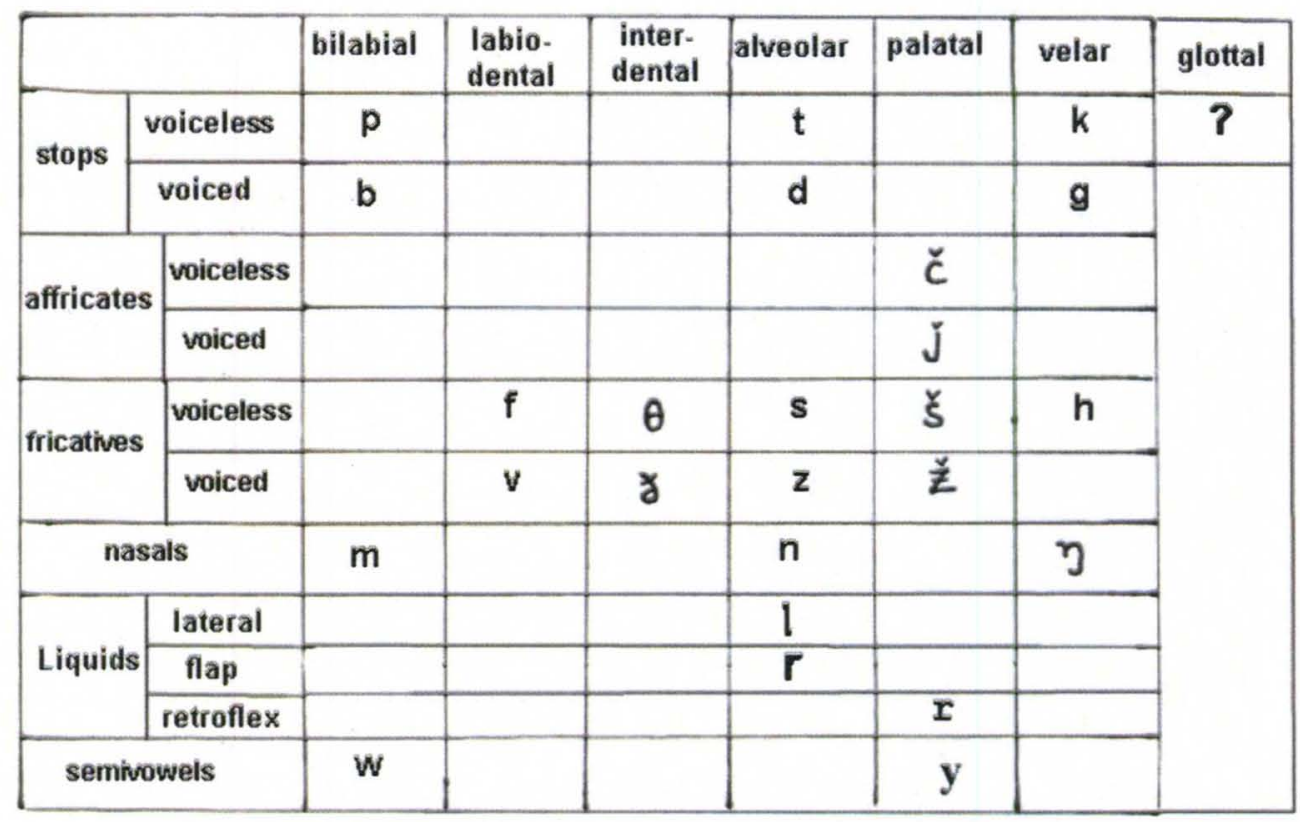

Fig. 5-3. Chart of consonant phonemes in English ${ }^{66}$.

The phonemes in this chart constitute a system of abstract sounds. The phonemes /p/ and /b/ exist because in English the sounds in "pit" and "bit" form a minimal contrast. One can hear the difference between a $/ \mathrm{p} /$ and a $/ \mathrm{b} /$. The same occurs with the phonemes $/ \mathrm{t} /$ and $/ \mathrm{d} /$. They exist because of the contract between "time" and "dime." Although the sounds that exist in the aforementioned minimal pairs of contrasting words are phonetic, i.e., they are concrete, the sounds that exist in the phonemic chart belong to a system. They are abstractions. The most interesting part of this story is that human beings hear concrete sounds but perceive only phonological abstractions (St. Clair, 2010a). Hence, these abstractions are psychologically real. This is why Lacan (1977b) says that the Symbolic Order has no positive existence. It constitutes a system. The signifiers are part

${ }^{66}$ Retrieved from http://mockingbird.creighton.edu/english/fajardo/teaching/eng520/phonology.htm on July 14, 2010. 
of a system of abstractions. The Symbolic Order belongs to a system of abstractions. There is another aspect of the Symbolic Order that merits comment. It is the field of radical alterity. It is where one finds the Other, the unconscious of discourse. It is the realm of the Law that regulates desire of the Other. It is the realm of the law. It regulates desire (Lacan, 1998, as cited in Leader and Groves, 2000: 81).

The third order constitutes the Real. This term was used to refer to the ontological absolute (the being-in-itself). However, for Lacan (1977b), the Real is not synonymous with reality. Not only is it opposed to the Imaginary, the Real is also located outside the Symbolic (the realm of oppositions). The Real is undifferentiated. Unlike the latter which is constituted in terms of oppositions, i.e. presence/absence, "there is no absence in the Real" (Lacan, 1991: 313). Whereas the Symbolic opposition presence/absence implies the possibility that something may be missing from the Symbolic, "the Real is always in its place" (Lacan, 1998, as cited in Homer, 2005: 82). If the Symbolic is a set of differentiated elements, signifiers, the Real in itself is undifferentiated, it bears no fissure. The Symbolic is the world of words that creates the world of things. Thus the Real is that which is outside language, resisting symbolization absolutely. Lacan (1977b) defines the Real as "the impossible" because it is impossible to imagine and impossible to integrate into the Symbolic, being impossibly attainable. It is this resistance to symbolization that lends the Real its traumatic quality. Finally, the Real is the object of anxiety in that it lacks any possible mediation, and is "the essential object which is not an object any 
longer, but this something faced with which all words cease and all categories fail, the object of anxiety par excellence" (Lacan, 1991: 164).

\section{Desire}

The concept of Desire (désir) is important to Lacan (1977a, 1991, 1992). It follows the concept of Desure (Wunsch) by Freud. Lacan (1991) argues that the purpose for psychoanalyst is for the therapist to uncover the truth about the patient's desire. This is possible only if that desire is articulated, or spoken. He argues that "the subject should come to recognize and to name his desire" (Lacan, 1991: 228). The recognition of desire comes about through naming it. By giving it a name, it has a new presence, a new existence.

Desire is the demand for love. Desire is different from demand. A neurotic is someone who hides his desire beneath his imposing demand. Demand is the demand for an object. Desire has no object. Desire emerges in the little details. A wish is something that you want consciously. But desire is fundamentally barred from consciousness. Desire does have an object: it is an absent one. Lacan follows Spinoza in arguing that "desire is the essence of man" (Lacan, 1998: 275). Desire is simultaneously the heart of human existence and the central concern of psychoanalysis. However, when Lacan talks about desire,

it is not any kind of desire he is referring to, but always unconscious desire. This is not because Lacan sees conscious desire as unimportant, but 
simply because it is unconscious desire that forms the central concern of psychoanalysis. Unconscious desire is entirely sexual; the motives of the unconscious are limited...to sexual desire...The other great generic desire, that of hunger, is not represented. (Evans, 1996: 37)

\section{Symptoms}

Freud ([1923] 1949) shows how symptoms could be literally trapped in the body. Words become the very stuff of symptoms, the fabric of life and torment of human beings. Lacan goes on to see symptoms are signs and uses a linguistic analogy. He begins with the Signifier which is an acoustic image; signified is a concept. We use signifiers to gain access to the signified. That is to say, words give us access to meaning. We use words to convey meanings and intentions. A word leads to other words in a linguistic chain. A group of meanings is organized by links between words. There is a priority of the signifier, the material verbal element. However, words generate meanings which are beyond the understanding of those who use them. Gestures also become signifiers. They generate meaning. They organize our world which is symbolic. We are born into symbolic networks. Signifiers are elements of identification. They situate the child in a symbolic universe. There is an identification which is both beyond and prior to the identification of the image (a symbolic identification with signifying elements). Lacan (1992) argues that this identification is one with the ideal. The ideal is not conscious. Hence, symbolism operates beyond conscious control. The symbolic identification with an ideal image removes the subject from being completely at the mercy of the imaginary 
images which captivate him or her. The relation to the image is structured by language.

Lacan $(1977 b, 1991)$ makes a distinction between the ideal ego, the image that the person assumes in his imaginary world, and the ego-ideal, the symbolic vantage point, a reference point from which you are looked at (1977b: 2-3). The way in which people look at you and judge you is the gaze (1977b:2). It is a concept that is more specific and more concrete than the concept of the social self. The social self has to do with how society judges you and makes you live in accordance with its laws and customs. The gaze has to do with an individual who judges you, what George Herbert Mead (1934) would call the "significant other."

Lacan is often associated with a "linguistic turn" in psychoanalysis, that is to say, "a turning away from biology in therapy and metapsychology so as to stress the element of language as dominant both in clinical practice and in theory" (Rabaté, 2003: xii). Lacan has a linguistic model of psychiatry. He calls it a structural model. What is important about his model is the fact that the structure that he is concerned with is linguistic. It has a simple quality based on oppositions. It is based on a system of differences. The central property of a linguistic system is its discontinuity. It is a digital system and not an analog system. It is a digital system created by patterns of oppositions. Now for Lacan (1988, 1991), the ego is imaginary, but the unconscious is structured just like language. It is constituted by chains of signifying elements. It turns words into symptoms. It inscribes signifiers into the flesh and turns them into tormenting thoughts or compulsions. One must find "a guide beyond the imaginary, on the level of the symbolic plane.... This guide 
governing the subject is the ego-ideal" (Lacan, 1988: 141). All that children remember is what their parents told them, words and gestures. Words are trapped in their bodies. They cause pain and in order to relieve this pain, the subject has to undergo translation from the repressed unconscious to the symbolic conscious. Symptoms are made up of words. One is substituted for another that is repressed.

Lacan (1977b) makes a distinction between language and speech. For him, language is an abstract structure, a formal system of differences. Speech, on the other hand, is an act, generating meaning as it is spoken. I find this dichotomy to be a rather strange one. Does human agency arise only when one speaks? Evidently, this is not the case. Human agency also occurs at the unconscious level. We think that what Lacan is trying to say is that speech is ontological (Lacan, 1977b: 31). It exists and because it exists it is more accessible. This accessibility allows us to better understand the agency of the speaker. We place him in a setting. We attribute him with a social position. The meanings that emerge are no longer unconscious which "is that part of the concrete discourse, in so far as it is transindividual, that is not at the disposal of the subject in re-establishing the continuity of his conscious discourse" (Lacan, 1977b: 49). Speech carries meanings beyond conscious meaning or understanding. It supposes the existence of the Other, a place from which you are heard. However, as Lacan (1977b) points out, words represent me but they are not me. Alienation is situated in the register of language. Language has the role of blocking identity. In his later works, the subject is no longer recognized. It has been abolished. The minute that one uses words to express something, he/she is in another 
register. Speaking thus introduces a form of loss in the world. Once you speak, the language that you use is outside of you. You are alienated from it. It is a code that you had to use to impact your feelings and moods on others. However, it fails to do just that.

Triangular Structure: Mother, Child, Love-Object

Lacan (1977a) sees the mother, the child, and object of mother's desire (phallus) as a triangular structure. The child wants to be the phallus for the mother. He wants to please the mother. The phallus is not associated with the Freudian concept but takes on a different meaning in Lacan. It is anything that the child can do to make his mother want him and love him. The child begins with the mirror phase and has an imaginary object that allows him to be whole. He uses these images to attract the mother's love. However, they fail to attract her attention. Lacan (1977a) argues that the imaginary object of the child's games must be given up and transported to the symbolic level. In this way, the child will be able to leave the triangular regulation with the mother. In this way, he will be able to leave the universe of the mother and enter the larger universe of the symbolic.

Next, based on Lacan's thoughts on psychoanalysis and interpretations of human development, we are going to focus on the thoughts of Julia Kristeva and Luce Irigaray on feminist theory in order to find a solution for working women's problems. 


\section{$\underline{\text { Julia Kristeva }}$}

Julia Kristeva does not refer to her own writing as feminist. However, many feminists turn to her work in order to expand and develop various discussions and debates in feminist theory and criticism. There are three elements of Kristeva's thoughts have been particularly important for feminist theory in Anglo-American contexts: the female body, the role of the mother in the subjectivity of the child, and Abjection.

The first context is her attempt to address the concept of the body because in the humanities the body has been associated with the feminine. It has been a pejorative associate in which the body of the woman was treated as weak, immoral, impure, and even putrefying. She argues that bodily drives are already part of the representation of the female body and that the logic of its meaning is already defined by the body. These drives act as a pivot between soma and psyche, and between biology and representation. She argues for a difference between the semiotic and symbolic (Kristeva, 1980, 1984a) (see

Fig. 5-4.). The semiotic element is the bodily drive as it is discharged in signification. The semiotic is associated with the rhythms, tones, and movement of signifying practices. As the discharge of drives, it is also associated with the maternal body, the first source of rhythms, tones, and movements for every human being since we all have resided in that body. For Kristeva, "the operation of the semiotic within signification opens up the possibility of explaining cultural change. The operation of the semiotic within signification continually proliferates cultural possibilities" (Oliver, 1993: 102). This is 
reminiscent of Lacan's distinction between the Imaginary and the Symbolic Order (see Fig. 5-2.).

The Semiotic (The Imaginary order) The Content of the Symbolic.

The Body (Symbolic Form) The Grammar and Structure of Meaning

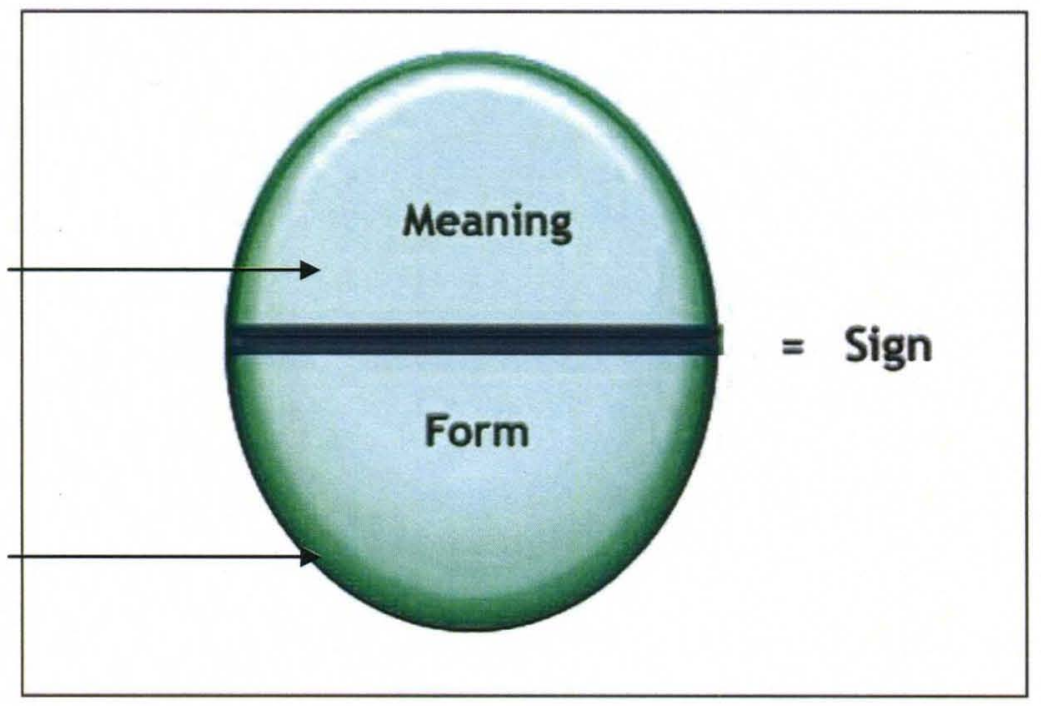

Fig. 5-4. Kristeva's Distinction between the Semiotic and Symbolic ${ }^{67}$

According to Kristeva $(1980,1984 a)$, the symbolic element of signification is associated with the grammar and structure of signification. The symbolic element is what makes reference possible. For example, words have referential meaning because of the symbolic structure of language. On the other hand, we could say that words give life meaning (non-referential meaning) because of their semiotic content. Without the symbolic element, there would be no meaning. The non-referential meaning of the signified comes from the referential meaning of the signifier. Life requires both the semiotic and the symbolic. Kristeva (1984a) describes the relation between the semiotic

${ }^{67}$ Fig. 5-4 is adapted from Fig. 5-2 and Kristeva's discussion on the Semiotic and Symbolic and their differences (1984a: 25-30, 38-42). 
and the symbolic as a dialectic oscillation:

Without the symbolic we have only delirium or nature; without the semiotic, language would be completely empty, if not impossible. We would have no reason to speak if it weren't for semiotic drive force. So the oscillation between the semiotic and symbolic is productive and necessary. This oscillation is the movement between rejection and stases, separation and recuperation, difference and identity. (Oliver, 1993: 96)

Oliver (1994) points out that Kristeva is trying to provide the context for her second argument. She (1982, 1984a, and 1987) argues that although the bodily drives are discharged and have meaning, the logic of signification is already operating within the materiality of the body. She adds that these bodily "identifications" and "differentiations" are regulated by the maternal body before birth and the mother during infancy (1982: 77). Hence, Kristeva (1987) proposes that there is a maternal regulation or law which prefigures the paternal law which Freudian psychoanalysts have maintained is necessary for signification. Therefore, the regulation or grammar and laws of language (the semiotic), then, are already operating on the level of matter (the symbolic).

Kristeva follows Melanie Klein (1882-1960) rather than Freud or Lacan in her discussion of the maternal role of the child entering into society. Freud and Lacan place greater emphasis on the paternal function of the father in guiding the child into society. Both Freud and Lacan argued that paternal threats cause the child to leave the safe haven of the maternal body. She questions this: Why leave this safe haven if all you have to look forward to is fear and threats? Kristeva agrees that "the mirror stage may bring about a sense of unity, but she thinks that, even before this stage, the infant begins to 
separate itself from others in order to develop borders between 'I' and other" (as cited in McAfee, 2004: 45). Hence, Kristeva concludes that subjectivity in the child begins in the womb. It does not begin with the mirror stage of Lacan. She (1987) calls for a new discourse of maternity that acknowledges the importance of the maternal function in the development of subjectivity.

Kristeva (1987) argues that we don't have adequate discourses of maternity. Religion, specifically Catholicism (which makes the mother sacred), and science (which reduces the mother to nature) are the only discourses of maternity available to Western culture. As a woman and as a mother, a woman both loves and desires and as such she is primarily a social and speaking being. "As a woman and a mother, she is always sexed. But, insofar as she fulfills the maternal function, she is not sexed" (Ritzer, 2005: 424). Kristeva's analysis suggests that to some extent anyone can fulfill the maternal function, men or women. She argues that the maternal body operates between nature and culture. Kristeva (1987) uses "the maternal body with its two-in-one, or other within, as a model for all subjective relations. Like the maternal body, each one of us is what she calls a subject-in-process" (as cited in Ritzer, 2005: 424). Like the maternal body, we are never completely the subjects of our own experience. Feminists have found Kristeva's notion of a subject-in-process a useful alternative to traditional notions of an autonomous unified (masculine) subject.

The third context is that of abjection. Kristeva (1982) describes abjection as an operation of the psyche through which subjective and group identity are constituted by 
excluding anything that threatens one's own (or one's group's) borders. The main threat to the fledgling subject is his or her dependence upon the maternal body. Therefore, abjection is fundamentally related to the maternal function. Kristeva (1982) claims that "I experience abjection only if an Other has settled in place and stead of what will be 'me'" and matricide is our vital necessity because in order to become subjects (within a patriarchal culture) we must abject the maternal body (1982: 10). However, this is not possible. Women cannot abject the maternal body with which they also identify as women, they develop what Kristeva calls a depressive sexuality. This is why she suggests that we need not only a new discourse of maternity but also a discourse of the relation between mothers and daughters, a discourse that does not prohibit the lesbian love between women through which female subjectivity is born. In Tales of Love (1987), Kristeva suggests that "misplaced abjection is one cause of women's oppression" (1987: 374). "In patriarchal cultures, women have been reduced to the maternal function. They have been reduced to reproduction. So, if it is necessary for them to abject the maternal function to become a subject, then within patriarchy, women, maternity, and femininity are all abjected along with the maternal function" (Oliver, 1998, para. 13).

\section{Is Kristeva A Feminist?}

Although many feminist theorists and literary critics have found Kristeva's ideas useful and provocative, Kristeva's relation to feminism has been ambivalent (Switala, 
1999). In her essay "Women's Time" in New Maladies of the Soul (1995), Kristeva argues

that there are three phases of feminism. She rejects the first phase because it seeks universal equality and overlooks sexual differences. She criticizes Simone de Beauvoir and the rejection of motherhood; rather than reject motherhood. Kristeva (1995) insists that we need a new discourse of maternity. She goes on to explain that she could not accept the way that existential feminism made women feel guilty for wanting to have children.

Kristeva (1984b) claims that one reason feminist movements fail is that they do not take up the question of maternity and its impact on women (1984b: 20). In "A New Type of Intellectual: The Dissident," Kristeva suggests that "real female innovation (in whatever field) will only come about when maternity, female creation and the link between them are better understood" (Kristeva \& Moi, 1986: 298).

Kristeva also rejects what she sees as the second phase of feminism because it seeks a uniquely feminine language, which she thinks, is impossible. Kristeva (1995) does not agree with feminists who maintain that language and culture are essentially patriarchal and must somehow be abandoned. On the contrary, Kristeva insists that culture and language are the domain of speaking beings and women are primarily speaking beings. Kristeva endorses what she identifies as the third phase of feminism which seeks to reconceive of identity and difference and their relationship. This current phase of feminism refuses to choose identity over difference or vice versa; rather, it explores multiple identities, including multiple sexual identities. (Oliver, 1998, para. 13) 
Kristeva proposes that there are as many sexualities as there are individuals (Switala, 1999). Kristeva et. al (1981) also define the phases of feminism by setting up her own hierarchies:

The most 'primitive' would be the position that women in the United States would call liberal feminism. While not denying the political importance of this phase, the struggle for universal suffrage, equal pay for equal work, abortion rights, and so on, Kristeva nonetheless sees the limits of this ahistorical, universalist; globalizing stage. (Saldivar-Hull, 1991: 3)

Next on the evolutionary scale is the radical feminist phase, a reductive, essentialist feminism where women "demand recognition of an irreducible identity, without equal in opposite sex and, as such, exploded, plural, fluid" (Kristeva et. al, 1981: 191). It is a mixture of these two feminisms that constitutes the dominant European feminism. For Kristeva it is the final "signifying space" that she privileges (Saldivar-Hull, 1991: 3). With her "optimism that there has been a real change in sexist institutions of power" (Saldivar-Hull, 1991: 4); Kristeva abandons "the very dichotomy man/woman as an opposition between two rival entities" (Kristeva et. al, 1981: 331). This dichotomy, she (1981) claims, belongs to the metaphysical. "What can 'identity,' even 'sexual identify,' mean in a new theoretical and scientific space where the very notion of identity is challenged?" (Kristeva et. al, 1981: 333).

Kristeva rejects feminisms that rally around the ideal of "woman" or the "feminine," even in the name of feminine specificity. She does not believe in a feminine essence (Kristeva, 1987). Rather, she criticizes feminist movements which maintain some fixed 
notion of a feminine essence or "woman" because they cover over differences between individual women. Elizabeth Grosz (1990) argues that Kristeva's concept of the semiotic in language is associated with the feminine but cut off from woman. Grosz maintains that Kristeva's

critical attitude to feminist texts is, I suggest, a function of the slippage she effects from the concept of woman to that of the feminine, a displacement of the question of identity by differentiation. By means of this manoeuvre, she is able, on the one hand, to evacuate women of any privileged access to femininity, and on the other, to position men, the avant-garde, in the best position to represent, to name or speak the feminine. (Grosz, 1990: 95)

Grosz (1990) claims that, as a result, Kristeva denies sexual difference by denying women any specific sexual identity. She complains that Kristeva refuses to see "the sexed body as the site of the inscriptions of masculine and feminine attributes" (Grosz, 1990: 96). For the purposes of feminist theory, it is important to recognize that "Kristeva does not deny that it may be necessary for women to use an identity as "woman" or "feminine" in order to get things done" (Oliver, 1993: 97). Kristeva acknowledges that women's liberation has depended on such identity politics, but at the same time, she argues for the need to go beyond identity politics. She wants a politics of individuals rather than of groups. She wants multiple sexualities: "I have the deep conviction that every person has a very particular sexuality" (Kristeva, 1984b: 24). Kristeva (1984b) criticizes feminisms which tend to classify by groups_-"woman," "heterosexual," "homosexual" (1984b: 23) — which are made of individuals with important differences. To identify people 
according to these types of classifications is to deny these differences. Kristeva does

recognize, however, that

struggles in the name of group identities will and must continue in order to overcome oppression. She acknowledges that feminist movements have made great advances by using the group identity "woman." Still, this tactic has its dangers. Kristeva warns that it must be practiced with care, or politics of liberation become mere politics of exclusion and counterpower. Political interpretations that claim group identities can lead to "dogmatism," "violence," and the annihilation of personal differences. (Oliver, 1993: 98)

Kristeva claims that women's movements "should demand attention to individual difference, particularly sexual differences and all individuals have their own unique sexuality" (1984b: 24). Yet, she admits that

at first the 'we women' of feminism got things done. Now, however, this 'we' has become problematic in so far as it covers over individual differences in the same way that the universal concept "man" has done. She points out, however, that even while each individual participates in this 'we', is the source of this 'we,' each is also its victim. This has become the fate of contemporary feminism. Individual women have become the victims of feminism's totalizing 'we.' Therefore, Kristeva endorses only those aspects of the feminist movement that have served to break down identity, including sexual identity, and render it ambiguous. (Oliver, 1993: 98)

As Foucault says, struggle for emancipation are struggles that question the status of difference on the one hand-:

people struggling for emancipation assert the right to be different and they underline everything which makes individuals truly individual. On the other hand, they attack everything which separates the individual, breaks his links with others, splits up community life, forces the individual back 
on himself and ties him to his own identity in a constraining way. (Foucault, 1983: 211-12)

Kristeva (1980) argues that "feminism can and should operate without fixed identities or women, feminine, or even female" (Oliver, 1993: 99). Each one of us, says Kristeva (1980), should find her own language:

This language will be by nature symbolic. Women cannot merely jump outside of the Symbolic order or patriarchy. This is why Kristeva criticizes feminists who argue that the Symbolic is essentially partriarchal and must be abandoned. Kristeva insists that without the symbolic dimension, there could be no love. And she wants nothing to do with feminists who would do away with love. (Oliver, 1993: 101)

In this sense, we can say that Kristeva is a feminist, whose foresighted theories on sexual identities and female identities provide the modern feminists with balanced views on the male-female relationship.

All in all, the problem of how to arbitrate between women's identity or equality and women's difference has been a central problem for feminists for centuries. "It requires that women take up their identity as an identity-in-process in order not to be linked to that identity in an oppressive way. Women need to take up identity always tentatively and never completely in order to avoid the annihilation of [our] difference" (Oliver, 1993: 110). Next, we will review Luce Irigaray's thoughts on feminism briefly. 


\section{$\underline{\text { Luce Irigaray }}$}

After the publication of Speculum of the Other Woman in 1974, Luce Irigaray, trained with the psychoanalyst Jacques Lacan, was expelled from the Freudian School of Paris, the psychoanalytic institute founded by Lacan because of her feminist beliefs and outspoken critiques in that book. As a radical feminist, Irigaray claims that "there is no place for the female subject within Lacan's theoretical models" (Burke, 1981: 292), and Lacanian theorists do not know or care what women want or feel. In other words, female pleasure and female desire are ignored in patriarchal culture. Next, I will compare and contrast Freud/Lacan and Irigaray on woman's desire in detail, through which a link between psychoanalysis and feminism will be set up.

According to traditional Freudian theory, penis is "a symbolic object dividing the two sexes in giving power to those who have it (presence of it)" and it "signifies and produces the exclusion of women" (Zhang, 2007). Since "the female sex offers nothing to see, female sexuality becomes the 'hole' in psychoanalytic theory" (Burke, 1981: 289), therefore, Freud believes that it is hard to predict what a woman really wants. Women may simply desire the penis, because they are regarded as "castrated one" and the penis is what they lack (Armour, 1997: 64). According to Lawtoo, Freud's definition of female sexuality is predicated upon a fundamental lack which deprives the female sexual organ from the status of being "one" (2006: 223). Thus, psychoanalysis "reduces the female genital organ to less than one sex (a 'zero,' or a 'nothingness')" (ibid.). 
Lacan further expressed that "woman does not exist" (Armour, 1997: 64). His theory puts women in phallogocentrism, which is a double centrism that puts phallus in the central position and has the same status of the word of God, as the "signifier of all signifiers" (Burke, 1981: 293). As a result, Lacan generates a simple binary opposition "penis/nothing" which means that male sexuality is based on having a penis, which is privileged because it can be seen; it is visible (and larger); therefore, it is superior. By contrast, a woman's sexual organ(s) cannot be seen; therefore it is inferior and becomes equated with having nothing. That is to say, male sexuality is based on having a penis; female sexuality is based on having nothing. Systematically, Freud/Lacan's psychoanalytical theory "associates woman and the feminine with certain things (nature, darkness, matter, the home, the body, the earth), and man and the masculine with certain other things (spirit, form, intellect, the sky)" (Armour, 1997: 69). In fact, taking male sexuality as the only standard, patriarchal societies regard woman as a form of property of man, and they are blind to sexual difference and female desires (Burke, 1981: 293).

In response to Lacan's infamous "woman does not exist," Irigaray explains it as "descriptive of woman's current status" (Armour, 1997: 66). Since Freud/Lacan's theoretical system is organized in terms of phallus, woman has remained uncaptured by the current phallogocentrism (ibid.). In Speculum of the Other Woman (1985a), Irigaray expresses that in the Freudian and Lacanian psychoanalytic framework, female is defined "as nothing other than the complement, the other side, or the negative side, of the masculine" (Irigaray, 1977: 63). In other words, male sexuality is privileged or superior 
to female sexuality and female sexuality is defined in terms of its relation to men. Therefore, female sexuality is dependent for its existence on male sexuality. It seems that if it does not start from male sexuality or phallus, the female sexuality does not exist. In this sense, the female sexuality in Freud/Lacan' psychoanalytic system, according to Irigaray, is not the sex of individual women, but instead the symbol of "otherness, alterity, the unconscious, and the unspoken" (Madsen, 2006: 19). Irigaray further proclaims that female desire is in fact located in male desire, because whenever we mention it, we have to refer to the penis. Therefore, in this phallogocentric model, woman cannot be a subject in the way man is and lacks the proper language to express their true desire. Green praises Irigaray's Speculum of the Other Woman as a first attempt to deal with female identity when it is accepted that "this is the identity of an Other" (2002: 7). Irigaray is looking for a potential position for women as speaking subjects, which is a process of what she terms "becoming woman" (1985a: 22).

In This Sex Which is Not One (1985b), Irigaray criticizes the Lacanian psychoanalytic theory claiming that "there is no place for the female subject within Lacan's theoretical models" (Burke, 1981: 292). According to Irigaray (1985b), Lacanian theorists do not know or care what women want or feel. Women's voice cannot be heard. Women have to express their desire in terms of the masculine subject, so the desire is actually not their desire; it is but men's desire. The whole theoretical system or culture is organized in terms of phallus. As Irigaray further declared "all Western discourse presents a certain isomorphism with the masculine sex: the privilege of unity, form of the self, of 
the visible, of the specularisable, of the erection" (Burke, 1981: 289). That is to say, all Western discourse or language is masculine in nature, or phallocentric.

Burke (1981) also introduces that Derrida made a small but significant modification for Irigaray. Derrida asserts that Lacanian theory puts woman in "phallogocentrism," which is a term combines "Phallocentrism" and "Logocentrism." "Phallocentrism" means the Phallus is put in the center position and "Logocentrism" is used in its theological sense which refers to the status of God. So phallogocentrism is a double centrism which puts phallus in the central position and has the same status of the word of God, as the "signifier of all signifiers" (Burke, 1981: 293). The phallogocentric system generates the simple binary opposition "penis/nothing." That is to say, male sexuality is based on having a penis, which is privileged because it can be seen; it is visible (and larger); therefore, it is superior. In contrast, a woman's sexual organ(s) cannot be seen; therefore it is inferior and becomes equated with having nothing. In other words, male sexuality is based on having a penis; female sexuality is based on having nothing. Therefore, in this phallogocentric model, according to Irigaray, woman cannot be a subject in the way man is and lacks the proper language to express their true desire. In fact, woman is seen as a form of property of man.

In This Sex Which is Not One (1985b), Irigaray challenges phallogocentrism and explores the possibilities of a system that is not set up on this simple binary opposition of "penis/nothing." This system will privilege the feminine as much as the masculine. She intends to find out something in woman that can balance the Phallus, and that the female 
sexuality can be based on. Irigaray (1985b) declares that the female sex organ, the vulval lips, can serve as the basis for female sexuality and guarantee the "multiplicity of female desire" (Lawtoo, 2006: 234). Since the female sex organ is plural, or in fact, "Woman has sex organs just about everywhere" (Irigaray, 1977, as cited in Humm, 1992a: 204), so it is diffuse and fluid in style.

Irigaray (1985b) further claims that women's sexual pleasure or desire cannot be expressed by the dominant, ordered, "logical," masculine language (Zhang, 2007), and "all Western discourse presents a certain isomorphism with the masculine sex: the privilege of unity, form of the self, of the visible, of the specularisable, of the erection" (Burke, 1981: 289). That is to say, all Western discourse or language is masculine in nature, or phallocentric. In order to create a realm where "woman is no longer defined in relation to man as his negative, other, or as lack" (Burke, 1981: 296), Irigaray believes that it is necessary to create a totally new female language with female logic to express women's desires. According to Irigaray (1985b), it is in language that her utopia (literally, no place) can be produced, where "difference can be articulated outside of hierarchical and dialectical binary oppositions" (Lawtoo, 2006: 236). Accordingly, Irigaray praises "the radical otherness of women's eroticism" by emphasizing the connections between women's bodies and women's meaning making in language (Humm, 1992a: 203). Therefore, "female language is plural, autoerotic, diffuse and indefinable within the rules of masculine logic, because female sexuality cannot be articulated within the Atistotelian logic" (Burke, 1981: 289). That is to say, female language should reject masculine reason, 
which is solid, unilateral and logical. Female language is fluid and unstable in meaning. In this way, "speaking (as) woman would, among other things, permit women to speak to men" (Lawtoo, 2006: 236). It seems that Irigaray is speaking from another territory, or the other side of the looking glass. Her approach is through deconstruction which according to Burke is not the end of the story, because "each deconstruction can be deconstructed" (Burke, 1981: 295), so "if one adopts the strategies of deconstruction, then no single text can pretend to have made a definitive statement" (ibid.). In general, Irigaray's emphasis on female sexuality, or the difference between masculinity and femininity, is to "disrupt the tyranny of unitary meaning and logocentric (phallogocentric) discourse" (Zhang, 2007).

Women's desire is further discussed in "When Our Lips Speak Together" (1980), in which Irigaray further examines "the ways in which women speak to each other and can disrupt symbolic or social language" (Nye, 1998, as cited in Humm, 1992a: 203). Irigaray (1980) symbolizes the mother-daughter relationship in this essay in order to "assert the importance of female affiliation" (Humm, 1992a: 203). Moreover, Irigaray (1980) believes that feminine writing or text also invites simultaneous multiple readings, including 'the 'two lips' of women's mouths, the 'two lips' of women's labia, mother and daughter, woman-friend and woman-friend, woman-lover and woman-lover, human-woman and divine-as-woman" (as cited in Armour, 1997: 73). In addition, Irigaray (1980) also seeks to rebuild the love relationship between women. In the phallogocentric system, or in the dominant male logic, the relationships of women with 
their mothers and with other woman are devaluated or not permitted by the dominant discourse. As Grosz (1990) puts it, Irigaray

attempts to traverse the Lacanian mirror of male self-representation which confirms woman in the position of man's specular double or alter-ego. His is a mirror, she implies, that can only reflect the masculine subject for whom it functions as a form of self-externalization. Her project, instead, like Alice's (A-Luce), is to pass through the looking glass into the 'wonderland' of women's own self representations 'on the other side'. In place of the 'platitude'/flatness, of the platonic mirror, Irigaray substitutes the speculum, the curved, distorted medium of women's self-representation. Her 'mirror', the speculum, surrounds, and is surrounded by, the contours and specificity of the female body. It is not a device of self-distance, but of self-touching, an implicated rather than disinterested self-knowledge. It represents the 'other woman', not woman as man's other, but another woman, altogether different from man's other. (Grosz, 1990: 173-174)

Irigaray finds that in the writing of Freud/Lacan's psychoanalysis in particular, and "throughout the entire Western philosophical tradition from Plato to Hegel, women are the 'sex' with is not 'one"' (Humm, 1992a: 203). Women's true sexuality and desire is not represented and the feminine is suppressed. "Only through the celebration of women's difference, of their fluidity and multiplicity, can women escape the conventional Western representations of women" (ibid.). This difference is best represented in language field. The creation of female language based on female sexuality is a way to express female desire.

According to Burke (1981), Irigaray's ideas are innovative and help to change our minds in two aspects: (1) the differences between male and female sexuality are emphasized. The multiple or plural form of female sex organ can be used to be the 
opposite of Phallus. In other words, instead of having the binary opposites such as "phallus/nothing," we have "phallus/vulval lips." (2) Theoretically speaking, Irigaray is innovative to intend to create a realm where female sexuality is not defined in terms of phallus, and women have an appropriate language to express their true desire. Her female language "conflates genitalia and the mouth, anatomy and gender, 'femaleness' and femininity" (Lawtoo, 2006: 223). This strategic move allows her to "dismantle the psychoanalytical focus on 'sameness' ('one' sex) while promoting the 'difference' ('at least two') inherent in female sexuality" (ibid.). Irigaray aims at the deconstruction of dominating masculine discourses and the stifling of the female voice and hence, of female subjectivity.

However, Irigaray's ideas are not perfect: first, she just puts forward a mode similar to Phallus. The vulval lips have the same function as Phallus and they cannot simply replace the Phallus; In fact, she didn’t deconstruct the binary opposition "penis/nothing," instead, she puts forward a solution—-"penis/ vulval lips"—-that just "shifts the valuation of masculine and feminine but retains the binary categories" (Zhang, 2007). Second, the change of female language should take place within the existing language or discourse system. It is impossible to create a totally new female language with female logic to express women's desire. As for Burke (1981), Irigaray is like the heroine of the famous Children's story Alice through the Looking Glass ([1872] 2010) by Lewis Carroll who goes into the other side of a mirror, a dream world. However, it is good to have dreams, but whether the dreams can come true is another story. 
To sum up, as the forerunner of psychoanalysis, Freud says that the Father greatly influences the child. Lacan argues for a revision of Freud. The women psychiatrists, or the Third Wave Feminists, who worked with Lacan have shown that Freud is wrong. They claim that Freud had devalued women, and mention that the child was in the mother's womb and that she greatly influenced the child. They reversed Freud. The Third Wave Feminists, especially Julia Kristeva, think that this puts the women's movement in a whole new light, one that is balanced. Kristeva believes that

a feminist practice can only be negative, at odds with what already exists so that we may say 'that is not it!' and 'that's still not it'. In woman, I see something that cannot be represented, something that is not said, something above and beyond nomenclatures and ideologies. (Marks \& Coutrivron, 1980: 137)

According to Grosz (1990), the traditional feminism has only the function of saying no, which is the "only possible political gesture that may have some effect from outside," because "women do not occupy the subject-positions accorded to men in patriarchal symbolic order, that is, because women are positioned as castrated and men as phallic, women are not inside the symbolic in the same way as men" (Grosz, 1990: 166); however, Kristeva's "mode of textual analysis, the analysis of the interplay of semiotic and symbolic processes, is tied, as she sees it, to modes of sexual differentiation within each sex and each text" (ibid.). This differentiation does not divide men and women into distinct categories, nor position them as "identities." For Kristeva, "feminism should aim at the annihilation of all identity, especially sexual identity" (Grosz, 1990: 167). Within 
such a feminism, which Kristeva regard as her own,

the very dichotomy man/woman as an opposition between two rival entities may be understood as belonging to meta-physics. What can 'identity' or even 'sexual identity' mean in a new theoretical and scientific space where the very notion of identity is challenged... What I mean is...the demasscification of the problematic of difference...( Kristeva, 1981: 34)

As Grosz (1990) summarizes,

ultimately she [Kristeva] regards feminism, in opposition to psychoanalysis, as a temporary rather than an interminable analysis, one that, ideally, should aim at its own demise. In her view, feminism has aimed towards equality of opportunity, it has either (over-valued) maternity or it ignores the 'real experience' of maternity, resulting in a rejection of maternity outright. (1990: 166-167)

In fact, the current wave of Feminism that is characteristically associated with Lacan,

Kristeva, and Irigaray is still emerges into the present as a new wave enters the cove and emerges onto the beach. We are living in that context of the situation. 


\section{CHAPTER VI}

\section{CONCLUDING REMARKS}

I began this dissertation with the metaphor of an epistemic rupture. It is a metaphor that Foucault (1972) mentions in his Archeology of Knowledge. The metaphor is an interesting one because it assumes that an earthquake was responsible for unearthing the underlying layers of the earth in which past knowledge were stored. By comparing the past with the present, one could understand the present. Earthquakes also create tidal waves (tsunamis) when seismic events occur close to shore. These waves of energy travel beneath the surface of the sea and emerge several continents away as a tsunami. Hence, the analogy was drawn between earthquakes and their tidal effects. The first big seismic upheaval was caused during the nineteenth century when Susan B. Anthony (1820-1906) fought for women's rights. She is equated with a seismological force that caused great social change. She also functions as a seismologist because she predicted future after-shocks. We refer to her impact as the first wave of feminism. The next big seismic event took place in the twentieth century with the work of Simon de Beauvoir, The 
Second Sex ([1949] 1984). Her earthquake could be seen as an after-shock of the original seismic event, but it was too strong for that. It was really a new seismic event, a new earthquake. We consider the social forces that she unleashed to be the second wave of feminism. Rebecca Walker and her work To Be Real: Telling the Truth and Changing the Face of Feminism (1995) introduces the Third Wave Feminism, but it was more of an after-shock than a new earthquake. Now, we are entering into the twenty-first century and the new upheaval is being caused by Julia Kristeva $(1980,1982,1984 a, 1987,1995)$. Her focus is on psychoanalysis and language. She studied with Jacques Lacan and uses his research as the basis for her new approach. Although she does not claim to be a feminist, her works have been used by advocates of the women's movement as evidence of the new wave in feminism. Her work and that of Lacan form the primary focus of this concluding chapter. Prior to discussing these major figures, let us review the literature leading up to this new view on feminism.

\section{Review of the Three Waves}

The First Wave Feminism (1848-1920s) focuses on the de jure inequalities, or officially mandated inequalities, and was concerned primarily with establishing that women are human beings and should not be treated like property. It began in the late 18th century with the publication of Mary Wollstonecraft's Vindication of the Rights of Woman ([1792], 2001), and ended when the Nineteenth Amendment to the U.S. Constitution was 
passed, granting women the right to vote. This major victory of the movement also included the opening of higher education for women; reform of the girls' secondary-school system, including participation in formal national examinations: the widening of access to the professions, especially medicine; married women's property rights, recognized in the Married Women's Property Act of 1870; and some improvement in divorced and separated women's child custody rights. Most importantly, it challenges the ideology of "separate spheres" and encourages women to ask for both personal and economic independence. However, we have to say that nothing serious has been changed at this stage although women were now accepted as humans, with the ability to vote. Moreover, there were still arguments in politics and education against the right of women to vote, such as "their limited brains would never be able to understand politics, etc..." and "women would never be able to learn what they were supposed to learn" (Luka, 2001, para.1). Women were seen as second class, below men. Even if they have most rights, they still don't have the status.

In the business world, for example, there were businesswomen who belonged to the group of so-called "New Woman" - "an independent person with a public role" (Todd, 1993: xxvii), who is "determined and fiercely independent, she was [is] a business executive, devoted to her family, a dedicated consumer of every conceivable new technology, and clear about women's proper roles-everything imaginable but the priesthood and the presidency" (Todd, 1993: xi). However, women's managerial role was well defined after the First Wave Feminism: "supportive, nurturing, lower in status and 
pay than that of men, composed of skills perceived to be intrinsically female, outside of the promotional track for male management positions, and expendable" (Kwolek-Folland 1998: 201). In fact, these businesswomen did not keep their jobs long. Most of the time, they quit their jobs after they were married and had children. Generally speaking, the first-wave of feminism was monumental to the women's movement, however, without the continuing second-wave, there would be no hope for women and feminism in current times.

As I discussed in Chapter I, the Second Wave Feminism (1960s-1980s) emerged in the wake of World War II, during which many women entered the workforce, and would have arguably ended with the ratification of the Equal Rights Amendment (ERA), had it been ratified. Unlike the first-wave, the second-wave's focus was on the de facto inequalities, or unofficial inequalities, and also felt that de jure and de facto inequalities were inextricably linked issues that needed to be addressed together if there was ever going to be any hope of change. Therefore, its goal is the total gender equality-women as a group having the same social, political, legal, and economic rights that men have.

The period following World War II saw many changes in the U.S. One of the most significant was that the women who had rallied to the workplace to fill the gap left by the fighting men didn't necessarily want to return to their old roles as homemakers. Many of them enjoyed working outside the home, and wanted to continue. Furthermore, the old stereotypes of what was "appropriate" work for women had been seriously undermined. There were several major moments during this wave, such as, Title VII of the Civil Rights Act of 1964 passed, Formation of NOW, the rise of radical feminism during the 1970s, 
Title IX in the Education Amendments of 1972 passed, the Feminist Sex Wars of the late 1970s and 1980s, and the Roe vs. Wade decision decided. It also tried and failed to add the Equal Rights Amendment to the United States Constitution. These movements and endeavors, together with Betty Friedan's cornerstone book The Feminine Mystique (1963), helped encourage women to "seek new roles and take on new responsibilities and to find their own personal and professional identities rather than have them defined by the outside, male-dominated society" (Hamby, 2006: 201). The traditional ideal woman's destiny of "finding a husband and bearing children" was challenged. In fact, the slogan "the personal is political" sums up the way in which Second Wave Feminism did not just strive to extend the range of social opportunities open to women, but also, through intervention within the spheres of reproduction, sexuality and cultural representation, to change their domestic and private lives.

With the encouragement of the Second Wave Feminism and the social conditions such as national monetary inflation, marriage at a later age, and soaring divorce rates, more and more women entered into higher education and the paid workforce. As a result, there was a considerable increase in women's earnings during the postwar period. This increase in income enables women to become economically independent and has reduced the likelihood of poverty for a given female-headed family despite the overall "feminization of poverty" (Caldwell, 1982: 90). In this case, women's attitudes toward their roles in society changed most dramatically during a comparatively brief span of time, the late 1960s and early 1970s. They became what Kobrin $(1973,1976 \mathrm{a}, 1976 \mathrm{~b})$ 
called the "primary individuals," who "live as heads of separate households, as well as the small proportion (mainly young) who head households containing nonrelatives" (Kobrin, 1976b: 233). In the broader sense, they have at least the potential for being economically self-sufficient and socially autonomous. They also entered traditionally male occupations (e.g., managerial positions and the professions) in much greater numbers and their self-identities and social identities began to take on new looks. Before we discuss the Third Wave, we would like to summarize these changes by focusing on white American corporate businesswomen and their new definition of womanhood from three aspects.

First, these businesswomen began to seek long-term careers rather than just regarding their work as jobs. Before WWII and the Second Wave Feminism, women identified family as the absolute priority. The reason why most businesswomen kept their jobs was that they wanted to make more money to support their families. In other words, most of them saw work as only a temporary or occasional source of family income. If there were enough income from their husbands, they would quit their jobs after marriage. In addition, their work itself was mostly clerical work which had little decision power. However, throughout the 1960 s women began to pursue their own careers. "Market work is a socially acceptable alternative to domesticity in providing women with a means of identity. Rather than structuring their lives to accommodate family needs and priorities, women increasingly choose a life course that maximizes their individual potential, inside and outside the family" (Caldwell, 1982: 122). According to Wandersee, "they were in a 
state of heightened awareness with respect to the new social significance given to employment outside of the home" (1988: 128). They have "found themselves pursuing careers with the increasingly accepted notion that their economic needs and career goals are as pressing as are men's, particularly owing to their increasing roles as heads of households" (Boozer, 2002: 50). As Alpenfels (1962) puts it:

The high recognition given the successful secretary and the satisfactions she derives from being closely identified with the successes of her employer often combine to forestall her desire to move from the clerical to the professional category. The stereotype of the American woman as the helper to the man is perpetuated and, besides, it is both comforting and safe. (1962: 80)

Most of the time, these businesswomen had to find ways to deal with the conflicts between femininity and career achievement. In their workplace, they tried their best to be respected by others for their skills and abilities, where they were able to develop supportive work-centered relationships with others and where as a consequence "they believed they had successfully mastered the environment" (Bryant, 1984: 152). Even more important, because of their concentration on the work to be done and their own confidence that they "were receiving very few negative signals about being a woman" and "they deliberately sought to minimize the possibility of this happening by seeking to establish relationships based on task and competence, and allowing any closer ties to develop solely on that basis" (ibid.). According to Hennig and Jardim (1976), this is a period in which they finally came to terms with who they were because: 
They were finally able to accept with who they were. They were finally able to accept the fact of their sexual identity, not as "special" or "different," but even in others' terms as an essential part of the person they were, and to bring that identity and their careers together into a coherent whole. They no longer felt driven to prove that they were persons despite the disadvantage of having been born women. They were women. They were managers. And they were capable of being both. They took account of what they had become and they redefined where they wanted to go. Their redefinition represented no drastic change in the over-all direction of their careers; rather it had to do with self-acceptance and with a bringing into balance and perspective parts of themselves which they had previously kept carefully apart. (1976: 174)

Second, their relationship with their families changed. After Industrialism, the popular idea that "a woman's place is in the home" brought separation of the home and workplace. The "cult of true womanhood" defined women of the middle and late $19^{\text {th }}$ century as domestic, pious, pure and submissive-the qualities for the "angels of the household." Women's roles became more narrowly defined as mothers and homemakers, while men earned a living away from home. Yet the decline in fertility and the increase in life expectancy, as well as "the economic vulnerability of such separate roles for men and women," brought further change (Caldwell, 1982: 27). Beginning from the 1960s, American women clearly indicate that they are spending less of their lives in traditional family living arrangements. "Their economic, social, and emotional needs will increasingly met by combinations of individuals outside the household and outside the family unit. Family-based networks will continue to decline in importance as more women remain single, migrate to find or keep a career, have fewer children, get divorced, and (perhaps) remarry" (McLaughlin et al., 1988: 5). However, this does not mean that 
family is no longer an important social institution. "Most women still value marriage and the family, and still spend a significant part of their lives as wives and mothers. Nevertheless, the family's influence over their lives is declining" (McLaughlin et al., 1988: 6).

As for businesswomen, they want to find great satisfaction in careers without entirely compromising their mates and/or their children. In other words, they want to keep both happy families and successful careers. Of course, most of the time, they have to find a balance between family and career. Mary Kay Ash said that "wearing the three hats of a full-time wife, mother, and career woman is no easy task" (Ash, 1995: 33). If a career woman has young children who need her concentrated care and attention, she will try her best to plan her daily schedule carefully, keep in touch with new developments in her profession and be prepared to take it up again as soon as possible. Given the modern aids to housekeeping, this is not impossible. In fact, her strong ambitions to climb the corporate ladder don't easily blend with expectations of being ideal wives and moms. Although there are conflicts, many businesswomen believe that the logical way to deal with them is to show everyone including themselves that they are perfect in both roles. On the whole, the basic relationship of women to the family has changed such that "even in the fact of economic prosperity we do not expect women to return to a dependent, family-centered lifestyle" (McLaughlin et al., 1988: 8).

Third, their relationship with their male counterparts, especially those in the workplace, also greatly changed. As we have mentioned that businesswomen's working 
role before WWII was basically "supportive and nurturing" (Kwolek-Folland 1998: 201), the businesswomen were regarded as help mates whose job description even included pouring coffee for their bosses. In some cases, the purpose of working for the office women was to find ideal husbands. However, after $1960 \mathrm{~s}$, as the businesswomen began to put more energy in pursuing their own personal career, they are more independent and demand equality with their male counterparts. They know that there will never be absolute equality because a man's career means more to him than just a weekly paycheck, and "his self-image, self-confidence and feelings of self-worth depend, to some extent, on his performance at the office," however, although woman's career means more than just a weekly paycheck, too, "her self-image depends on her ability to manage her career and family responsibilities, too" (Scott, 1977: 63). In addition, the success in men's work is seen as necessary for the well-being of the whole family; organizational requirements for overtime, travel, and relocation are seen as necessary evils to be fully supported by the wife (Wallace, 1982). This division of labor and these assumptions result in what has been called the "two-person career"-two people, in their different ways, enhancing one career. Corporate organizations, of course, have been implicitly aware of this situation:

most would much prefer to have a married man in a top position, for he has a support system in his personal as well as in his occupational life. Women have never had such double support system, as is evident by the often repeated lament of the career woman that all she needs is a wife. Rather, the 'best' that most career-oriented women can do is not to have a family at all. (Wallace, 1982: 47)

The businesswomen after 1960s were fully aware that, in comparison to men with 
traditional family support systems, they are doubly deprived, and the workplace is impersonal and objective, and roles are defined by performance. Therefore, they usually "low-keyed who they were and used competence as their primary definition of themselves" (Bryant, 1984: 152), which

allowed and compelled the men around to deal with them on the most objective basis available - their own individual capacity, a basis which they controlled. It permitted men to say quite legitimately: 'In spite of the fact that she's a woman she's terribly good at her job-and I can and will and need to benefit from working with her.' (ibid)

All in all, from the above-mentioned three aspects, we can see that businesswomen after 1960s have formed their new self-identity and their new definition of womanhood. For the first time in history, women want it all: family, career, equal relationship with men, especially in the workplace, and everything....Their lives are profoundly affected by the social roles she occupies, such as wives, mothers, and jobholders. The significant role transitions after the Second Wave Feminism are obviously important for individuals, but they are also important for the society at large. The majority of white American businesswomen who move into the labor force in the 1970s "[seek] individual solutions to the inevitable tensions in both the private and public spheres of their lives" (Wandersee,

1988: 128). However, the timing and sequencing of these transitions and adaptations

determine the size and fundamental character of a society's primary social institutions, such as the educational system, the economy, and the family, which are all grounded in the expectation that individuals will conform to the typical patterns of age and ordering that characterize entry into and exit from these institutions. (McLaughlin et al., 1988: 10) 
In fact, these businesswomen became more real to themselves and they knew what they really want. According to Bryant (1984),

they became increasingly aware that their own need to be what they felt they were resulted in their behaving toward others in ways which others perceived to be more honest and real, and there were many outcomes of this development. In their accounts of this period they consistently added the word "happy" to their descriptions of themselves, where previously they had used the words "rewarded" and "satisfied." They became aware of a new sense of self-acceptance, of a coherent, put-together self. They enjoyed the rediscovery of social skills they had long abandoned. They said that for the first time they felt able to discuss openly their earlier feelings about work and a career in relation to marriage - they felt free to talk about their new choices in ways which no longer left them with the uncomfortable feeling that somehow others saw them as diminished women for having chosen as they did. (Bryant, 1984: 176)

The Third Wave Feminism began in January 1992, when Rebecca Walker, daughter of author Alice Walker and godchild of activist Gloria Steinem, wrote an article entitled "I Am the Third Wave" for Ms. Magazine, in which she articulated a rage, anger, and hunger for action. It arose as a response to the failures of and backlash against the Second Wave Feminism in the 1990s. It seeks to challenge or avoid any universal definition of femininity, or what it deems the second wave's "essentialist" definitions of femininity, which often assumed a universal female identity and over-emphasized experiences of upper middle class white women. As Shukla puts it: "third-wave feminism grew out of the belief that second-wave feminism ignored the idea of intersectionality and falsely attempted to treat the experience of white, middle class, heterosexual women in Women countries (particularly the United States) as representative of a universal women's 
experience" (2006: 11).

Concerning what is a feminist, Rebecca Walker writes in the introduction of To Be

Real: Telling the Truth and Changing the Face of Feminism (1995):

For many of us it seems that to be a feminist in the way that we have seen or understood feminism is to conform to an identity and way of living that doesn't allow for individuality, complexity, or less than perfect personal histories. We fear that the identity will dictate and regulate our lives, instantaneously pitting us against someone, forcing us to choose inflexible and unchanging sides, female against male, black against white, oppressed against oppressor, good against bad... Whether the young women who refuse the feminist label realize it or not, on some level they recognize that an ideal woman born of prevalent notions of how empowered women look, act, or think is simply another impossible contrivance of perfect womanhood, another scripted role to perform in the name of biology and virtue. (1995: xxxiii)

A post-structuralist interpretation of gender and sexuality as its central ideology, the third-wave feminism deals with issues that seem to limit or oppress women, as well as other marginalized identities. Consciousness raising activism and widespread education is often the first step that feminists take toward social change. In their book Manifesta: Young Women, Feminism and the Future (2000), Jennifer Baumgardner and Amy Richards write:

Consciousness among women is what caused this [change], and consciousness, one's ability to open their mind to the fact that male domination does affect the women of our generation, is what we need... The presence of feminism in our lives is taken for granted. For our generation, feminism is like fluoride. We scarcely notice we have it-it's simply in the water. (2000: 16-17) 
Some third-wave feminists prefer to call themselves feminists and few of them even bother to define feminism-"perhaps they see feminism as the domain of their mothers. Perhaps they see it as journalists do, simply as an image. In any case, they critique this thing called feminism and skip over what feminism is composed of-women's lives" (Baumgardner \& Richards, 2000: 255). In fact, the word feminist itself can be misinterpreted as insensitive to the fluid notion of gender and the potential oppressions inherent in all gender roles. The Third Wave Feminism claims that it allows women to define feminism for themselves by incorporating their own identities into the belief system of what feminism is and what it can become through one's own perspective. Baumgardner and Richards (2000) suggest that feminism can change with every generation and individual:

The fact that feminism is no longer limited to arenas where we expect to see it-NOW, Ms., women's studies, and red-suited Congresswomenperhaps means that young women today have really reaped what feminism has sown. Raised after Title IX and 'William Wants a Doll', young women emerged from college or high school or two years of marriage or their first job and began challenging some of the received wisdom of the past ten or twenty years of feminism. We're not doing feminism the same way that the seventies feminists did it; being liberated doesn't mean copying what came before but finding one's own way-- a way that is genuine to one's own generation. (2000: 130)

The Third Wave Feminism has by no means ended. On the contrary, it is just a beginning and Julia Kristeva's thoughts bring a new earthquake, although she refuses to claim that she is a feminist. 


\section{$\underline{\text { Contributions and Implications }}$}

The purpose of this dissertation is to explore how the epistemic ruptures, WWII and the Second Wave Feminism, change American society between 1963 and 1985. From a humanistic and historical point of view, it focused on (1) the "self-identity" of modern white American corporate businesswomen between 1963 and 1985, (2) the change of their self-identity in comparison with the historical period between 1920 and 1963, and (3) how their self-identity is socially and culturally constructed by analyzing evidence from historiography, literature, and popular culture. The major theories used for the hermeneutic interpretation of the cultural evidence include the identity theories, social constructivism, and post-structural feminism.

The results show that the self-identity of the white American corporate businesswomen between 1963 and 1985 has changed great deal. First, in the attitude toward their work, they began to seek long-term careers in the business world, the traditional man's word, rather than just regarding their work as temporary job which they would give up if there were enough income from their husbands; they believe that they can find great satisfaction in careers. Second, in their relationship with their families, they tended to believe that they should wear all the hats of full-time wives, mothers, and career women, which means that they wanted to find great satisfaction in careers without ignoring their mates and/or their children; most of the time, they have to find a balance between family and career. Third, in their relationship with their male counterparts, 
especially those in the workplace, they changed from supporters of businessmen to the ones who worked hard to be respected for their skills and abilities. All in all, after the early 1960 s, businesswomen began to surface as an organized segment of society. Their role of both women and business persons gradually changed people's way of life and "began to generate a positive image of ourselves [themselves] as persons in our [their] own right" (Kozmetsky, 1989: 138-139). The period between the late 1970s to early 1980s was perhaps the decade when "women were most optimistic about the possibility of merging husband, children, and major-league jobs" (Collins, 2009: 293).

However, the second wave feminist movement did not solve all the problems of the working women. They still suffer from a series of problems. In her 1981 book The Second Stage (1998), Betty Friedan argues that there has been "a blind spot in feminism that is both personal and political in its implications and consequences" (1998: 22). She is referring to the letters she receives from young women asking how they can possibly combine a career and a marriage and motherhood without making terrible compromises, such as "How can I have the career I want, and the kind of marriage I want, and be a good mother?" "I can't count on marriage for my security—look what happened to my mother-but can I get all my security from my career?" and "Can I make it in a man's world, doing it the man's way? What other is there? But what is it doing to me? Do I want to be like men? What do I have to give up? What are the tradeoffs?" (Friedan, 1998: 22-23) Neither Friedan nor other feminist have answers for these types of questions, but women are going ahead anyway, trying the best they can to "have it all." Indeed, although 
the "new women" after 1960s felt "rewarded" and "satisfied" toward their newly gained "equal status" with men, we should not deny the fact that they are still suffering from the "double burden of working wives and the accompanying feminist aspiration that women can, through their own heroic effort, "have it all"' (Currie, 1999: 28). As Friedan (1998) argues:

after nearly twenty years of the women's movement, it becomes clear that most women are still saddled with the work they used to do in the family (serving the physical needs of children, men, home) in addition to their hard new "male" jobs, at a price of fatigue and stress only superwomen can endure. Or they are facing economic misery in divorce and the loss of whatever power they had through that "female" family role-devalued and sometimes even replaced by other women who got into the men's world and sometimes took away their husbands. (1998: 70)

Friedan also raised the specter of "the insatiable demands of female machismo" (1998: 101) which could leave the liberated woman alone in the bedroom with her computer console, frightened and depleted, and lead to a new "crisis of confidence"- "she does not feel grounded in life. She shivers inside. She is depleted by female machismo. And she does not ask the new questions that have to be asked now to get beyond the no-win power battles in the family, and to change the terms at work" (1998: 101-2). According to Friedan (1998), women of the 1980s needed to "recognize the limits rather than the potential of women's power, and the possibilities of transcending those limits through a new kind of power. This new power can be realized only when women reject the false polarization between sexual equality and family" (Currie, 1999: 28). In fact, Betty Friedan made a plea in The Second Stage, for 
"recovering and reaffirming the values women have traditionally held, and she reflected on the consequence of feminism which seems women's traditional roles were devalued - that a worthwhile life could no longer be seen as wife, mother and community worker" (Apter, 1993: 217). In other words, women should seek a balance among the social roles. In general, the feminist movement still has a long way to go.

This study on the social and cultural construction of the self-identity of white American corporate businesswomen between 1963 and 1985 has made the original contributions to knowledge in the following three aspects:

First, although the Identity Theory is popular now, the self-identity of businesswomen is seldom touched. Most research on businesswomen is from sociological point of view. This is partly because businesswomen have little voice in history, literature or popular culture. Through the hermeneutic interpretation of the cultural evidence, this humanistic study digs out the long-buried self-identity of white American corporate businesswomen.

Second, none of the previous research has been done through a cross-disciplinary approach. This study offers cultural evidence from three different disciplines-historiography, literature and popular culture, which helps to depict a comparatively complete picture of the self-identity of white American corporate businesswomen. In addition, this study is cross-disciplinary also because the hermeneutic interpretation of the cultural evidence concerns several other disciplines, i.e. humanities, sociology, psychology, history, and linguistic. 
Third, from a historical point of view, rather than focusing only on one isolated period of time, this study examined the change of the self-identity of corporate businesswomen before and after 1963, as the result of social and cultural construction through the driving forces, i.e. the epistemic ruptures, including WWII and the Second Wave Feminist Movement. As a result, we see a clear picture of these businesswomen's new definition of success and womanhood. In addition, through the comparison of the cultural evidence from two periods of time, this change offers evidence for the upheavals began in early 1960s when many of American institutions were going through periods of great changes. What is more, the scope in this research also extends into the 1990s and demonstrates that Feminism has not achieved the complete success in solving women's old problems, such as balancing among the social roles of wives, mothers and workers. This study claims that the Third Wave Feminism, led by Julia Kristeva and Luce Iragaray, which aims for "the annihilation of all identity, especially sexual identity" (Grosz, 1990: $167)$ and a new subjectivity in the feminist voice, may be the solution. Both Kristeva and Irigaray offer a balanced way for women to avoid looking at their identity in an oppressive way. This new wave is still developing and its balanced views and transgender claims may serve as another epistemic rupture in the new era, which brings feminism to a higher level of humanism. Although it is difficult for theories to change human attitude, bahavior and culture, we know that as time goes by, the later feminists may read and reread the third wave feminist theories, and they may discover the essense of them and wage movements for solving women's problems in society. This process may be similar 
to the influence of Beauvoir's theories on Feminism. Beauvoir finished her seminal work The Second Sex in 1949; however, it took the later feminists many years to rediscover the value of her work. Anyway, we may have to wait for twenty, thirty, or even more years to let this happen, but there is still hope.

Due to the limitation of time and space, this research cannot offer a complete picture of the self-identity of American businesswomen. More research should be done in the future on the following three points. First, more cultural evidence of the black American businesswomen, or businesswomen of other races is needed to see the whole picture of American businesswomen who were active in American society. Second, the discourse of American businesswomen should also include the periods before 1920s and after 1985, and the businesswomen of diverse social classes. In this sense, our study is just part of the whole picture which needs a lot more further research. Third, the three dimensions of the self-identity, i.e. the three types of relationship (1) businesswomen's relationship with their work; (2) their relationship with their families; and (3) their relationship with their male counterparts, especially those in the workplace, are far from enough. Although these are the most important ones, there are a lot of other types of relationships which are relevant to their self-identity, such as their relationship with other businesswomen. Even within these three types of relationships, there are still different layers which should be considered in the future study. For example, in their relationship with their families, we can separate the relationship with their children from that with their husbands, or other family members. In order to get a comparatively complete picture, this research 
oversimplifies these types of relationship to a certain degree.

In conclusion, feminism in the United States is not a topic about which people can generalize, or that men and women must be equal at all costs. Feminism is a movement that has been a necessary journey for American women to travel so that they can negotiate prominent space within feminist thought for subjectivities, and discover and create their own unique identity in the society. 


\section{REFERENCES}

Alcoff, Linda. (1988). "Cultural Feminism versus Post-Structuralism: The Identity Crisis in Feminist Theory." Signs, 13.3, 405-36.

Alpenfels, Ethel J. (1962). "Women in the Professional World." In Beverly Benner Cassara (Ed.). American Women: The Changing Image (pp.73-89). Boston: Beacon Press.

Amott, Teresa L. \& Julie Matthaei. (1996). Race, Gender, and Work: A Multi-Cultural Economic History of Women in the United States (Rev. ed.). Boston, MA: South End Press.

Apter, Terri. (1993). Working Women Don't Have Wives: Professional Success in the 1990s. New York: St. Martin's Press.

Armbruster, Verona. (1932). “Keep quotable!” Independent Woman, Mar, 93.

Armour, Ellen T. (1997). "Questions of Proximity: 'Woman's Place' in Derrida and Irigaray." Hypatia: A Journal of Feminist Philosophy, Vol. 12, No. 1, 63-78.

Ash, Mary Kay. (1981). Mary Kay: the Success Story of America's Most Dynamic Business Woman. New York: Harper \& Row.

Ash, Mary Kay. (1995), You Can Have It All: Lifetime Wisdom from America's Foremost Woman Entrepreneur. Rocklin, CA: Prima Pub.

Averill, J. (1982). Anger and Aggression. New York: Springer-Verlag. 
Awkward, Edgehill B. (2005). "How Sixteen Professional Business Women in the Northeastern USA think about Career Success and how Their Thoughts Influence Their Approach to Achieving It." PhD disst. Columbia University.

Baldwin, E., Longhurst, B., Smith, Greg., McCracken, S. \& Ogborn M. (2005). Introducing Cultural Studies. Beijing: Peking University Press.

Barker, Chris. (2003). Cultural Studies: Theory and Practice. London: SAGE,

Barry, L. H. (1932). "From An Office.” Independent Woman, Feb, 53.

Barthes, Roland. (1967). Elements of Semiology. New York: Hill \& Wang.

Basinger, Jeanine. (1993). A Woman's View. Hanover, H. H.: Wesleyan University Press.

Basow, Susan A. (1992). Gender: Stereotypes and Roles. Pacific Grove, California: Brooks/Cole.

Baumgardner, Jennifer \& Amy Richards (2000). Manifesta: Young Women, Feminism, and the Future. New York: Farrar, Straus and Giroux.

Bayard, Vern. (1947). "Sidelight on the Teacher Shortage: She Still Carries Our Banner." Independent Woman, April, 108.

Beauvoir, Simone de. (1972). Coming of Age. (P. O'Brian, Trans.). New York: Putnam.

Beauvoir, Simone de. (1964). Ethics of Ambiguity. (B. Frechtman, Trans.). New York: Citadel Press.

Beauvoir, Simone de. ([1949] 1984). The Second Sex. (H. M. Pashley, Trans.). Harmondsworth: Penguin.

Bein, Ethel J. (1932). "Is Success Within Our Grasp?-An Interview With Dr. Joseph Justrow." Independent Woman, Feb, 45 and 70.

Bem, Sandra Lipsitz. (1993). The Lenses of Gender: Transforming the Debate on Sexual Inequality. New Haven, Connecticut: Yale University Press.

Berger, Peter \& Thomas Luckmann. (1966). The Social Construction of Reality. Garden City, New York: Anchor Books. 
Bernard, Jessie. (1981). The Female World. New York: Free Press.

Berry, Sarah. (2000). Screen Style: Fashion and Femininity in 1930s Hollywood. Minneapolis: University of Minnesota Press.

Bodichon, Barbara Leigh Smith. (1859). Women and Work. New York: C. S. Francis \& Co..

Boozer, Jack. (2002). Career Movies: American Business and the Success Mystique. Austin: University of Texas Press.

Borus, M. E., Crowley, J.E., Rumberger, R.W., Santos, R. \& Shapiro, D. (1980). Pathways to the Future: A Longitudinal Study of Young Americans. Columbus: Ohio State University Press.

Boyle, G., Kerry, T., \& Mark, O. (2005). One Tough Mother: Success In Life, Business, And Apple Pies, U.S.A.: Graphic Arts Center Publishing Co.

Bromley, Dorothy Dunbar. (1932). "The Worm Turns." Independent Woman, July, 245 and 265 .

Brown, Helen Gurley. (1982). Having It All: Love, Success, Sex, Money, Even If You're Starting With Nothing. New York: Simon and Schuster: Linden Press.

Bryant, Gay. (1984). The Working Women Report: Succeeding in Business in the 80s. New York: Simon and Schuster.

Burke, Carolyn. (1981). "Irigaray through the Looking Glass." Feminist Studies, Vol. 7, No. 2, 288-306.

Burke, Peter J. \& Judy Tully. (1977). "The Measurement of Role/Identity." Social Forces, 55, 880-897.

Caldwell, John. C. (1982). Theory of Fertility Decline. New York: Academic.

Campbell, Kirsten. (2004). Jacques Lacan and Feminist Epistemology. Oxford: Routledge.

Cantor, D. \& Brown, J. (1981). "Explanatory Roles" In C. Antaki (Ed.), The Psychology of Ordinary Explanations (pp. 221-242). London: Academic Press. 
Carroll, Lewis. ([1872] 2010). Alice through the Looking Glass. Illustrations by Sir John Tenneil. New York: Cosimo, Inc.

Carroll, Maureen Anne. (1995). "Office Girls/Business Women: Work, Gender, and Civicism in Atlanta, Georgia, 1919-1940.” PhD disst. Emory University.

Chafe, W. H. (1972). The American Woman: Her Changing Social, Economic, and Political Roles, 1920-1970. New York: Oxford University Press.

Collins, Gail. (2009). When Everything Changed: The Amazing Journey of American Women from 1960 to the Present. New York: Little, Brown and Company.

Cooley, Charles Horton. ([1902] 1964). Human Nature and the Social Order. New York: Charles Scribner's.

Currie, Dawn H. (1999). Girl Talk: Adolescent Magazines and Their Readers. Toronto Baffalo London: University of Toronto Press.

Curry, T., Jiobu, R. \& Schwirian, K. (2002). Sociology for the Twenty-First Century (3 ${ }^{\text {rd }}$ ed.). New York: Prentice Hall.

Darcy, Louise. (1949). "Woman Must Serve Completely..." Independent Woman, Feb, 40.

Davies, Margery. (1982). Woman's Place is at the Typewriter: Office Work and Office Workers, 1870-1930. Philadelphia: Temple University Press.

Davis, Joseph E. (2000). Identity and Social Change. New Brunsvick and London: Transaction Publishers.

Deaux, K. (1996). "Social identification." In E. T. Higgins \& A. W. Kruglanski (Eds.), Social psychology: Handbook of basic principles (pp. 777-798). New York: Guilford.

Desjardin, Mary. (1992). "Baby Boom: The Comedy of Surrogacy in Film and Television." Velvet Light Trap, 29, spring, 25.

Dillingham, Pauline. (1932). "Popularity." Independent Woman, Feb, 267.

Drachman, Virginia G. (2002). Enterprising women: 250 Years of American Business. Chapel Hill: The University of North Carolina Press. 
Dunn, Robert G. (1998). Identity Crises: A Social Critique of Postmodernity. Minneapolis: U of Minnesota Press.

Eisenberg, Bonnie \& Ruthsdotter, Mary. (1998). "Living the Legacy: the Women's Rights Movement 1848 - 1998." The National Women's History Project. Retrieved from $<$ http://www.legacy98.org/move-hist.html $>$ on April 16, 2010.

Erikson, Erik H. (1959). "Identity and the life cycle: Selected papers." Psychological Issues, 1, 1-171.

Evans, Dylan. (1996). An Introductory Dictionary of Lacanian Psychoanalysis. London \& New York: Routledge.

Evans, Ruth. (Ed.). (1998). Simone de Beauvoir's The Second Sex: New Interdisciplinary Essays. Manchester and New York: Manchester University Press.

Evans, Sara Margaret. (1997). Born for Liberty. (2 ${ }^{\text {nd }}$ ed.). New York: Free Press Paperbacks.

Ferguson, Harvie. (2000). "Deception and Despair: Ironic Self-Identity in Modern Society." In Joseph E. Davis (Ed.), Identity and Social Change (pp. 179-208). New Brunsvick and London: Transaction Publishers.

Fiorina, Carl. (2006). Tough Choices: A Memoir. New York: Penguin Group Inc.

Flagg, Fannie. (1987). Fried Green Tomatoes at the Whistle Stop Cafe. New York: McGraw-Hill.

Ford, Mary Constance. (1932a). "New Ways To Beauty." Independent Woman, Aug, 287.

Ford, Mary Constance. (1932b). "The Witchery of Lovely Hands." Independent Woman, Feb, 59.

Foucault, Michel. (1994). The Order of Things: An Archaeology of the Human Sciences. New York: Vintage Books.

Foucault, Michel. (1972). The Archaeology of Knowledge. (A. M. Sheridan Smith, Trans.). New York: Pantheon Books.

Foucault, Michel. (1983). "The subject and power." In Michel Foucault: Beyond 
Structuralism and Hermeneutics (pp. 208-226). $2^{\text {nd }}$ ed. (Hubert Dreyfus \& Paul Rabinow, Trans.). Chicago: University of Chicago Press.

Friedan, Betty. (1963). The Feminine Mystique. New York: Laurel.

Friedan, Betty. (1976). It Changed My Life: Writings on the Women's Movement. New York: Dell Publishing Co., Inc.

Friedan, Betty. (1998). The Second Stage: with a New Introduction. Cambridge: Harvard University Press.

Freud, Sigmund. ([1923] 1949). The Ego and the Id. (Joan Riviere, Trans.). London: Hogarth Press Ltd.

Freud, Sigmund. (1914). "On Narcissism: An Introduction." SE ${ }^{68}$ 14: 73-102. .

Garber, Marjorie. (1992). Vested Interests: Cross-Dressing and Cultural Anxiety. London: Routledge.

Gardner, Catherine Villanueva. (2006). Historical Dictionary of Feminist Philosophy. Lanham, Maryland: Scarecrow Press, Inc.

Gecas, Viktor. (2000). "Value Identities, Self-Motives, and Social Movements." In Sheldon Stryker, Timothy Owens, \& Robert W. White (Eds.), Self, Identity, and Social Movements (pp. 93-109). Minneapolis, MN: University of Minnesota Press.

Geertz, Clifford. (1973). The Interpretation of Cultures. New York: Harper Colophon Books.

Geertz, Clifford. (1983). Local Knowledge: Further Essays in Interpretive Anthropology. New York: Basic Books.

Gergen, K. J., \& Gergen, M. M. (1982). "Form and Function in the Explanation of Human Conduct." In P. Secord (Ed.), Paradigms in the Social Sciences (pp. 127-151). Beverly Hills, CA: Sage.

Gergen, K. J. (1977). The Social Construction of Self-knowledge. In T. Mischel (Ed.), The Self, Psychological and Philosophical Issues (pp. 139-169). Oxford, England: Blackwell.

${ }^{68} \mathrm{SE}=$ Standard Edition of the complete Psychological Works of Sigmund Freud. 
Gergen, K. J. (1985). "The Social Constructionist Movement in Modern Psychology." American Psychologist, 40 (3): 266-275.

Gergen, K. J. (2001). The Social Construction in Context. London: Sage Publications.

Gergen, Mary. (2001). "Social Constructionist Theory." in Judith Worell (Ed.), Encyclopedia of Women and Gender: Sex Similarities and Differences and the Impact of Society on Gender (pp.1044-1052) (Vol. 2, L-Z.). San Diego, Calif.: Academic Press.

Giddens, Anthony. (1984). The Constitution of Society. Cambridge: Polity Press.

Giddens, Anthony. (1991). Modernity and Self-Identity: Self and Society in the Late Modern Age. Oxford: Polity Press.

Gilman, Charlotte Perkins. (1966). Women and economics: A Study of the Economic Relation Between Men and Women as a Factor in Social Evolution. New York: Harper \& Row Publishers, Inc.

Goetz, Anne Marie. (Ed.). (1997). Getting Institutions Right for Women in Development. London: Zed Books.

Goffee, Robert, \& Scase, Richard. (1985). Women in Charge: the Experiences of Female Entrepreneurs. London; Boston: Allen \& Unwin.

Goldstein, Irwin. (2002). "Are Emotions Feelings? A Further Look at Hedonic Theories of Emotions." Consciousness and Emotion, 3 (1): 21-33.

Green, Karen. (2002). "The other as another other." Hypatia: A Journal of Feminist Philosophy, Vol. 17, No. 4, 1-15.

Greer, Germaine. (1989). Daddy, We Hardly Knew You. New York: Knopf.

Griffiths, Morwenna. (1995). Feminisms and the Self: the Web of Identity. London \& New York: Routledge.

Grosz, Elizabeth A. (1990). Jacques Lacan: A Feminist Introduction. London and New York: Routledge.

Hacking, Ian. (1999). The Social Construction of What? Cambridge: Harvard University 
Press.

Hailey, Arthur. (1984). Strong Medicine. Garden City, New York: Doubleday \& Company, Inc.

Hamby, Alonzo L. (2006). Outline of U.S. History. Hauppauge, New York: Nova Publishers.

Handel, Gerald. (2006). Childhood Socialization. New Brunswick, NJ: Aldine Transaction Publishers.

Harden, Verna Loveday. (1948). "From Woman unto Woman." Independent Woman, Feb, 64.

Harding, Sandra. (1986). The Science Question in Feminism. New York: Cornell University Press.

Harding, Sandra. (1991). Whose Science, Whose Knowledge? Thinking from Women's Lives New York: Cornell University Press.

Harris, Marvin. (1968). The Rise of Anthropological Theory. New York, NY: Columbia University; HarperCollins Publishers, Inc.

Harris, Marvin. (2001). Cultural Materialism: The Struggle for a Science of Culture (updated ed. With an introduction by Allen Johnson and Orna Hohnson). New York: Altamira Press.

Harris, Marvin. (1981). Why Nothing Works: The Anthropology of Daily Life (a.k.a. America Now). New York: Vintage Books.

Harris, Marvin. (1989). Our Kind: Who We Are, Where We Came From, Where Are We Going. New York: Vintage Books.

Haskell, Molly. (1973). From Reverence to Rape. Baltimore: Penguin Books.

Heidegger, Martin. ([1927] 1996). Being and Time. (Joan Stambaugh, Trans.). Albany, NY: State University of New York Press.

Henifin, Helen. (1932). "Your Feet on the Ground." Independent Woman, Feb, 51 and 68.

Hennig, Margart, \& Anne Jardim. (1976). The Managerial Woman. New York: Pocket 
Books.

Hesse-Biber, S. N. \& Carter, G. L. (2005). Working Women in America: Split Dreams $\left(2^{\text {nd }}\right.$ ed.). New York: Oxford University Press.

Hill, Daniel Delis. (2002). Advertising to the American Woman 1900-1999. Columbus: Ohio State University Press.

Hochschild, A. R., \& Machung, Ann. (1989). The Second Shift: Working Parents and the Revolution at Home. New York: Viking.

Hoffert, Sylvia D. (Ed.). (2003). A History of Gender in America: Essays, Documents, and Articles. New York: Prentice Hall.

Hoffman, L. W., \& Nye, F. I. (1974). Working Mothers. San Francisco: Jossey-Bass Publishers.

Holland, D., Lachicotte Jr., W., Skinner, D. \& Cain, C. (1998) Identity and Agency in Cultural Worlds. Cambridge, Mass: Harvard University Press.

Holmes, M. (2007). What is Gender? Sociological Approaches. Thousand Oaks, CA: Sage.

Homer, Sean. (2005). Jacques Lacan. New York: Routledge.

Humm, Maggie. (Ed.). (1992a). Feminisms: A Reader. Hertfordshire: Harvester Wheatsheaf.

Humm, Maggie. (Ed.). (1992b). Modern Feminisms: Political, Literary, Cultural. New York: Columbia University Press.

Humm, Maggie. (1995). The Dictionary of Feminist Theory. Columbus: Ohio State University Press.

Irigaray, Luce. (1977). “Women's Exile.” Ideology \& Consciousness, 1, May, 62-76.

Irigaray, Luce. (1980). "When Our Lips Speak Together." (Carolyn Burke, Trans. with Introduction). Sign 6, No. 1, Women: Sex and Sexuality, Part 2, 66-79.

Irigaray, Luce. (1985a). Speculum of the Other Woman. (G. Gill, Trans.). Ithaca: Cornell University Press. 
Irigaray, Luce. (1985b). This Sex Which Is Not One. (C. Porter, Trans.). Ithaca: Cornell University Press.

Jacobs, Mary. (1932). "Business as an Aid to Cupid: an interview with Helen Woodward." Independent Woman, Jan, 5 and 38.

Jagose, Annamarie. (1997). Queer Theory: An Introduction. New York: New York University Press.

Jung, Carl G. (2004). On the Nature of the Psyche. (R. F. C. Hull, Trans.). London: Routledge.

Jung, Carl G. (1969). Man and His Symbols. New York: Doubleday.

Kanes, Candace A. (1997). "American Business Women, 1890-1930: Creating an Identity." PhD disst. University of New Hampshire.

Kanter, Rosabeth Moss. ([1977] 1993). Men and Women of the Corporation. New York: Basic Books.

Kessen, W. (1979). "The American Child and other Cultural Inventions." American Psychologist, 34, 815-820.

Kessler, S. \& McKenna, W. (1978). Gender: An Ethnomethodological Approach. New York: Wiley.

King Jr., Martin Luther. (1963). “On Social Justice.” (Speech Transcription). Retrieved from Western Michigan University Libraries Web site: $<$ http://www.wmich.edu/library/archives/mlk/transcription.html $>$ on April, 15, 2010 .

Kitzinger, Celia. (1987). The Social Construction of Lesbianism. Newbury Park, CA: Sage.

Kobrin, F.E. (1973). "Household Headship and Its Changes in the United States, 1940-1960, 1970." Journal of the American Statistical Association, 68: 793-800.

Kobrin, F.E. (1976a). "The Fall in Household Size and the Rise of the Primary Individual in the United States." Demography, 13:127-38. 
Kobrin, F.E. (1976b). "The Primary Individual and the Family: Changes in Living Arrangements in the United States Since 1940." Journal of Marriage and the Family, 38: 233-39.

Kozmetsky, Ronya. (1989). Business: Succeeding As A Manager, Professional, or Entrepreneur. Austin: Texas Monthly Press.

Krisman, Carol H. (2005). Encyclopedia of American Women in Business: from Colonial Times to the Present. Westport, Conn.: Greenwood Press.

Kristeva, Julia, et al. (1981). In A. Jardine, A. Kuhn, H.V. Wenzel, \& L.S. Robinson (Eds.), French feminist theory. Chicago: The University of Chicago press.

Kristeva, Julia. (1980). Desire in Language: A Semiotic Approach to Literature and Art (Leon Roudiez, Ed.; Thomas Gora, Alice Jardine \& Leon Roudiez, Trans.). New York: Columbia University Press.

Kristeva, Julia. (1981). "Women's Time." (Alice Jardine \& Harry Blake, Trans.). Signs, Vol. 7, No. 1, 13-35.

Kristeva, Julia. (1982). Powers of Horror: An Essay on Abjection. (L.S.Roudiez, Trans.). New York: Columbia University Press.

Kristeva, Julia. (1984a). Revolution in poetic language. (M.Waller, Trans.; with an introduction by L.S.Roudiez). New York: Columbia University Press.

Kristeva, Julia. (1984b). "Julia Kristeva in conversation with Rosalind Coward." Desire, ICA Documents, 22-27.

Kristeva, Julia. (1987). Tales of love. (L.S.Roudiez, Trans.). New York: Columbia University Press.

Kristeva, Julia. (1995). New Maladies of the Soul. (R.Guberman, Trans.). New York: Columbia University Press.

Kwolek-Folland, Angel. (1994). Engendering Business: Men and Women in the Corporate Office, 1870-1930. Baltimore: Johns Hopkins University Press.

Kwolek-Folland, Angel. (Ed.). (1998). Incorporating Women: A History of Women and Business in the United States. New York: Twayne Publishers. 
Lacan, Jacques. (1977a). "Desire and Interpretation of Desire in Hamlet." from The Seminar of Jacques Lacan: Book VI: Desire and Its Interpretation. (J. Hulbert, Trans.). Yale French Studies, 55/56, 11-52.

Lacan, Jacques. (1977b). Écrits: A Selection. (Alan Sheridan, Trans.). New York: Norton.

Lacan, Jacques. (1988). The seminar of Jacques Lacan: Book I: Freud's papers on technique, 1953-1954. (John Forrester, Trans.). New York: W. W. Norton.

Lacan, Jacques. (1991). The Seminar of Jacques Lacan: Book II: The Ego in Freud's Theory and in the Technique of Psychoanalysis, 1954-55. (Sylvana Tomaselli, Trans.). New York: W. W. Norton \& Company.

Lacan, Jacques. (1992). The Seminar of Jacques Lacan, Book VII: The Ethics of Psychoanalysis, 1959-1960 (Jacques-Alain Miller, Ed.; Dennis Porter, Trans.). New York: W. W. Norton \& Company.

Lacan, Jacques. (1993). The Seminar of Jacques Lacan, Book III: The Psychoses, 1955-1956. (Jacques-Alain Miller, Ed.; Russell Grigg, Trans.). New York: Norton.

Lacan, Jacques. (1998). The Seminar of Jacques Lacan: Book XI: The Four Fundamental Concepts of Psychoanalysis. (Alan Sheridan, Trans.). New York: W. W. Norton \& Company.

Lauder, Estée. (1985). Estée: A Success Story. New York: Random House.

Lawrence, Mary Wells. (2002). A Big Life in Advertising. New York: Alfred A. Knopf.

Lawtoo, Nidesh. (2006). "Dissonant Voices in Richard Rodriguez's Hunger of Memory and Luce Irigaray's This Sex Which Is Not One." Texas Studies in Literature and Language, Vol. 48, No. 3, 220-249.

Leader, Darian. \& Groves, Judy. (2000). Introducing Lacan. Cambridge: Icon Books Ltd.

Lewis, Susan Ingalls. (1992). "Female Entrepreneurs in Albany, 1840-1885." Business and Economic History, 21: 65-73.

Lewis, Susan Ingalls. (1995). "Beyond Horatia Alger: Breaking Through Gendered Assumptions about Business 'Success' in Mid-Nineteenth Century America." Business and Economic History, 24, (1): 97-105. 
Lewis, Susan Ingalls. (1997). "Business Women in the 'Land of Opportunity': First and Second Generation Immigrant Proprietessess in Albany, New York, 1880. Hudson Valley Regional Review, 14, (2): 56-70.

Lewis, Susan Ingalls. (2003). "Susan Lewis on Businesswomen in Albany, New York, 1830-1885" [Interview online]. Talking History, 3 April. Retrieved from:

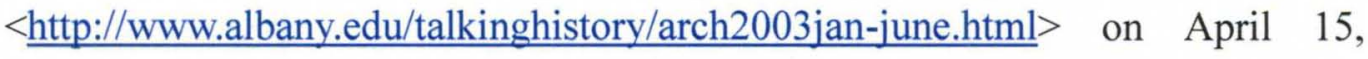
2009.

Lorber, Judith, (1994). Paradoxes of Gender, New Haven, Connecticut: Yale University Press.

Lorber, Judith, \& Susan, A. F. (Eds.). (1991). The Social Construction of Gender, Newbury Park, California: Sage Publications.

Lutz, Alma. (1932). "Penalizing Marriage." Independent Woman, Feb, 76-77 and 92.

MacGibbon, Elizabeth Gregg. (1936). Manners in Business. New York: Macmillan.

Madsen, Deborah L. (2006). Feminist Theory and Literary Practice. Beijing: Foreign Language Teaching and Research Press-Pluto Press.

Maltz, Maxwell. (1960). Psycho-cybernetics: A New Way to Get More Living Out of Life. Englewood Cliffs, N.J.: Prentice-Hall.

Marcel, Gabriel H. (1951a). The Mystery of Being, Vol. 1, Reflection and Mystery. (G. S. Fraser, Trans.). London: The Harvill Press.

Marcel, Gabriel H. (1951b). The Mystery of Being, Vol. 2, Faith and Reality. (René Hague, Trans.). London: The Harvill Press.

Marks, E \& Coutrivron, J. (1980). New French Feminisms. Amherst: University of Massachusetts Press.

Marx, Karl. (1967). Capital: A Critique Of Political Economy. Edited by Frederick Engels. New York, International Publishers.

Maule, Frances. (1937). She Strives to Conquer: Business Opportunities and Job Requirements for Women. New York and London: Funk \& Wagnall's Company. 
McAfee, Nö̈lle. (2004). Julia Kristeva. New York: Routledge.

McIntyre, Lisa J. (2002). The Practical Skeptic: Core Concepts in Sociology (2 ${ }^{\text {nd }}$ ed.). New York: McGraw Hill.

McLaughlin, S. D., Melber, B. D., Billy, J. O. G., Zimmerle, D. M., Winges, L. D., \& Johnson. T. R. (1988). The Changing Lives of American Women. Chapel Hill: The University of North Carolina Press.

McLaughlin, Jane. (1992). Up and Running: Women in Business. Reading, Berkshire: Cox \& Wyman Ltd.

Mead, George Herbert. (1934). Mind, Self and Society. Chicago: University of Chicago Press.

Mead, Margaret. (1949). Male and Female, A Study of the Sexes in A Changing World. New York: W. Morrow.

Melucci, Alberto. (1995). "The Process of Collective Identity." In Hank Johnston \& Bert Klandermans (Eds.), Social movements and culture (pp. 41-63). London and New York: Routledge.

Merriam, S., \& Caffarella, R. (1999). Learning in Adulthood. A Comprehensive Guide $\left(2^{\text {nd }}\right.$ ed.). San Francisco: Jossey-Bass.

Metheny, Eleanor. (1949). "Inventory of Frustrations." Independent Woman, Jan, 12-14.

Mighell, Marjorie Holmes. (1937). "Romance Versus the Boss." Nation's Business, 25, Aug, 25, 21.

Mill, Harriet Taylor. ([1851]1994). "Enfranchisement of Women." Westminster Review, 55, pp. 149-161. Reprinted in Ann P. Robson and John M. Robson (Eds.), Sexual Equality: Writings by John Stuart Mill, Harriet Taylor Mill, and Helen Taylor (pp. 178-203). Toronto: University of Toronto Press, 1994.

Mills, Jon. (2004). Psychoanalysis at the Limit: Epistemology, Mind, and the Question of Science. Albany: SUNY Press.

Miller, Jean Baker. (1976). Towards A New Psychology of Women. Boston: Beacon Press.

Molloy, John T. (1977). The Woman's Dress for Success Book. New York: Warner Books. 
Moussa, Helene. (1992). "The Social Construction of Women Refugees: A Journey of Discontinuities and Continuities." PhD Disst. University Of Ottawa.

Mulvey, Laura. (1992). "Visual Pleasure and Narrative Cinema." In John Caughie, Annette Kuhn \& Mandy Merck (Eds.), The Sexual Subject: A Screen Reader in Sexuality (pp. 22-34). London: Routledge.

O'Brien, Virginia. (1998). Success on Our Own Terms: Tales of extraordinary Ordinary Business Women. John Wiley \& Sons, Inc.

Oakley, Ann. (1972). Sex, Gender and Society. London: Temple Smith.

Oakley, Judith. (2000). "Gender-based barriers to senior management positions: Understanding the scarcity of female CEOs." Journal of Business Ethics, 27, 321-334.

Oliver, Kelly. (1993). "Julia Kristeva's Feminist Revolutions." Hypatia: A Journal of Feminist Philosophy, Vol. 8, No.3. 94-114.

Oliver, Kelly. (1998). "Summary of Major Themes: Kristeva and Feminism.” Retrieved from http://www.cddc.vt.edu/feminism/kristeva.html on Sep. 5, 2010.

Oppedisano, Jeannette M. (2000). Historical Encyclopedia of American Women Entrepreneurs: 1776 to the Present. Westport, Conn. : Greenwood Press.

Palmer, Hazelle. (Ed.). (1997). But Where Are You Really From? Stories of Identity \& Assimilation in Canada. Toronto: Sister Vision Press.

Pennyfield, Jane. (1932). "Chic Is the Thing." Independent Woman, Mar, 94 and 116.

Plato. ([around 382 BCE] 2006). The Republic. (R.E. Allen, Trans. and with an introduction). New Haven: Yale University Press.

Plopper, Murray. (1963). (Speech Transcription) "A condition we can ill afford: Debating the Equal Pay Act of 1963." Hearings on Amending the Equal Pay Act of 1963, Subcommittee on Labor, Committee on Labor and Public Welfare, United State Senate, 88th Congress, 1st session, April 2, 3, and 16, 1963. Washington D.C.: Government Printing Office. Retrieved from

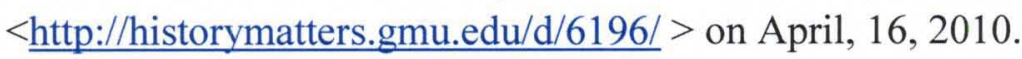


Pollock, Lewette Beauchamp. (1947). "Oddity.” Independent Woman, April, 96.

Putnam, R. A. (1990). "The Moral Life of a Pragmatist." In O. Flanagan \& A. O. Rorty (Eds.), Identity, Character, and Morality: Essays in Moral Psychology (pp.67-89). Cambridge: The MIT Press.

Puzyrei, A. (2007). "Contemporary Psychology and Vygotsky's Cultural-Historical Theory." Journal of Russian and East European Psychology, 45 (1), 8-93.

Rabaté, Jean-Michel. (2003). The Cambridge Companion to Lacan. Cambridge University Press.

Ritzer, George. (Ed.). (2005). Encyclopedia of Social Theory. Vol.1. Thousand Oaks, CA: Sage.

Rockler-Gladen, Naomi. (2007). "Third Wave Feminism: Personal Empowerment Dominates This Feminist Philosophy." Retrieved from

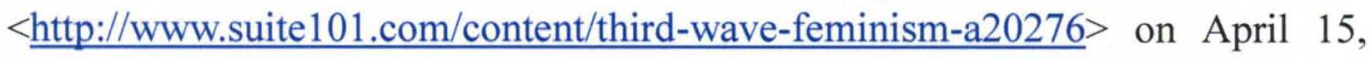
2010 .

Roper, Inc. (1986). The 1985 Virginia Slims American Women's Opinion Poll. New York: Roper Organization.

Sabini, J., \& Silver, M. (1982). The Moralities of Everyday Life. New York: Oxford University Press.

Saldivar-Hull, Sonia. (1991). "Feminism on the Border: From Gender Politics to Geopolitics." In Hector Calderon \& Jose Davod Saldivar (Eds.), Criticism in the Borderlands: Studies in Chicanpo Literature, Culture and Ideology. Durham and London: Duke U.P. see also

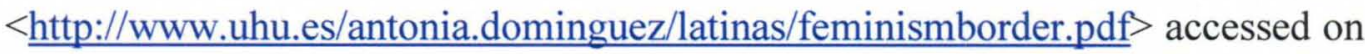
30 August, 2010.

Sarup, M. (1996). Identity, Culture and the Postmodern World. Edinburgh: Edinburgh University Press.

Sartre, Jean-Paul. (1956). Being and Nothingness: An Essay on Phenomenological Ontology. (Hazel E. Barnes, Trans. and with an introduction.). New York: Philosophical Library.

Saussure, Ferdinand de. ([1916] 1974). Course in General Linguistics (Wade Baskin, 
Trans.). New York: Basic Books.

Schroeder, Jonathan E. (1998). "Consuming Representation: A Visual Approach to Consumer Research." In Barbara B Stern (Ed.), Representing Consumers: Voices, Views and Visions (pp.193-230). London: Routledge.

Scott, Niki. (1977). The Working Woman: A Handhook. Kansas City: Universal Press Syndicate.

Luka, Thom. (2001). Blog Comment toward "First Wave Feminism: 1848-1963." By Terri Senft (2001). Retrieved from http://www.livejournal.com/talkread.bml?itemid=9820854 on Aug. 20, 2010.

Shapiro, D., \& Crowley, J.E. (1983). "Hope and Plans: Education, Work Activity, and Fertility.” In M.E. Borus (Ed.), Tomorrow's Workers (pp. 149-171). Lexington, Mass: Lexington Books.

Shepard, Jon M. (2002). Sociology ( $8^{\text {th }}$ ed.). Belmont, CA: Wadsworth.

Sherwood, Ada Simpson. (1949). "We Earn Our Future.” Independent Woman, Feb, 52.

Shukla, Bhaskar A. (2006). Women On Women: A Feminist Study. New Delhi: Sarup \& Sons.

Slappey, Sterling G. (1970). "Those Powerful Powder Puff Executives." Nation's Business, 58 (November), 81.

Smith, M. B. (1963). "Personal values in the study of lives." In R. W. White (Ed.), The study of lives (pp. 324-347). New York: Atherton Press.

Snow, David, \& McAdam, Doug. (2000) "Identity Work Processes in the Context of Social Movements: Clarifying the Identity/Movement Nexus." In Sheldon Stryker, Timothy J. Owens, \& Robert W. White (Eds.), Self, Identity, and Social Movements (pp. 41-67). Minneapolis: University of Minnesota Press.

St. Clair, Robert N. (2006). Theories of Culture. Course book for Humanities 672, Beijing Program.

St. Clair, Robert N. (2009). Course description of Humanities 671, Culture Theory, Summer 2009. Retrieved from $<\underline{\text { http://structural-communication.com/Summer-2009-Hum671/culture-theory-su }}$ 
mmer-2009.html > on July 9, 2010.

St. Clair, Robert N. (2010a). "English Metrical Phonology." Retrieved from $<$ http://epistemic-forms.com/R-Eng-Morphology.html $>$ on Aug.15, 2010.

St. Clair, Robert N. (2010b). Reality-Loops and Activity Theory. Retrieved from $<$ http://www.structural-communication.com/Articles/reality-loops.html $>$ on Aug. 20, 2010.

Stam, Robert. (2000). Movie Theory: An Introduction. Malden: Blackwell Publishers Inc.

Steele, P. M. (1947). “Pleasure Before Business.” Independent Woman, Oct, 296.

Strom, Sharon Hartman. (1992). Beyond the Typewriter: Gender, Class, and the Origins of Modern American Office Work, 1900-1930. Urbana: University of Illinois Press.

Stryker, Sheldon. (1980). Symbolic Interactionism: A Social Structural Version. Menlo Park: Benjamin Cummings.

Stryker, S., Ovens, T. J., \& White, R. W. (Eds.). (2000). Self, Identity, and Social Movements. Minneapolis, Landon: University of Minnesota Press.

Switala, Kristin. (1999). Summary of Major Themes: "Kristeva and Feminism." Retrieved from $<$ http://www.cddc.vt.edu/feminism/Kristeva.html $>$ on Aug.30, 2010.

Sydie, R. A. (1987). Natural Women, Cultured Men: A Feminist Perspective on Sociological Theory. Milton Keynes: Open University Press.

Tajfel, Henri. (1981). Human Groups and Social Categories. Cambridge: Cambridge University Press.

Tasker, Yvonne. (1998). Working Girls: Gender and Sexuality in Popular Cinema. London and New York: Routledge.

Taylor, Charles. (1985). Self-interpreting animals. In C. Taylor (Ed.), Human agency and language: Philosophical papers (Vol. 1, pp. 15-44). Cambridge: Cambridge University Press.

Taylor, Gene Allen. (1932). "Scuttling For Home." Independent Woman, Feb, 46-47. 
Taylor, Russel R. (1988). Exceptional Entrepreneurial Women: Strategies for Success. Foreword by Arthur Lipper III. New York: Quorum Books.

Thomas, Dorothy. (1932). "Does It Pay To Be a Good Secretary?" Independent Woman, Sep, 314 and 333.

Thompson, W. E., \& Hickey, J. V. (2002). Society in Focus $\left(4^{\text {th }}\right.$ ed.). Boston: Allyn and Bacon.

Todd, Ellen Wiley. (1989). "Isabel Bishop: The Question of Difference." Smithsonian Studies in American Art, 3(4): 25-41.

Todd, Ellen Wiley. (1993). The "New Woman" Revised: Painting and Gender Politics on Fourteenth Street. Berkeley: University of California Press.

Tripp, Anna. (Ed.). (2000). Gender: Readers in Cultural Criticism. New York: Palgrave.

Turner, J.C. (1985). "Social Categorization and the Self-concept: A Social Cognitive Theory of Group Behavior." In E. J. Lawer (Ed.), Advances in Group Processes: Theory and Research (Vol. 2, pp.77-122). Greenwich, CT: JAI Press.

Turner, Ralph. (1968). "The self-conception in social interaction." in Chad Gordon \& Kenneth J. Gergen (Eds.), The Self in Social Interaction (Vol. I, pp.93-106). New York: John Wiley and Sons.

Tyson, Lois. (1999). Critical Theory Today: A User-Friendly Guide. New York: Taylor \& Francis, Inc.

Vernier, Verna. (1932). "The Use of Adversity." Independent Woman, Jan 12-13 and 37.

Vygotsky, L.S. (1978). Mind in Society: The Development of Higher Psychological Processes. Cambridge, MA: Harvard University Press.

Vygotsky, L.S. (1981). "The Genesis of Higher Mental Functions." In J.V. Wertsch (Ed. and Trans.), The Concept of Activity in Soviet Psychology (pp. 144-188). White Plains, NY: M.E. Sharpe.

Vygotsky, L.S. (1983). "From the Notebooks of L. S. Vygotsky." Soviet Psychology, XXI (3), 3-17.

Vygotsky, L. \& Luria, A. (1994). "Tool and Symbol in Child Development." In R.van der 
Veer \& J. Valsiner (Eds.), The Vygotsky Reader (pp. 99-174). Oxford, UK: Blackwell.

Waldman, Michael. (2003). My Fellow Americans: The Most Important Speeches of America's Presidents. Naperville, IL: Sourcebooks, Inc.

Walker, Rebecca. (1995) To Be Real: Telling the Truth and Changing the Face of Feminism. New York: Anchor Books.

Wallace, Phyllis A. (Ed.). (1982). Women in the Workplace. Boston, Massachusetts: Auburn House Publishing Company.

Walters, Suzanna Danuta. (1995). Material Girls: Making Sense of Feminist Cultural Theory. Berkeley: University of California Press.

Wandersee, Winifred D. (1988). On the Move: American Women in the 1970s. Boston: Twayne Publishers.

Weedon, Chris. (1987). Feminist Practice and Poststructuralist Theory. UK: Basil Blackwell Inc.

Wilson, Catherine Cathcart. (1932). "Paging Mr. Plato." Independent Woman, Mar, 84 and $112-113$.

Wittgenstein, Ludwig. (1999). Philosophical Investigations (G. E. M. Anscombe, Trans.). New York: Prentice Hall.

Wollstonecraft, Mary. ([1792] 2001). A Vindication of the Rights of Woman: With Strictures on Political and Moral Subjects (Introduction by Katha Pollitt; notes by Katherine Lee). New York: Modern Library.

Woodward, Helen. (1926). Through Many Windows. New York: Harper \& brothers.

Yorke, Liz. (1991). Impertinent Voices: Subversive Strategies in Contemporary Women's Poetry. New York: Routledge.

Zhang, Zaixin. (2007). Lecture notes on the course " $200^{\text {th }}$ Century Critical Theory" in Beijing Foreign Studies University. 
APPENDICES

\section{LIST OF ACRONYMS}

ABWA American Business Women's Association

BPW Business and Professional Women

BWN Business Women's Network

EPA Equal Pay Act

ERA Equal Rights Amendment

HMF Higher Mental Functions

IW Independent Woman (Magazine)

LMF Lower Mental Functions

NOW National Organization for Women

NWP National Woman's Party

PCSW Presidential Commission on the Status of Women

WACB White American Corporate Businesswomen

WB Women's Bureau

ZPD Zone of Proximal Development 


\section{CURRICULUM VITAE}

NAME: $\quad$ Qin Ma

ADDRESS: International Business School

Beijing Foreign Studies University

No.19 West Third Ring Road, Haidian District

Beijing, P.R. China. 100089

DOB: $\quad$ November 15,1974

EDUCATION

\& TRAINING: Doctoral student/candidate of Studies of Culture, Division of Humanities, University of Louisville, the USA (in Collaboration with Beijing Foreign Studies University)

2006- 2010

Master of Arts, School of English and International Studies, Beijing Foreign Studies University, China

2001- 2004

Advanced study, College of Education and Humanities, Alturo Prat University, Chile 1999- 2000

Bachelor of Arts, School of Foreign Languages, Beihang University (Beijing University of Aeronautics and Astronautics), China 1993- 1997

AWARDS: "Margaret Turner" Teaching Award of Beijing Foreign Studies University, 2005 


\section{PUBLICATIONS:}

Wang, Zhenping, \& Ma, Qin. "Action Research on Video Course." Journal of Cambridge Studies, Vol. 5, No.1, Mar. 2010: 51-73.

Ma, Qin. "Cross-cultural Comparison of the Speech Act of 'Promising' in E-business." Multi-angle View of the Transformation of Chinese Economy. Beijing: China Economy Publishing House, 2009: 188-199.

Ma, Qin. "On Gender Stereotyping in Pictorial Sports News: A Case Study." Intercultural Communication Studies, Vol. XVII: 1, 2008: 54-63.

\section{CONFERENCE PRESENTATIONS:}

Ma, Qin. "Cross-cultural Comparison of the Origin of Women Business Leadership in America and P.R. China in the Context of Globalization." presented at the 8th Northeast Asia Management \& Economics Joint Conference, Daegu, Korea, October 14-17, 2009.

Ma, Qin. "On Gender Stereotyping in Pictorial Sports News: A Case Study." presented at the $13^{\text {th }}$ International Inter-cultural Communication Conference (CAFIC \& IAICS), Harbin, China, June 22-24, 2007.

Ma, Qin. "Complains: An Empirical Study of Speech Act Behavior among Speakers of Chinese." presented at the $12^{\text {th }}$ Annual Conference of the International Association of Chinese Linguistics \& the $2^{\text {nd }}$ International Symposium of Chinese Linguistics (IACL12), Tianjin, China, June 18-20, 2004.

Ma, Qin. "Comparison of the Speech Act of Promising in English and Chinese." presented at the $8^{\text {th }}$ National Symposium on Pragmatics, Guangzhou, China, December 18-20, 2003. 